\title{
Fable, method, and imagination in Descartes
}

James E. C. Griffith

DePaul University, jgriff20@depaul.edu

Follow this and additional works at: https://via.library.depaul.edu/etd

\section{Recommended Citation}

Griffith, James E. C., "Fable, method, and imagination in Descartes" (2014). College of Liberal Arts \& Social Sciences Theses and Dissertations. 172.

https://via.library.depaul.edu/etd/172

This Dissertation is brought to you for free and open access by the College of Liberal Arts and Social Sciences at Digital Commons@DePaul. It has been accepted for inclusion in College of Liberal Arts \& Social Sciences Theses and Dissertations by an authorized administrator of Digital Commons@DePaul. For more information, please contact digitalservices@depaul.edu. 


\title{
FABLE, METHOD, AND IMAGINATION IN DESCARTES
}

\author{
A Dissertation \\ Presented in \\ Partial Fulfillment of the \\ Requirements for the Degree of \\ Doctor of Philosophy
}

September, 2014

\section{BY}

James E. C. Griffith

Department of Philosophy

College of Liberal Arts and Social Sciences

DePaul University

Chicago, IL 
Copyright (C) 2014 James E. C. Griffith All rights reserved 
To my mother 
... la fable de mon Monde me plaist trop pour manquer à la paracheuer.

—René Descartes, letter to Marin Mersenne, November 25, 1630 


\section{Contents}

Acknowledgments $\quad$ vi

Abbreviations vii

Introduction 1

Endings and Beginnings $\quad 4$

$\begin{array}{ll}\text { What Is a Fable? } & 7\end{array}$

$\begin{array}{ll}\text { Why Fable in Descartes? } & 18\end{array}$

Ending the Beginning $\quad 30$

Part I

Chapter One: Fable Proper $\quad 34$

Fable against Poetry $\quad 35$

Fable and Pedagogy $\quad 56$

Chapter Two: Fable Expanded 81

Fable and Other Forms $\quad 82$

$\begin{array}{ll}\text { Fable and Deception } & 108\end{array}$

Part II

Chapter Three: Method 141

Simplicity and Complexity 142

$\begin{array}{ll}\text { Error and Inexact Science } & 170\end{array}$

Histoire and Rule-Obedience and Rule-Generation 190

Chapter Four: Imagination 210

Pedagogy and Imagination $\quad 211$

Space, Fable, and Argumentation $\quad 230$

Wonder and Learning 253

$\begin{array}{ll}\text { Imagination and Comedy } & 270\end{array}$

By Way of a Conclusion: An Objective Formality 287

$\begin{array}{ll}\text { Bibliography } & 301\end{array}$ 


\section{Acknowledgments}

I would like to thank Richard A. Lee, Jr., Michael Naas, and Peg Birmingham for their comments and guidance in completing this project. I should also thank the Graduate Research Conference Funding Program at DePaul University for monetary support to present early stages of this research and the Doctoral-Undergraduate Opportunities for Scholarship Program at DePaul University for a research grant.

There are too many people to name and too many moments to remember, but my friends and colleagues in the graduate student community of the Department of Philosophy should also be thanked for invaluable conversations that helped shape the research. Four

people in particular should be named, however: Amanda Parris, Will Meyrowitz, Ian Moore, and Gucsal Pursar. In addition, Sarah Prusik's contributions as a DUOS partner were invaluable.

I would especially like to thank Alicen Beheler for her beyond infinite emotional support and challenging conversations over the course of the writing. Maggie Griffith Williams, Jermaine Williams, and Molly Fitzgibbon were also central to my not considering myself demens.

Finally, I would like to thank Tony, Ed, Dox, Noah, Jen, James, Jenny, and Kelly for their sometimes overzealous reminders that taking breaks from writing and research is healthy. 


\section{Abbreviations}

AT René Descartes, Oeuvres de Descartes, ed. Charles Adam and Paul Tannery, 12 vols. (Paris: Librairie Philosophique J. Vrin, 1897-1913). Followed by volume number in Roman numerals.

CED Princess Palatine Elisabeth of Bohemia and René Descartes, The Correspondence between Princess Elisabeth of Bohemia and René Descartes, ed. and tr. Lisa Shapiro (Chicago: The University of Chicago Press, 2007).

CSM René Descartes, The Philosophical Writings of Descartes, tr. John Cottingham, Robert Stoothoff, and Dugald Murdoch, 2 vols., (Cambridge: Cambridge University Press, 1984-1985). Followed by volume number in Roman numerals.

CSM-K René Descartes, The Philosophical Writings of Descartes, tr. John Cottingham, Robert Stoothoff, and Dugald Murdoch, and Anthony Kenny, (Cambridge: Cambridge University Press, 1991).

DCB René Descartes, Descartes' Conversation with Burman, tr. John Cottingham (Oxford: Clarendon Press, 1976).

E René Descartes, Discourse on Method, Optics, Geometry, and Meteorology, tr. Paul J. Olscamp (Indianapolis, IN: Hackett Publishing Company, Inc., 2001).

HR René Descartes, The Philosophical Works of Descartes, tr. Elizabeth S. Haldane and G. R. T. Ross, 2 vols. (Cambridge, University of Cambridge Press: 1985). Followed by volume number in Roman numerals.

LMD Adrien Baillet, The Life of Monsieur Des Cartes, Containing the History of his Philosophy and Works: as also, The most Remarkable Things that befell him during the whole Course of his Life (abridged), tr. S. R. (1693).

TM René Descartes, Treatise of Man, tr. Thomas Steele Hall (Amherst, NY: Prometheus Books, 2003).

VMD Adrien Baillet, La Vie de Monsieur Des-Cartes, 2 vols., (1691). Followed by volume number in Roman numerals. http://princeton.edu/ hos/mike/texts/descartes/world/world.htm, accessed 1/10/2008. 


\section{Introduction}

If there is a standard description of Descartes' method to be found, John Cottingham is one of the most likely sources:

Descartes's method, then, consists in breaking a problem down and taking it back to its simplest essentials, until we arrive at propositions which are simple and selfevident enough to serve as reliable 'principles' or starting points, from which the answers to the questions that perplex us may eventually be deduced. Such eventual results may come only at the end of a long chain of deductive reasoning, but Descartes maintains that our conclusions can enjoy the same certainty and selfevidence as our starting points, provided we proceed slowly and cautiously, step by step, and provided we make sure that each step in our chain of reasoning is transparently clear. ${ }^{1}$

Descartes developed this method in imitation of mathematics, especially geometry and what will become, through Descartes, algebra, where knotty problems are resolved through a process of simplification until the essential points are revealed and the solution clear. One of his major contributions to philosophy is the generalization of this method, known as analytic reduction or analysis, beyond mathematics proper, into all scientific pursuits ("scientific" here being used in the broadest sense so as to include metaphysics).

However, Descartes did not develop this method in a vacuum. It was in explicit distinction from the investigative methods dominant in at least the universities of the time, in particular with what in mathematics is called the synthetic method and that Descartes associates with syllogisms. Whereas a synthesis operates via "assumed abstract objects and statements about them, and, by a series of steps conventionally admitted to be valid, arrived at a desired conclusion," a syllogism's conclusion emerges from previously accepted

\footnotetext{
${ }^{1}$ John Cottingham, The Rationalists (New York: Oxford University Press, 1988), p. 36.
} 
premises. ${ }^{2}$ Such a method is unacceptable for Descartes because he wants to be able to claim that his scientific knowledge is clear and distinct precisely because it does not emerge from assumptions or premises that have not been arrived at from an analytic reduction.

He wants to be able to claim to have shown to himself clear and distinct ideas as concerns the truth of the world. He needs to be able to make such a claim, and thus to be able to show others how they can show such things to themselves, because the world taken as it appears is deceptive or at least dubitable, despite and because he himself came across it by chance and not by method (see CSM I, p. 112; AT VI, p. 3). Descartes begins many of his texts - in particular the Discourse on Method, the Meditations on First Philosophy and the Principles of Philosophy - by saying we should take note of facts such as, at a distance, a square tower can appear round. If the world is sometimes deceptive, it is dubitable, and there would seem to be no escape from this doubt, especially if "All teaching and all learning through discourse proceed from previous knowledge" when this previous knowledge would itself be based on deceptive, dubitable sensation. ${ }^{3}$ Thus, Descartes' search is for a method that will allow for correcting some of the errors involved with synthesis and syllogism.

However, he runs into the problem of justifying this new method. More, the question at hand in much of Descartes' project is how any method is justified. On the one hand, it might appear as though utility could be a satisfactory explanation. On the other, this explanation works on the assumption that a method has already been deployed because, to judge something as useful, a method must have already been used in order for its utility to be discovered. What is at stake in Descartes is how anyone can inaugurate a new method.

\footnotetext{
2 Alexander Jones, "Introduction," in Pappus of Alexandria, Book 7 of the Collection, pt. 1, ed. and tr. Alexander Jones (New York: Springer-Verlag, 1986), p. 66.

3 Aristotle, Posterior Analytics, tr. Hippocrates G. Apostle (Grinnell, IA: The Peripatetic Press, 1981), 71a. See also Aristotle, Physics, 184a-184b.
} 
Inaugurating a method requires a shift in thinking, in the most basic standards of what even constitutes thinking. Thus, it is impossible for Descartes, for the most part and in most of his works, to engage in the syllogistic or synthetic reasoning of the universities of his day. One cannot inaugurate a new method through an old one, at least not when the methods at hand are the fundamental methods for all education. But then how can a new method be inaugurated? Some technique other than that of logic, of proofs, premises, and conclusions, is required. In at least three crucial moments throughout Descartes' career, he has recourse to an interesting choice of technique: the fable. In the beginning of The $W$ orld, or a Treatise on Light, the Discourse, and in a late portrait made of him, Descartes (or a book he holds in the portrait) refers to his work (or to the world itself) as a fable. In the context of the pedagogical reorientation at the heart of the Cartesian project, 'fable' is not just one literary genre among others in that it is a genre with pedagogical intent embedded within it in a way other genres do not necessarily have. It also cannot be forgotten that the fable is a literary genre, and thus a genre of writing associated with the imagination. That Descartes has recourse to an imaginative, literary technique to inaugurate his new method should not be dismissed too easily. Rather than engaging the reader directly in how he can justify his method-an impossible task when the method is at the heart of justification itselfDescartes focuses on how he can get his reader into his method. Doing so is accomplished through the fable, through telling a (mere) story that draws the reader into his way of thinking such that he or she begins thinking along with Descartes, begins deploying this method on his or her own. Thus, utility is not a justification for the method until after the reader has already been immersed within the method. The new method is inaugurated by the imaginative act involved in telling a fable, and this new method becomes the operation of a 
new kind of pedagogy that Descartes is interested in developing-one of a self-instruction

that involves no assumptions (save, of course, that of the fable's story).

\section{Endings and Beginnings}

From beginning to end, then, we can associate Descartes with fable, poetry, fiction, and

imagination, even if he frequently attempts to undermine these associations at the same time.

Thus, I begin at the end: The portrait of Descartes by Jan Baptist Weenix, where Descartes

holds a large book with the words "Mundus EST fabula" seen on the verso page, was

painted between 1647 and 1649, hence between three years and one before his sudden death

in Sweden. Before this, the last time "fable" appears in his published work with anything

close to a positive inflection is in the Discourse on the Method, published in $1637 .{ }^{4}$ In the end,

whether the Weenix portrait constitutes a final positive reference to fables could appear

somewhat debatable. What would become of the firm ground for the existence of the world

\footnotetext{
${ }^{4}$ Readers of the 1647 Louis-Charles d'Albert French translation of the Meditationes de Prima Philosophia or readers of the HR may disagree with this statement, since, in the First Meditation, Descartes writes, in French, "Mais ne leur resistons pas pour le present, \& supposons, en leur faueur, que tout ce qui est dit icy d'vn Dieu soit vne fable" (AT IX, p. 16; my emph), and, in English, "But let us not oppose them [i.e., extreme skeptics] for the present, and grant that all that is here said of a God is a fable," (HR I, p. 147; my emph.). However, this is an instance where the French translation is different from Descartes' original Latin. In the first, 1641, edition of the Meditationes, this sentence reads, "Sed iis non repugnemus, totumque hoc de Deo demus esse fictitium" (AT VII, p. 21). Because he primarily follows the Latin text, John Cottingham translates this sentence as "Let us not argue with them, but grant them that everything said about God is a fiction" (CSM II, p.14; my emph.).

Cottingham explains his preference for the Latin as being because "the French version stays fairly close to the Latin" and is sometimes a paraphrase of or simply clumsier than the Latin, so "There is no good case for giving the French version greater authority than the original Latin, which we know that Descartes himself composed" (ibid., pp. 1 and 2). However, Cottingham also claims that, citing Adrien Baillet's biography, Descartes not only approved d'Albert's translation, but also used it to "retouch his original work"” (VMD II, p. 172; cited in CSM II, p. 1). Because it is unclear whether Descartes ever published a 'retouched' edition of his Meditationes, we are left with a handful of possibilities for this discrepancy between the Latin and the French: (1) D'Albert made the change and Descartes did not notice it; (2) d'Albert made the change and Descartes did not think the two words were different enough for him to ask d'Albert to change it to "fiction"; and (3) d'Albert made the change and Descartes noticed it, approved it as an improvement, and retouched his manuscript to accord with d'Albert. Without knowledge of any publicly available retouched Latin manuscript or a second edition of the Meditationes, deciding between these three options seems impossible.
} 
as laid out in the Meditations, the Replies, the Principles of Philosophy, and so on if the world remains a fable? Perhaps taking the world as a fable is to take it as the pedagogical tool par excellence, since we are to learn from the world and not from Scholasticism or its books. If that were the case, the world would have its rules ready-made for discovery, provided we have habituated ourselves to a more realistic method of engagement with this world and its rules, all of which would have been authored by the omnipotent and omniscient god who does not deceive. This god can still be said not to deceive because the fabular quality of the world would be so only for the purpose of stirring the human mind to engage its rational and therefore uniquely human qualities.

Of course, none of this would explain the fading of the fable from Descartes' favor. The word simply fails to appear in any of his writings composed for publication or more general distribution after the Discourse. More to the point, it seems to have taken on a decidedly negative connotation in at least two letters written after the publication of the Discourse: In one letter, he writes, “As for the likenesses of little dogs, which are said to appear in the urine of those who have been bitten by mad dogs, I must admit that I have always thought it was a fable" (CSM-K, p. 144; AT III, p. 20), while in a letter to Mesland from May, 1645, he writes that, regarding his Principles, “one must either reject everything contained in the last two parts and simply take it as a pure hypothesis or even a fable, or else accept the whole of it" (CSM-K, p. 249; AT IV p. 217).

The following may remain only a hypothesis, but if the fable returned in the Weenix (whether or not "Mundus EST fabula" was Descartes' idea), thereby returning at the end of his life (whether or not Descartes or Weenix knew it was the end), such a return may indicate a return to the beginning of his career, and to beginnings in general. This return to the beginning, as a return to fable positively invoked (if it is invoked positively here) may 
then be seen as the reverse of Descartes' other treatments of the fable, both within given works and through the course or path of his career, treatments that usually operate by beginning with positive invocations that are undermined either simultaneous to or some time after the positive invocation, whether that time is long or not. Here, in the Weenix, right at the very end, he seems to be telling us to return to the beginning, to return to his fables, to return to fables and the related imaginative genres of poetry, fiction, novels, and so on, that always appear, whether they appear explicitly or not, at the beginnings of his works.

Now for the beginning: In the ornately written dedication to his maternal uncle for the announcement of his 1616 law thesis defense, Descartes writes that he first "eagerly desired to drink in the poetical waters, dripping with honey," but soon enough "searched finally with keen application for that most immense ocean of the sciences and from that ocean all the streams flowing most abundantly in different directions." ${ }^{5}$ Referencing Lucretius, Juvenal, and Horace as well as Artemis, Actaeon, and Themis before and after his description of his turn from poetry, he thanks his uncle, René Brochard, for the purity of Brochard's soul "so that you may deign to unite to me the favor and benevolence of so lovable a goddess" as Themis. ${ }^{6}$

Only some of the poetic appeal of these passages can be attributed to "the idea of generosity ... [that] did not altogether lose something of its archaic grandeur" which Marvin

\footnotetext{
${ }^{5}$ René Descartes, "1616 Law Thesis," tr. Holly Johnson and Kurt Smith, http://plato.stanford.edu/archives Lfall2005/entries/descartes-works/tenglish.html, accessed 1/30/2008; http://plato.stanford.edu/entries descartes-works/tlatin.html, accessed 11/1/2010. This is a text that was discovered in 1981, but not made public until 1986 (see http://plato.stanford.edu/entries/descartes-works/history.html, accessed 11/1/2010), which is why it can be found in neither AT nor CSM.

${ }^{6}$ Ibid.
} 
B. Becker finds throughout Descartes' work and in his age generally. ${ }^{7}$ Indeed, as I will show, Descartes' rhetoric, in particular in the beginnings of his works throughout his career, not only undermines his claims of disregarding rhetoric in favor of content strictly understood. ${ }^{8}$ It also shows that the beginnings, the supposedly 'merely' rhetorical beginnings of Descartes' writings repeatedly establish what he cannot establish within the content of his workjustification for the development of method-precisely because they allow him to show (faire voir, montrer, démontrer) the method to his readers.

\section{What Is a Fable?}

This question will be answered in two, interrelated ways. The first way is to address the history of what has come to be called the fable, how it has developed, such that it attained the particular generic qualities associated with it. The second way is to hold the fable up in contradistinction with other, closely related genres or literary forms: the folktale, the fairy tale, and the myth.

\section{A History of the Fable}

The word 'fable' has a history distinct from the genre or form that it signifies insofar as it is drawn from Latin, while "the earliest surviving fable is found in Hesiod (Works and Days 202-

\footnotetext{
${ }^{7}$ Marvin B. Becker, The Emergence of Civil Society in the Eighteenth Century: A Privileged Moment in the History of England, Scotland, and France (Bloomington, IN: Indiana University Press, 1994), p. 16.

${ }^{8}$ For instance, in the Discourse on the Method: "Those with the strongest reasoning and the most skill at ordering their thoughts so as to make them clear and intelligible are always the most persuasive" (CSM I, p. 114; AT VI, p. 7).
} 
212)."' 'Fable' comes from Latin's fabula, which can refer to a narrative account or even a conversation as much as it can refer to the formal genre of the fable, and is itself drawn from fari, to be spoken or to be said, a verb which in turn is related to fatus, the word for 'word' or 'a saying'. ${ }^{10}$ Only by this last word does a more explicit connection to the origins of the literary or generic form come into play. The Greeks did not refer to what we call fables as fables, obviously. Rather, a fable was referred to as either a logos or a mythos, depending on the era in ancient Greek history — in the Archaic and Classical eras, it was logos, and mythos from the Hellenistic era on. ${ }^{11}$ Thus, insofar as a mythos means "word," "speech," or "story", and logos means "word" or "narrative" (along with so many other things), fabula is an adequate translation of the literary form, though it does remain a translation from Greek to Latin. $^{12}$

It is out of the fact of this translation, especially as it relates to Aesop, however, that this history of the form will begin. As Aristotle points out, Aesop's fables fall under the rhetorical category of exempla. ${ }^{13}$ Aesop, who seems to have been a slave captured in war, was a personal clerk or secretary who worked as an agent for his owners, told many of his fables, some of which are clearly borrowed from ancient India and/or Egypt, as illustrative stories on behalf of these owners, in the manner of a lawyer or diplomat, many of which were "little animal stories in discussion and negotiation and [he] scor[ed] devastatingly clever points with

\footnotetext{
${ }^{9}$ Niklas Holzberg, The Ancient Fable: An Introduction, tr. Christine Jackson-Holzberg (Bloomington, IN: Indiana University Press, 2002), p. 13

${ }^{10}$ See Charlton T. Lewis and Charles Short, A Latin Dictionary (1879), s.vv., "fabula," "fari," and "fatus."

${ }^{11}$ See Robert Temple, Introduction to Aesop, The Complete Fables, tr. Olivia and Robert Temple (New York: Penguin Books, 1998), p. xiv.

${ }^{12}$ See Henry George Liddell and Robert Scott, A Greek-English Lexicon, revised and augmented by Sir Henry Stuart Jones and Roderick McKenzie (Oxford: Clarendon Press, 1940), s.vv., "mythos" and "logos."

13 See Aristotle, Rhetoric, 1393a-1394a.
} 
them." ${ }^{\prime 14}$ However, if there is one feature that is retrospectively attached to fables in addition to their being animal stories, it is the moral. Because Aesop used these fables as rhetorical techniques, though, he did not always deploy morals since the context did not always require their articulation. Instead, morals "were added by later collectors" and "intended as guides to someone thumbing through the collection looking for an apt story for a particular use," even if some of them can be considered fairly sophisticated. ${ }^{15}$ Because of these contingencies concerning the moral, it is difficult to define the form of fable as it might currently be understood merely from out of the Aesopian tradition. Holzberg takes this point further, noting that "Even in the archaic period a fable could consist not only of the short narrative form that defines it today-a text culminating in a moral expressed by one of the two characters involved ... - it could also be an explanatory legend ... or a 'vying match' between two rivals." 16 addition, he shows that the fable need not be an animal story in the ancient texts, but can involve humans and animals, humans and inanimate objects, humans alone, gods and animals, gods alone, or personifications. As a result, Holzberg is resigned to the ancient definition of fables: “"a fictional narrative which portrays a truth,' i.e., from which can be gathered a truth applicable in real life," this last point being the moral. ${ }^{17}$ Avianus, the Roman who rewrote many of Aesop's fables in Latin, based on Babrius' Greek collection, and whose rewriting became the basis for much of the medieval collections of Aesop, wanted "to make his poems fulfill even more proficiently the requirement this literary form is expected to meet. What must he do? He must ensure that his fables combine fictional

\footnotetext{
14 Temple, Introduction to Aesop, The Complete Fables, p. x.

15 Ibid., p. xv.

${ }^{16}$ Holzberg, The Ancient Fable, p. 19.

${ }^{17}$ Ibid., p. 20.
} 
narrative with moral edification." ${ }^{\prime 18}$ Avianus does not include specific morals to his fables, even if Babrius does. That the truth is gathered, however, reiterates that the moral was not necessarily, in the ancient world, a formal aspect of the fable. What is consistent in what will come to be called fables, however, is their attachment to both rhetoric and pedagogy. The collections of Aesop and others were detached from their original, exemplary context and given morals in order for other rhetoricians to be able to find an appropriate fable quickly. In addition, since the study of rhetoric was necessary for an elite education, fables were "the first literary writings with which students had to acquaint themselves." ${ }^{19}$ The connection to the formally written moral is a result of this detachment from an original context, and not necessarily associated with the literary form, qua rhetoric or qua literature, as understood by Aesop or even Avianus.

Though Avianus does not include morals in his fables, a second surviving source for the medieval understanding of the Aesopian fable, the so-called Romulus collection, considered to be a collection by Phaedrus, which does contain morals. Distinct from Aesop, another tradition which informs the medieval understanding of fables in general is the Panchatantra, "Indian fables which entered Persia in the sixth century ..., originally written in Persian, and translated into Arabic in the eighth century. The work was essentially a frame story into which various animal fables were fitted." ${ }^{, 20}$ It appears that, in this era, morals begin to be almost necessarily associated with the form, insofar as the fables of both Marie de

\footnotetext{
${ }^{18}$ Ibid., p. 68.

${ }^{19}$ Ibid., p. 29.

${ }^{20}$ Moses Hadas, Introduction to Berechiah na-Hakdan, Fables of a Jewish Aesop, tr. Moses Hadan (Boston: Nonpareil Books, 2001), p. xv.
} 
France and Berechiah na-Hakdan all have morals attached to them. ${ }^{21}$ In addition, it is in this era, especially in France with its folklore tradition of the Roman de Renard, that fables begin to be associated with animal stories, which is perhaps one reason why both the na-Hakdan and the de France fables are known as 'fox stories'. ${ }^{22}$ However, insofar as the Renard stories have "anti-establishment attitudes," are "anything but pedantic," and have "no overt moral purpose," they should be distinguished from fables proper, despite their similarities. ${ }^{23}$

With that, we begin to enter into the period that Descartes knew. Jean de la Fontaine, the great fabulist who was approximately Descartes' contemporary, "plays with this tradition" that fables always have morals: He places the moral in either the beginning or the end, or fails to include one at all. ${ }^{24}$ The actual fable of Bernard Mandeville's The Fable of the Bees, titled "The Grumbling Hive," places its moral at the end.$^{25}$ However, regardless of the placement or non-inclusion of a moral, according to René Le Bossu, "the Fable is a discourse invented in order to form morals by disguised instructions under the allegories of an action." ${ }^{26}$ Le Bossu divides the fable into three species, (1) those concerning humans and gods, which he calls raissonables; (2) those concerning animals and human morals, which he calls moralae; and (3) those which mix different kinds of personages together, which he calls mixtes. Following Aristotle, he explains that a fable is composed of two things, the truth that

\footnotetext{
21 See Berechiah na-Hakdan, Fables of a Jewish Aesop, and Marie de France, The Fables of Marie de France: An English Translation, tr. Mary Lou Martin (Birmingham, AL: Summa Publications, Inc., 1984).

22 See Louis Kukenheim and Henri Roussel, Guide de la Litterature Française du Moyen Age, 3 ed., (Leiden: Universitaire Pers Leiden, 1963), pp. 59-62.

23 Patricia Terry, Introduction to Renard the Fox, tr. Patricia Terry (Berkeley, CA: University of California Press, p. 1992), p. 3.

${ }^{24}$ Stanley Applebaum, Introduction to Jean de la Fontaine, Selected Fables/Fables Choisies: A Dual-Language Book, ed. tr. Stanley Applebaum (Mineola, NY: Dover Publications, Inc., 1997), p. xiv.

${ }^{25}$ See Bernard Mandeville, The Fable of the Bees (New York: Penguin Books, 1970), p. 76.

${ }^{26}$ René Le Bossu, Traité du Poёme Epique (1708), p. 31; my trans.
} 
is the foundation of the fable and the fiction that disguises the truth and gives the fable its particular form. What is more, it is necessary for the truth to be hidden because "this is the point of the Moral that the Author wants to teach." 27

What remains consistent in the history of the fable, from its earliest formation and appearances in ancient India and Egypt, through Greece and Rome, into medieval Europe, and up to the early modern period, is its explicit connection to rhetoric and pedagogy. It is a form that need not be associated with animal stories, though it frequently is, but that, once it has been detached from its explicitly diplomatic and legal origins in the Greek context, becomes associated with both rhetoric in general as well as the pedagogy of rhetoric. As the ancient world fades, the didactic quality in the pedagogy of rhetoric —a result of detaching fables from their original contexts and placing them in collections, with morals attached to ease a rhetorician's search—begins to attach itself more and more to the specific form of the fable. The fable also begins to be associated with folklore in that both frequently involve animal stories. However, the moral, and therefore the pedagogical element, is what distinguishes the fable from at least certain folklore. By the early modern period, a moral, whether explicit or implicit, is a requirement in literary theory for a story to be considered a fable. The moral is, indeed, the purpose of a fable. Thus, the fable becomes explicitly associated with education and pedagogy in general. A fable always teaches.

Fable contra Folktale, Fairy Tale, and Myth

The above historical tracing of the fable was necessary as a precursor to this distinction between fable and other, related literary forms. This distinction is necessary because there

27 Ibid., p. 35; my trans. 
has been, at times, a confusion of terms in the history of literary history. Tracing the history of the fable as done above was in approximate harmony with Descartes' use of the word and deployment of the concept, at least when he does so positively. The distinction that will be presented here, against the folktale, fairy tale, or myth, will help clarify what is meant by the fable, at least in the most positive Cartesian use, and from sources other than Descartes himself.

According to Ruth B. Bottigheimer, the folktale must itself be separated from the fairy tale, even though they have been frequently associated, because "Folk tales differ from fairy tales in their structure, their cast of characters, their plot trajectories, and their age."28 On her reading, folktales are born from and reflect the world of peasants, and so have characters such as husbands, wives, thieves, and sometimes doctors, lawyers, and priests. Their plots tend to revolve around marital strife or theft of property or a spouse, and do not tend to have happy endings. Insofar as this can be associated with the folk revival in Europe from the middle of the eighteenth through the early twentieth centuries, this seems fairly familiar. The folktale, especially as it can be connected to the rise of the nation-state and stricter political and linguistic boundaries, even if it emerged from a pan-European interest, can thus be connected to foundational myths and psychological avatars. This position is the one taken by Bruno Bettelheim, Jack Zipes, and Joseph Campbell, though they, unsuccessfully for Bottigheimer, refer to fairy tales in this way, too. ${ }^{29}$ For two reasons, then, the folktale must be separated from the fable: First, because it emerges from out of a peasant

${ }^{28}$ Ruth B. Bottigheimer, Fairy Tales: A New History (Albany, NY: SUNY Press, 2009), p. 4.

${ }^{29}$ See, for instance, Bruno Bettelheim, The Uses of Enchantment: The Meaning and Importance of Fairy Tales (New York: Vintage Books, 2010), pp. 27-28; Jack Zipes, Fairy Tale as Myth/Myth as Fairy Tale (Lexington, KY: The University Press of Kentucky, 1994), pp. 5-6; and Joseph Campbell, "Folklorist Commentary," in Jacob Grimm and Wilhelm Grimm, The Complete Grimm's Fairy Tales, tr. Margaret Hunt and James Stern (New York: Pantheon Books, 1972), p. 864. For Bottigheimer's critique of Bettelheim and Zipes, see Bottigheimer, Fairy Tales, pp. 23. 
culture, regardless of any foundational element it may have gained over time, the folktale attains almost none of the significance for rhetoric that the fable has. A folktale is a story of and by a peasant class (albeit one that was disappearing over the course of its literary revival), whereas a fable is a story with an explicitly rhetorical history, and is therefore of and by at least a certain level of education. Second, "the fable always explicitly states a moral truth," whereas in the folktale, "It is up to us whether we wish to make any application to our life. ${ }^{30}$ Especially given the lack of happy endings, this lack of moral truths would separate the folktale from the fable insofar as the former could potentially even be anti-moral.

Bottigheimer also argues against the distinction between oral and literary fairy tales, where the oral tradition would be the 'pure' transmission of the stories, which were then reworked by literary scholars such as the Grimms, Charles Perrault, and others: "the existence of oral fairy tales ... among any folk before the nineteenth century cannot be demonstrated." 31 Instead, for example, "Perrault got most of his tales from Italian books," and then censored them "for the taste for genteel seemliness in 1690s Paris." 32 What most specifically marks fairy tales for her, then, is their plots — of which there are two types: restoration (especially to royal origins) and rise (from poverty to wealth) — and their brevity, as compared to the medieval romances and histories from which many fairy tales were adapted as the rise of the printing press made possible "books prepared for a popular audience." 33 Thus, while it could appear as though the fable and the fairy tale are linked insofar as they are associated a little more closely with an educated class than the folktale, Bettelheim's claim that there is no moral to fairy tales distinguishes them from fables as well,

\footnotetext{
${ }^{30}$ Bettelheim, The Uses of Enchantment, pp. 42-43.

${ }^{31}$ Bottigheimer, Fairy Tales, p. 7.

32 Ibid., p. 57.

33 Ibid., p. 9.
} 
unless the happy endings associated with both types of fairy tale plot can be considered morals or if Perrault's censorship could be considered as such (Bottigheimer makes no such claim). Either way, such stand-ins for a fable's moral (even if the moral is not explicitly stated) are a far cry from the explicitly didactic and/or pedagogical element to the fable.

Finally, then, myth. Fables have frequently been associated or even conflated with myths, though incorrectly insofar as the definition of fable at hand goes. ${ }^{34}$ This association is understandable, of course, given the post-Classical Greek word for collections of Aesop, but it remains incorrect. Before distinguishing myths from fables, however, myths first need to be distinguished from holy books. To follow Blumenberg, "myths are stories that are distinguished by a high degree of constancy in their narrative core and by an equally pronounced capacity for marginal variation," where their constancy allows for recognition while their variation allows for individual variation. ${ }^{35}$ The Bible was thus unable to stimulate "the imagination and the formal discipline of the European literatures" in the way that the Greek myths were able to do because the Bible is a fixed text and "images that are fixed in written form . . . imply a sort of verbal "prohibition of images."'36 There are, however, different kinds of myth. A unit myth is similar to a holy text insofar as the former "resists modification." ${ }^{, 37}$ Indeed, this resistance leads to an exposure of a "fundamental pattern," which can itself become "overtaxed." ${ }^{38}$ In addition, and more flexibly, there are radical,

\footnotetext{
${ }^{34}$ See, for instance, Bernard le Bovier de Fontenelle, "De l'origine des fables," http://www.eliohs.unifi.it/testi L700/fontenelle/fables.htm, accessed 5/28/2013, and Thomas Bulfinch, Bulfinch's Mythology: The Age of Fable (1855).

${ }^{35}$ Hans Blumenberg, Work on Myth, tr. Robert M. Wallace (Cambridge, MA: The MIT Press, 1985), p. 34.

36 Ibid., p. 216.

${ }^{37}$ Ibid., p. 150.

${ }^{38}$ Ibid.
} 
fundamental, and original myths. A radical myth can be understood as the most basic elements of a myth's constancy, while a fundamental myth is "what remains visible in the end, what was able to satisfy the receptions and expectations" in terms of historical and literary success, and the original myth would seem to be that which was first told. ${ }^{39}$ Beyond the ancient or at least Archaic worlds, however, there are art myths and final myths. Art myths show "the characteristics of fundamental myths" insofar as art myths try to bring about the same effect of a fundamental myth via "the elaboration of elementary fundamental patterns." 40 The final myth develops from out of "the absolutism of reality," where there is a final, mythical (and thereby constant and varying) attempt to exhaust the form of myth. ${ }^{41}$ For Blumenberg, this is the hallmark and indeed "the fundamental myth of German Idealism," even modernity more generally. ${ }^{42}$ I will return to this point below, but for now let it stand as an overarching claim, one that can link the myth with the folktale (even though Bettelheim distinguishes them by claiming that "myths project an ideal personality acting on the basis of superego demands, while [folktales] depict an ego integration which allows for appropriate satisfaction of id desires, ${ }^{43}$ which could explain the crucial role of law, divine or otherwise, in so many Greek myths as opposed to the illicit actions related in folktales, even if myths do not purport to contain or institutionalize "what amount to 'eternal facts"'). ${ }^{44}$ Nonetheless, Blumenberg distinguishes myth from fable in that Aesop represents "a late transfer of the

\footnotetext{
${ }^{39}$ Ibid., p. 175.

${ }^{40}$ Ibid., p. 176.

${ }^{41}$ Ibid., p. 266.

42 Ibid.

${ }^{43}$ Bettelheim, The Uses of Enchantment, p. 41.

${ }^{44}$ Blumenberg, Work on Myth, p. 132.
} 
anthropomorphic world of the gods back onto their preliminary theriomorphic stages," with anthropomorphism being a crucial element in myth and epic because it forces the gods to have motives. ${ }^{45}$ However, for Blumenberg, the animals in Aesop are reflections of human beings, even if they might also be "old animal gods in whom the mythical characteristics had been further humanized, but where 'man,' instead of being made heroic as in the epics, was moved forward to his bourgeois condition." 46 Bettelheim distinguishes fable from myth in that the former is "a cautionary tale ... which, by arousing anxiety, prevent us from acting in ways which are damaging to us." ${ }^{47}$ What unites the various types of myth in Blumenberg, whether exhausted or fundamental, and this includes the final myth, and what would unite Blumenberg and Bettelheim's concepts of myth, is the relationship to law in the broadest sense. For Blumenberg, myth emerges from anthropomorphizing the animal gods such that they have motivations, such that motive exists in the world, and a mythical hero engages the gods on this plane. For Bettelheim, a myth, whether involving anthropomorphized animal gods or heroes, is a projection of the superego making a demand. For Blumenberg, a fable is an animalization of the bourgeois, and thus already law-obedient, human. For Bettelheim, a fable does not portray the superego as an ideal person, but as a law or moral as such, before or after provoking the anxieties of the ego before that superego. Thus, a fable is not a myth insofar as the latter is associated with the foundational moments of law-giving, or rulegeneration. The heroes and gods do not of themselves necessarily obey the laws and rules which they give or generate, but the characters in fables are punished or rewarded for obedience or disobedience to laws and rules and morals which are already in operation. It

\footnotetext{
${ }^{45}$ Ibid.

${ }^{46}$ Ibid.

${ }^{47}$ Bettelheim, The Uses of Enchantment, p. 38.
} 
would be for this reason that fables are now (or at least within the framework of modernity) so frequently associated with rhetoric and pedagogy, while the myths are associated with art and literature as highly cultured institutions, institutions claim to interrogate their own foundations as well as those of society — fables are more ready-made for the requirements of rhetoric and pedagogy.

Thus, a fable is not a folktale because it is a literary form associated with some degree of education and because it is always in pursuit of a moral. A fable is not a fairy tale because fairy tales frequently remain 'just stories', without moral edification attached to them. And a fable is not a myth because the fable's morals are established prior to its telling, hence their utility for rhetorical deployment, while myths are in many ways the stories of what and who should be obeyed, hence their utility for art. As I hope to show, the Cartesian fable does not always adhere very well to the categorizations and distinctions of 'fable' as laid out here, but there are reasons for this. Nevertheless, Descartes does deploy the concept at crucial moments and what has been discussed of its history and distinctions from other forms are more or less what informed Descartes' understanding of the word. Why Descartes would use this particular word is the question for the next section.

\section{Why Fable in Descartes?}

The confusion and conflation of the fable with other literary forms notwithstanding, the question in the title of this section has two meanings, but both will be answered with the same approach. The two meanings of this title are: (1) Why does Descartes turn to fables as the literary reference for his philosophy at certain moments in his career? (2) Why is it an 
interesting question to ask after the fable in Descartes? Both these questions need to be addressed from a historical register.

If his status as the founder of modernity is to be taken at all seriously, Descartes is a transitional figure. He emerges at the end of the Renaissance, at the height of the Baroque, or at the beginning or modernity, depending on one's perspective on the seventeenth century. The story is familiar: Aristotelian explanations for physical phenomena are becoming difficult to sustain in the face of various discoveries, particularly in astronomy and mathematics but hardly these alone, leading to-in tandem with the Protestant Reformation, the Church's Counterreformation, and the beginnings of the nation-state and colonialismdeeper questioning of the metaphysical foundations for physics as well as for ethics and politics. It is, in short, a period when many Europeans are beginning to question how and why they learn what they learn. Because the status and meaning of education itself is in flux, the fable is a perfectly understandable literary form to which to appeal in philosophicoscientific essays. The appeal to the fable is not an appeal to a set of morals or laws that already exist and merely need to be articulated, especially for a young and/or undereducated audience. Rather, the appeal to the fable in Descartes is an appeal to the form as pedagogical, as a literary form explicitly associated with education. Yet Descartes is not laying out myths proper in these moments because he is not merely giving or generating the laws or rules, especially in the fable on physics. Something more difficult to pin down is at play in Descartes' fables. And, because the Cartesian fable itself is difficult to place into an isolated literary category, it needs to be understood in an expansive fashion, even if it still differentiates itself from other forms at times.

Perhaps what will be most helpful here will to be to compare these claims about Descartes with two other periods in the history of Western philosophy. The first of these, 
the nineteenth century, is a period where fable takes on a denigrated status in comparison to other literary and art forms. At least part of the reason for this denigration is that, after Kant and the scientism that arises from out of his transcendental revolution, the how and the why of learning again becomes relatively settled, especially in comparison to the first half of the seventeenth century. Thus fables can only be for children, fools, or possibly satirists, whereas myth is for artists and other geniuses. The second period in philosophical history with which to compare Descartes' time is the twentieth century. In this period, a resurgence of interest in the fable as a philosophical question returns, though in a different fashion from the interest found in the seventeenth century.

\section{Nineteenth Century}

Periodization in the history of philosophy is always a risky if not an impossible gesture. However, in certain eras, certain questions and concerns become more relevant, others less so, for a variety of interrelated reasons which can probably only very rarely be fully elaborated. In the nineteenth century, there is a consistent desire to categorize and qualify that did not exist to the same degree in the seventeenth or eighteenth centuries. This being an era of rising power within the industrial class; the upheavals of the Industrial Revolution and its concomitant communistic revolutionary moments, as well as increasing literacy, especially among women, and the 'dangers' of the romantic novel that came along with it, a concern for what qualified as 'real' or 'true' or 'pure' truth and/or art also developed, and philosophy often took up the mantle of securing the differences between the high-, the low-, and the middlebrow. All of this is, of course, occurring at the same time that science and scientism continue to rise, with evolution, scientific explanations to defend slavery, Marxist 
and utilitarian economics, and the explosions of electromagnetism opening up significant claims to well-secured truths. And it is in this century that the fable becomes more consistently associated with mere children's stories, not the stuff of serious art for people of the serious arts and sciences.

At least one of the most famous border agents in nineteenth-century philosophy would be Hegel, as the opening words of his lectures on aesthetics proclaim: "These lectures are devoted to Aesthetics. Their topic is the spacious realm of the beautiful; more precisely, their province is art, or, rather, fine art." ${ }^{48}$ With this categorization in mind, Hegel places the fable, in particular the Aesopian fable, as emerging just barely out of the religious interpretation of natural events and allowing for these events, especially the natural activities of animals who have similar natural drives to humans, to be represented such that ethical maxims may be extracted. There are, then, three requirements for the fable: (1) "the specific case which is to supply the so-called moral shall not be merely fabricated, and especially that it shall not be fabricated in a way contradicting similar phenomena actually existent in nature," (2) "the narrative must report the case not in its universality . . . but according to its concrete individuality and as an actual event," (3) "the maximum of naïveté, because the aim of teaching and consequently on general and useful meanings appears only as something arising later and not as what was intended from the beginning." ${ }^{.49}$ It is the third requirement, the naïveté that allows the explicitly pedagogical element of a fable to emerge, regardless of whether it appears intended from the beginning, that places the fable in a lower category of art for Hegel because "from every genuine work of art a good moral may be drawn, yet of

\footnotetext{
${ }^{48}$ G. W. F. Hegel, Aesthetics: Lectures on Fine Art, tr. T. M. Knox, vol. 1 (Oxford: Clarendon Press, 1975), p. 1.

${ }^{49}$ Ibid., p. 385.
} 
course all depends on the interpretation and on who draws the moral." ${ }^{50}$ In a footnote to this sentence, he clarifies that the better character someone has, the more moral the interpretation of a genuine work of art will be. That a fable has a moral, that it exists to instruct, means that "the universal nature of the content represented is supposed to emerge and be explained directly and explicitly as an abstract proposition, prosaic reflection, or general doctrine," and this is a distortion of the work of art as a work of art because the concrete material of the work itself, i.e., the story told, becomes "a useless appendage, a veil and a pure appearance" to the universal nature of the moral. ${ }^{51}$ Thus, the fable is a merely instructive form of art, one that can form the character of someone such that he or she, later, on encountering a genuine work of art, can interpret it morally. The fable is for children, not for thoughtful and sensitive adults.

In addition, at the other end of the nineteenth century, there is Nietzsche. It is with a similar disdain for the explicitly pedagogical quality of the fable that he rails against it, and against Socrates and Plato, in The Birth of Tragedy: "We know the only kind of poetry [Socrates] comprehended: the Aesopian fable." ${ }^{" 52}$ When Socrates and/or Plato themselves rail against tragedy, it is of course because this art form belongs only to imitation and flattery. The Socratic-Platonic rescue in contemporary arts is found in "the novel-which may be described as an infinitely enhanced Aesopian fable, in which poetry holds the same rank in relation to dialectical philosophy as this same philosophy held for centuries in relation to theology: namely, the rank of ancilla." ${ }^{, 53}$ Thus, the fable (and, in the nineteenth century, the

\footnotetext{
${ }^{50}$ Ibid., p. 52.

51 Ibid., p. 51.

${ }^{52}$ Friedrich Nietzsche, The Birth of Tragedy, or: Hellenism and Pessimism, in Basic Writings of Nietzsche, tr. and ed. Walter Kaufmann (New York: The Modern Library, 2000), p. 89.

${ }^{53}$ Ibid., p. 91.
} 
novel) is a handmaiden to philosophy. It is a didactic art form that has no internal purpose of its own. It serves the Apollinian tendency over the Dionysian. It is perhaps in this way that the true world become fable (Fabel) should be understood, where the abolishing of the true and apparent worlds once the true world becomes useless makes the true world a handmaiden to the Nietzschean overturning of Socrates-Plato, a handmaiden to the Dionysian/Anti-Christian overturning of the Apollinian/Pauline. ${ }^{54}$ The true world, as fabular, would teach a new logic or a new song of logic where "art is even a necessary correlative of, and supplement for science. ${ }^{, 55}$ Now, insofar as the overturning of the Apollinian would transform the fable, Nietzsche's critiques of the fable form might no longer stand. However, insofar as that overturning has not happened as yet, the fable remains criticized as a didactic handmaiden to philosophy. It teaches lessons, not very artfully, to children and those who are not very thoughtful.

Such is, more or less, the status of the fable in the nineteenth century. It is a low art form, barely even art perhaps, and generally useful only as the assistant to some other, higher, usually pedagogical, purpose. But modernity had had two hundred years to establish itself by this time, and had done so rather successfully, even if this success also set off a wave of nostalgia for simpler, more 'natural' times such that, as Blumenberg notes with the "fundamental myth of German Idealism," there are frequent calls for some kind of return, even if transformed, to myth and mythology (see, for instance, "Das älteste Systemprogramm des deutschen Idealismus"). The low status of the fable is understandable in this environment. As the handmaiden to, if neither specifically science nor philosophy, at least Wissenschaft, it is something merely pedagogical, and only for those who are incapable, if

\footnotetext{
${ }^{54}$ See Friedrich Nietzsche, Twilight of the Idols, or, How to Philosophize with a Hammer, in Twilight of the Idols and The Anti-Christ, R. J. Hollingdale (London: Penguin Books, 2003), pp. 50-51.

55 Nietzsche, The Birth of Tragedy, p. 93.
} 
only for the time being, of thinking for themselves. As pedagogical, it is not for those who have already been through the process of learning how and why to learn, even if those same people may question the how, the why, and the what of that education.

\section{Twentieth Century}

Like Descartes, like all great thinkers, Nietzsche is a transitional figure. He marks the end of the nineteenth as much as the beginning of the twentieth century. It is for this reason that Philippe Lacoue-Labarthe is able to look at the same selections in The Birth of Tragedy and Twilight of the Idols examined above, in an essay titled "The Fable." What he finds in the section on how the world became a fable, however, is not "'naïvely' anti-Platonic," but rather that "the world becomes a fable again because it already was one; or, to be more precise, because the discourse that constituted it as such was already a fable." ${ }^{, 56}$ It is this observation on Nietzsche's part, on which Lacoue-Labarthe expands, which both opens onto a significant distinction between the nineteenth and twentieth centuries as to the question of fable, and which allows for the blurring of lines of conceptual distinction. That is, in the twentieth century, there is a return to the question of the fable in general, or at least an attentiveness to the fabular and/or fictional qualities at the heart of the project of establishing and established knowledge which much of the nineteenth century, with its faith in mechanical and/or technological progress and scientism in general (even in and even through the face of Romanticism's nostalgias), is unwilling or incapable of engaging. When this attentiveness is born, the hierarchy of literary categories begins to blur because what had appeared as adult forms of genius built on a strong foundation of myth begin to look more

${ }^{56}$ Philippe Lacoue-Labarthe, “The Fable," tr. Hugh J. Silverman, in The Subject of Philosophy, ed. Thomas Trezise (Minneapolis, MN: University of Minnesota Press, 1993), pp. 5 and 6. 
fabular and novelistic, as though perhaps for children and the bourgeoisie, simultaneous to the rise of the conceptualization of the novel as itself capable of the mythic. Thus, LacoueLabarthe, among others, is able to link fable and myth while still distinguishing them from logos, which is the center of the discourse on truth.

It is for this reason that two thinkers at the beginning of the century as different as Hans Vaihinger and Martin Heidegger can turn their foci in different ways to fictionality or fabularity. The neo-Kantian Vaihinger writes that there is a fictive activity in logic insofar as there is a "production and use of logical methods, which, with the help of accessory concepts—-where the improbability of any corresponding objective is fairly obvious—seek to attain the objects of thought." 57 He means by this that logic introduces the "hybrid and ambiguous thought-structures" of fiction when it cannot attain an object directly. ${ }^{58}$ Meanwhile, the phenomenologist Heidegger focuses on a fable (Fabel) by the Roman author Hyginus to show how "Dasein's interpretation of itself as 'care' has been embedded." 59 This fable takes on more of the qualities of what has here been considered myth since it is the story of a personified Care forming human beings from out of the earth and the gods naming them after the source of their production (bumus for 'earth' and homo for 'human'). However, in that Heidegger understands this fable to be a "pre-ontological document" and an "ontical interpretation," it can thus be read as operating according to an understanding of the being of human beings as ontologically enmeshed with care, an understanding which signifies what is necessarily more originary than the ontical interpretation even if understood

\footnotetext{
${ }^{57}$ Hans Vaihinger, The Philosophy of 'As If': A System of the Theoretical, Practical and Religious Fictions of Mankind, tr. C. K. Ogden (Mansfield Centre, CT: Martino Publishing, 2009), p. 12.

${ }^{58}$ Ibid., p. 13.

${ }^{59}$ Martin Heidegger, Being and Time, tr. John Macquarrie and Edward Robinson (Malden, MA: Blackwell Publishing, Ltd., 1962), p. 242.
} 
as such chronologically later. ${ }^{60}$ To the extent that this is so, this pre-ontological document can still be understood as a fable because it is following out a rule or law of being that has already been established. In both Vaihinger and Heidegger, then, there is a turn or return to the fabular, to the fictions or stories told to make sense of the world. In this return to the fable or fabular, strict categorical hierarchies are no longer as relevant and the categories themselves are justifiably blurred insofar as what is at stake is the relationship of the fictional or fabular to truth.

However, this is not to say that categories are utterly useless. They can be profitable, even if for the purpose of undermining their justification. Thus, one of the most famous such smugglers in twentieth-century philosophy would be Derrida, for whom 'genre' is an "enigma." ${ }^{11}$ On reading Francis Ponge's poem, "Fable," he indicates that it is "constructed like a fable right through to its concluding 'moral'," but that this particular fable reverses the traditional relationship between tale and moral since "this 'moral' is the only element that is explicitly narrative." 62 In doing so, "the performance of the 'Fable' respects the rules [for the genre], but does so with a strange move .... This move consists in defying and exhibiting the precarious structure of these rules, even while respecting them, and through the mark of respect that it invents." ${ }^{63}$ Here, then, in the twentieth century, in the era of turning back to reexamine the foundations of why and how what is learned, those foundations are not only seen to be fabulated or fictive, but are also transformed from being merely foundational to

\footnotetext{
${ }^{60}$ Ibid., p. 243.

${ }^{61}$ Jacques Derrida, "The Law of Genre," tr. Avita Ronell, in Acts of Literature, ed. Derek Attridge (New York: Routledge, 1992), p. 224.

${ }^{62}$ Jacques Derrida, "Psyche: Invention of the Other," tr. Catherine Porter, in Psyche: Inventions of the Other, vol. 1, ed. Peggy Kamuf and Elizabeth Rottenberg (Stanford, CA: Stanford University Press, 2007), pp. 8 and 15.

${ }^{63}$ Ibid., p. 44.
} 
being, in addition, already embedded with the rules or laws of categorizations that are simultaneously part of the heritage of the very turning back.

Again, it is dangerous to engage in periodization or epochalization. Such activities always open the door to lazy assumptions that allow one not to engage in the particularities of a given moment or a given text. Nonetheless, there are certain themes and questions that can unify a period or an epoch. In the nineteenth century, hierarchies and categories are among those themes and questions. In the twentieth century, a reexamination of the foundations for those hierarchies and categories becomes a theme and question. In this reexamination, achieved through literature as well as philosophy, "new modes of fiction were admitted into the literary work" such that "it again becomes possible to read, according to their own architecture, texts that ... had become excluded from literature." ${ }^{64}$ The fable is one of those modes.

$$
\text { Again, Why? }
$$

The question of why we should turn to the fable in Descartes in particular has yet to be directly addressed. That the seventeenth century is a transitional period is not enoughevery period is always transitional, which is the risk of periodization even if it can be a helpful technique of historical analysis. Nonetheless, because it was "the dawn of what we might call technoscientific and philosophical 'modernity'," the seventeenth century is not fully immersed in technoscience or modern philosophy. ${ }^{65}$ In addition, the eighteenth century

${ }^{64}$ Michel Foucault, "Behind the Fable," tr. Robert Hurley, in Aesthetics, Method, and Epistemology: Essential Works of Foucault, 1954-1984, vol. 2, ed. James D. Faubion (New York: The New Press, 1998), p. 138.

${ }^{65}$ Derrida, "Psyche," p. 29; my emph. 
can be seen on the whole as a transition from the earliest stages of modernity as found in the seventeenth century, where the how and the why of what is to be learned is in flux because it is a dawn, to the nineteenth, where this how and why and what have become settled. Thus, in discussing Pierre-Daniel Huet and Jean-Pierre de Crousaz, Geoffrey Bennington can write that "with the fable, fiction is introduced not only into the content of teaching, but into the scene of education itself," a scene which is "determined by a 'natural' adversion in the pupil to that scene itself," which thus demands, from a pedagogue's perspective, the supplement of the fiction to demonstrate the moral and, form a student's perspective, the supplement of the moral to justify the story. ${ }^{66}$ However, later in the century, Rousseau exposes this defense as problematic and "would like the guiding maxim of the fable always to be 'suppléée' by the reader," even if this opens the risk that a student will 'misread' the moral, because "the master here is the final controlling instance of reading: he has read the whole text before and knows what it means; ... the possibility of 'play' . . . is rigorously controlled by the master's control over the reader." ${ }^{67}$ To use Rousseau's own words: "Thus, from a fact he draws a maxim; and by means of the fable the experience he would soon have forgotten is imprinted on his judgment. There is no moral knowledge which cannot be acquired by another's or one's own experience. In the cases where this experience is dangerous, instead of having it oneself, one draws one's lesson from the story." ${ }^{98}$ This process of dislodging explicit morals from fables, of seeing morals, explicit or otherwise, as problematic for education because not helpful for the student's self-education continues throughout the century until it reaches its culmination with Kant claiming that "beautiful objects of nature or of art are often called by

${ }^{66}$ Geoffrey Bennington, Sententiousness and the Novel: Laying Down the Law in Eighteenth-Century French Fiction (2008), pp. 85 and 84.

${ }^{67}$ Ibid., pp. 88 and 90.

${ }^{68}$ Jean-Jacques Rousseau, Émile, or On Education, tr. Alan Bloom (New York: Basic Books, 1979), p. 248. 
names that seem to presuppose that we are judging [these objects] morally. ... Taste enables us, as it were, to make the transition from sensible charm to a habitual moral interest." ${ }^{, 69}$ Over the course of the eighteenth century, then, there is a transition from requiring the fable in education in order to draw students' attention to what will emerge as the fable to the thought that habituating good taste will allow moral interest to develop.

It is for that reason that we can both agree and disagree with Heidegger's claim that "Kant took over Descartes' position quite dogmatically." ${ }^{70}$ Heidegger's point in this context is that Kant never interrogates the ontology of the Cartesian subject as a being whose being is a matter of concern for it. Though it is not a question here of whether Kant fails to interrogate this ontology. Rather, what is at stake is whether Descartes himself in fact establishes a subject in the way the tradition that develops after him assumes he does. This tradition, developing over the course of the eighteenth and nineteenth centuries such that the fable steadily becomes a degraded and denigrated literary form, is also what establishes the subject as a given. It is only from the twentieth century, following on a crisis of the European sciences, that a return to the question of the fable becomes possible again. In the return to this question, it is of course transformed, but the hope for a pure return is a nostalgic, romantic, and Romantic hope. Such nostalgia is marked as much by appeals to 'what an author really meant' as by the periodization that demarcates what qualifies as legitimately modern, Enlightenment, or idealism in a thinker. In every great thinker, insofar as each is a transitional thinker, there is something of what precedes and what follows from the thought. In turning back to them, we can attend not only to what was missed or dismissed in that thought by the tradition that inherits it, but also to what can be

\footnotetext{
${ }^{69}$ Immanuel Kant, Critique of Judgment, tr. Werner S. Pluhar (Indianapolis, IN: Hackett Publishing Company, Inc., 1987), p. 230.

${ }^{70}$ Heidegger, Being and Time, p. 45.
} 
transformed within that thought such that it becomes our own. Descartes' time is, like our own, like the twentieth century, a time of explicit flux, and Descartes has recourse to fable as a technique for inaugurating that flux. In the traditional readings of Descartes, many if not most of which have built themselves on a presumption of the givenness of the subject, we have forgotten, and forgotten how to attend to, this recourse to fable. Here, I hope to begin the process of such an attending.

\section{Ending the Beginning}

Following from all of this - that the twentieth century resembles in certain ways the seventeenth century more than the eighteenth or nineteenth centuries do; that the fable maintains a particular relationship with rhetoric and pedagogy that distinguishes it from other, similar literary forms; that Descartes has recourse to the fable and to appeals to other imaginative forms at crucial moments in the course of his career and at crucial loci in his texts insofar as those loci are in the beginning of the texts, in order to establish a method which retroactively justifies said method on the ground of utility; and that a new method can never fully justify itself because it itself establishes a new form of thinking which is then the ground for justification - following from this, the Cartesian use and deployment of fable as an overarching concept which unifies otherwise seemingly disparate attempts to inaugurate the new Cartesian way of thinking is a fruitful beginning point for an investigation into much of Descartes' philosophy. From the investigation of fable, in which the role and limitations of the concept will be delimited before expanding it to other literary forms with which Descartes associates his works and then focusing on hyperbolic doubt as operating according to the fabular logic that can be seen throughout his corpus (chapters 1 and 2), it 
will then be necessary to return to the very beginning of this work: method. With fable understood as that which allows for a method to begin, the simplicity of the Cartesian method begins to look interwoven with the inexact sciences it hopes to displace and begins to seem involved in a supplementation of the ethico-political in the same moments that the ethico-political supplements the ostensibly exactly scientific method (chapter 3). Having exposed the method as more complex than it appears, it will then be possible to turn back to the mind which would deploy the method and which must have already been led onto its path thanks to the fable, such that it will become clear that, contrary to numerous contemporary assumptions, there is no preformed faculty psychology which neatly divides the will from the intellect from the imagination from the senses. Rather, the mind, like the plenum of external space, forms its own faculties in the inauguration of mental motion thanks to the deployment of that imaginative form called the fable (chapter 4). With that laid out, it is now possible to draw this inaugural moment to a close and to begin properly, with the question of the Cartesian fable. 
Part I 
Does my story bore you? That is evidence that you do not know how to read your own from it.

—Witold Gombrowicz, Diary 


\section{Chapter One}

\section{Fable Proper}

Since a method would seem so difficult, not to say impossible, to inaugurate, since it seems to require a method by which it could justify its own existence, a turn to how Descartes begins and ends his works, as well as his career, seemed appropriate. The question of how to begin, how to inaugurate a new form, style, or path of thinking is one which pursued Descartes and which Descartes pursued throughout his corpus, from beginning to end. This question led us to the question of the fable, concerning what it is generally and defending interest in it, both in Descartes' time and our own. For Descartes, because so much of his metaphysical as well as epistemological claims hinge on methodological problems in the very inauguration of the how and the why of what is learned, a defense of his new form or style of thinking cannot itself develop through that selfsame methodology. As a result, Descartes deviates from the course of thinking not precisely by defending his new form, style, or path of thinking, but by inaugurating it such that it may defend itself in its operation, if only by the utility of its operation. This change in course occurs through Descartes' telling us that a given text is a fable, a literary form associated with explicit pedagogical goals.

In order to trace out the effects of this change in course, a procedure of investigating the fable and its relationship to other forms of writing will be necessary. First, however, a clarification on Descartes' more positive uses of 'fable' needs to be made, in order to justify the expansion of the concept into other forms. This will occur by (A) distinguishing between fable and poetry in a specific text, The World, and (B) clarifying how the fable as a form 
serves a pedagogical purpose, in particular through its relationship to potential vs. possibility, in the Discourse.

\section{Fable against Poetry}

For the moment, this analysis is isolated exclusively to The $W$ orld. It is not meant to be a general claim concerning Descartes' concept of poetry. ${ }^{1}$ I begin from this text, however, because of its import for other claims Descartes makes, both earlier and later in his career, concerning the relationship between rule-generation and rule-obedience as well as their relationships between rhetoric, language, pedagogy, and epistemology.

\section{Chaos and Light}

I want to begin, then, by turning to the world of The World. That is, I want to first treat the status of the physical operations of the world as laid out in this treatise on light that understands itself as a fable. Without light, there is no world, even if there is matter. Descartes begins by noting that "there can be a difference between our sensation of light ... and what is in the objects that produces that sensation in us." However, before the world can be a world, either insofar as it is in itself or insofar as it appears, light needs to come into being. Before light, there is the dark, solid matter of chaos. Descartes describes a pre-world and -light universe that occupies precisely the same extent of space as our own world of

\footnotetext{
1 As William Stewart traces out, Descartes' "love of poetry survived to the end" (William Stewart, "Descartes and Poetry," The Romanic Review 29 [1938], p. 242). Though Stewart relies too heavily on the now-disputed ballet La Naissance de la Paix as evidence for this love at the end of Descartes' life, he is still correct that Descartes had a respectful, though complex, relationship with poetry throughout his life. In The World, the association of poetry with chaos is not even necessarily meant as insulting, and this association cannot be taken as operating throughout Descartes' career. The association in The World, however, is helpful for bringing other aspects of his philosophy and his physics to attention.
} 
light, but that is constituted not of the three fundamental elements of earth, air, and flame (or light), but constituted "as a real, perfectly solid body" as an absolute plenum. This, as it were, vision of space, not as a vessel filled with objects but as a plenum from out of which objects are carved, is both consistent throughout Descartes' career and crucial for making sense both of how a geometrized world can be understood from out of an algebraicized geometry and of the relationship between the imagination and the understanding, though I will be concerned only with the latter in this section. ${ }^{2}$ (W, pp. 1 and 10; AT XI, pp. 3 and 33) It is a vision declared in the description of a fabular new world that matches perfectly the world that we experience. However, before either the fabular new world or the world that we experience come to be, this solid body not constituted of earth, air, or light remains a perfectly knowable, imaginable, supposable, and conceivable matter because it is that from out of which the three elements come to be. ${ }^{3}$ The fact that this solid matter remains precisely

\footnotetext{
${ }^{2}$ The terms 'geometrized world' and 'algebraicized geometry' are taken from Nancy L. Maull, "Cartesian Optics and the Geometrization of Nature," Review of Metaphysics 32:2 (1978), pp. 253-273; Danielle Macbeth, "Viète, Descartes, and the Emergence of Modern Mathematics," Graduate Faculty Philosophy Journal 25:2 (2004), pp. 87117; and Neil M. Ribe, "Cartesian Optics and the Mastery of Nature," Isis 88:1 (1997), pp. 42-61, though the latter two do not use the phrase 'algebraicized geometry'. These phrases are my shorthand for the two stages of the mathematico-physical revolution Descartes inaugurated, most clearly in the Optics and the Geometry. The first stage occurs when he demonstrates that algebra, with its symbols, notations, and formulae, is capable of calculating geometric relationships more accurately than the pre-Cartesian reliance on figures as such. This demonstration constitutes the algebraicization of geometry. The second stage occurs when he demonstrates that geometry is applicable to an engagement with physical phenomena, for example through an explanation of measuring distance as operating according to a method of triangulation where the eyes serve as the endpoints of the base of a triangle and the object in question as the third point. This demonstration constitutes the geometrization of nature or of the world. Through these stages, the application of algebra to the physical operations of the world becomes conceptually possible.
}

${ }^{3}$ Nancy understands this non-elemental matter, to which I refer as 'pre-motive', as the "primary matter [matière primitive]" that is the model for the "fiction" of The World's fable as distinct from thought insofar as that fiction includes the material of thought within its chaotic, non-elemental, and pre-motive structure or status (Jean-Luc Nancy, "Mundus Est Fabula," tr. Daniel Brewer, MLN 93 [1978], p. 650; in Ego Sum [Paris: Flammarion, 1979], pp. 118-119). Nancy's alignment between the primitive material of the fable (or fiction) and that of chaos leads him to claim, further, that the thinking self which emerges from the fable both is and is impossible to conceive (conçu) via thought (see ibid., p. 651; p. 119). While there is much with which I agree in "Mundus Est Fabula," this alignment is, on my reading, incorrect because chaos is aligned with poetry in The World, not fable. The alignment between chaos and poetry, I will argue, hinges on the pre-motive status of chaos and poetry in the modeling relationship between them, and the consequent relationship to rules that fable and light have. That Nancy's misreading of this seemingly minor point leads him to consider the thinking self as emerging from a fabular, inconceivable chaos that is already the self (see especially his use of the second 
not any of the elements of the world, whether fabular or experienced, is an important point to bear in mind, however. This solid matter is not the world proper, even if it is that from out of which the world emerges. Insofar as it is not the world proper, this solid matter is "chaos." Chaos is no knowable, imaginable, supposable, or conceivable world. Its matter may very well be all of those things, but that does not mean it is a world as such. The world, to be a world, needs light. (W, p. 11; AT XI, p. 35)

The emergence out of chaos occurs with movement. Although Descartes does not specifically claim that god initiates the movement of the pre-motive solid chaos, he does specifically claim that god created the world as a world that operates according to rules ("loix de la Nature"). After this initiatory creation-qua-motion, the movement of the solid matter of chaos follows three "principal rules [principals regles]" that lead to the emergence of the three fundamental elements of earth, air, and light as they operate in both the fabular and experienced worlds such that the specifics of the remaining laws of nature also emerge. (W, p. 12; AT XI, pp. 37 and 38)

Here, a word about these fundamental elements, which are described before the movement into the fable of the new world, is in order. Following "The philosophers," though excluding water, Descartes understands the three elements as distinguished according to their liquidity, size, and motive speed. Light is the most liquid, smallest, and fastest element; earth the most solid, largest, and slowest element; and air in between the other two. From out of pre-motive solid chaos, then, the divine initiatory creative motion breaks apart the solidity such that pieces of this solid break off from each other-some smaller, others

person in ibid.) leads me to conclude that he begins from an assumption of the self as such, which I contest as possible in the Cartesian world and The World as I hope to show, and so as to at least wonder if Nancy's ontology does in fact come from a consideration that "the extra is the place of differentiation," or if the extra has not already been incorporated within a pre-formed and/or transcendental self, thereby disrupting its "extraneity' and capacity to differentiate (Marie-Eve Morin, Jean-Luc Nancy [Cambridge: Polity Press, 2012], p. 129). 
larger. The smaller pieces move faster and fit into smaller and deeper crevices within the remaining portions of pre-motive solid chaos, breaking it apart more as they do so. The movements of all these pieces follow the three principal rules, the first two of which roughly align with Newton's three laws of motion_- "each individual part of matter always continues to remain in the same state unless collision with others constrains it to change that state" and "when one of these bodies pushes another, it cannot give the other any motion except by losing as much of its own at the same time; nor can it take away from the other body's motion unless its own is increased by as much"-while the third claims that all motion is rectilinear, even when it may appear circular or curved. ${ }^{4}$ In other words, there are no curved or circular motions in the precise sense, only increasingly or decreasingly minute straight lines construed within three spatial dimensions_-spatial dimensions that do not in themselves exist except as constituted by the material which moves in straight lines through

${ }^{4}$ Daniel Garber actually finds a fourth, hidden law here: "the principle of conservation of quantity of motion" (Daniel Garber, Descartes' Metaphysical Physics [Chicago: The University of Chicago Press, 1992], p. 199). This hidden law appears when Descartes writes that "God is immutable . . , acting always in the same way, He always produces the same effect. For, supposing [supposant] that He placed a certain quantity of motions in all matter in general at the first instant He created it, one must either avow that He always conserves as many of them there or not believe that He always acts in the same way" (W, p. 14; AT XI, p. 43). Garber also finds "clear differences" between the three laws of motion and the conservation principle. While the latter "is universal and general in the sense that it is supposed to apply to all of the created world, and it does so unconditionally," it does not say anything about particular bodies, but the three laws of motion "do determine the behavior of specific bodies" (Garber, Descartes' Metaphysical Physics, pp. 201 and 202).

In addition, Garber recommends against referencing Newton in connection with these Cartesian laws because of the difference in the meaning of the term 'interia' for their respective eras (see ibid., p. 203). Garber never explicitly explains this point, but it can be surmised from other points in his text. In Descartes' era, 'inertia' was most commonly associated with its etymological source as 'laziness' (objects have an innate laziness as shown in their resistance to motion), though Descartes rejects this position and comes to understand inertia “as a kind of 'imaginary' force; while bodies behave as if there were some kind of internal resistance to being set into motion, all there really is is bare extended substance, behaving in accordance with the laws that an immutable God's continual sustenance imposes on it" (ibid., p. 254). This understanding of what will be called inertia in the Newtonian sense is similar to Newton's own in that it involves the claim that "motion persists in and of itself" (ibid., p. 228). Because it is Newton who is generally credited with articulating this understanding of inertia as a real force, rather than, in Descartes' case, as an imaginary force, or, in the case of most of Descartes' contemporaries, as no force at all, it would seem that maintaining the difference between their inertias is important for Garber (see Sir Isaac Newton, Newton's Principia: The Mathematical Principles of Natural Philosophy, tr. Andrew Motte [1846], p. 73). The question of the force of the imagination in Descartes will be taken up in chapter 4 below, but here it is enough to note that Garber's position on Descartes relies on the standard understanding of the imagination as only capable of working with images to which it has passive access while also noting his warning on associating Descartes' laws of motion and the law of its preservation with Newton's concept of inertia. 
those dimensions. That is, matter does not move through space, but the motion of matter constitutes what is understood as space. Space is not a container within which matter moves, but is the equivalent of matter itself. As the matter of pre-motive solid chaos breaks apart, developing into the elements of earth, air, and light, the mutual ricochet among these pieces erodes the pieces more or less into spheres composed of one or more element. The movement of matter may not be curved, but matter itself can be because of the increasingly subtle and glancing collisions that occur over the course of those pieces of matter following their laws of motion. As these collisions render pre-motive solid chaos into the three elements that are more or less spherical according to their material status (light is most spherical, earth least so, air in between), light gathers itself into the stars around which air, having gathered itself into the heavens, revolves thanks to a constant pressure from the movement of light from out of its gathering points. The movements of air in turn put pressure on the places where solid earth has gathered together in the form of planets and comets. The farther from the stars that the pieces of air and earth get from the pressure and collision of light, however, the slower the movements of air and earth become. ${ }^{5}$ (W, pp. 7 , 12-14, and 16-18; AT XI, pp. 23, 38-44, and 51-54)

\footnotetext{
5 Thomas L. Prendergast, in considering rectilinear motion and duration, considers rectilinear motion as conceivable "without reference to duration" to be paradoxical (Thomas L. Prendergast, "Motion, Action, and Tendency in Descartes' Physics," Journal of the History of Philosophy 13:4 [1975], p. 462). He resolves the paradox through the possibility that rectilinear motion can be conceived through the instantaneous tendency toward such motion whether the motion itself is present or not. That is, because tendency toward motion is a mode of bodies in motion and measured according to the size and velocity of the body, it is in a body, whether that body is in motion or otherwise, and it is instantaneous because, once in motion, said body instantaneously moves rectilinearily. He draws from this resolution that "this explains why Descartes calls light both action or motion and action or inclination (tendency) to move" and that light itself "is simply the instantaneously transmitted motion or tendency move" (ibid.). If light is both the transmission of motion into all other pieces of matter and the tendency within those other pieces toward motion, then it is the mode of bodies in motion or not toward which those bodies tend. However, in that light is itself also a material element of the world of The World, Prendergast would also appear to be claiming that this tendency is not merely a mode of the matter of the world, but its potential to be a world in motion at all. A world not in motion is, for The World, no world at all, but pre-motive, solid chaos without elements. Light and its tendency to act as the tendency toward motion for the other elements is the potentia (or, as I will show below, the puissance) of the world and this thereby makes
} 
From this description of the motive relationship between light, air, and earth, it would appear that the movement of light is crucial to the preservation of the world as a world or in its worldliness. If air and earth both slow their movement in proportion to their distance from light, then it stands to reason that, without light, air and earth would settle back down into the pre-motive solidity of chaos. If so, this motive relationship would explain the distinction Descartes makes between divine creation and preservation. For Descartes, "if God preserves [conserve] them [i.e., the parts of matter] in the same way that He created [creées] them, He does not preserve them in the same state." It is in this way that Descartes is able to claim that there is a divine, perhaps miraculous, moment of creation along with a persistent divine preservation of the world as such, even while excluding miracles from the mechanical, algebraic, and geometric operations of the world. God inaugurates the world through the initial motion from out of the pre-motive chaos by inaugurating light, the motion of light and light as motion, and light's motions preserve the worldliness of the world insofar as its motions preserve the world's other elements from settling away from motion. Thus, the divine creation of light functions as the divine preservation of the world, even while the operations which follow from the creation of light are not a preservation of the world in the same state in which they were at the moment of creation, or even in the same state as the moment or moments wherein liquid and earth emerged from out of the pre-motive chaos. (W, p. 12; AT XI, p. 37).

Divine creation is the same as divine preservation, then, insofar as divine creation is the initiatory movement from which the three elements emerge and divine preservation is the maintenance of the movement of light, thanks to which movement the maintenance of the movements of air and earth are themselves preserved, even if air can settle into earth and 
earth can speed up into air. Divine creation is movement. Divine preservation is the maintenance of light. Divine creation and preservation are identical. Light sustains the movement of the world. The movement of the world is the playing out of the three principal rules of motion. These principal rules have no meaning, however, without the motion of matter because, without matter moving in the form of the three elements, there is no rule, only pre-motive solid chaos. Light, then, can be understood both as the world and as the rules by which it operates. It is not merely that the world and its rules depend on light or even that light embodies the rules by which the world operates. Rather, light, in this fabular world that matches our own, is the world and is the rules by which it operates. There is neither world nor rule in pre-motive chaos. Light does not only obey the rules of motion; it also generates them.

\section{Poetry and Fable}

Even though there is a difference between the sensation of light and what is in the objects that produces the sensation of light, what is in the objects that produces the sensation of light obeys the rules of motion that themselves result in the sensation of light even while these rules are themselves generated by light itself. It is possible to make the claim that the rules that result in the sensation of light are themselves generated by light because there are no rules for any sensation whatsoever without light, without at least its inaugural motion which in turn inaugurates motion as such. Light itself obeys the rules of motion, of course, but it also generates these rules insofar as they do not exist since nothing exists in any proper fashion before the movement of light moves the pre-motive chaos from chaos toward the world, toward its elements, their motions, and thus toward the world. It is, in other words, 
important to bear in mind that light is both of the world and that which allows the world to come to be as a world - it obeys and generates the rules of motion.

In a similar distinction, Descartes claims that "words bear no resemblance to the things they signify." An effect of this rupture emerges when Descartes looks at Aristotle's Physics. He claims that "Motus est actus entis in potentia, prout in potentia est" is uninterpretable, and no less so when translated as "le mouvement est l'acte d'vn Estre en puissance, entant qu'il est en puissance." ${ }^{6}$ This claim to uninterpretability appears in the context of the first principal rule, concerning the tendency of pieces of matter to continue in the same state unless a collision with another piece of matter changes the state. What is uninterpretable about the Aristotle passage hinges on the different conceptions of motion between Aristotle as well as 'the philosophers' and Descartes. They exclude motion from the list of qualities that do not change unless and until a given piece of matter meets another, such as size, shape, rest, etc.; suppose kinds of motion that do not result in a change of place, such as motions to form, heat, and quality; conceive of rest as a privation of motion, and, following from this conception, attribute a tendency toward self-destruction to motion, in contrast to any other qualities of matter. For Descartes, motion occurs when "bodies pass from one place [lieu] to another and successively occupy all the spaces [espaces] in between." Here it is important to again bear in mind the world Descartes is fabulating, where space is not an empty vessel but a carved-out plenum even if certain places therein appear empty, thus linking the geometrical motion of point to line to surface with the movement of bodies ‘within' space. In addition, Descartes conceives of rest as a quality equally as attributable to a piece of matter as motion may be attributed to it, and as identical to other qualities of matter

\footnotetext{
${ }^{6}$ In English, "a motion is [defined as] the actuality of the potentially existing qua existing potentially" (Aristotle, Aristotle's Physics, tr. Hippocrates G. Apostle [Grinnell, IA: The Peripatetic Press, 1980], 201a).
} 
in that it tends to remain in its state unless changed by a collision. (W, pp. 1 and 12-13; AT

XI, pp. 4 and 39-40).

That Descartes grounds his conception of motion in the geometrical motion from

point to line to surface and that he opposes this grounding to Aristotelian being in potentia or en puissance insofar as he "cannot interpret $[$ ne . . sçaurois interpreter $]$ " the latter conception are

both important to bear in mind. ${ }^{7}$ He does not claim to be unable to conceive, suppose,

know, or imagine being in potentia or en puissance. Rather, he cannot interpret it. The

Aristotelian conception is a conception, even if an uninterpretable one. For this reason,

\begin{abstract}
7 Variations on interpretatio and interprétation are not very common in Descartes' corpus, but they are not entirely rare either. In Latin, interpretatio frequently carries the meaning of 'translation', though not always (translatio is a bearing across, while traductio is a transferring). By Descartes' time, traduction meant 'translation', as does translation, while interpreter meant "giving to knowledge" (Robert Estienne, Dictionnaire francois-latin, [1549], s.v. "interpreter"; my trans.). In the writings at least initially intended for publication, Descartes uses interpretatio to mean the equivalent of the English cognate by far most frequently in the Objections and Replies, telling Johannes Caterus, Antoine Arnauld, Marin Mersenne, and Pierre Bourdin that they have misinterpreted what he wrote or that he cannot interpret what they mean (see CSM II, pp. 80, 162, 167, 288, 308, and 309; AT VII, pp. 112, 231, 239, 426, 459, and 461). Pierre Gassendi himself uses interpretatio in this way in the Fifth Set of Objections, when he writes, 'You also say that you derive from your own nature 'your understanding of what truth is', by which I take it [interpretor] you mean your idea of truth" (ibid., p. 196; p. 281). Descartes also uses interpretatio in this way in the Comments on a Certain Broadsheet and in the Rules for the Direction of the Mind (see CSM I, p. 308 and 59; AT VIII-B, p. 365, and AT X, p. 443, respectively). In addition, however, he also uses interpretatio to mean an explanation to someone else, rather than the explanation to oneself that 'interpretation' might normally mean, in the Rules (see CSM I, 37; AT X, p. 408). Rarely if ever does he use interprétation in this somewhat private sense in the published writings, though interpretatio is used this way once in the Seventh Set of Objections and Replies (see CSM II, p. 351; AT VII, p. 516). He almost never uses either interpretatio or interprétation in this way in his letters. There is, however, at least one letter, to Mersenne, dated November 20, 1629, where he uses interprétation for 'translation' (see CSM-K, pp. 10-13; AT I, pp. 76-82), and at least two other letters, in French to Mersenne and in Latin to Henricus Regius, dated March 1636 and December 1641, respectively, where he uses interprétation and interpretatio for 'explanation' (see CSM-K, pp. 50-52 and 200-201; AT I, pp. 338-341 and AT III, 460-462, respectively.

For Gadamer, hermeneutics is defined as "the theoretical tools of the art of interpetation" (HansGeorg Gadamer, "On the Scope and Function of Hermeneutical Reflection," tr. G. B. Hess and R. E. Palmer, in Philosophical Hermenentics, ed. David E. Linge [Berkeley, CA: University of California Press, 2008], p. 24). He sees a specifically philosophical hermeneutics as "the opening up of the hermeneutical dimension in its full scope" (ibid., p. 18). On this reading, Descartes' lament that Aristotle is not interpretable should be seen as operating within hermeneutics generally, though probably not a philosophical hermeneutics, if only because what is immediately at stake in the uninterpretability of Aristotle is the tools of an interpretation of a statement about physics and not necessarily "our entire understanding of the world and thus for all the various forms in which this understanding manifests itself" (ibid.). In the context of the fable of The World, though, and in terms of how that understanding of the fable will be expanded below, the question of interpretability and systems of physics expands into something like a philosophical hermeneutics. However, I am not inclined to use this term for a few reasons. For one, to my knowledge, Descartes never used any variation on the word 'hermeneutics'. For another, the etymological association of 'hermeneutics' with 'hermetic' seems problematically associative of the cliché of Descartes as the philosopher of the poêle. A third reason, closely related to the second, is that the etymology of 'interpretation' carries associations opposed to the hermetic, as an economy or a movement between, which ties in nicely with some of the claims I will make below, especially as concerns the imagination.
\end{abstract}


Descartes can claim that the Aristotelian conception of motion was able to give rise to "the

old world." It is, then, a world, a world with order, rules, and laws. Indeed, one of the critiques of the old world is that its conception of motion obeys a rule of self-destruction in distinction from the other laws of nature. The language of Aristotelianism may not be interpretable, but that does not place it outside the realm of rules, outside worldliness as such where the world as a world that may be interpreted emerges. ${ }^{8}$ It is not chaos but merely an uninterpretable world. In neither the old nor the new worlds do words resemble the things they signify. The language of Aristotelianism fails to cause conception for Descartes, but that does not mean it fails in itself to conceive of the world to the extent that rules may appear to be obeyed by what is signified by that language. ${ }^{9}$ (W, p. 12; AT XI, pp. 38 and 39; my emph.).

\footnotetext{
${ }^{8}$ It is because of this orderly relationship between the old and new worlds as expressed in The World that Yves Charles Zarka finds the comparison between this Cartesian fable and the Hobbesian fable of De Corpore to be "insufficient” (Yves Charles Zarka, La Décision Métaphysique de Hobbes: Conditions de la Politique, 2 ed. [Paris: Librairie Philosophique J. Vrin, 1999], p. 39; my trans.). That is, Descartes merely poses his fable as an alternate, imaginary, and new world, and does not expound on its metaphysical theses beyond posing them. Hobbes, however, poses an annihilatory fable in the beginning of De Corpore, which requires him to lay out a metaphysics that would explain how a single surviving man could maintain a memory of the operations of that annihilated world's motions. As a result, for Zarka, the more appropriate Cartesian moment for comparison to the Hobbesian fable is the literal apotheosis of annihilation as found in the evil genius. Zarka is undoubtedly correct on this point-Descartes has no interest in engaging in metaphysical debate in The World and his breaking off of the text in the wake of Galileo's trial speaks to his reticence on this point—and Zarka's discussion of De Corpore and the evil genius will be considered below. However, for the moment let me claim that, as I expand the concept of the fable in Descartes' pedagogy and metaphysics, to the extent that these two things can in fact be considered separate for him, this distinction between the Cartesian supposed and the Hobbesian annihilatory fable may become harder to maintain. That is, the appearances of supposons and imaginons throughout The World should draw our attention to the metaphysics of good sense as laid out in the Discourse, especially insofar as the Discourse is a preview or early attempt at the metaphysics of the Meditations.

${ }^{9}$ In distinguishing the new world from the old on the ground of its interpretability may indicate that The World holds onto a residue of what Michel Foucault identifies as the difference between the classical and Renaissance worlds: "This relation to Order is as essential to the Classical age as the relation to Interpretation was to the Renaissance" (Michel Foucault, The Order of Things: An Archeology of the Human Sciences, tr. unnamed [New York: Vintage Books, 1994], p. 57). However, in that Descartes also claims that words and things are distinct from each other, he cannot be considered, in the Foucauldian sense, to remain fully in the Renaissance, which for Foucault is marked by the proliferation of commentary and interpretation on an original, originary, and sovereign "Text" (ibid., p. 41). In that words are distinct from things for Descartes, there may be interpretation of the original text of nature but there is no sovereign Text of nature to which commentary would refer. The fable of the world shows the Text as already unoriginal in that it may be imagined differently from its origins. Yet, it is important to bear in mind that, for The World, 'interpretation' remains crucial both for the justification
} 
If the orderly uninterpretable language of Aristotelianism is neither itself chaos nor

aligned with it, however, poetry is aligned with chaos. While discussing the motion at the

beginning, in the transition from pre-motive solid chaos to the world as orderly elements in

motion, Descartes insists that god makes the parts that had been constitutive of chaos move

in numerous directions and at numerous speeds, from then on preserving (in the sense of

preservation described above) their motion in accord with the laws of nature. The

movement from chaos to world will occur because

God has so wondrously established these laws that, even if we suppose that $\mathrm{He}$ creates nothing more than what I have said, and even if He does not impose any order or proportion on it but makes of it the most confused and most disordered chaos that the poets could describe [décrire], the laws are sufficient to make the parts of that chaos untangle themselves and arrange themselves in such right order.

Poetry, then, is aligned with chaos. It is perhaps not in itself chaotic, but it has the capacity to describe chaos. ${ }^{10}$ Despite this descriptive ability of poetry, however, the rules of motion,

of the fable as presented and for the critique of Aristotelian physics. That is, both Cartesian and Aristotelian physics conceptualize an order to the world, even if only one of these conceptualizations is precisely interpretable in its use of language. The order that is to be preferred, then, is an order of interpretability. While this preference may not re-suture words and things, it does place Cartesian linguistics, at least in The World, in a more complex relationship with Cartesian physics than may at first appear because the interpretation of the words used to explain the order of things in the world will be done as much with language as with concepts, hence Descartes' complaint that he cannot interpret Aristotle in any language. Thus, even if resemblance between words and things has been disrupted in the fable of The $W$ orld, this is not precisely the same as claiming that the interpretation of the things of the world's signs is to be aligned "with doubtful repetitions, with misty analogies," even if interpretation may still be aligned with imagination (ibid., p. 71). Indeed, Cartesian interpretation as presented here and as it can be expanded as the Cartesian concept of the fable is expanded, requires a reconsideration of the Cartesian imagination, along with the imagination's role in the whole of the Cartesian corpus and discourse.

10 Jean-Pierre Cavaillé compares Descartes' conception of poetry insofar as it can be aligned with chaos to a long poetic tradition of cosmogony that seeks to describe the world before the world as it appears, from Ovid and Lucretius to Milton and Guillaume de Salluste du Bartas, focusing in particular on this last poet. Du Bartas "transfers the negative path of theology to physics" (Jean-Pierre Cavaillé, Descartes: La Fable du Monde [Paris: Librairie Philosophqiue J. Vrin, 1991], p. 281; my trans.) through rhetorical techniques that critique and undermine logic like antitheses, oxymorons, and irrational and unrepresentable images such as " aair ... without clarity, .. . / Earth without firmness"' (Guillaume de Salluste du Bartas, La Sepmaine; ou, Creation du Monde (1581), v. 249-250, quoted in Cavaillé, Descartes: La Fable du Monde, p. 281; my trans.). As Cavaillé points out, this understanding of chaos is not what is at work in Descartes' fable because "the physicist solicits the poet only in order to better exclude him [the poet] from his [the physicist's] world” (ibid., p. 282; my trans.). The matter and qualities of what will become the new world of the Cartesian fable, according to Cavaillé, correspond to the world as experienced, which is not the status or description of chaos by the cosmogonic poets in that they describe a matter that does not have the qualities of the matter signified by the same word that would normally be used to describe the matter as experienced in the world (see ibid.). However, Cavaillé 
especially the three principal rules, will allow the pieces of matter to fall into their

appropriate places once god has begun the process of motion. Poetic language, nonetheless, has an ability to describe chaos, and thus the words it uses would signify things which are not yet things, not yet matter, but only the pre-motive solid chaos. Perhaps one could claim that the chaos that the poets would describe would be the demi-motion of the transition between pure chaos and the world, but if this demi-motion would be in any way prior to the emergence of light, that motion would not be the motion of any world, old or new, and thus the conventions of language used by poetry would describe that which is not of the order of orderly motion. Poetic words, then, would not be merely uninterpretable, but would signify nothing at all. There is no order in this poetry, no world being described or signified. (W, p. 11; AT XI, p. 34; my emph.)

Chaos as the poets would describe it, however, is not what the fable of The $W$ orld describes or fabulates, even when the fable describes pre-motive solid chaos. In fact, the fable does not describe at all. The fable fabulates, makes, or even is a world. There are three moments that indicate this fabulating quality of fable as distinct from the descriptive quality of poetry. First, the fable does not itself begin until chapter 6. Prior to its beginning,

seems to miss a certain subtle similarity between the cosmogonic poets and Descartes, a similarity that simultaneously draws a perhaps more important distinction between them. The poets and Descartes both engage in a retroactive form of description of 'pre-worldly' chaos, though in different ways. The poets undermine the signifying logic of words in describing unrepresentable and irrational forms of matter, but in doing so signify the selfsame matter in the act of undermining it, while Descartes fabulates an imaginary world that corresponds to the world as experienced, thus justifying the fable's operations on the grounds of experience. Where they most completely differ is in the precise form of the description of chaos. While the poets describe a chaos that is unrepresentable because the qualities of its chaotic matter contradict what would qualify said matter in experience, Descartes describes a chaos that precedes experience as such in that it is premotive and only solid. The Cartesian chaos is not, in fact, matter qua experiencable at all, but is rather precedent of the experiencable because there is neither air nor, more importantly, light. The poetic chaos of the Cartesian fable does not, in itself or in the way of the cosmogonic poets, refer to experience. Only what emerges from Descartes' poetic chaos in the wake of divine inauguration of motion can refer to experience. The chaos of the cosmogonic poets is something more akin to the uninterpretable claims of Aristotelian physics than it is of the pre-motive, solid chaos of Descartes. In short, the chaos of the cosmogonic poets is a chaos that remains in the realm of order by undermining the order of experience through linguistic and rhetorical virtuosity, while the Cartesian chaos is not of the order of order at all. 
Descartes, as he so frequently does to inaugurate his thinking, makes note of the ways in which our senses are deceived, even the most seemingly reliable sense of touch. In noting sensory deception in this context, Descartes indicates that the world is not necessarily what we think it is. Such perhaps pre-theoretical deception, a deception of the senses distinct from the uninterpretable significations of Aristotelianism, sets Descartes on a path not just of distrust of the world of experience but also on a path of conceiving of the world (perhaps of worldliness) as something other than merely given. ${ }^{11}$ In conceiving of the world as something other than given, combined with the claim that words do not resemble what they

\footnotetext{
${ }^{11}$ Because of the distrust which Descartes takes up, Maurice Merleau-Ponty critiques the consequent claim that perception is reduced to "the thought of perceiving" as "an insurance against doubt" because it results in disregarding the world as experienced (or perceived) and thereby "will never restore to us the 'there is' of the world" (Maurice Merleau-Ponty, The Visible and the Invisible, Followed by Working Notes, tr. Alphonso Lingis [Evanston, IL: Northwestern University Press, 1968], p. 36). For him, Cartesian doubt either renders obscure the sheer fact of experience and thereby teaches nothing or teaches in a specific and aggressive form such that the doubt qua act circumscribes the self within a particular form (see ibid., pp. 36-37). Earlier, Merleau-Ponty also argues, in a somewhat Kantian fashion, that "no ontology is exactly required by the thought proper to physics at work" in that the activities of the physicist do not demand an understanding of the object in itself, as does classical physics demands, and thus do not have a principled claim on the reality of objects per se (ibid., p. 17). Thus, physics can be understood as either "an imaginative translation" of objects such that they may be conceived by physics, or such that physics describes can in fact make claims on "what is" in itself (ibid.). However, something else, something more seems to be at stake in deception as what sets Descartes on the path of distrust in the world if that distrust extends to worldliness. The distrust in worldliness, which again finds its apotheosis in the Meditations, is at the very least implied in the fable of The World because of what has opened up in the doubt as found here, and which may be even more extreme than in the Meditations. In The World, if worldliness itself comes to be conceived as other than what is given, and thus not precisely doubted, but excessive of what is given, then the imaginative translation which it could take up in the fabulation of a new world is not precisely a translation because there is no 'Text' in the singular, to use Foucault's terminology (see above) from which to translate. Instead, the imaginative translation, as imaginative, would establish the 'otherthan' quality not just of things of the world but of the sheer possibility of world as such. The ontology and/or metaphysics implied in this possibility, inaugurated by this fable, would thereby be an ontology and/or metaphysics of otherness, of excess, and it would gain its proof in the imaginative translation or otherness inaugurated by the telling of the fable's story. If the physics that follows from The World, as articulated by Descartes or others, makes the mistake of thinking it describes what is in articulating an imaginative translation, this is not precisely the fault of the fable of The $W$ orld as a text, but of a fundamental misinterpretation of what is at stake in the fabulation of a new world that is another interpretation, ostensibly more orderly and interpretable, of the operations of the world as it presents itself, but which, in its very telling, is an interpretation that demonstrates and inaugurates a world without Text that remains interpretable on the ground of the selfsame excessiveness indicated by the lack of a singular reference point for its linguistic signs of interpretation.
} 
signify, Descartes has already begun to indicate that this fable may be able to make a world appear, to fabulate a world. ${ }^{12}$ (W, p. 2; AT XI, p. 6)

Second, in introducing the fable at the end of chapter 5 , he explains why he will turn his treatise into a fable: "to make the length of this discourse less boring for you." Descartes wants to stimulate the reader's mind, to prompt thinking, to inaugurate conceiving. His fable, then, developed from out of an experience of the world that shows itself as other than what is given, leading to an engagement with another world which is uninterpretable, is primarily interested, insofar as it is a fable, in not being boring. The goal, the motivation, or the motive of the fable is to begin a motion in the mind of the reader. What the fable fabulates is "another, wholly new" world in the imagination of the reader, a new world in “imaginary spaces [espaces imaginaires]" where space is imagined as a plenum set into motion such that light begins and maintains the orderly motion of the parts of the world's matter (W, p. 10; AT XI, p. 31). As becomes clear with the democratization of reason declared

\footnotetext{
12 If it is the case that conceiving the world as other than what is merely given can combine with the separation of things and words as leading to the fabulation of the world, this is perhaps a modification of the Husserlian epoché or parenthesizing that itself leads to the transcendental ego. For Husserl, the deceptions and possible dream-ness of the world leads to the conclusion that "a non-being of the world is conceivable," leading to the affirmation that there is a transcendental ego that "practices abstention with respect to what he intuits" (Edmund Husserl, Cartesian Meditations: An Introduction to Phenomenology, tr. Dorion Cairns [London: Kluwer Academic Publishers, 1999], pp. 17 and 20). This abstention is a parenthesizing of existential positions concerning objects of the world, which also serves to prove the ego as a self-apprehending ego because "Anything belonging to the world, any spatiotemporal being, exists for me-that is to say, is accepted by mein that I experience it, perceive it, remember it ..." (ibid., p. 21). Thus, even if no world exists, the transcendental ego exists insofar as it has experiences, perceptions, etc. of a world, and the continual reproof of this ego can thereby become the transcendental foundation of experience. Yet, noting that the conceiving of the world as other than what is given and can thereby fabulate a world through words that are separate from the things that it generates and/or describes, may be a modification of the Husserlian position, if not a questioning of it. That is, if the world is conceived as other than what is given while words can fabulate a new world distinct from the words that create it, it appears that there is not merely a parenthesizing of the world but also a generation of the rules for the world, and for worldliness itself. The non-being of the world is conceivable in this way just as much as the operations of an old and new world. That the world is other than what is given requires, for Descartes, a world as fabulated, whether said world is old or new, and its fabulation will generate the rules which these worlds may obey, even while the fabulation itself follows rules of generation in the telling of its fable. Such generation would be the fabulation of worldliness as well as the fabulation of the world, and doing so is neither specifically nor necessarily transcendental through the Husserlian ego because the otherness of or within the given world is always already at hand, always already informing the 'fabulatibility' of the supposedly transcendental ego, even while that selfsame fable of the new world generates the rules obeyed by that world, both as a fable and as a world.
} 
explicitly in the Discourse (see CSM I, p. 111-112; AT VI, p. 1- 2), and as is implied by the deployment of French in The World, even the densest (or at least the least academically educated) minds can be set into the motion of thinking, so long as they are not bored.

\section{Descartes imagines world and mind as stimulated both to order and to ordering through}

light and fable, respectively. ${ }^{13}$ Poetry, in being aligned with chaos, cannot stimulate

conception in this way. Indeed, the descriptions of poetry, in being of "the most confused

and disordered [embroüille] chaos," have nothing to do with order even in the sense of being a

privation of order. ${ }^{14}$

${ }^{13}$ This stimulation to order and to ordering is what Dennis L. Sepper means when he discusses the 'biplanarity' at work in the early Descartes. Beginning from the note in the Early Writings (or Cogitationes privatae) in Descartes' notebook from 1619-1622 (see CSM I, p. 4; AT X, p. 217), Sepper shows that there is "a strict analogy between the material universe (geometric space) and the space of the imagination to be found in the later Descartes" (Dennis L. Sepper, Descartes's Imagination: Proportion, Images, and the Activity of Thinking [Berkeley, CA: University of California Press, 1996] p. 57). For Sepper, this analogy remains within the Cartesian corpus longer than traditional readings would normally have it. The analogy, however, is also important for understanding Descartes generally insofar as it demonstrates an ontological basis for the method because it shows an ontological similarity between things insofar as they can be figured, whether pictorially, spiritually, or intellectually (see ibid.). However, the early claims, from the notebooks and at least up until The World, where, "If we limit ourselves simply to this realm of the corporeal, we can derive from these considerations a comprehensive technique or method of solving problems of this realm" (ibid., p. 58), are not possible for later Descartes. Without wanting to engage on the chronological accuracy of possible claims by Descartes, since Sepper is most likely right as to what Descartes would be willing or able to admit or claim, my point of focusing on this inaugural motive in the physical and mental and/or imaginable worlds through attention to the link between light and fable brings more attention to what does continue throughout Descartes' career, in particular the interest in motivating conception, thinking, and so on in the minds of readers of various types and levels of education. Insofar as this motive for inaugurating motion is consistent, then, the status of the fable is extendible to points of Descartes' career where he most likely would deny a biplanarity that allows us to develop a corporeal technique for solving corporeal problems. Though I intend to show this in more detail below, some of Sepper's unwillingness or inability to notice this continuation is a result of one of his fundamental motivations in writing his book, which to one degree or another traces Descartes' concept of the imagination from roots in faculty psychology, even if the divisible faculties are later displaced by the unitary mind (see ibid., pp. 5, 13, and 208). For myself, this focus on faculty psychology gives itself too easily to a presumption of a pre-formed self at work in Descartes. Much of my argument against such a presumption will, I hope, develop through attention to the relationship between analysis and synthesis as well as the reproof of the self that all other proofs are, but for the moment I simply want to note that the faculties, divisible or otherwise, of a presumed self is still the result of a presumed self.

${ }^{14}$ This point as to the relationship between pre-motive solid chaos and order is what Nancy seems to have missed when he claims that "The matter of poetic chaos turns out to be the same thing... as the primary matter of divine creation. It thus occupies the structural position of the cogito" (Jean-Luc Nancy "Larvatus Pro Deo," tr. Daniel E. Brewer, Glyph II: Johns Hopkins Textual Studies [1977], p. 26). The cogito is not of the order of chaos precisely because it is orderly. That is, the orderliness of the cogito dislodges it substantially from chaos and/or poetry because chaos is non-elemental, even if solid, and thereby not the world, even if chaos remains the pre-motive foundation for the elements that constitute the world. Thus, poetry is distinct from the cogito that is set into motion by the fable just as chaos is distinct from the world that is set into motion by light. 
Third, building on the previous point, Descartes, having explained the three principal rules of motion, explains that he could give more rules to determine motion in more detail, but that he will not do so because he only wants to "suppose" the rules "that most certainly follow from the eternal truths on which mathematicians are want to support." The rest of The World is concerned with those few certain rules, including, in the next chapter, the process of the breaking apart of the pre-motive solid chaos into the ordered world of experience, though it remains a fabulated experience within imaginary space that also happens to match the world we do experience (and experience as other than what is given). In that the rest of the fable of The World is dedicated to laying out the clearest rules that follow, it is dedicated to showing the rules of conceiving, knowing, supposing, and imagining. The fable of The $W$ orld, then, fabulates a world without miracles, and thus a world where even god, as the fabulated "author of all the motions of the world," must obey the laws laid out here. ${ }^{15}$ As was made clear above, when discussing divine preservation of the

Because of these distinctions, I am willing to claim that Nancy illegitimately confuses poetry and fiction when he writes that "In the instant of the cogito," this cogito which occupies the structural position of poetry and chaos, "thinking is but the self-positioning of the fiction-making operation of doubt" (ibid., p. 35n. 21). The fiction-making operation of doubt may indeed be a fiction, a fable, a story, but it should not also be structurally conflated with poetry and chaos, which are not of the order of order. It is the perhaps double movement, the double responsibility or status of fable, of obeying and generating rules of and for the order and operation of the world that is the precise status of light and fable and/or fiction that makes these things distinct from poetry and chaos in the context of The $W$ orld. Following from this error, Nancy further cites "the formlessness and unnamableness of the subject that indeed here has no form" as an argument against the presumption of the Cartesian self or subject (ibid.). However, in having conflated cogito and chaos, Nancy seems to have accepted a certain type of understanding of the Cartesian self, even if he has accepted it in order to demonstrate its formlessness and thereby to undermine its presumption. Taking the distinction between fable and poetry seriously, the formlessness of the self need not be considered as such thanks to a connection with chaos, but rather because of its double movement between rule-generation and rule-obedience that is not necessarily a movement which indicates a virtuous circle of proof of self, but an internally disruptive and disorienting proof.

${ }^{15}$ Jean-Luc Marion, however, seems to draw a nearly opposite conclusion from quite similar material. For him, the reference to chaos and poetry indicates "an elegy for poetic power" over and above any limitation on divine power or on "the initial freedom of God in the encounter with the Fates" (Jean-Luc Marion, "God, the Styx, and the Fates: The Letters to Mersenne of 1630," in On the Ego and on God: Further Cartesian Questions, tr. Christina M. Gschwandtner [New York: Fordham University Press, 2007], pp. 104 and 115). Marion sees this elegy and non-limitation as a result of the time it took for Descartes to fully develop his thinking on these subjects (see ibid., p. 103), but also as in line with considerations on the relationship of divinity to fate that run back to the ancient Greeks. Citing Descartes' letter to Mersenne dated May 6, 1630 (see CSM-K, pp. 24-25; AT I, pp. 148-150), Marion claims that Descartes rejects a limitation on god by either "the univocity of reason" or 
world-qua-motion through the preservation of light as well as through poetry's inability to prevent the ordering of the world once motion has begun, these rules, these "eternal truths," clear and mathematically certain, shown through the rest of the fable, are the world as interpretable and conceivable. But if the rules that constitute the fable are the world, then this fable, as a fable of the world, is also those rules. The story the fable tells is a story that fabulates the world as a rule-bound world. (W, p. 15; AT XI, p. 47)

But all of this means, then, that the telling of the fable is nothing more than the generating of the rules that the world obeys, even while the fable itself, in being rules, obeys the rules that it also generates to stimulate the reader's mind to conceive the world that is the fable. The words of the fable fabulate their own signified, their own world. There is no difference between the words of this fable and what they signify_a non-difference predicated on the rule that differentiates or distinguishes between fabular regularity and poetic chaos, a rule itself made possible by the potential for an imaginative moment which fabulates a fabular world so like our own from the beginning-even while it remains a fabulated world, though more interepretable than the old world of Aristotelianism and even

by fate (Marion, "God, the Styx, and the Fates," p. 107). Instead, Descartes says that the gods (or god) did not need to accept the same necessity of reason or fate, at least not "in the doctrine of the creation of the eternal truths" (ibid., p. 108). By the Fifth Meditation, however, Marion notes another position held by Descartes, which is that the poets have an authority by bearing witness to divine freedom over the fates. Insofar as Marion is correct, then poets for the Descartes of The World, written between 1629 and 1633, would be blasphemous in seeking to limit divine power by the univocity of reason. However, perhaps this is one more reason to take the distinction between poetry and fable all the more seriously. That is, if poetry is aligned with chaos as deliberately distinct from the elemental matter of the ordered world of light, and therefore poetry is aligned with what is not even uninterpretable, then, even if the divine power in itself is not limited by the rules of the physical operations of nature, this power, insofar as it would create the world as a world of order, interpretable or not, is limited by the very rules it simultaneously generates in the motion it inaugurates. The world as a world of order is subject to the univocity of reason or fate. That this is the world god creates in the inauguration of motion, regardless of the specifics involved in that inaugural moment, was always and necessarily going to find itself falling into the specific form of motion as it is experienced, then it appears that this motion, the rules generated by this motion, also needed to follow these selfsame rules. If god is not limited by these rules, the creation of the world qua inaugural motion certainly appears to be limited by these rules, even if it simultaneously generates them. If the world, as world, is to be without miracles, and thereby comprehensible by an orderly and ordered mind, then god as creator of this world is limited. The elegy of the poets that Marion identifies when discussing the poetry of The World does not, ultimately, have much purchase either way on the discussion of the limitation on divine power in this text, because what is important in The World is the fable, especially in its distinction from poetry. 
while it could not necessarily claim to be the same world as the deceptive world of experience that shows Descartes there is more to the world than what is given. This movement between the deceptive world whereby more than what is given is shown and the fabular world whereby signs and signifieds find themselves in interpretive harmony, a movement where the deceptive world demands imagining a fabular world without deception that itself requires a self-deception that this fabular world is 'truly' the world, thus calls attention to the method whereby this fabulation can occur. Even still, the method whereby this fabulation can occur requires a kind of method, lest the fable be simply one more uninterpretable world in a long history of them. The method for generating a method is required, and this requirement signifies the work of fabulation as such, fabulation as that which generates what will come to be interpreted as the world of harmonious sign and signified. In other words, the fable does not merely obey the rules of conceiving the world. It also generates them.

\section{Light and Fable}

For these reasons, poetry as understood in The World cannot be conflated with the fable. I will expand the concept of the fable beyond the precise and traditional genre limitations of literature, but in this context, where poetry is aligned with chaos, it cannot be aligned with fable. Fable is to the conception of the mind of the reader as light is to the motions of the world: They both are the rules of their respective activities. The world is light insofar as its motion orders and preserves the motions of the world. The world is a fable insofar as the 
telling of the fable is a laying out, even if not an Auslegung, of the rules of conceiving the

world. ${ }^{16}$ Light, and the world, is a fable.

This means that light and fable are not just parallel or biplanar foundations of their

respective spaces. Rather, they are co-constitutive. The action of light is the basis for the

experiences that are linguistically interpreted. However, the conventions of language that

give meaning to the interpretations are also necessary for light itself to have meaning, to be

interpreted, and thereby for light to be conceived in terms other than as merely given. The

potential of interpretation distinguishes light from pre-motive solid chaos. If the telling of

the fable of The World is the telling of the rules for interpretation that the fable itself also

obeys, then, as much as light is the ground for what is linguistically interpreted, the fable is

also the ground for maintaining an interpretable relationship to what is experienced. This co-

constitution also means, then, that the fable, in generating the rules of interpretation that it

\footnotetext{
${ }^{16}$ To a certain extent, in understanding the interpretation at hand in The World, or even beyond, as a 'laying out' in the Heideggerean sense of an Auslegung, the distinction of Descartes from what I argue is Foucault's overdetermination of the disappearance of interpretation in the move from the Classical to the modern worlds (see above) can be understood. In the third note to their translation of Sein und Zeit, John Macquarrie and Edward Robinson accurately explain Heidegger's use of Auslegung (which they translate as 'interpretation') as "any activity in which we interpret something 'as' something," and Interpretation (which they translate as 'Interpretation') as "interpretations which are more theoretical or systematic, as in the exegesis of a text" (John Macquarrie and Edward Robinson, in Martin Heidegger, Being and Time, p. 19n. 3). That is, Cartesian interpretation in the sense being presented here need not be understood in the theoretical, preconceived sense of Interpretation, but as a laying out of the connection between distinct objects, different worlds. Insofar as the 'as' of Auslegung places such laying out in the realm of the transcendental and/or theoretical, as can be seen in Division Two, however, the laying out of the rules of the fable that the telling of this particular fable is marks the Cartesian fabular laying-out as distinct from Heideggerean Auglegung. Heidegger himself further clarifies Auslegung in the Preface to the Second Edition of Kant and the Problem of Metaphysics, when he defends the violence of his interpretation as resulting from "attempts to set in motion [in Gang bringen] a thoughtful dialogue between thinkers," as opposed to the "agenda [Aufgabe]" of historical philology (Martin Heidegger, Kant and the Problem of Metaphysics, tr. Richard Taft, 5 ed., enlarged [Indianapolis, IN: Indiana University Press, 1997], p. xx; Kant und das Problem der Metaphysik. [Frankfurt am Main: Vittorio Klostermann GmbH, 1951], p. xvii). If an Auslegung is an attempt to set or bring a dialogue into motion, onto a path or course, then it would be something closer to the Cartesian concept of the fable in that the fable, the structure of the fable for Descartes, is the persistent attempt to set thought into motion on the part of his readers, who are always already themselves thinkers, at least potentially, regardless of their educational background, and it is from the Aufgabelike questioning of academic quaestiones that Descartes repeatedly attempts to break via his fables, no more so than in The World. This clarification of Auslegung may still not precisely match onto the Cartesian fabular layingout insofar as the thoughtful dialogue "is bound by ... laws [Gesetzen]" which it does not itself generate, while the Cartesian fable lays out the rules for its own internal motion, as well as the motion in the mind of the reader it hopes to inaugurate, in the very act of laying itself out qua fable (ibid.).
} 
obeys, generates its own signifieds, the things which it describes. In doing both of these

things, qua fable, the fable is its own moral. The moral of the fable of The $W$ orld is not

external to the story itself, not even in a deconstructed sense, but weaves its meaning within

its telling. ${ }^{17}$ That Descartes himself focuses for the most part on light in this co-constitutive

relationship through the rest of his work does not mean that it is illegitimate to focus on

fable. Indeed, to focus on fable may reveal more about Descartes' work than he himself may

have conceived.

Insofar as the light and fable are co-constitutive, what is important to bear in mind in this conception of the fable is its relationship to rule-obedience and rule-generation. Both light and fable, the former in the world of material motion and the latter in the world of conceiving, obey the rules they generate and vice-versa. If this is true of fable in The World, then Descartes' pedagogical motive with the words that stimulate the minds of readers has a

${ }^{17}$ In discussing La Fontaine's “The Wolf and the Lamb," Jacques Derrida points to the cruelty and irrationality of the wolf's devouring of the lamb: "an exercise of force, then, as punitive justice in the interests of a sovereign who sets up no tribunal, not even an exceptional or military tribunal and who, in the name of his self-defense, his self-protection, his supposed 'legitimate defense,' annihilates the defenseless enemy, the enemy who doesn't even have the defense given by a defense counsel in a regular trial, etc." (Jacques Derrida, The Beast and the Sovereign, vol. 1, tr. Geoffrey Bennington, ed. Michel Lisse, Marie-Louise Mallet, and Ginette Michaud [Chicago: The University of Chicago Press, 2009], p. 211). This irrationality and cruelty is given reason and morality ahead of the showing of the irrational and cruel act, however, thanks to the moral at the beginning of the fable, which explains that "The reason of the strongest is always the best" and thereby functions like a prosthetic on or supplement to the body of the text such that what the reader will be made to know (faire savoir) how the fable proper is determined in the moral (ibid., pp. 34-35). Leaving aside, for now, Derrida's drawing out of the ethico-political implications to this traditional structure of fables (though this structure of moral to fable is not precisely traditional from Aesop, but from later collections of Aesopian fables), what is important in this moment is to note that the structure of the Cartesian fable, at the very least as it appears in The World, is not that of a fable without moral, but of a fable that generates its own moral in its telling, lays out its own rule within its story. Insofar as this fable generates its own signifieds, it brings to light its own meaning. In bringing to light its own meaning, this fable is not without moral, without meaning, but rather is its own moral. The Cartesian fable is not, then, in a strict sense, subject to the same deconstruction between moral and fable proper to which Derrida subjects La Fontaine and at least a certain history of Western political discourse, primarily through Hobbes and Schmitt. Not that the Cartesian fable is undeconstructible, but that the deconstruction must find a different externality to bring inside the system. That externality may be, it is my wager, the fabular as such, the structure or logic of fable as it runs throughout the Cartesian corpus, regardless of any attempt by Descartes to excise that logic from the logic of his system, method, or faculty structure. Not that I would precisely understand myself as performing a deconstruction here. Rather, I understand myself, I believe more modestly, as indicating a locus whereby we might come to a different understanding of Descartes drawn from out of his work. Such an indication may be more accurately and/or more modestly understood as an unworking or even an immanent critique of, at the very least, Cartesianism, which may or may not be distinct from Descartes himself. 
crucial relationship to rhetoric insofar as rhetoric can be understood as the art of persuasion. His rhetoric is always motivated by the hope or conception of stimulating his readers' minds to think on their own, within the parameters of rules which guarantee truth. In this treatise, the old world of Aristotelianism is uninterpretable, even if perhaps conceivable, while the fable of the new world is both interpretable and conceivable by others because its telling is the generation of the rules for obedience, which the reader obeys in the reading itself. The interpretability and conceivability of the old and new worlds shows the mind's potential for both. The mind set into motion with the fable of the new world is not one created from out of a chaos, but the fable of the world that shows the world as operating in an interpretable and a conceivable fashion is possible because minds, like the fabulated world itself, have the potential for rule-obedience within them. If the Aristotelian world was uninterpretable, its conceivability remained potential from the beginning of its formation. The fable reforms this potential rule-obedience in a more regulated and interpretable fashion by reforming the world as more than what is given and ultimately more obedient to the order of algebra and geometry than what had been conceived. It is the potential for a conception of a world interpretable by such order that the fable sets into motion. Obedience to these rules then generates the parameters for truth, even while this "naked" truth remains veiled within a fable which is less boring than other treatises. To expand the concept of the fable to novels, dialogue, and history, then, will require attention to this complicated relationship between rhetoric, language, pedagogy, and epistemology as found in the Cartesian fable. ${ }^{18}$ (W, p. 10; AT XI, p. 31)

\footnotetext{
${ }^{18}$ Roger Ariew agrees with my assessment of the persistence of the status of rhetoric and fable throughout Descartes' career to one extent: "Descartes's scientific discourse now [i.e., in the Principles] requires the use of some rhetorical tropes, that is, the fable . . a as necessary to the method of the new science" (Roger Ariew, "Descartes's Fable and Scientific Methodology," Archives Internationales d'Histoire des Sciences 55 [2005], p. 138). However, he also notes the shift away from the fabular and toward the hypothetical within Descartes' rhetoric
} 


\section{Fable and Pedagogy}

A few more words about words, especially about the words for 'potential', seem in order here. An examination of these words will help clarify how Descartes understands pedagogy, especially how it is that the fable educates, especially through the other great fable in his corpus called the Discourse.

Potentia, Facultas, and Puissance

In The World, Descartes considers potentia and puissance to be synonyms, or at least that the latter can translate the former. As was shown above, the fact that Descartes does not know how to interpret the Aristotelian definition of motion ("the actuality of the potentially existing qua existing potentially") does not by itself mean that this definition is a chaotic, non-conception of motion. Nor, however, does it mean that Descartes considers potentia or puissance to be inconceivable words.

In The $W$ orld s definition of motion, Aristotelian potentia is not a concern since motion, as derived from geometry and really distinct from rest, is a real quality of matter insofar as the matter passes from one place to another 'within' the plenum of space. This

between The World and the Principles, and considers this shift indicative of Descartes having "given up the possibility of deriving all his principles with the same kind of self-evidence and certainty" such that the "convenience" of not boring his readers is replaced by the necessity of recognizing the impossibility of discerning "the initial size, shape, and motion of particles from the infinite possibilities from which God could have chosen," a recognition which leads to fabular, or fable-like, hypotheses (ibid., p. 136). Thus, what Ariew sees in the shift of vocabulary from fable to hypothesis is a shift of assurance. What he does not draw attention to, then, is the structure or logic of fable as more than 'mere' rhetorical trope, but as conception central to the very possibility of Cartesian knowledge claims, i.e., central to the Cartesian method as a method for having clear and distinct ideas. It is not merely that fable is "a necessary component of a deep rhetoric of scientific method," but that there is a logic of fable that is, to one extent or another, indistinguishable from the logic of method (ibid., p. 138). To pay attention to this structure or logic of fable, again, requires extending the concept of fable beyond the concept of trope and opening ourselves to its centrality throughout the Cartesian corpus. 
passing from one place to another is inaugurated and maintained thanks to light, which both generates and obeys the rules of motion. Now, insofar as there is a connection between light and fable since fable generates and obeys the rules for conceiving the world, there is also a connection between the motion of the world and the motion of conceiving. The mind that conceives the new world of the fable of The World is set into motion by that fable, and this mind can be considered a plenum of imaginary space, even the densest of which can be set into motion by the fable.

Nearly twenty years after beginning The $W$ orld, Descartes addresses potentia again in a fashion that is helpful in this context. In the Comments on a Certain Broadsheet, he responds to public criticisms of the Cartesian system by Henri de Roy (Henricus Regius). In article 14 of his broadsheet, Roy claims that "Even the idea [Idea] of God which is implanted in the mind [menti] has its origin either in divine revelation, or in verbal instruction [traditione], or in observation of things." In his reply, Descartes explains that things derive their being either from a primary and proximate cause or from a remote and accidental cause. Neither verbal instruction nor observation can proximally cause the idea of god, however. These can only give ideas of either the printed word 'god' itself or the picture or sound generated by a painter, speaker, or perhaps musician. For Descartes, this leaves only the "faculty of thinking [cogitandi facultate]" as the cause of the idea of god, and the ideas of this faculty are always 'within' us potentially “since the term 'faculty' [facultatis] denotes nothing but a potentiality [potentiam]." ${ }^{19}$ (CSM I, pp. 296 and 305; AT VIII-B, pp. 345, 360, and 361).

\footnotetext{
${ }_{19}$ This understanding of 'idea' agrees with the account of the history behind Descartes' use of the word and the conclusions about the changes he introduces to that history given in Roger Ariew and Marjorie Grene, "Ideas, in and before Descartes," Journal of the History of Ideas 56:1 (1995), pp. 87-106. There, they show that the traditional literary use of the word considered ideas to come from sense and identified them with exemplars, but that, over the course of the end of the sixteenth and the beginning of the seventeenth centuries, 'idea' had taken on "a new, psychological sense" (ibid., p. 94). Descartes' intervention into this new concept of idea, they claim, was to completely dislodge it from the archetype model that survived into the early developments of the psychologization of ideas. That is, for Ariew and Grene, a Cartesian idea can no longer be conceived as
} 
All of this fits neatly with how Descartes conceives of physical and imaginary space in The World. While god may be the "author of all the motions of the world," there is no divine interference in the operations of nature save the preservation of light. Here, in the Comments, observations of things cannot proximally give an idea of god because god is too remote from things. Nor can verbal instruction be a proximate cause of the idea of god according to the Comments because, as it is put in The World, "words bear no resemblance to the things they signify." If the connection holds, however, then the author of the words that inaugurate the motion of the mind to conceive the idea of god can be a remote cause of that idea in the same fashion that god as the author of the motions of the world is the remote cause of those motions. This remoteness is perhaps 'de-mediated' thanks to the plenum at hand, in the same way that a stick can immediately give a sense to a blind man of his surroundings, to use an example Descartes himself consistently uses. However, since the speed of motion tends to slow as objects get farther from the sources of light, the mediation

“[informing] its imitations and [giving] them, or their 'images,' such reality as they have" (ibid., p. 105). Ariew and Grene speculate that this break from the model context was (1) epistemological, and was intended to shift the concept of 'idea' into thought and away from imagination, which agrees with what has been seen in the Comments; and (2) metaphysical, which aimed to break thinking from hylomorphic ontology. Though it does seem odd that Ariew and Grene never examine the long, parodic dialogue between the architect and the bricklayer in the Seventh Set of Objections with Replies, to Bourdin, nowhere in that parody does Descartes refer to the architect's plans and methodology as emerging from a psychological idea. Thus, this moment does not necessarily contest the claim that Descartes completely breaks from the model context of ideas. However, Ariew and Grene do not consider the relationship between epistemology, metaphysics, and physics in their investigation, maintaining themselves only within speculation on Descartes' epistemological and metaphysical innovations. Attending to the relationship to physics could perhaps have complicated the claim of an innovation in itself on Descartes' part. This is not to say that Descartes was not innovative in his epistemology and metaphysics, but that the potentiality of cognitive motion as operating in an identical fashion to the potentiality of material motion should indicate that ideas are products of a motion that is, at the very least, parallel to if an inversion of a motion that produces things. Such a parallel ought to be investigated more fully, especially if it is possible that its supposedly non-coincidental lines will reveal themselves as not parallel, but as having a doubly informative relationship between each other. In other words, it may be that Descartes' innovation in the concept of ideas is not as far from the imagination that Ariew and Grene seem to assume, even if a given idea is not imagistic. 
of intervening space cannot be disregarded. The question of the continuation of mental

\author{
motion will be important for understanding the fable of the Discourse. ${ }^{20}$ \\ The faculty of thinking remains, as a faculty, potential or puissance. ${ }^{21}$ Thus, the faculty
}

of thinking, as a faculty, is not thinking proper, is not a quality of the motion of the mind.

\begin{abstract}
20 Though this will be more important in chapter 4, below, here it is important to note what Nancy L. Maull notes about Descartes' conception of motion. As she points out, for Descartes, color is "merely the effect of the extendedness and the motion of bodies" (Maull, "Cartesian Optics," p. 258). Colors are perceived thanks to reflecting light instantaneously transmitted from the sun into the eyes of the perceiver (see E, p. 67; AT VI, p. 84). For Maull, such a theory of color perception is to be understood as "psycho-physiological," and explains the distinction between primary and secondary qualities such that there can be mental access to primary qualities through the motions of light that also gives rise to the motions of primary qualities (Maull, "Cartesian Optics," p. 258). Thus, colors do not resemble anything in the object any more than being tickled resembles something in the feather (see ibid., p. 260). If anything, they would seem to resemble or be in light itself, the effects of light's reflections off objects and into the eyes. Since light is itself an element in the physical system that never seems to be abandoned by Descartes over the course of his career, allowing the perception of color would be the perception of the motion and/or rays of light, a perception that itself opens the possibility of the "triangulation" that allows for the judgment of distance, position, size, and shape of material bodies, the question of the role of the fable in terms of the mental motion Descartes intends to inaugurate is clearly important for comprehending the selfsame Cartesian psycho-physiological theories (ibid., p. 264). What is being pursued in the question of the fable, then, is the question of the color of perception as such, over and above the objects perceived. If the fable and light operate in seemingly parallel motions, if the mind and the world move in similar fashions, and if light could potentially be perceived thanks to color perception (in that color is nothing in the object), then the fable is perceived in its colors, in the effect it has on other minds, in its reflection. If fabular reflection or motion speeds up rather than slows down as it gets farther from its source, as opposed to the slowing down of material the farther it gets from its light source, this distinction in itself does not mean the psycho-physiological theory of perception itself cannot move between the psychological and the physiological. Rather, it all the more calls for paying attention to that source of mental motion that would open up perceiving color as resembling the light that itself inaugurates and continues the material motions of the world. That is, it all the more calls for paying attention to the fable as intertwined with perception of the motions of bodies, whether those bodies be composed primarily of light, liquid, or earth. The hoped-for effect of this attention would be a kind of triangulation on the status and/or 'location' of the faculties, in particular the imagination. Such a triangulation is the focus of chapter 4, but attending to the status of the fable in the overarching psycho-physiological system (a system where discussion of the psyche is not limited to the pineal gland, animal spirits, and cognitive substance) is crucial to establish the method or operations of that triangulation.
\end{abstract}

${ }^{21}$ In his entry on puissance, Gilson does not cite any appearance in AT XI, where The World appears. However, he does cite the appearance of "potentiam" in the Comments. Placing this citation under the heading of "Puissance et acte," he explains further divides this use of puissance or potentia into three categories: (1) "potential [puissance] opposed to activity [acte], that is to say considered as one of the transcendentals. In this sense, potential and activity are entirely separate [se partagent tout l'être]," (2) "potential...as a species of the predicate [prédicament] of quality. Potential thus envisaged is divided into natural, obedient [obédientielle], supernatural, and neutral potential," and (3) "potential which relates to logical potential; this potential is confused with possible logic because it only consists in the non repugnantia extremorum." (Étienne Gilson, Index Scolastico-Cartésien [New York: Burt Franklin, 1964 \{Paris: 1912\}], s.v., "puissance,” p. 248; my trans.). In addition, Gilson gives headings of puissance, insofar as it is a potential of the soul, as falling under the Thomistic species of quality ("habitus et dispositio; naturalis potential vel impotentia; passio vel passibilis qualitas; forma, vel circa aliquid constans figura" [ibid., s.v. "qualité," p. 251]); as natural potential; and as falling under the ordinary and extraordinary potential of god (ibid., s.v. "puissance,"pp. 249-251). Given that he does not cite the appearance of puissance in The World, but does cite potentia as it is used in the Comments, it seems fair to 
The faculty of thinking, as a faculty or potentia or puissance, can be thought of like the pre-

motive solid chaos of The World. This faculty, then, is disordered and unmoved, though with

the potentia for a motion that will change the substance of the pre-motive faculty from chaos

to the order of discrete faculties. However, Descartes, as the author of the work or works

understand puissance in The World as falling under the distinction from acte laid out by Gilson, and thus as distinct from the possible or possibility and from the motions of energy, so long as the conceptual link is established, as I hope to do here. This understanding of puissance or potentia can further be categorized as at least falling under the first subcategory of puissance. That Gilson's entry for pouvoir is merely "What can make greater can also make lesser [Quod potest facere majus potest etiam minus]," it could appear as though pouvoir is linked to potentia, but this quote, from the Second Set of Replies, primarily to Mersenne, develops from Descartes' attempt to give a geometrical explanation of the Meditations' arguments for god and the distinction between the soul and the body (ibid., s.v. "pouvoir," p. 237; my trans.). Specifically, it comes from the ninth axiom of the geometrical presentation. When this axiom is deployed in the propositions, neither potentia nor possibilitas is the focus. Rather, vis is. In these instances, the claim is that he does not have the "power [vim]" to give himself the divine perfections he lacks, nor is god able to (non potest) perceive perfections that god lacks (CSM II, pp. 118; AT VII, p. 168; prop. 3). Further, in an April 21, 1641, letter to Mersenne, which Gilson also categorizes under powvoir, Descartes explains that this axiom's description of power refers only to what requires "a single power [potentiam]" (CSM-K, p. 181; AT III, p. 362), which CSM-K refers in a footnote to the argument for deriving our existence from god in the Third Meditation (i.e., the same argument from the third proposition in the geometrical rearticulation of the Meditations in the Second Set of Replies). What appears to be the case here, in Gilson's explanations of puissance and pouvoir, is that powvoir is in consistent reference to god, where it can be understood as in overlap with vis and potentia. Such overlap only appears in this case to be conceivable for the divine. Descartes follows up his clarification of the seventh axiom in his letter to Mersenne by saying that, "among men, who doubts that a person who could not make a lantern may be able [pourra] to make a good speech" (ibid.). Pouvoir, in the case of human life, remains distinct from puissance and potentia because it is a power at hand insofar as motion is engaged. But the faculty of thinking, as a faculty, is a puissance, a potentia, a capacity not yet at work. In god, such distinctions are unnecessary, because god's potential is always already at work.

Marion goes so far as to call potentia one of the divine names, the one under which "the attributes ... creation and supreme power" fall (Jean-Luc Marion, On Descartes' Metaphysical Prism: The Constitution and the Limits of Onto-theo-logy on Cartesian Thought, tr. Jefrey L. Kosky [Chicago: The University of Chicago Press, 1986], p. 244). Human life is, for him, relegated to possibility, though possibility is the one mode of human existence that "exceeds necessary presence" (ibid., p. 203). Possibility gives to humans our temporality in that necessity is distinct from the past and the future since "representation necessarily produces what is in presence," while the future is linked to possibility through freedom (and thus Descartes is linked to Kant for Marion), the past linked to it through "inattentive memory" (ibid.). Because we must abandon the cogitatio in order to think the possibilities of the past or future, these temporal modes "confirm ... the primacy of presence in the present" in Descartes (ibid.). While I do not want to contest Marion's argument on temporality here, I am concerned that he defines too strongly the futural mode of possibility while also isolating potentia to a divine name. In discussing freedom, he says "Freedom is not represented, since representation implies the presence of an object to the cogitatio" (ibid., p. 201). This much is undoubtedly true, but that does not necessarily mean that the future remains purely a possibility in the human sphere. If possibility, pouvoir, for Descartes is the power exerted once motion has already begun, then it is unclear that the future would necessarily be precisely possible for Descartes when linked with setting the faculty of thinking into motion. In terms of an already determined, Scholastic set of resources for this s faculty, as a faculty of an already developed mind, the future would remain 'merely' possible. However, in terms of the project of setting the faculty of thinking into motion where 'faculty' is associated with puissance and potentia, this setting into motion looks to open onto a freedom perhaps wider, more indeterminate than the freedom of a possible future. I would claim that such a future is the potentia being engaged in the Cartesian fabular project, even from out of minds already set into motion, insofar as the very conceptualization of that mental motion by Scholasticism is already problematic. (On vis, see chapter 1, below.) 
that will set this motion into effect, as the remote cause of that motion, is still not like god:

God never needs to demonstrate any distance from the motions that follow from the

inaugural motion because god is of a distinct substance from matter, while Descartes needs

to distance himself from the thinking and conceiving of those who follow him because he is

a thinking thing just like those who follow him. ${ }^{22}$ In fact, such distancing is precisely what

Descartes is doing with respect to Roy in both the Comments and the preface to the French

edition of the Principles. In the latter, he writes:

I am well aware that there are some people who are so hasty [hastent] and use so little circumspection in what they do that even with very solid foundations [fondements bien solides] they cannot construct anything certain. Since such people are normally quicker [plus prompts] than anyone else at producing books, they may in a short time wreck everything I have done. For although I have carefully tried to banish doubt and uncertainty from my style of philosophizing, they may introduce these elements into it if their writings are accepted as mine, or as containing my opinions. I recently had some experience of this from one of those who were reckoned to be particularly anxious to follow [suiure] me; indeed, I had written of him somewhere that I was "so confident of his intelligence [esprit]" that I did not think he held any views that I would not "gladly have acknowledged as my own." ... Because he copied the material [of Descartes' writing] inaccurately and changed the order [ordre] and denied certain truths of metaphysics on which the whole of physics must be based, I am obliged to disavow his work entirely. And I must also beg my readers never to attribute to me any opinion they do not find explicitly stated in my writings.

\footnotetext{
${ }^{22}$ Martin Joughin notes that, for Deleuze, puissance is distinguished from pouvoir in that the former means “"actual' rather than merely 'potential' power: power 'in action,' implemented” (Martin Joughin, "Translator's Notes," in Gilles Deleuze, Expressionism in Philosophy: Spinoza, tr. Martin Joughin [New York: Zone Books, 1990], p. 407n. b). However, he also notes that "this distinction remains merely implicit in the Latin potentia" (ibid., pp. 407-408n. b). Thus, Deleuze finds in Spinoza a correspondence between potestas and potentia in that "To potentia there corresponds an apitudo or potestas; but there is no aptitude or capacity that remains ineffective, and so no power [puissance] that is not actual" (Deleuze, Expressionism in Philosophy, p. 93). This position emerges from an identification of essence with puissance in Deleuze's Spinoza since "existence, whether possible or necessary, is itself power [puissance]" (ibid., p. 89). As a result, Spinoza is able to claim that god essentially exists as an actual, active power from which an infinity of things proceed. A similar distinction occurs in Descartes, though with a more explicit connection of puissance to potentia. That is, potentia and puissance both indicate a power which is potential, and not necessarily enacted, while possibility and pouvoir indicate a power at work in action. However, one distinction at work here that does not appear to be at work in Deleueze or Spinoza is that the potential of potentia and puissance is a power from out of which any action is at all made. There is no action in the pre-motive solid chaos, though the potential for action within it is the potential for order as such. It may be that this distinction is why Spinoza has a difficult time imagining a world radically different from our own that remains identical with ours, a world of a fable or fiction where what occurs is not so much the creation of a new order of the world but the imagining of the world anew. Instead, he isolates himself to the possibility of god's creating a new world with a different order which would be understandable in terms of that new order (see Benedictus Spinoza, The Principles of Descartes' Philosophy, tr. Halbert Hains Britan [La Salle, IL: The Open Court Publishing Company, 1961], p. 160).
} 
What has happened here is that Roy, and others like him, move too quickly from Cartesian foundations. Descartes' constant interest in inaugurating the motions of his new thinking is to inaugurate a slow process of reduction to the simplest elements of the world, and then an equally slow process of building back up from those simples to more fully understand their complex workings. It may be tedious, but the ideas that emerge from this process will be clear and distinct. Insofar as he does not want to bore his readers, he himself takes shortcuts or inaugurates fables, but he does believe that being engaged in the slow process he endorses will lead to the truth of the world. However, when those who are not as careful as Descartes begin to work with the Cartesian system, things go astray, in particular because such people move too quickly. They speed up the process and skip or even change steps in it, which results in a reintroduction of doubt into areas where it should have been eradicated. Thus, unlike material motion, where the farther the other elements get from the source of light, the more they slow down, the farther from Descartes as the author of the mental motions at hand one gets, the more that thinking speeds up. As a result, not only is Descartes not equivalent to god in that Descartes must explicitly place himself at a distance from the effects of what he has set into motion because what he has set into motion is of the same substance as himself, but those effects move faster the farther they get from their source. In addition, the motions inaugurated by Descartes can even allow for 'miracles' in that those who follow him can change the order, the rules of operation, necessary for his method. ${ }^{23}$

\footnotetext{
${ }^{23}$ The question of distance from the inauguration of physical and mental motions and the relative speed of those motions can be further elucidated by looking to Husserl. There, in attempting to distinguish between "de facto sciences" and "sciences "in the true and genuine sense," Husserl tries to show the difference between "immediate and mediate judgments" (Husserl, Cartesian Meditations, pp. 9-10). Mediate judgments relate to other judgments, both immediate and mediate, as things that must necessarily already be believed in order for the mediate judgment at hand to be believed. Thus, whatever correctness or truth may be shown in a mediate judgment, "the showing is itself mediate" because it depends on other mediate and/or immediate judgments, and ultimately refers to an originary " "judicative' doing" that claims evidence for having or being in a "complex (or state) of affairs, instead of being merely meant 'from afar', is present as the affair 'itself"' (ibid., p. 10). De facto science grounds its claims within a complex of mediate and immediate judgments made possible by a judication
} 


\title{
However, what remains important here is that both god and Descartes set a potentia into
}

\author{
motion and do not proximately cause the subsequent effects of the inaugural moment. ${ }^{24}$ In
}

of the affairs which serve as evidence for those claims, all of which is distinct from though also includes "prepredicative judgment and ... pre-predicative evidence" (ibid., p. 11). Whether Descartes' inaugurations are prepredicative or predicative immediate judgment, they are not meant to be understood as mediate judgments. Those who follow Descartes are engaged in mediate judgments in reference to a ground he establishes in the inaugurations of motion. Those mediate judgments can easily gain speed beyond their original source, especially if not carried out with enough careful reference back to the source. If material motion loses speed as it moves farther from light, that is because its operations of mediation encounter other material that slow it down, but, following Husserl, mental motion is its own mediation, and thus can impel itself to greater speeds if the mediation itself comes to be understood as the ground for its claims rather than consistent and careful reference back to the immediate judgment and judicative doing that inaugurated said motion. Now, Descartes would appear to understand his self-inauguration, and the inauguration to self-instruction-i.e., the fable of the Discourse - as pre-predicative judgment and evidence, in that such an inauguration would establish the ground for the possibility of any judicative doing, of being able to comprehend the intuitive legitimacy of the cogito, for instance. However, the fable, as I hope to show below, is already informed by some predicates, whether literary, historical, or otherwise. Yet, this does not necessarily mean that the fable in its structure is not prepredicative. Rather, if the structure of the fable can be consistently placed in relation to light, then that structure takes on something of a pre-predicative judgment and evidence because the fable establishes the evidence for itself.

${ }^{24}$ Cavaillé takes this structural similarity between god and Descartes as indicative of a Diocletian-esque, isolated sovereignty of the philosophic, or at least Cartesian, 'I'. Much of his evidence for this position comes from Descartes' April 15, 1630, letter to Mersenne, where Descartes compares the known but impossible to grasp "greatness of God" to the majesty of a king, saying that "a king has more majesty when he is less familiarly known by his subjects, provided of course that they do not get the idea that they have no king" (CSM-K, p. 23; AT I, p. 145). From this point, Cavaillé notes that "Descartes engages Mersenne to diffuse [his doctrine on divine greatness], but under the seal of anonymity," such that Descartes can be understood as having "with his public a relationship similar to that which God holds with his creatures," thereby "surreptitiously applying to himself these considerations of political theology" by "exploiting Mersenne's zeal, in order to be made known while jealously defending his studious solitude from public intrusions" (Cavaillé, Descartes: La Fable du Monde, p. 297; my trans.). Marion disagrees with the reading of Descartes' position in relationship to his audience, finding that the very fact that Descartes consistently solicited responses to his writings, especially in the Discourse and Meditations, indicates that he is not "anything like a solitary, or even autistic, thinker, soliloquizing, in the manner perhaps of Spinoza" (Marion, "The Responsorial Status of the Meditations," in On the Ego and on God, p. 33). Rather, by soliciting responses, Marion's Descartes intends to operate "the double function of evidence: to make a thing manifest and to give proof (evidence) of it to another. Cartesian reason is communicative, precisely because truth manifests itself as a display of evidence; indissolubly, at one and the same time, it is to one's own reason and to the community of those looking on that the thing appears" (ibid.). Kevin Dunn seems to find himself somewhere between these two positions, claiming that Descartes' claims to isolation are "figurative," even "“fictional"” than anything else (Kevin Dunn, "A Great City Is a Great Solitude': Descartes's Urban Pastoral," Yale French Studies 80 [1991], p. 94). What Descartes does is distinguish his audience "neatly between different tracts," one formally educated and the other undereducated, as found in the audiences for the Meditations and Discourse, respectively, with the effect that he "[offers] only a partial version of his researches, a partial version of his self," even if "he has...pointed the way to a new rhetoric in which the author is figured as a public judge, a spokesman for a shared discourse, rather than a private advocate arguing for the relevance and legitimacy of his words vis-à-vis an authoritative tradition to which he can make reference but not ever fully represent" (ibid., pp. 102 and 107). Thus, for Dunn, there is something of an anonymous fiction at work that effects readers, and effects different readers in different ways, but this does not appear to place Descartes in the position of a sovereign, divine or mortal. Rather, the anonymity and the fiction preserves the capacity for the generation of the thing which his evidence and demonstration would prove, and prove in dialogue with others. Such a position would explain more clearly the differences between the speeds of physical and mental motions as they get farther from their sources, but it also would answer the difficulty of the 
addition, the faculty of thinking, or faculties in general, as potentia or puissance that can be conceived as not unlike pre-motive solid chaos, can also not be conceived as being of the same elements as thinking itself, which means that the faculties should never be conceived as formed qua ordering and ordered faculties prior to the inauguration of motion. ${ }^{25}$ (CSM I, pp. 293 and 189; AT IX-B, pp. 19-20)

phenomenological position on predicative evidence as articulated by Husserl and Marion, which would depend on a pre-predicative evidence. Husserl recognizes this difficult position, while Marion seems to disregard it in terms of the fictionalizing or fabulating that inaugurates the mental motions of Descartes' readers of any educated stripe. But the Cartesian fable inaugurates his readers' motions which have as yet remained in potentia and, as a fabulating moment, it is a fictionalization, the generation of a new world which can be interpreted differently even while its effects remain identical to the witnessed world. Thus, there is a kind of sovereignty, though not exactly one like god's, not exactly like a monarch's, both of which would appear in their nonappearance or their epiphenomal appearance in the regular operations of the universe or the application of sociopolitical laws. Descartes' sovereignty can only appear in the distancing of himself from the too-fast motions of others' minds over which he lacks control, over which he can exert no concurrence. But the motion itself remains inaugurated by him in the way god inaugurated the legally operative motions of the world and in the way a sovereign inaugurates the sociopolitical motions of a realm. It is for this reason that Descartes could say, in a letter from 1643, to an unknown priest or Jesuit, that "I find [Hobbes] much more astute in moral philosophy than in metaphysics or physics. Not that I could approve in any way his principles or his maxims. They are extremely bad and quite dangerous in that he supposes all persons to be wicked, or gives them cause to be so. His whole aim is to write in favour of the monarchy; but one could do this more effectively and soundly by adopting maxims which are more virtuous and solid [plus vertueuses \& plus solides]" (CSM-K, pp. 230-231; AT IV, p. 67; my emph.). On the complex relationship between authority and authorship, see Jean-Luc Marion, "Annotations," in René Descartes, Règles Utiles et Claires pour la Direction de l'Esprit en la Recherche de la Vérité, tr. Jean-Luc Marion, conceptual notes Jean-Luc Marion, mathematical notes Pierre Costabel (The Hague: Martinus Nijhoff, 1977), pp. 112-114.

${ }^{25}$ Here, I am following the logic of Stephen H. Daniel's description of light as an action, where he distinguishes between light as movement, as action, and as both movement and action. Light as an action is in fact "an inclination to move rather than a movement itself” (Stephen H. Daniel, "The Nature of Light in Descartes' Physics," The Philosophical Forum 7:3-4 [1976] p. 328). Light is here an inclination as opposed to movement proper because light is here considered as within the medium that is the plenum of the world, so there is no empty place to which light can move. The inclination to move that is the action of light cannot be conflated with movement until "we begin to speak about inter-medium interactions," such as the transmission of motion from light to liquid, which is why the transmission of light from one end of a ray to the other is instantaneous, but takes time if it involves reflection and refraction in the production of colors and the capacity to triangulate distance, shape, etc. (ibid.). Thus, there is the possibility of "a non-moving action, an inclination to move without the actual moving" in light as action insofar as this action "“includes not only the [puissance] or inclination to move, but also the movement itself"' (ibid., p. 329; quoting and translating AT II, p. 143). What Daniel is pointing out here is Descartes' recognition of the inaugural position of light, distinguishing that element, to some degree, from liquid and earth as well as from the interactions between light, liquid, and earth. What Daniel does not seem to recognize, in his zeal to lay out distinctions between 'kinds' of light, is that light is the generation of the laws which it will obey insofar as its inaugural movement begins the motions of the world. Prior to motion as such, the world is solid chaos, and so precisely not light at all. However, in that light was in potentia, in that it was a puissance 'within' the pre-motive solid chaos, which the inaugural motion of light set to work, light as an action was there. The faculty of thinking, as a faculty, is in potentia in a similar fashion, requiring the inaugural motion of the fable to set it to work. There is, in this sense, unthinking thought (if only in the form of good sense, only as bona mens) as easily as there is non-moving action. The faculty of thinking is not of the same elements as thinking itself because it is thinking only to the extent that it is in potentia, is a 
The above process of aligning facultas, potentia, and puissance was necessary to understand what exactly Descartes is doing when he begins the other fable in his corpus, that of the Discourse. There, he famously begins with the claim that "Good sense [bon sens] is the best distributed thing in the world" in that everyone thinks he or she has as much of it as he or she could ever want. From this, Descartes draws the conclusion that it is equal in all. However, he further explains good sense as "the power [puissance] of judging well and of distinguishing the true and the false" as well as "“reason'." Thus, the puissance of good sense is the potentia for the mind, reason, and judgment. It is this puissance that Descartes intends to set into motion in the Discourse. ${ }^{26}$ (CSM I, p. 111; AT VI, pp. 1 and 2)

However, there is one more word related to facultas, potentia, and puissance that requires a degree of clarification, if only to exclude it from the list of crucial Cartesian concepts. This word is vis. There is a discrepancy between Descartes' French and the Latin translation of the Discours et Essais by Descartes' friend Étienne de Courcelles, titled Specimina Philosophiae and published in 1644 but begun soon after the original's publication (VMD II,

puissance that has not yet emerged from its pre-motive potentiality. It is a faculty in the most literal sense, without form or distinction from other faculties that also exist in the pre-motive, chaotic, solid mind prior to the motions inaugurated by the fable which allow the elements of said mind to emerge from out of the selfinstructive movement that the fable itself is.

${ }^{26}$ Gilson notes two different significations of the term bon sens. The first is "the natural faculty of distinguishing the true from the false," while the second is the Stoic sense of wisdom (Étienne Gilson, "Commentaire Historique," in René Descartes, Discours de la Méthode: Texte et Commentaire [Paris: Librairie Philosophique, 1947], p. 81; my trans.). Between them, "bon sens is the instrument which, if we use it well, allows us to attain bona men, or Wisdom; and, inversely, Wisdom is only good sense reached at the point of the highest perfection of which it may be able" (ibid., p. 82; my trans.). However, both meanings must be distinguished for Gilson to avoid attributing perfection to everyone. In the context being noted here, significantly more emphasis is thus placed on the first meaning of bon sens. In addition, Gilson considers puissance, potentia, and facultas to be equivalent terms (see ibid., p. 84). 
p. 214). ${ }^{27}$ There, "bona mens" is "vim." There are numerous discrepancies in Courcelle's

translation, although it was approved and corrected by Descartes before publication, but this

one is of particular importance. ${ }^{28}$ If the puissance of good sense were a vis and not a potentia, then the concept of good sense as a pre-motive potential would be lost. Good sense as a vis would carry an implication of energy, which in turn implies motion already occurring. ${ }^{29}$ If the motion is already occurring, then the faculty of judging as a puissance that can be set into

motion is already in motion. In that no one is without some mental motion already at hand, this is true. However, since Descartes' pedagogical goal is to begin motion anew by inaugurating a new motion, as if this new motion were always already in potentia, even while acknowledging the pre-Cartesian motions at hand, maintaining the faculty of good sense as a puissance seems structurally necessary for Descartes. That he writes in the Comments that

${ }^{27}$ Corinna Lucia Vermeulen, "René Descartes, Specimina Philosophiae. Introduction and Critical Edition,” Ph.D. diss., Utrecht University, 2007, contests Baillet's account of the translation. Beginning from Baillet's general unreliability, she says that the translation began earlier than Baillet claims and that there is scant evidence that Courcelles had a personal relationship with Descartes - although it does appear that the translator would have been a friend (Vermeulen, "René Descartes," pp. 10-12 and 27). In addition, it appears to her difficult to know whether Courcelles would in fact have translated the Disours et Essais since his student does not mention it at a eulogy for Courcelles and since Courcelle's Latin was overall better than what appears in the Specimina, even suggesting that there may have been a second translator of at least the marginalia, summaries, and table of contents (ibid., pp. 11, 14, and 31-33). However, in that Baillet is the only source for anyone's claim to translating the Discours et Essais, and given that there is some mild evidence external to Baillet that Courcelles could have done the translation, Vermeulen concludes that "I will on occasion refer to Courcelles as the translator" (ibid., p. 14). I see no reason to argue with her on this point.

${ }^{28}$ On the discrepancies and Descartes' responsibility, and abdication of responsibility, for them, as well as other general issues concerning the discrepancies, see ibid., pp. 27-31. This particular discrepancy need not necessarily be laid at Descartes' feet, but only because there are only three corrections he is known to have made (see ibid., pp. 61-63). Vermeulen does specifically attribute translating bon sens with bona mens as a Gallicization of a living seventeenth-century Latin, but she does not concern herself with the translation of puissance with vis, either in her introductory material, in her notes to the Specimina itself, or in her appendix on postclassical words in the text (see ibid., pp. 35, 43-61, 108, and 383-388). The mere fact that Vermeulen does not concern herself with this specific discrepancy should not in any way be taken as indicative of a failure in her impressive research into the Specimina.

${ }^{29}$ Lewis and Short, s.v. “vis," accessed March 8, 2013, http://www.perseus.tufts.edu/hopper/text?doc $=$ Perseus $\% 3$ Atext $\% 3$ A1999.04.0059\%3Aentry\%3Dvis. Though in I.2. of Lewis and Short there is a link between vis and potentia, that link is identified as particularly literary and in reference to "herbs, drugs, etc.," and so would appear to be too specific to an energy already in motion. Indeed, this definition also links vis to "Energy," thus further distinguishing a Cartesian potentia and puissance from vis insofar as the former are understood as pre-motive. In no other aspect of the definition is there an explicit link to potentia, even if there are other references to "power." 
facultas and potentia are synonyms and in The World that puissance translates potentia gives

further credence to consider the Specimina's use of vis to be a mistranslation of puissance.

(CSM I, p. 122; AT VI, pp. 540 and 22)

Setting this puissance into motion will be the demonstration of the proper use

(“appliquer") of reason. Thus, mind, reason, and judgment no longer only in potentia are

defined and delineated according to their application. That the applications of reason are

diverse is due to the fact that "we direct our thoughts along different paths [voies] and do not

attend to the same things." What Descartes wants to set into motion, then, is the directing of thoughts along a path such that attention is paid to the same things. This setting into motion would be the proper application of reason. Once this application of reason is set into motion, Descartes and his readers can see that most human activities prove themselves "vain and useless [inutile]." The proper application of reason shows that most applications are useless, thus the implication is that the proper application of reason can be delineated according to its usefulness. The proper application, the proper use of reason, is in utility, in good use. The potentia of good sense is properly used in good use. ${ }^{30}$ (CSM I, pp. 111 and 112; AT VI, pp. 2 and 3)

\footnotetext{
${ }^{30}$ In this way, Descartes would appear to be more modern in the Foucauldian sense than perhaps Renaissance or classical. For Foucault, modern thought, the eighteenth- and early nineteenth-century period of ordering, is haunted by the imperative that it "be both knowledge and a modification of what it knows" such that this thought "immediately causes to move [fait aussitôt bouger]" whatever it touches, with the risked result that thought changes or fails to come to know the unthought quality or essence of the unthought (Foucault, The Order of Things, p. 327; Michel Foucault, Les mots et les choses: Une archéologie des sciences humaine [Paris: Éditions Gallimard, 1966], p. 338). This imperative drives thought to a distinctly modern amoral 'morality' of humans cut off from themselves by the very movements, the very action of the imperative to know, which is why modern thought "is no longer theoretical" or speculative (Foucault, The Order of Things, p. 328). Certainly, the issue at hand in Descartes would appear to align with this assessment of modern thought, insofar as Descartes' setting into motion the puissance of good sense is an action such that reason can find its proper application, and find it in utility. And yet, in the same section, Foucault writes that "the modern cogito is as different from Descartes' as our notion of transcendence is remote from Kantian analysis” (ibid., p. 324). Foucault's understanding of the Cartesian cogito's concern is "to reveal [mettre au jour] thought as the most general form of those thoughts we term error or illusion" so that error and illusion can be explained with and through a method against error laid out (ibid.; Foucault, Les mots et les choses, p. 335). The modern cogito, however, "must traverse, duplicate, and reactivate in an explicit form the articulation of thought on everything within it, around
} 
There is a rhetorical strategy in addition to the metaphysical, ethical, and pedagogical claims involved in these opening paragraphs. The metaphysical claim is that the mind is the mark of the human species and thus it is potentially the same in all individuals of that species. The ethical claim is that reaching the potential, achieving the capacity that all humans have, hence becoming truly human is dependent on learning how to apply this metaphysical marker of the species, choosing the accurate path, but a path which is equally open to all. The pedagogical claim is that this path open to all requires applying the techniques that most fully express the humanity of the human, that is, the mind, reason, rationality. Finally, then, the rhetorical strategy is to begin this discourse by telling the audience, the lenscrafters, those who have been trained in technical skills, that their potential for rationality is as powerful as that of the learned and that all they need to become as learned as the learned is to learn how apply their rationality.

This text is written in French for a reason, regardless of any subsequent academic influence thanks to the Specimina. ${ }^{31}$ Descartes is involved in a democratization of reason in the Discourse, expanding the potential for thinking beyond the walls of the academy and its syllogisms, quaestiones, and so on. One might be tempted to say that there is a new kind of

it, and beneath it which is not thought" (Foucault, The Order of Things, p. 324). Thus, it would appear that the difference between the Cartesian and modern cogitos is that the former finds its proper place while latter extends itself to where there is no thought. To be sure, at this point of the Discourse, where Descartes is setting good sense into motion, we are not quite at the cogito proper, and there is no thought of anything but minds and sense, even if in potentia. However, what is lost in translating 'mettre au jour' as 'to reveal' is the motion set to work that Foucault clearly recognizes in Descartes. The question is how mettre au jour is not the same as faire bouger for Foucault. Here in the Discourse, of course, what is put into play is good sense, while what modern thought makes move is what does not think, but in addition the Cartesian cogito has not yet been put into play. Indeed, the Cartesian cogito requires something else to have happened, requires a prior play or motion to have been set to work, before it can itself emerge as putting a generalized thought into play toward the identification of erroneous thoughts. That 'something else' is the fable, Descartes' histoire of the poêle, the dreams and meditations, the travels, and so on, the fable that will draw our attention to the same things in order to find the proper application of reason, which is, following Foucault, to thought. If the motion set to work here is not operating via a faire bouger, it is because, first, what is being set into motion is good sense and, second, this motion itself is not even yet the play of the cogito but the opening of the fabular motion which will itself open up the cogito's field of play.

31 On the influence on academic philosophy of the Specimina as opposed to the Discours, see Vermuelen, "René Descartes," p. 29, esp. p. 29n. 8. 
elect, closer to craftspeople, created here insofar as the good application of good sense is limited to utility. However, considering what Descartes does say on the rare occasion that he discusses politics and what he says to Latin readers about the masses, it is clear that his appeal to the good sense potentially in useful application on the part of all can be understood to be as much of a rhetorical strategy as the praise for the faculty of the Sorbonne. Here, in the Discourse, he merely hopes to convince craftsmen of the value of grinding lenses through a geometrization of nature as demonstrated in the Essays. (CSM II, pp. 5-6; AT VII, pp. 5-6)

Thus, he writes in French, and deploys a rhetoric of technical, craft-like application of reason to demonstrate to his readers that reason is as potentially theirs as anyone's. Indeed, he even confesses an averageness of mind, wit, imagination, and memory on his own part. What has allowed Descartes to exceed the potentials of others is the method, which was discovered thanks to fortune. In his hope to demonstrate the utility of the method, however, Descartes will not teach it. Teaching, enseigner, is not Descartes' aim at all. Rather, he will "reveal [faire voir] ... what paths [chemins] I have followed." Descartes, then, is no teacher, but a revealer or demonstrator. The method as the méthode is not a method as a methodus, then, insofar as methodus is associated with the useless syllogistic reasoning of the universities. In the Seventh Set of Objections, Father Pierre Bourdin challenges Descartes by "[proposing] to deploy the traditional [veterem] form and method [methodum] which is familiar to all the ancients—indeed to everyone." But the méthode is not "a way of teaching" in that Descartes is not concerned with teaching or with "belonging to a particular school," but with showing, demonstrating, faire voir. ${ }^{32}$ Twice within two paragraphs Descartes says he will show

\footnotetext{
32 Lewis and Short, s.vv. "methodus" and "methodicus," accessed March 7, 2013, http://www.perseus.tufts .edu/hopper/text?doc $=$ Perseus $\% 3$ Atext $\% 3$ A $1999.04 .0059 \% 3$ Aentry $\% 3$ Dmethodus and http://www.perseus .tufts.edu/hopper $/$ text?doc $=$ Perseus $\% 3$ Atext $\% 3$ A $1999.04 .0059 \% 3$ Aentry $\% 3$ Dmethodicus, respectively.
} 
or make his readers see the method in the hope that doing so will open them onto "selfinstruction [m'instruire]" (CSM I, pp. 112 and 345; AT VI, pp. 3-4 and 507). Descartes will reveal, show, make seen, demonstrate, or faire voir through the telling of his own fortunate discovery of the method for self-instruction. To faire voir the method, he will faire voir his own path, voie, chemin to the method, opening the judgment of his own path up to the good sense of the reader, which is always already the potential equal of anyone else. ${ }^{33}$ This judgment of Descartes' path to his method hinges on the fact that, as he says to Burman, "no two people think alike," which means that every judgment of the faire voir will be highly individualized, and so there are as many paths to the method as there are readers (DCB, p. 45; AT V, p. 175). ${ }^{34}$ This method of showing the method is more complex than teaching a method.

\footnotetext{
${ }^{33}$ In his reading of the Discourse, André Vidricaire shows that, first of all, enseigner appears only ten times, while faire voir and variations on it (dire, parler, montrer, représenter) appear a total of 100 times (see André Vidricaire, "La vision comme procédé de communications dans le Discours de la Méthode," Philosophiques 15:1 [1988], p. 97). In reading these appearances closely, he finds that the faire voir can be understood as having two aspects that are "utilized in an equivalent manner within the two fields," which follow Emile Benveniste's distinction between discourse and bistoire, meaning that, against Sylvie Romanowski, faire voir "cannot ... have the meaning of "récit" or a simple (biographical) story (ibid., p. 103; my trans.). Dire and parler, however, "take the form of a récit and more precisely that of a history [bistoire] of the discovery of metaphysical principles" while enseigner "is the attribution of an object from a sender [destinateur] to an addressee [destinaire] (ibid.; my trans.). Vidriciare's primary interest in this distinction is to show that "what is presented as an bistoire or a fable is a discursive form in perfect concordance with philosophical theses," in particular those concerning the status of light and vision (ibid., p. 97; my trans.). However, if there is a problem with his reading, it would seem to be in the maintenance of the distinction between faire voir and dire, and their correlates, light and thought. It is not that Descartes does not recognize the distinction between light and thought, of course, but rather that there does not seem to be a recognition on Vidricaire's part here that Descartes' fable or bistoire is an attempt to faire voir self-instruction, to set into motion the mind such that it is possible for light to be understood in an appropriate manner. That is, it is true that the fable of the Discourse is no simple récit, but that does not mean that the telling of it itself can be understood simply as a récit either. The telling of the fable or bistoire of the Discourse sets the mind into motion such that the metaphysical principles, the histoire of their discovery, can be comprehended. It may not be that what is sent to the reader is not an object, as an enseigner would accomplish, but that does not mean that the relationship between light and thought can be so easily distinguished as Vidricaire would seem to think. As in the fable of The World, the fable or histoire of the Discourse tells a particular tale, this time of method, méthode over methodus, and that method intends to allow for the comprehension of both the histoire of the discovery of the metaphysical principles and for the method itself. As a fable or histoire that faire voir what would allow for the faire voir of self-instruction, a self-instruction toward a better comprehension of light, the telling of the fable or bistoire cannot then be so easily distinguished from the speaking about the metaphysical principles it purports to faire voir.

${ }^{34}$ In his commentary on this passage, Cottingham points out that there is a discrepancy between the Discourse and the Conversation in that "the fact that everyone thinks his judgement is good does not of course entail that it is good" (John Cottingham, "Commentary," in Descartes' Conversation with Burman, p. 113). He offers up a
} 
Descartes is no teacher and the Discourse is no seminar, even if it is discursive. ${ }^{35}$ In telling his story, Descartes hopes to inaugurate a storytelling on the part of each of his readers. Since there is no one path to the method but there are as many paths as readers, those readers' judgments of the utility of his story must involve their telling themselves their own stories, recalling their own lives, their own experiences, in order to find their own paths to the method. ${ }^{36}$

possible reconciliation of the discrepancy by saying that good sense may be a "potentiality" rather than an actuality, citing the Specimina as evidence (ibid., p. 114).

${ }^{35}$ Thus, the Discourse does not fall under the categorization of what Derrida calls "the noblest tradition of the university institution, a seminar," and which he distinguishes from a fable (Derrida, The Beast and the Sovereign, p. 34). What a seminar can do is "present itself as a discourse of knowledge on the subject of that law of genre that is called the fable," but it cannot be a fable or fabular (ibid.). Thus, because a seminar is only supposed to dispense knowledge while a fable makes something known (faire savoir) in the sense that knowledge is brought to another and in the sense of giving an impression or effect of knowing on one's own part, the seminar and the fable remain distinct, even if linked to some degree. However, the Discourse, even as a discourse, is not a "discourse of knowledge," but of method, and the method by which the method of the Discourse will be shown is through a story, not through a discourse proper, not through discussing the supposed subject at hand (method) but through faire voir what can be faire savoir should one follow Descartes on his path, but in one's own way because there is no absolute savoir-faire to the faire voir, save the telling of the story itself. The savoir-faire of the faire voir itself can only be determined and judged by those who have told their own stories, moved their own minds in the wake of Descartes' fable, faire voir for and to themselves. Thus, what comes to be known in the Discourse is not dispensed in the manner of a discursive seminar, but is generated in the telling, is an effect of 'knowing' the story of knowing. This failure of the Discourse to operate as a discursive seminar and instead as a fable makes all the more sense when attention is called to Derrida's description of the seminar. The Descartes of the Discourse is not concerned with nobles but lenscrafters, not with traditions but self-instruction, not with universities but with those with good sense. To the extent he is concerned with institutions, it is limited to what those with good sense properly applied can establish. It is not so much that the Discourse escapes the distinction between discursive seminar and fable that Derrida lays out here, as much as it is that Descartes is engaged in something like an ironic, if not deconstructive, relationship to the language of that noble tradition and institution because the knowledge, the savoir, being dispensed is not being dispensed with savoir-faire and therefore cannot faire savoir anything useful. To be clear, Descartes is not a deconstructive thinker, even in the Discourse, where he simultaneously tears down and rebuilds the house of knowledge, if only because he finds another place to live while doing so (see CSM I, p. 122; AT VI, p. 22), but the fable of the Discourse, insofar as it explicitly does not teach, cannot be held on either side of the distinction Derrida lays out between the discursive seminar and the fable. It is not a discursive seminar for the reasons laid out above, but it is not a fable in the way Derrida describes, either, precisely because it is a discourse. Because it is a discourse on méthode, because it is a discourse on how knowledge would be dispensed, a discourse on the savoir-faire of savoir, it cannot ever have been a simple repetition of dispensation, but must itself show how to know how to make known.

Such a showing remains or involves a dispensation even while distinguishing itself from the noble traditions of university dispensation. Despite Descartes' attempts or interests in finding a new home while he teaches himself how to dispense in this way, the dispensation itself makes the Discourse both a seminar and a fable.

${ }^{36}$ When Daniel Brewer focuses on the showing aspect of the Discourse, he writes that Descartes "shows more than he proves" thanks to the support that his "strategic self-portrayal" gives to the discourse proper insofar as, following Nancy, Descartes undermines authoritative argument "in favor of authorial argument, ... the Cartesian model for the communication of truth" (Daniel Brewer, "The Philosophical Dialogue and the 
Fable, Histoire, and Books of the Past

So the méthode of the Discourse is no methodus, is not even a method. No more is it a "projet d'vne Science universelle," as Descartes had initially considered titling what became the Discourse (AT I, p. 339). ${ }^{37}$ There is no methodus, no project in this discourse, and perhaps not even a universal science since the full title of the Discourse refers to "the sciences [LES SCIENCES]."

Instead, there is the democratization of reason found in the universalization of good sense as a potential and potentially useful application of itself which can apparently begin to be applied not through teaching but only through a self-instruction set into motion by a telling of a story, "a history [histoire] or, if you prefer, a fable." ${ }^{38}$ This fable, this histoire is a story of Descartes' fortunate discovery of the méthode as the path of self-instruction. But this histoire

Forcing of Truth," MLN 98:5 [1983], p. 1238). For Brewer, the rhetoric of self-portrayal allows Descartes to elide the argument for the self in an identical fashion that the construction of the fable of The World allows Descartes to portray the world as he does without having to argue for it. Thus, the model for communication would appear to be a strategically posited, fabulated I with a story to tell, opening the risk that turns the search for truth into a fable because the I that tells its story, that wants to communicate truth, that opens up the search for truth, is itself fabulated (see ibid., p. 1237). At this point it could appear as though Brewer is taking a position not unlike Cavaillé in that he seems to assert or imply that the rhetorically strategic positing of the I as the storyteller is a way to maintain control over the minds of the readers in some kind of sovereign fashion. However, in that the bulk of Brewer's article is on The Search for Truth, and thus on a dialogue, he ultimately finds that dialogue is a response to "being able to posit a meaning yet remaining powerless to impose meaning absolutely" (ibid., p. 1246). Brewer never returns to the Discourse, but perhaps he should have, and should have done so with something like Marion's 'responsorial' position in mind, to recognize that the positing of the I in the Discourse, while clearly a rhetorically strategic move designed to inaugurate a mental motion on the part of its readers, does not and cannot lay claim to a divinely sovereign control over that motion. The Cartesian model for the communication of truth, insofar as it is grounded in authoriality over and above authority, 'communicates' truth in the way motion is communicated in the physical world, by transferring it over to the recipient. All the readers must tell themselves their own stories after reading Descartes' story in order to learn how to instruct themselves.

${ }^{37}$ This passage is translated as " The Plan of a Universal Science," but I would like to maintain the French in this context (CSM-K, p. 51). To understand a plan as distinct from a project is to understand that what Descartes rejected was not necessarily planning as such, which would imply that he rejected méthode as much as methodus, but that he rather rejected throwing forward ahead of his readers a plan that he had already laid out for them. Such planning is not what Descartes had in mind. Rather, discourse, the discourse of the Discourse, opens up the field, the plain, whereby reason can find its useful application, and does so on its own, without having been projected into a particular application, even if the search was itself set into motion thanks to the fable, the bistoire of the Discourse.

${ }^{38}$ In the Specimina, this passage is translated as "historiae, vel, si malitis, fabulae" (AT VI, p. 541). Following Lewis and Short, s.v. "historia," the Latin and the French both carry the double meaning of a 'history' and 'story', so what is said here concerning the Discours applies to the Specimina as well. 
cannot begin simply with the discovery, the famous moment in the stove-heated room.

Rather, the scene must be set, the mood established, the reason for his being in a poêle in the first place_-and the reason why he finds himself, why the histoire or fable places him in the poêle is in itself multiple. But I am getting ahead of myself and, in retracing Descartes' path to that famous place and that famous moment, I should set the scene along with Descartes. (CSM I, pp. 111 and 112; AT VI, pp. 1 and 4)

In setting the scene, in the background that is the necessary beginning of the bistoire or fable, he turns to his beginning in education. Having been raised on books, Descartes was convinced that they could lead him to "a clear and certain knowledge of all that is useful [vtile] in life." It is only after his formal education has ended and he is ready to take on the title of "learned [doctes]" that he finds himself in doubt and error such that "my attempts to become educated [m'instruire]" had failed. Thus, only after Descartes had already been on an educational path does he find himself at a crossroads and begin to question the direction of his studies. Only once he had become educated does he find himself questioning that education's utility. 'Utility' is the key word here. Having already established that it is not enough to have the potential of good sense but the application of that potential in useful deployment, the ground of his complaint about his education is thereby again its uselessness. Descartes is laying out the failure of his education as a failure in useful application, and that failure in useful application leads him to consider himself a failure in becoming educated (m'instruire) such that he must learn to instruct himself (m'instruire). (CSM I, p. 113; AT VI, p. 4)

To learn to instruct himself, however, necessarily involves learning to unlearn how he had been educated, and this is not an easy process to inaugurate. Indeed, he explains that he could not bring himself to immediately abandon all his learning. Specifically, he still 
values certain areas of the academic path: languages, oratory, poetry, mathematics, ethics, theology, jurisprudence, medicine, and even "subjects full of superstition" since they help him guard against being deceived by them. The subjects of most import here are fables, histoire, and books of the past. Poetry, in its focus on sweetness of expression and being rejected for that same reason, is thus not the poetry of The World and is therefore unhelpful in this analysis. Oratory's power ultimately comes from reasoning and the order of its expression, which is precisely what Descartes is attempting to show in this selfsame fable, and so does not rely on a formal education. In that both poetry and oratory are "gifts of the mind rather than fruits of study," they are both irrelevant to the pedagogical status of the fable or histoire of the book titled the Discourse on the Method. ${ }^{39}$ (CSM I, pp. 113 and 114; AT VI, pp. 6 and 7)

However, the value of fable is that it "awakens the mind," that of histoire that "the memorable deeds told in [it] uplift [the mind] and help shape one's judgement," and that of a book of the past that it "is like having a rehearsed conversation in which the authors reveal to us only the best of their thoughts." ${ }^{40}$ Descartes ultimately rejects these three elements of

\footnotetext{
${ }^{39}$ Donald Philip Verene sees the importance of paying attention to the fact that Descartes presents the work wherein he criticizes fables as itself a fable. It is, of course, first of all ironic and intellectually interesting for that reason alone- "Descartes, the most antirhetorical of modern thinkers, rivals Plato in his use of rhetoric to portray his ideas to the reader"-but is also, second, because it should open up a different way of teaching not only Descartes but philosophy in general since, even though "Most philosophical education directs the student immediately to look for the arguments in a text," nonetheless "Argumentation without a larger context of thought is a dead end" (Donald Phillip Verene, "Philosophical Aesthetics," Journal of Aesthetic Education 40:4 [2006], p. 101). However, because Verene is focused on the activity of teaching Descartes, and others, he does not focus on Descartes as teacher, as someone who is deploying the rhetoric of antirhetoric via a rhetorical trope (fable, histoire). In focusing on the relationship between the fable or histoire of the book titled the Discourse on the Method and that selfsame book's argument against fable, histoire, and books of the past, Descartes as teacher may possibly emerge.

${ }^{40}$ Nancy recognizes the importance of the ironic position of the antirhetorical rhetoric and the rhetorical antirhetoric in the fable or histoire of the Discourse as arguing against "classic readings of Descartes" even when they "single out and interpret this proposition" to read the Discourse as a fable or histoire, because these readings are "dead ends" insofar as they treat the proposition "as a literary covering," a rhetorical trope not to be taken seriously for the generation, the discursivity, of method (Nancy, "Mundus Est Fabula," pp. 641-642). For Nancy, then, in recognizing the non-ornamental status of the supposed ornament of the fable or bistoire of the Discourse, "Our difficulty lies then in bringing to light the original of the Discours" because its original issue
} 
his education because the fables of the ancients' books "make us imagine [font imaginer] many events as possible [possibles] when they are not," while their histoires omit the less glamorous events of the past. There are two aspects to this rejection that are important to note for understanding the fable or histoire of the Discourse. First, Descartes did not reject ancient fables and histoires out of hand, but rather decided that he had spent enough time on them. Books of the past are not precisely to be rejected because they are of the past, then, but rather only because one has reached a saturation point with them. In other words, only once one has already learned, whether in the formal arena of the classroom or in average everyday experience of the world, will one be prepared to unlearn this learning, thanks to the fable or bistoire of this book, and to be shown how to instruct oneself. Second, this rejection is grounded in the way that reading books of the past for too long makes one like "one who spends too much time travelling [voyasger]," a stranger to the native land of experience. It is in response to the estrangement from experience, an experience that will come to teach him not to trust experience, that Descartes takes up the process of learning to unlearn through self-instruction and travelling the world, a process he calls seeking knowledge "in myself or in the great book of the world." Reading ancient fables and bistoires is like travelling and travelling is like reading a book, and the latter will show its readers to unlearn what the former taught, a teaching that appears to have been necessary for Descartes if we follow this fable or histoire carefully. The voyage of his formal education is necessary to begin the voyage

cannot be a frank storytelling of one's own life insofar as the storytelling would be fabular (ibid., p. 644). Nancy finds this original would thus be in the frankness of the fabular storytelling, in calling attention to the fabulousness of the Discourse, making it "the original of all fables" (ibid., p. 646). One aspect of the list of things to be rejected and within which the Discourse can be said to participate - that is, books of the past —of which Nancy perhaps does not take account, however, is that the pleasures to be found in books is that they are like rehearsed conversations. In that sense, then, the fable of the Discourse would not be original, but a repetition of a conversation Descartes had with himself and with the reader, a reader who then would repeat this conversation anew, in an original and originary fashion, with him- or herself in the generation of his or her own fable or bistoire, a new fable or bistoire that would jettison fables and bistoires. The originality of the Cartesian fable in Nancian terms, then, is in its non-originality, in placing and displacing its own origins onto a reader with whom Descartes has rehearsed as much as with himself. 
of his self-instruction, then. Their two paths meet in the crossroads at which he found himself at the point of completing his formal learning. (CSM I, pp. 113-115; AT VI, pp. 5-9)

What is the value of this fable, this histoire, this book? If it awakens the mind, the fable of the Discourse awakens it to its own potential, which can potentially explain the whole of the universe, prove the existence of god, and so on. This fable, then, awakens the mind to itself, to accomplish what it exists to do, and in doing so pulls the mind from its reveries. It does so by mentioning his retreat to the famous "stove-heated room [poësle]" where he had the three dreams that awoke him to his method, though Descartes does not, in this instantiation of the fable that would awaken the mind to itself, describe his dreams in their particulars, nor does he even mention the dreams themselves. ${ }^{41}$ Instead, in the Discourse, he has "thoughts." Thus, this particular fable, a fable written to lenscrafters and others who are not of the learned class, does not specifically awaken the mind by mentioning dreams, but by exposing the limits of formal learning. ${ }^{42}$ This fable awakens the mind of his undereducated

\footnotetext{
41 Though there is some minor controversy over the translation of "poêle" as "stove-heated room," since the French word literally means "stove," "There is no need to allege that Descartes sat in or on a stove. A poêle is simply a room heated by an earthenware stove" (Donald A. Cress, in René Descartes, Discourse on Method, tr. Donald A. Cress [Indianapolis, IN: Hackett Publishing Company, Inc., 1998], p. 7n. 3). On the political and literary contexts of the poêle, and of Descartes' work in general, see Timothy J. Reiss, "Descartes, the Palatinate, and the Thirty Years War: Political Theory and Political Practice," Yale French Studies 80 (1991), pp. 108-145, esp. pp. 110-12 and 122-25. The dreams are described in VMD I, pp. 80-6; quoted in AT X, pp. 180-88; and described in CSM I, p. 4n. 1.

${ }^{42}$ For Donald B. Kuspit, "The fable and the dream are the brackets of the epoché" (Donald B. Kuspit, "Epoché and Fable in Descartes," Philosophy and Phenomenological Research 25:1 [1964], p. 51). As he explains it, there is an external doubt in the Discourse which, like an unconscious Husserlian epoché, brackets the world by isolating it and doubting god, and there is an internal doubt which is the mixture of "what is known indubitably and what is suspect" as found in the dream and/or fable of his story (ibid., p. 49). The external doubt brackets science from the world, while the internal doubt helps Descartes distinguish between dreamworld and waking life, between madness and certainty, such that "external doubt brackets the natural world which is the realm of inquiry... but brackets it only for the sake of isolating from it truths which are established and certain" (ibid., p. 50). It is with Kuspit's "for the sake of" that I take issue here, though in many ways he is correct about the bracketing in which Descartes engages. In saying that the external doubt brackets the natural world for the sake of the internal doubt's extraction of certain truths, Kuspit seems to claim that the fable or histoire of the Discourse follows from an established doubt in the external world such that this fable would allow the reader to discern the legitimacy of the claims to certainty laid out in the text. However, when the Discourse establishes itself as a fable or histoire, the world has not yet been bracketed. Indeed, the only intimations of doubt are doubts in the possibility that everyone would be mistaken in their self-assessment of good sense and in the utility of most human activities, which are significantly closer to the internal doubt than the external. It is in the
} 
readers by narrating, by telling the histoire of his education and rejection of said education-it shows the reader how to awaken him- or herself, in imitation of this storyteller, but in imitation judged on personal utility. (CSM I, p. 116; AT VI, p. 11)

This histoire, this history uplifts the mind and helps to shape one's judgment because its writer hopes his readers will find something to imitate in this story of education and rejection of education, though clearly one should not imitate everything in this histoire. The history Descartes tells in this histoire or fable, his fabular history or historical fable, is to ignore or reason beyond the bodily experiences of history, and certainly to ignore traditional education. What seems to be claimed here, then, insofar as the histoire qua history is concerned, is that Descartes hopes his experience may give rise to a reasoning beyond experience, that his experience may itself move beyond his experience and affect the experiences of his readers such that their minds are lifted up to follow him beyond experience, each according to their own experiences.

Such are the best of Descartes' thoughts, then, in this book, this history, this fable. The conversation he has rehearsed is to undercut the lessons we have inherited, to distrust the explanations of the world that we have been given up to now, when we read this histoire or fable, which itself does not purport to teach the world but to present the path taken by one person to uncover a method. It is the usefulness of this new, individualizable method that is the test for the intended readers of the Discourse, those craftsmen who will hopefully test out Descartes' geometry, optics, and meteorology. They will determine the value of this new method, which they generate on their own, inaugurated by the fable or histoire presented

telling of the Discourse as a fable or bistoire where bracketing the world itself appears, and specifically from the doubts that beset Descartes from out of his formal education. Thus, it is in the telling of the fable or histoire that both the external and internal doubts emerge - the external from the doubt in the world of his education, the internal from the doubt in the certainty or utility of the discoveries laid out in this fable or bistoire. The distinct forms of bracketing that Kuspit identifies, while operative in the Discourse, are not as precisely distinguishable between two levels in terms of the fable or histoire of the Discourse itself. 
here. The best of Descartes' thoughts, then, are not his, nor can he know or interpret on his own which of them are the best, even while he is the author of them. The value or quality of his thoughts will be determined by these craftsmen, by taking on his thoughts as their own and adapting them as utility and necessity dictates. This is the unstated premise or moral of the fable of the Discourse as it awakens the reader's mind through the histoire of Descartes' own discovery of 'his' méthode: This most individuated of approaches to uncovering the truth is not purely, solely, fully individual, even while the investigation into the truth through this individuated method undercuts the authority of tradition and its methodus, because its value will always depend on the judgments of others. ${ }^{43}$

The scene has been set, then, the mood created, the lighting established. Descartes has laid out the potential for the motion of the mind in his readers, grounding it in an appeal to a craft-like application of reason oriented around utility. He himself cannot be sure of the value or utility of what he will write, nor can he control the motions of those other minds once they have begun to think along their own paths, but he can inaugurate that motion by showing his own path. He has not so much established a moral to this fable or histoire ahead

\footnotetext{
${ }^{43}$ Perhaps here the corrective to Ariew's claim that the Cartesian fable is a "necessary component of a deep rhetoric of scientific method" can be shown (Ariew, "Descartes's Fable and Scientific Methodology," p. 138; my emph.). Earlier in this essay, he writes that "Descartes also uses the word [i.e., fable] negatively, something akin to a false story" (ibid., p. 131; my emph.). That Descartes rarely if ever refers to his work as fable in his later texts indicates to Ariew that the Descartes of the Discourse and The World thought "he could ground the hypothetical principles in non-hypothetical, self-evident ones" insofar as the fable of The World was merely convenient, but that hypotheses of the Principles are "necessary," leaving its fable crucial for the structure of and for certain claims in the text (ibid., p. 136). Ariew is able to find a Descartes with non-hypothetical principles at the ground of his method in the Discourse because Ariew sees the negative use of 'fable' in that text as "also," as distinct from the self-description of the text as a fable. That is, Ariew seems not to see a connection between two uses of 'fable' in the Discourse, even though they are only separated by a paragraph. Such an understanding of these uses would allow Ariew, despite himself, to see the fable or histoire of the Discourse as remaining ornamental, where the later texts embed the fable more deeply within their structures. However, to read the fable or histoire of the Discourse not as merely ornamental, not as a convenient positive use of a genre that is otherwise negative, and so to read this fable as interwoven with the ostensibly ornamental quality of the genre is to find the relationship between the supposedly positive and supposedly negative uses as indistinguishable. Thus, it does not seem to be that "Descartes's scientific discourse now [i.e., in the 1640s] requires the use of some rhetorical tropes" (ibid., p. 138; my emph.), but that his discourse always required these tropes. What is more, in following out the interwoven connection between the positive and negative uses of 'fable' in the Discourse, Ariew's final claim can perhaps be modified to claim that the fable is indicative of a rhetoric as scientific method, or method as rhetorical.
} 
of the telling, since this setting of the scene is neither a demand for a certain interpretation of the histoire or fable nor is it even distinct from the histoire or fable that he is telling, but the scene-setting has made the unstated premise of his fable or histoire clear insofar as its value or utility will be determined by the very minds he is setting into motion.

To be sure, the motion inaugurated by the fable of the Discourse is different from the inauguration of motion explained in the fable of The $W$ orld, if only because motion has already been inaugurated in the minds of the readers of the fable or histoire. That is, the author of the fable or histoire of the Discourse is not attempting to make a wholly new world, as the author of the world in the fable of The World will do. In the Discourse, the motion to be set is a renewal of motion, an interruption of the motion having been established by the conceivable if uninterpretable motions established by formal education and/or average everyday experience. The author of the Discourse enters the scene in media res, while the author of "the great book of the world" inaugurates a true beginning. Nevertheless, in renewing the motion of the minds of its readers, the fable or histoire of the Discourse is attempting, like the fable of The $W$ orld, to help the reader suppose an entirely new world in imaginary spaces, this time in the incorporeal 'space' of the mind and beginning with an histoire or fable of the author's own fortunate discovery of the method that will bring this new world to light. The puissance of good sense, like pre-motive solid chaos, as puissance, is what makes this motion not merely inaugurable, but interpretable, and thereby a motion that can be self-instructed in the selfsame moments of unlearning the uninterpretable motions already in motion. ${ }^{44}$ It is thanks to this potential that Descartes has hope for self-instruction through the telling of his histoire or fable, which is the great hope of his pedagogy.

\footnotetext{
${ }^{44}$ In a Working Note, Merleau-Ponty claims that "meaning is not nihilation, nor a sacrifice of the For Itself to the In Itself" because this sacrifice, as "a creation of the truth," remains in the model of the In Itself such that the For Itself brings the In Itself about (Merleau-Ponty, The Visible and the Invisible, p. 216). For him, the model
} 
where the For Itself sacrifices itself in service to the generation of the In Itself "is still to think the Weltlichkeit of minds according to the model of that of Cartesian space" (ibid.) What is required instead is to think the Weltlichkeit of minds via the In Itself such that minds push forth into "the aesthetic world," as opposed to Cartesian space that lacks "an In Itself of the For Itselfs" (ibid.). To think the Weltlichkeit of minds via the In Itself would push meaning into an aesthetic world where the world is understood not in terms of "objectiveimmanent [i.e., Cartesian] space," but in terms of "a space of transcendence" and the "indivision of being and nothingness," letting meaning escape from nihilism (ibid.). In practical terms, this aesthetic world of the space of transcendence whereby there is an indivision of being and nothingness mean that 'right' and 'left', for instance, are no longer loci or parts "within a relational spatiality," but are total in themselves, "cuts in an encompassing, topological space” (ibid., pp. 216-217; my emph.). In identifying Cartesian space as an "objective-immanent space" of "relational spatiality" within which objects take up space, Merleau-Ponty seems to understand Descartes' concept of space as an empty vessel. Perhaps this empty vessel would apply to Cartesian space, but it is at least unclear that it applies to Descartes himself. Neither the mind in being modeled on space nor space itself can be understood in Descartes as operating on the model of an empty vessel within which objects relate to each other, at least if the plenum concept of the world, and, by the modeled extension, the concept of the mind, has any traction. The modeled extension can be found by attending to the deployment of the fable in the Discourse and The World in terms of mind and world, and the world is always a plenum for Descartes. Insofar as the world is a plenum, objects to not appear within it, but constitute it. To this extent, then, Descartes' Welktlichkeit of mind and world would seem to operate much closer to the aesthetic world of the For Itself, where meaning is derived from the indivision of being and nothingness, and the For Itself is not sacrificed to the nihilistic model of the In Itself of relational spatiality. Merleau-Ponty seems to in fact recognize that the modeled relationship between mind and world in Descartes does not necessarily operate on the Cartesian sacrifice of the For Itself to the In Itself in a later Working Note, when he writes that "The Cartesian idea of the human body as human non-closed, open inasmuch as governed by thought-is perhaps the most profound idea of the union of the soul and the body. It is the soul intervening in a body that is not of the in itself, (if it were, it would be closed like an animal body), that can be a body and living - human only be reaching completion in a "view of itself which is thought" (ibid., p. 234). Here, he seems to recognize that the body is not understood in terms of the In Itself, which would at least indicate that it could be understood, by Descartes and/or Cartesians, in terms of the For Itself. These two Working Notes are separated by four months, so perhaps Merleau-Ponty would have recognized the discrepancy had he lived. However, it does seem important to note that Descartes' concept of space, and the model it makes for the mind, via the fable of the world and the fable of inaugurating the motions of good sense, is not in fact as different as it might at first appear from what Merleau-Ponty offers as an alternative. 


\section{Chapter Two}

\section{Fable Expanded}

Thus far, an investigation into Descartes' use of the fable in the strict sense has shown how Descartes distinguishes the rule-generation and rule-obedience of fable from the chaos of poetry and shown that this form serves the pedagogical purpose of inaugurating a mental movement on the part of his readers. However, since 'fable' is mentioned and used only a few times positively over the course of Descartes' career, an analysis of the form cannot be isolated to its precise mention. To do so would limit the analysis to two texts and a portrait, but the contention here is that attending to the fable understood as an expansive and expanded form will show that it runs straight to the heart of the Cartesian project. Thus, what is now necessary is to show why the form called 'fable' can be expanded. Doing so will hopefully show in turn that there is a fable-structure or -logic at work throughout Descartes. If it can be shown that there is such a structure or logic at work, the pedagogico-literary form of fable can be taken as a prism for engaging method and imagination.

Accomplishing this expansion such that it opens onto a way to return to the Cartesian method and imagination anew will require two steps: (A) expanding the logic of and pedagogical purpose to the fable specifically to other forms of writing, in particular history, treatise, dialogue, novel, and hypothesis; and (B) examining and clarifying how deception and the technique of self-deception relate to the fable as deployed in Descartes and how this relationship exposes the deployment of the fable as a method for the construction of the self and for that self's self-instruction. 


\section{Fable and Other Forms}

The potential of everyone's good sense, regardless of the conceivable if uninterpretable motions in which they may have already been engaged, is what makes the fable pedagogically effective. The rhetoric of fable allows the reader to take on the rules laid out by and as fable, whether these rules are of physical or mental motions, as though they are the reader's own. For each reader, the path that generates obedience to the rules will be different, individual. And that same good sense that is each of our potentials for reason will judge the utility of the method according to our individual histoires or fables. Fable for Descartes, then, is an expansive and expanded concept, and it must be prepared for in various fashions.

\section{In the Poêle and in Histoire}

Having set the scene, having shown to his readers why he abandoned his education to begin the process of self-instruction that will ultimately lead by fortune to the method, Descartes and his readers enter the poêle, where the 'true' content of the fable is held, to the extent that the scene-setting histoire of Part One of the Discourse could ever be distinct from the fable. That part of the fable or histoire does not explain why Descartes finds himself in the poêle. Indeed, much more background, much more history, is needed to make sense of the poêle of the fabled location of the fabled dreams. ${ }^{1}$

\footnotetext{
${ }^{1}$ Ricoeur, in explaining why he prefers the phrase 'historical condition' over 'historicity', identifies two aspects to 'historical condition': first is the "situation in which each person is in each case implicated" and second is the "condition of possibility on the order of the ontological, or ... the existential, in particular in relation to the categories of critical hermeneutics" (Paul Ricoeur, Memory, History, Forgetting, tr. Kathleen Blamey and David Pellauer [Chicago: The University of Chicago Press, 2004], p. 284). Thus, if the project in which Ricoeur engages is to have coherence, there must be a passage "from historical knowledge to critical hermeneutics and from the latter to ontological hermeneutics," though the necessity is not a priori and thereby remains hypothetical (ibid.). To engage in a critical hermeneutics that arises from the historical situation, then, involves
} 
The book called the Discourse takes the reader to November 10,1619, somewhere "in Germany" (CSM I, p. 116; AT VI, p. 11). Descartes has rejoined the army of the Catholic Maximilian I, Duke of Bavaria, also known as Maximilian the Great, after witnessing the coronation of the new Holy Roman Emperor, Ferdinand II, on August 30. From about 1618 to 1619 , he has been a volunteer noble soldier in the army, one of the "Attendans," of the Protestant Maurice of Nassau, who becomes the Prince of Orange on February 20, 1618. He joins Maurice's army not with an eye to being a career soldier, "but only to Study the different natures of men more according to nature, and to make himself proof against all the accidents of life." Because life in Maurice's army failed to provide him with the "variety of occupation...that he promis'd himself upon his leaving France," and because of the outbreak of the Thirty Years' War, at the Cessation of Arms between Maurice and Don Ambroglio Spinola Doria, First Marquis of the Balbases, he leaves for the coronation. Before leaving in September, however, he joins the Duke's army, and was resolved to rejoin it after the coronation. He reaches the army's winter quarters on the banks of the Danube near Nuremberg in October. It is there that he finds himself in the poêle. (LMD, pp. 22, 27 and 30; VMD I, pp. 45 and 77-78)

\footnotetext{
“imposing limits on any totalizing claim attaching to historical knowledge," while to engage in an ontological hermeneutics that arises from the critical form, is to "[explore] the presuppositions that can be termed existential, both those of actual historiographical knowledge and those of the preceding critical discourse" (ibid., p. 283). What is being engaged here, then, remains more or less within the realm of the historical situation of the historical condition in which Descartes finds himself when he has his dreams in the poêle. However, insofar as the condition of the situation of finding himself in the poêle are historical, they have bearing on the status of history as Descartes understands, and criticizes, it. That is, not unlike the fashion in which Descartes criticizes the fable even while telling his story as a fable or histoire, the fact that Descartes is telling this fable or bistoire of having been in a location with a particular, and telling, historicality should also open the reader onto a reading, a suspicious reading and a reading of suspicion, of the selfsame telling. The precise question of history in the Cartesian system and its relationship to the method, i.e., something like a critical and ontological hermeneutics of the Cartesian concept of history, will be taken up more explicitly in chapter 3, below, but for the moment it is worth noting the importance of attending to the historical condition of the poêle itself.
} 
This is the history of his travel leading him to the poêle, almost none of which is indicated in the histoire or fable of the Discourse. ${ }^{2}$ But there is more to this history, beyond Descartes' histoire and his history. A poêle is no ordinary place in theologico-political and literary history. A century before Descartes, poêles were used by Protestants as locations for rebellious meditation. A century before that, they were used in poetry as symbols to debase the chilvalric ideal because they were used by errant or erring knights-errant as winter quarters where they could pretend to run errands and instead "'se rigollent avec ces fillectes tout l'iver' [play around with girls all winter]."3

\footnotetext{
${ }^{2}$ For Flynn, it seems as though this very excising of the personal history involved in Descartes' travels leading up to the poêle is indicative of a dehistoricization of the Cartesian method. Descartes "finds more perfection in cities which architecturally have no history," "prefers societies which have no constitutional or juridical history," and "would prefer to be a man without a personal history" (Bernard Charles Flynn, "Descartes and the Ontology of Subjectivity," Man and World: An International Philosophical Review 16:1 [1983], pp. 17-18). What such dehistoricization establishes, then, is an I, a subject, a self that has been ruptured from its own history, to the extent that the self that emerges from the poêle is a different self from the one that entered it. Thus, this later self, the self writing this fable or histoire "has never been to Germany" (ibid., p. 18). According to Flynn, then, the hyperbolic doubt, the hyperbolicity of the doubt of the Cartesian method allows Descartes to annihilate or annul the history that led him to the poêle. Such annulation or annihilation of one's own history in telling a story that accomplishes this annulation is the Cartesian resolution of a tension within Cartesian discourse because it generates an absolute self, one "given to itself absolutely and existing absolutely" (ibid., p. 16). However, as Flynn also acknowledges, the Discourse "addresses a contemporary reader," and so a reader who would have known what was at stake in the Thirty Years War, as well as what it was for Descartes to have been called back to war as an attendant after witnessing a coronation in Germany (ibid., p. 17). For Flynn, addressing a contemporary reader while excising the history indicates that Descartes is engaged in a process of making the self absolute. Yet, because these readers are also to judge the method of this histoire or fable, and judge it after or simultaneously to having engaged their own learning how to unlearn, the absoluteness of the self that emerges from the poêle cannot fully be understood as being self-given. What is more, given the literary history at hand here, whether contemporary readers themselves would have known it, would itself seem to both reinforce and further undermine Flynn's claims. The poêle's status as a locus of personal and theologicopolitical rebellion would reinforce Flynn's claims in that it is clearly a place where one reinvents oneself. However, in that this status emerges as a result of literary and theologico-political history, Flynn's claims are undermined. What seems to emerge in the poêle, in the deployment of the use of the poêle as the location of his dreams, is a Descartes with a more complex relationship to history, personal and otherwise, than mere rebellion. The self cannot extract itself from this history, even if it would like to, and the complexity of this relationship to history is indicative of a complexity involved in the method itself that may not have been properly acknowledged by subsequent history, or perhaps even by Descartes himself.
}

${ }^{3}$ Reiss, "Descartes, the Palatinate, and the Thirty Years War," p. 23; Reiss's translation. Reiss explains that he is not necessarily claiming that Descartes is in fact referencing this history in referencing the poêle, but that this metaphor "was a familiar one for a break with the past and an implication of revolt and renewal" (ibid.). However, the very fact that it was a familiar metaphor indicates that it would have been known by at least some of Descartes' readers, those whom he addresses as contemporaries. Regardless if all of them would have understood the details of the references, insofar as many of those readers would not have had a formal education, and so may not have known the literary references, Reiss's implication about the familiarity of the 
This is the place where Descartes "stayed shut up alone," he writes, "where I was free to converse with myself about my own thoughts." It is in this place, this earthenware stove "in the German style," where Descartes sets himself down to think and, in thinking, where he has prepared himself to dream. ${ }^{4}$ This place is already embedded within his personal history, as the fable or histoire tells us in the telling, but it is also embedded within military and political history, which it only glancingly mentions. It is also embedded within religious, political, and literary history, at which it does not even hint, though at least some of his readers would probably have known the reference, no matter their formal education. (CSM I, p. 116; AT VI, p. 11)

Two elements of this poêle must be noted, then. First, within the fable or histoire, Descartes tells us that he is able to think, first, that a more perfectly crafted object is the result of one mind over and above many minds, whether the object is a building or a legal system. As a result, he can only focus on reforming his own thoughts, though he recognizes that his own example "may be too bold for many people," especially those who think themselves more clever than they are and those who are honest enough to recognize their modest abilities to judge. That Descartes was able to extract himself from the ranks of the former is due only to the fortune of having come across this poêle at the right time and because of his particular personal history of never being able to imagine anything so strange and incredible as to not already have been thought. It is this combination that allows him to begin to develop the method of slow procedure, especially once he disregards the logic, geometry, and algebra of his education because of logic's confused precepts, geometry's

reference, and that Descartes himself most likely knew it, indicates that Descartes could very well have expected these readers to understand the reference.

${ }^{4}$ Gilson, "Commentaire Historique," p. 157; my translation. Gilson notes that French travelers were particularly appreciative of poêles because they were used to smoky chimneys. 
tendency to tire the imagination, and algebra's inability to engage in the concrete world of experience. Thus, he determines the four logical laws of his method: only accept as true that for which he has evidence, divide what is difficult into its simplest parts, direct his thinking in an orderly fashion from those simplest parts, and be as comprehensive as he can in his determinations. (CSM I, pp. 118-120; AT VI, pp. 11-13 and 15-19)

None of this thinking is possible without his particular history, without the formal education he was able to gain throughout his life, without having been able to travel with armies in such a manner that he can, at a propitious moment, find himself alone in the poêle for an extended period. These are his thoughts in the poêle before the dreams. His dreams have been prepared for, even "from the time he left the Colledge." Where, in the histoire or fable, he specifically has this dream, he does not tell us. The dreams seem to have given rise, through interpretation and "reflections," to the four logical laws of this method, but the dreams themselves arose through having begun to think of crafted objects as more perfectly designed by a single person, a single mind. This is the story he is telling the reader, a series of preparations that are the histoire or fable of his discovery of his method, in the hope that this histoire or fable might inaugurate a motion in the mind of the reader, in particular the mind of the lenscrafter. ${ }^{5}$ (LMD, pp. 34 and 36)

\footnotetext{
${ }^{5}$ Thus Kuspit is onto something when he explains that "the trick of hypostazing doubt is to say that others are for it, i.e., others are susceptible to its 'Method"' (Kuspit, "Epoché and Fable in Descartes," p. 35). For Kuspit, this trick is indicative, however, that Descartes has only changed himself, not the world, and so the cogito is merely the beginning of a new belief that remains merely "a thorough shaking up of the old beliefs," which takes the form of a fable such that the external doubt that brackets the world maintains the world through the internal doubt of the fable (ibid., p. 36). This new belief needs to be established through a fable "because mechanics was not perfected, and so not quite trusted" (ibid., p. 37). What Kuspit is onto is that Descartes does not think the world is inherently changed through the fable and the doubt, but that the fable and the doubt can give rise to a new belief in the world's operations by shaking up and bracketing the way the world has been understood up until the moment of doubt. Doubt can do its work because others are susceptible to it. However, Kuspit seems not to have thought through the status of the fable as a structure for approaching the world insofar as he claims that the fable is necessary "because mechanics was not perfected." That is, because the bistoire or fable of the Discourse is fable intended to inaugurate mental motion on the part of readers, and because that newly inaugurated motion itself is to be the ground for judging the utility of the fable that inaugurates said motion, the fable as a structure is necessary in order for the possibility of motion to be
} 
But this story, this history, extends beyond the story itself, in being in a poêle. He is in the poêle because of his relationship to the Protestant Maurice of Orange and the Catholic Maximilian I. Not having taken a side in the Thirty Years' War, despite his own Catholicism, he finds himself ready to serve a Catholic army. But, in finding himself ready to serve a Catholic army, he also finds himself in a locus of Protestant meditation, and rebellious meditation at that. Descartes, by and large unwilling to take a side in this debate (see CED, pp. 129-130; AT IV, pp. 351-352), finding it generally speaking a matter of the same "custom" that tends to persuade most, confirms that position without saying a word here, provided we know the history that he does not mention, but that many of his readers would have known, despite the initial anonymity of the Discourse. What the history-personal, religious, and political—of this fable or histoire does is further lay the ground for a rebellion against authority, regardless of the content, insofar as the rebel begins with modesty and focuses solely on him- or herself. ${ }^{6}$ The unmentioned history behind this histoire or fable tells us that Descartes finds himself between Catholicism and Protestantism, unwilling to adhere to any authority other than his own judgment. (CSM I, p. 119; AT VI, p. 16)

inaugurated since the mental motion is that which will itself allow for mechanics to be perfected. It is because of this complex relationship between the fabulist and his readers' good sense that Descartes cannot consider the Discourse as a project, or even plan. This fable can only be discursive, and the mechanical physics to which it will give rise can only be perfected insofar as the discursive fable does its inaugurating work. It is not merely a fable for any coincidence of early-stage mechanical physics which could be shown to be superior if only Descartes' (contemporaneous) readers were to look back on it in the wake of more and more useful deployments of that physics, though that may be partly the case, and all the more so for us, who read this fable as a book of the past. But the Discourse is also a fable because, as a book that seeks to inaugurate the mental motion that would establish the usefulness of a mechanical physics, it cannot show its usefulness except in a preparatory fashion, which requires a distinct literary approach, one that is not mere demonstration, one that opens the possibility of a distinct kind of demonstration.

${ }^{6}$ For a helpful history of some of this personal, political, and religious rebellion — not only Descartes' —with which Descartes came into contact and others in which he participated over the course of his travels in this period in his life, see Michael H. Keefer, "The Dreamer's Path: Descartes and the Sixteenth Century," Renaissance Quarterly 49:1 (1996), pp. 44-54.

${ }^{7}$ Dalia Judovitz identifies something similar in her claim that, for Descartes, "Epistemology absorbs the historical" (Dalia Judovitz, "Autobiographical Discourse and Critical Praxis in Descartes," Philosophy and Literature 5:1 [1981], p. 101). As she explains it, the Cartesian concept of philosophical thinking that establishes 
And yet, the reader should not be too sure of this stance on Descartes' part, because this background history, on the literary side, also draws the reader's eye to deception. If the poêle is also a place where knights-errant would retreat in order to pretend to be on their errands, to deceive their masters as to their honest chivalry, then the reader, to whose good sense Descartes offers up his fable or histoire like an honest and honoring gift, should read this fable or histoire with a skeptic's eye. Not only does the fable or histoire not draw attention to the history behind it, but part of that unacknowledged history is a history of deception. This history would uplift the mind insofar as it brings the reader's judgment to consider the possibility of deception, but Descartes does not mention it. Of course, insofar as his readers read in French, perhaps they could be assumed to understand the vulgar debasement of the good, honest authority of the medieval world, itself a goal of the Cartesian project in general. Thus, in not mentioning it, he perhaps thought he was inaugurating a suspicion not only of authority and tradition but of the honesty of the author, that evil genius who claims an interest in inaugurating a more proper mental motion on the part of modest and skeptical readers. Such a suspicion is the necessary inaugural step to the Cartesian method, of course,

itself as primarily epistemological must exclude the historical quality of its own development, to the extent that Descartes "implies a new metaphysics whose virtual subject resembles the subject presupposed by geometric proofs," that is, a subject all of whose proofs are submitted to the method's measure, thereby restricting the subject who would otherwise be all-inventing and absolute (ibid., p. 102). Thus, for Judovitz, there is an irony to the autobiographical nature of the Discourse in that it "remains impersonal and "typical" and produces a subject evacuated of personal content and extended beyond its particular self to the point where, following Heidegger, it anthropomorphizes metaphysics itself (ibid., p. 104). If Judovitz is missing something, however, it would appear to be the historical particularity at hand in what Descartes does say about the development toward the histoire or fable at hand. That is, even if the Discourse was published anonymously, its bistoire or fable is not impersonal, if only because Descartes explains that he arrived in the poêle after being called back to war upon having witnessed a coronation. Being called back to war in this way, if it does not indicate an attendant specifically, a nobleman casually learning the ways of Europe and war, certainly indicates that the author is no mere footsoldier or peasant. Further, if the use of the poêle itself, in its literary and political history, indicates to a reader a history of rebellion, the epistemological rebellion against and absorption of history is never fully complete, and can never be so precisely because the location of the epistemological rebellion is already the location of several other rebellions. An attendant is no typical soldier, a poêle is not just any place, and a French attendant who finds himself in a poêle after a coronation is not telling an impersonal story. If that story, in its telling, would aim to absorb or eradicate the personality and a-typicality of itself, personality and a-typicality would come rushing back in the telling and retelling of other, personal stories by the readers of this bistoire or fable, returning history to or placing it before what would otherwise intend to eradicate or absorb it. 
and is possible on the part of French readers because of the democratization, not to say

vulgarization, of reason as potential in all readers, all the more inaugurated in the unstated

history of debasing the motivations of authority, regardless of the religious persuasion as

persuaded by custom or meditation. ${ }^{8}$

What is brought to light here, then, is that the fable or histoire should indeed be

extended to history, though to the extent that history and storytelling are inseparable and

insofar as this histoire uplifts the mind to skeptical good sense and judgment. This fable,

inaugurating motion in its reader's good sense, which tells the story of Descartes' fortunate

discovery of his method, is histoire, is historical, both in the story it tells and in the history it

does not. Its telling of the method, then, will involve history, will be historical and

historicized. The Cartesian fable extends itself into the realm of history. ${ }^{9}$

\footnotetext{
8 As Becker points out, when discussing the Passions of the Soul, Descartes sought to "substitute the discipline of [generosity] for Aristotelian magnanimity or the scholastic's conception of prudence," especially if generosity could be combined with humility (Becker, The Emergence of Civil Society in the Eighteenth Century, p. 16). Generosity and humility come to replace the more aristocratic, medieval values and passions of glory and shame for Descartes but also, according to Becker, throughout England, Scotland, and France, as civil society arises in response to the religious wars of the seventeenth century. Following Descartes, Becker claims that the universally achievable value of "Good will" can give rise to a generosity of spirit that remained humble in its presentation (ibid.). However, Cartesian generosity, "while considerably scaled down from its pretensions to grandiosity, munificence or extravagant display, did not altogether lose something of its archaic grandeur" (ibid.). The status of honesty will be examined in particular below, but this reading of Becker's can be seen in the suspicion of the honesty of the medieval world being laid out through the literary history implied with the poêle. Knights-errant clearly err when they find themselves holed up in poêles with girls. They err and sin in displaying themselves as good, noble men who in fact disappear from their duties and fornicate. This history informs the suspicion that one should have from the moment this clearly noble man, this attendant, describes his own time holed up in a poêle. In referencing a literary history that debases the medieval world in general, there is a reference to the dishonesty of that world. However, in himself being something of a knight-errant delayed in his return to duty, the reference to dishonesty should also be applied to the fabulist himself, and the suspicion that should arise from the reference to this history of dishonesty is already beginning the suspicion to which Descartes himself will draw the reader's attention. Descartes, here, is humble, even humiliating himself, being generous and honest about his place, his non-elevated or even ignoble place in a world where good sense is potentially spread throughout people. But such humble generosity and honesty can only be made sense of in reference to the histoire or fable in the poêle, and in reference to the history of the poêle.
}

9 Thus again there is a residue of the Renaissance in Descartes, in a fashion to which Foucault may be blind. Citing the astonishment of the father of natural history, George-Louis Leclerc, Comte de Buffon, "at finding in the work of a naturalist like [Ulisse] Aldrovani such an inextricable mixture of exact descriptions, reported quotations, fables without commentary ...." Foucault, again, explains that the Renaissance episteme gives rise to a knowledge the function of which is "interpreting" (Foucault, The Order of Things, pp. 39-40; my emph.). What was necessary to move from a Renaissance mode of interpreting things' history "within the whole semantic 


\section{The Fable-Treatise in the Fable or Histoire}

In leading up to his discussion of the fable of The World within the fable or histoire of the

\section{Discourse, Descartes concludes Part Four by dismissing dreams and perceptual deception}

thanks to the power of reason over the imagination, as well as to knowledge of god and the

soul (l'âme). Sleeping does not prevent a true idea from being true, and the deceptive

phenomenal content of dreams is of no more consequence than sensory deception is in

waking life. The reason inaugurated by the fable or histoire at hand here is set into motion

network that connected it to the world" to the Classical mode whereby history is itself natural was for a gap to open between things and words such that the historian of nature engages in "a meticulous examination of things themselves ..., and then of transcribing what it has gathered in smooth, neutralized, and faithful words" (ibid., pp. 129-131). Even if words and things are separate for Descartes, as they are, in examining his personal history as a fable or histoire, he is engaged, as he always has been engaged, in an interpretation of the semantic network between himself and the world, in the ways in which words, his words, his words of the formation of his very self, words that can help others form themselves. Despite Descartes' claims that words are distinct from things, there remains a non-neutrality to their status in the fable or bistoire he sets out to tell, and it is their non-neutrality that will allow them to inaugurate motion in others, even as his control over the effects of these words exceeds his control. Indeed, it could very well be that because of Descartes' claims to the separation between words and things that his words take up a non-neutral status in the fable or histoire in that these 'neutral' words tell the story of a rebellious suspicion of the 'faithful' words of authority and words of fidelity to authority.

To the extent the above is true, Nancy is correct when he writes, "Beyond the order of authority, beyond that of demonstration, there must be produced the presentment of the author, or more exactly, of the 'becoming-oneself-author'," which thereby explains "the narrative mode of Cartesian exposition" (Nancy, “Larvatus Pro Deo," pp. 16 and 34n. 4). In other words, Descartes must present himself as becoming an author in order to gain the authority for his demonstrations to be believed and judged as clearly and distinctly accomplished. However, Nancy also considers the presentation of the self as becoming an author as being derived from the method: "The truth/certitude of the method accordingly imposes a certain organization upon its presentation" (ibid., p. 16). For him, the way in which truth is communicated in Descartes, by different authors who judge each other's claims, depends on "the very process whereby this truth is constituted as certitude" (ibid., p. 15). Thus, the certification of truth by different authors in their attempts to communicate truths would give rise to the narrative mode of exposition to show how one became an author, distinct from authority. Nancy offers a parenthetical alternative here, where "this constitution [of certitude] is dependent in turn upon the project itself of communicating truth" (ibid., pp. 15-16). Such an alternative is what is on offer here. That is, it is not entirely the case that the communication of truth is dependent on a process of constituting its certitude, which would be truth as communicated simply by readers judging the claims in the Discourse to be certain. Rather, to communicate truth depends on the constitution of certitude, which itself depends on a communication of truth, because the fundamental truth being communicated is a truth that would constitute the different authors who would certify the truths that follow. It is not so much, then, that the truth and/or certitude of the method imposes the narrative mode, but that the narrative, fabular, historique mode generates both the method and the minds who will judge the method's certitude, which in turn opens up the truths that can be certified. The fable, then, imposes a certain organization onto the truth and/or certitude of the method at least as much as that truth and/or certitude imposes something on the fabular mode of presentation. 
from out of the good sense in potentia for all, a fable or histoire that tells the story of a man in a poêle, which itself is already an appeal to meditation and solitude as much as to deception, such that the world's phenomenal rules and its history, may be given and interpreted according to the rules laid out in the meditative solitude of the deception-laden poêle by a reader who will tell, retell, him- or herself his or her own fable or bistoire to arrive at the method to apply his or her own reason or good sense in a useful manner. This reason is what should convince, over and above the deceptions of the senses and the imagination or even the persuasiveness of custom, at least the old custom that the reader must unlearn in order to instruct him- or herself. While the senses may be deceived, my own imagination can deceive me, generating chimeras and griffins. Reason must be convinced, however, in dreamworld and waking life (see CSM I, pp. 130-131; AT VI, pp. 39-40).

At this point of introducing Part Five, Descartes explains that he would be happy to continue to show the other truths exposed by the method's deduction from the fundamental truths of soul and god. However, such truths would involve engaging the learned (les doctes), which would not be a useful digression for lenscrafters, so he opts to explain what questions are raised by the fundamental truths, in order to "let those who are wiser [plus sages] decide whether it would be useful [vtile] for the public to be informed more specifically about them." ${ }^{\prime 10}$ Thus, Part Five is a summary of The World and Treatise of Man, which were begun with the intention of being published together. (CSM I, p. 131; AT VI, p. 40)

Part Five is written to the learned as much as to craftspeople. Perhaps as a result of this supplementary reader — a reader who will judge the value and utility of what the general

\footnotetext{
${ }^{10}$ Gilson explains that the sages whom Descartes addresses here are specifically "cardinals and other ecclesiastical dignitaries" in the hope not only that he would gain interest from the Church but also that he would be able to publish The World without being placed on the Index (Gilson, "Commentaire Historique," p. 371).
} 
reader of French, whose good sense is equal to that of the learned, cannot judge, and thus a supplementary reader not unlike the god whose existence guarantees the proof of the soul in Part Four-Descartes does not refer to The World as a fable but as a "treatise," which it is in the title, but not within the text. If The $W$ orld is a treatise here, however, that does not make it any less of a fable, any more than calling it a fable in the text makes The World, or Treatise on Light, any less of a treatise. As he explains in the two-page summary of the fable-treatise, because he "did not want to bring ... too much into the open [ombrager]" the metaphysical and/or religious depths of his claims on light, he opted to suppose the divine creation of a new world "somewhere in imaginary spaces [Espaces Imaginaires]" that would suffice to explain his theories. ${ }^{11}$ Thus, two paragraphs after explaining that reason must take the lead in conceiving and understanding over and above the imagination, Descartes describes his treatise as being located in imaginary space. It is an imaginary treatise, then, or a treatise of

${ }^{11}$ Cavaillé discusses this understanding of imaginary space as an ironic deployment of Scholastic terminology on Descartes' part. Specifically, Descartes "adroitly exploits a simultaneous linguistic and doctrinal ambiguity" where, "beyond the fixed spheres, for a strictly Aristotelien physics, there is nothing," but such a place "remains conceivable: whence this other distinction between true space (locus verus) and imaginary space (locus imaginarius)" (Cavaillé, Descartes: La fable du monde, pp. 213-214; my trans.). At stake in this possibility, then, is whether imaginary space would be simply imagined and thus would not extend beyond the imagination, or whether "this image possesses an objective value, if, in other words, an empty space is really understood, to the infinite, beyond the material world" (ibid., p. 214; my trans.). Descartes, in exploiting this ambiguity, places the fabulated world in an imaginary space which replicates our own, such that he can claim that "Our imagination is . . . incapable of having an image of the infinite," but only of the indefinite, and, in having an image of the indefinite, "The imagination indefinitely exceeds the limits that we want to fix for it" (ibid.; my trans.). Thus, the Scholastic imaginary space, insofar as it would be non-material space and separated from a prime matter, is unimaginable, but an imaginary space whereby an indefinite amount of material exists, is perfectly imaginable. Such a possibility is why the fable can be a "passage to pure imagination" (ibid., p. 220; my trans.). A further difficulty arises from this situation, however, in that the fable does not in itself allow for the substitution of "the 'true' bistoire of the world," such that the very possibility of a true world is called into question (ibid., p. 226; my trans.). Cavaillé sees Descartes' solution in metaphysics that the very use of the fable suggests is "already largely constituted," thus indicating a further dissimulation on the part of the fabulator, and which indicates that the "principal personage of the fable" operates as the equivalent of god (ibid., p. 227; my trans.). Placing the author on the level of god is part of Cavaillé's transition to the development of his concept of the sovereign 'I', to which I will not return here, except to say that Cavaillé seems to be working on the assumption not only that the teller of this fable already knows how the fable will be received by those who tell their own fables and bistoires in coming to be able to judge it, but that the teller of the fable is already in the sovereign and/or divine position of having been transformed beyond the history that informed his transition. If the teller of the fable cannot be said to already know how others will receive this fable or histoire, then it is difficult to claim that Descartes himself has fully transformed into the sovereign and/or divine figure in concurrent control over the mental motions of his readers. 
the imagination. It is unclear, within the fable or histoire of the Discourse, whether this treatise is a treatise in a normal, academically accepted fashion, or whether it should be placed in a separate literary category, perhaps under 'fable'. (CSM I, p. 132; AT VI, p. 41)

But the Discourse, insofar as it itself remains a fable as well as a history and histoire, has the goal of inaugurating motion in the potential of good sense or reason such that its readers may judge the value of this work for themselves. Insofar as Part Five is written to the learned as much as to craftspeople, the learned whose judgments of utility will supplement or perhaps even correct the judgments of the modest craftspeople, and the goal of inaugurating motion remains, then naming The $W$ orld a treatise here is an excusable rhetorical gesture to the learned, who perhaps might not take a fable as seriously as it deserves and who therefore deserve to be deceived as to the metaphysico-theological seriousness of the fable-treatise of The World when they encounter its summary in the fable or histoire of the Discourse. The treatise thus becomes connected to the fable insofar as the goal is to inaugurate mental motion, and the Cartesian concept of the fable can be extended to the treatise as well as to history.

\section{Treatise and Dialogue}

If the fable can be extended to the treatise, then there may be other connections to the fable through the treatise. The question is where to search for the further expansion of the concept of fable. That search turns in the direction of the natural light, the light of reason that is set into motion thanks to the structure of the inauguration of motion that fables have, regardless of the specific literary form they may take. In moving from the fable of light that is the world of The World to the fable or histoire of the Discourse that opens that inaugurating 
structure of fable to history and storytelling in general—-to history beyond the histoire of the story told within the Discourse but which tells the reader, learned or lenscrafter, much about the anonymous author who wants to set good sense into useful motion-even the treatise as a form can take on the appearance of a fable as much as a fable can take on the appearance of a treatise. In the portion of the fable or histoire of the Discourse that prepares the reader to enter the fabled poêle with Descartes, the preparatory work of the fable, the preparation of good sense in potential good use, the perhaps necessary relationship between fable and preparation is shown, though this preparation is decidedly not of the same order as the moral in the traditional fable because it prepares the reader to tell his or her own fable or bistoire. ${ }^{12}$ Nonetheless, preparation is necessary as a way to move the reader away from the

12 When Derrida investigates La Fontaine's fable, “The Wolf and the Lamb," he notes that its moral appears "before the story, before the narrative moment which is thus, somewhat unusually, deferred" (Derrida, The Beast and the Sovereign, p. 7). If the moral's appearance before the narrative is unusual, the appearance of a moral is not unusual in fable. As he continues with La Fontaine, in that the moral precedes the narrative in "The Wolf and the Lamb," "the difference between monstration and demonstration, between the intuitive image of the story, which is an audiovisual scene, and the discursive reasoning of the moral, is here suspended" because the discursive reasoning of moralizing would normally seem to be best served after the intuitive imagery of the story (ibid., p. 34). It is necessary that the moral come first in this particular fable, of course, because the narrative's imagery would not necessarily lead to the conclusion ("La raison du plus fort est toujours la meillure"), and so this moral must be shown within the narrative. However, what Derrida is pointing out is the supposed intimate relationship in fables between narrative and moral. This relationship is intimate, at least to the extent that 'fable' is indicative of a pedagogical exercise, even if it is not precisely historically accurate since not all of Aesop's fables had fables until much later. The intimacy of this relationship thus shows that the moral always precedes the narrative, regardless of the order of presentation. But here, in the fable of the Discourse, the preparatory work is not of the order of a fable, certainly not in the classical rhetorical sense, and even less than in the sense that La Fontaine seems to use it. This rupture in the intimacy between fable and moral occurs because the work being prepared for does not simply serve a particular moral since the pedagogical status of the Cartesian fable is never quite in the service of some external system, but always for itself, for itself as a system and for itself as a story. But the rupture of the supposed intimacy of the relationship between fable and moral is no simple rupture in that the fable is its own moral. Thus, the rupture can only be understood as a rupture if one reads the Discourse as needing to operate in the service of a pedagogical goal external to itself, which would be the case if it were a fable of Scholastic philosophy. It is not such a fable, but is a fable that is intended to inaugurate and participate in an already established suspicion of the medieval philosophico-ethicotheologico-political systematics that would give rise to a fable's moral in the sense that La Fontaine deploys it, in reference to an external system that must impose itself on the narrative, even if the narrative itself, in its telling, would give rise to a discourse about the same moral whether the moral is explicitly stated or not. Here, the narrative, in its telling, might give rise to a discourse about a moral, but that moral is not in reference to an external system. This is why the Cartesian fable has no moral: In its telling, it generates its own moral; it is its own moral. There is nothing to demonstrate distinct from its monstration. None of this, of course, is to suggest that the Cartesian fable is a-moral. Only a Scholastic would suspect such a thing. Rather, the Cartesian fable is generating a system that will give rise to a moral from within, which is why there is no need to point out its moral before or after the narrative. And even if preparatory work has been engaged for the reader to 
path of thinking on which he or she had been, whether formal academics or average

everyday experience, such that the relationship to history-personal, political, religious, or

literary-is always already incorporated in the movement inaugurated by the Cartesian fable.

What appears as a treatise can thus take on the inaugural and preparatory structure of

a fable, especially when what the treatise prepares the reader to encounter is another

explicitly didactic or pedagogical literary form, like a dialogue. This treatise-fable leading up

to the dialogue does, however, have a moral, where Descartes writes that the natural light, which he will set into motion, "determines what opinions a good man [honeste home] should hold"

on any topic, and that it can determine these opinions outside the realm of philosophy or

religion. ${ }^{13}$ Such a good, honest man does not need to read every academic book, and he

should especially determine, thanks to the natural light set into motion by this very rule, how

to "measure out his time so as to reserve the better part of it for performing good actions

[bonnes actions]." ${ }^{\prime 14}$ Thanks to the moral placed where it is in the text, leading to a certain

understand the fable, that preparatory work does not precisely faire voir the moral in the way La Fontaine, or another fabulist, would intend to do.

13 As Becker analyzes it, the question of honetteté is crucial for understanding seventeenth-century moralists like Corneille and Racine, who introduce "a new lexicon" to rival "the language of fidelity, magnanimity, and the varied shades of affection betokening loyalty and good lordship" (Becker, The Emergence of Civil Society in the Eighteenth Century, p. 11). That is, "the essence of l'bomme honête" is found in the civility, moderation, and tolerance that come to rival the strong feelings of the sixteenth and seventeenth centuries' world of religious and political bombast (ibid., p. 12). He places Descartes in this world of the moralists in that Descartes "“accepts his social role as a role, while remaining free of it as a mind" (ibid., p. 132n. 17). The good, honest man being invoked in this moment of The Search is the kind of man Becker describes: one who can assess the world without dependence on philosophy or religion, and especially without the strong passions of the latter. However, Becker also links honêteté with honestas, which "may denote either a superficial decency bereft of innermoral worth or it may imply a more genuine and deeper quality" (ibid., p. 138n. 52). There seems to be implied here the possibility of a suspicion on the part of those who claim to be honete, that the very invoking of that position is already suspicious. If that is so, and it is thus a suspicion Descartes would hope to invoke in the reader, the very possibility of superficiality may itself indicate a depth to the honeteté being invoked.

${ }^{14}$ It should be noted that the quote is slightly different in French, where Descartes writes that one should measure out the course of one's life: "Il a beaucoup d'autres choses à faire pendant sa vie, le cours de laquelle doit ester si bien mesuré" (AT X, p. 495). The importance of the difference between the French original and the English translation is certainly debatable, but the phrase le cours de sa vie could perhaps be an indication of a quasi-Bergsonian or quasi-Hegelian, spatialized Interpretation of time in Descartes' thinking in the sense that Heidegger describes it in Being and Time in that the course of one's life is one which would be walked, in a particular direction, from one point to another (see Martin Heidegger, Being and Time, pp. 500-501n. xxx). Such 
interpretation of even the preparatory treatise-fable that precedes the dialogue, this appeal to the pragmatic or useful ways of spending time, or good actions, The Search for Truth by Means of the Natural Light may appear to be less of a fable than either The World or the Discourse. It might appear as if the treatise-fable is interested in teaching rather than showing. Descartes even writes in the second paragraph that his intention is "to explain [enseigner]." However, it must be remembered that this treatise-fable is the preparation for a dialogue, where characters speak. These characters_-Polyander, Epistemon, and Eudoxus_embody and enact the roles of an everyman, a man of knowledge, and a man of good or right opinion, where Polyander is shown, shows himself in fact, through, by, and with Eudoxus' help, that Epistemon's claims to knowledge are unfounded. The reader of this dialogue, perhaps sympathizing or identifying with Polyander, is also shown the truth of Eudoxus' opinions and the falsity of Epistemon's knowledge claims. In addition, what Descartes wants to teach here is the falsity of the knowledge claims of the learned as well as of average everyday experience. What he will teach is unlearning, which is neither necessarily the learning which a good, honest man could have achieved without the misguided lessons of his past nor that which a good, honest man could achieve thanks to the fortune of a "great natural talent, or else the instruction [instructions] of a wise teacher [sage].” What will be shown, what will be brought in as evidence (mettre en evidence), and so what will be presented before sight or seeing, will be the value of the soul that can teach itself proper pragmatic conduct and useful

a spatialization is not Heidegger's direct critique of Descartes in that text (see for instance ibid., pp. 44 and 71 72), but perhaps it could have been, perhaps in particular as a way to connect this Interpretation of time with the Interpretation of nature as geometrizable and of the human body as a measuring machine, even if (perhaps even because) that measuring body does not need the cogito (cf. Maull, "Cartesian Optics and the Geometrization of Nature," esp. pp. 270-71). However, to the extent that the fable will have an effect on the method, especially insofar as the method does not precisely demand the fable, such a reading of this moment in The Search may ultimately prove untenable. That is, if, as I hope to show in the next chapter, the method is never a single method, but is always disruptive of itself, splitting and moving in more than one direction simultaneously, then the course of a life might never be conceivable as a single course, let alone a course dictated ahead of its measuring by an all-encompassing method. 
application of reason such that true knowledge is acquired. Such is what will be shown in this dialogue, though Descartes never completed it. In preparing the reader for this showing, in showing the reader what will be shown, the treatise-like propaedeutic to the dialogue takes on the qualities of a fable. (CSM II, p. 400; AT X, p. 495 and 496)

What is more, in its structure of showing the average everyday man his own potential to himself, with as little interruption from the learned as possible, the reader is shown the very same potential. The potential as a potential, as having been less applied in the useless endeavors of the learned, will make this showing to Polyander within the showing that is the dialogue all the more beneficial to Polyander because he is "unprejudiced [n'estes pas préoccupe]," i.e., has less to unlearn, less to be taught of unlearning, and can therefore begin on the Eudoxian path for himself all the easier. Epistemon, all the learned, must admit of their prejudices and useless preoccupations. His words are preoccupied with useless syllogisms and the interrupting quaestiones of academic life, not directed toward good actions. He wants to teach Polyander, not show him how to set his natural light into motion and conduct his life. Such is what is shown within the dialogue itself, for which the reader has been prepared by the treatise-like introduction, which itself is given an organizing principle not unlike a moral at the beginning of this beginning. That treatise-like beginning brings the dialogue proper within the inaugurating structure of the fable. Thus, fable is expanded to include treatise and dialogue as well. ${ }^{15}$ (CSM II, pp. 404 and 403; AT X, pp. 504 and 502)

\footnotetext{
${ }^{15}$ Daniel Brewer references the "suspect" lineage of the philosophical dialogue as taken over from "the Sophists, Mineppean satire and the Greek carnival" (Brewer, "The Philosophical Dialogue and the Forcing of Truth," p. 1234). In taking over this lineage, philosophy begins, he claims, by eradicating, effacing, and silencing "its other and previous beginnings" (ibid.). Thus, The Search continues this silencing tradition insofar as it ends "at precisely that moment when Poliandre, the 'joyeux compagnon,' becomes no more than the dummy for the ventriloquist Eudoxe" and thereby becomes a mechanism for imposing a master-student relationship between them and, by extension, between Descartes and reader (ibid., p. 1239). Epistemon is silenced and so, obviously, is the Scholastic tradition he represents. As Brewer indicates, however, "the way Descartes is read depends entirely on how his readers understand the term faire voir" (ibid., p. 1238). Brewer seems to think that faire voir should be read precisely in its forceful capacity to silence critics and others. This may be true, but what he does
} 


\title{
Hypothesis-Fable-Novel
}

\section{The fable is a crucial concept and device in Descartes' career, whether it is an histoire or a}

\author{
fable proper, if these can be distinguished. The fable is a flexible form for Descartes. ${ }^{16} \mathrm{It}$
}

\begin{abstract}
not seem to acknowledge is who that other is that is being silenced in the content of this dialogue, and what relationship of that other itself has to others. If the other is Epistemon, then this other is not that of the ancient satire or poetry in general, à la a certain Plato. Epistemon and Scholasticism are other than Descartes' philosophy in their own attempts to silence others-such is why they teach as opposed to make shown. A teacher for Descartes is a master, a master with all knowledge, who brings the truth from on high to his or her students. Thus, what is at stake in the silencing of Epistemon cannot be precisely understood as a silencing of an other to philosophy, but a silencing of another philosophy, another philosophy which may be conceivable but remains uninterpretable. What the forcing of a truth that occurs in The Search for Truth is doing, in operating as a faire voir, is a counterforce, a force that inaugurates the unlearning of what has been learned, a counterforce to the force of Scholasticism. No doubt, Brewer is correct when he claims that we need "to read this classical form [i.e., dialogue] against itself" via the fiction at its structural heart that is all-too often disregarded (though perhaps more so with Plato's than with other dialogues), but this reading against its form, as a form that would appear to efface its fictionality in the very appearing as fiction, need not limit itself to the force of dialogue qua form, and qua forming of truth (ibid., p. 1246). Reading the form against itself can also address, as is the case with The Search, the force of dialogue as counterforce to a force that has already enforced itself within, against, and upon the reader as well as the interlocutors. The original and originary force of the Cartesian dialogue, of the dialogue as brought within the structure or logic of fable in the Cartesian corpus, is in itself a reaction not to say repetition of the force already at hand. In its repetition, not just of a form but of a force, even the treatise-like beginning, which prepares the reader for what is to come (a beginning which Brewer refers to as a "narrative introduction" that brings the reader into a master-student relationship with the author [ibid., p. 1237]), can be understood as establishing the Cartesian subject not simply as a student who repeats the movements of the sovereign Cartesian self, but as establishing what it was incapable of doing under the force of teaching and traditional, Scholastic treatises. Thus, it would appear difficult for the Cartesian dialogue and treatise-like beginning at hand as operating through a "mirror function" as a "product of the theoretical desire to possess in and through language an untarnished means of representation" except insofar as this theoretical desire is already at hand in the very context of the Cartesian dialogue, a desire which needs to be redirected, not precisely invented anew, and so is not silencing an other, but another (ibid., p. 1245). The mirror, the mimesis of Descartes' dialogue, is never understood as mirroring nature or language as such, but as mirroring what already presents itself as a mirror, as a mimesis that silences what would oppose its linguistic representation of nature. The context in which a dialogue would silence is at least as important as attending to the force of its silencing.
\end{abstract}

${ }^{16}$ It is to this flexibility that Stephen H. Daniel seems to be pointing when he notes that, "In place of turning to the Aesopic animal fables or to the classical myths as appropriate contexts in which to renew the fabular enterprise, Descartes substitutes a new form of fabular thinking" (Stephen H. Daniel, "Descartes on Myth and Ingenuity/Ingenium," The Southern Journal of Philosophy 23:2 [1985], p. 163; my emph.). This kind of thinking, according to Daniel, is one that can allow for "the not-yet-fully-grounded character of certain discussions," especially discussions concerning the fundamental aspects of the metaphysics that would itself ground the scientific enterprise (ibid.). Like Bacon, Descartes' restraint concerning these discussions "does not depend on the inherently inaccessible nature of the objects with which such thinking is concerned," but unlike Bacon, "Descartes raises into prominence the feigning mind behind the fabular construction" (ibid., pp. 163-164). Thus, a fabular thinking, one which can draw attention to the mind that fabulates, can be considered a kind of thinking that is flexible beyond the precise form of fable, and can incorporate into the fabular form other literary genres that would otherwise appear quite distinct from it. However, Daniel also claims that the fabular form gives an appealing adornment to his discussions and is "consciously intended to attract and hold the attention of readers concerned more with enlightenment than with exacting demonstrations" (ibid., p. 163). 
appears in many forms and ways. Appearances, of course, can be deceiving, and this applies to philosophico-pedagogico-literary forms as well as to things in the world. Indeed, that appearances may deceive is all the more important to bear in mind when encountering what will establish the possibility of clarifying the true nature of things in the world. These things, these books, fables, treatises, may all deceive us in their appearances, but if we are attentive to the fabular nature, to the truly fabulous essence that they are- not that they possessthen perhaps we can see the foundational demands of the fable as a form for Descartes. What appears to be a treatise may be deceptive and in fact truly be a fable. That much is clear, even if it is not novel.

In this way, we can make sense of what Descartes means when he writes to Denis Mesland a year after the Principles' 1644 publication that the last two parts of the Principles can be taken "as a pure hypothesis or even a fable" should the reader decide to doubt their truth. The book remains a "treatise" since its form is that of laying out principia rather than explicitly telling an histoire, but its second half can be taken for hypothesis or fable (CSM-K, p. 249; AT IV, p. 217). Descartes has changed his approach to laying out principles primarily in order to "make it easy to teach [enseignée]," as he writes to Mersenne in 1640 (CSM-K, p. 167; AT III, p. 276). Thus it appears as though Descartes is abandoning the fabular quality of his earlier work that would show to his readers how to think along with him in their own

Here, and in combination with the claim that the restraint indicated by the fable is independent of the "inherently inaccessible nature" of foundations to his metaphysics, I would part ways to a certain extent with Daniel because he appears to indicate that the fable is deployed with the intent of entertainment, though of a higher register than other forms of entertainment, and is done in the service of what cannot be demonstrated. However, what seems to be more appropriate, especially if this fabular thinking indicates that the fable as a structure can be extended beyond the precise form of fable, is that fabular thinking is necessary to what will come to be demonstrated about the metaphysics that only appears to be indemonstrable. It only appears to be indemonstrable to those who have not been set into motion by the fable itself. The fabular thinking at hand may leave certain aspects in suspension, but that suspension is only operative as a suspension until the motions the fable inaugurates have begun. If the fable of The World, Daniel's focus in this portion of his essay, is indicative of a fabular thinking, then the thinking that would be fabular can extend itself beyond fable itself, and this thinking is a thinking that, in drawing attention to the feigning mind, begins the motion that itself will set out the metaphysics that would ground the thinking that calls itself fabular. 
ways. Now, and especially when writing in Latin, it would appear that he is writing a

textbook, a technique for teaching the learned how to unlearn all that they have learned, but in a fashion more amenable to the methods and forms of presentation to which they are accustomed. ${ }^{17}$ It would seem that way, but the letter to Mesland ought to cause skepticism not to say cynicism concerning Descartes' interest in writing the Principles in the way he did. That is, as soon as he meets resistance as to the content of his claims about the physical operations of the universe, he offers up these writings as hypothesis and fable, even while they remain part of a treatise. This relationship of treatise to fable and hypothesis is the case even within the text itself. In Part Three, titled “The Visible Universe," he writes that he will make false assumptions in order to explain all physical phenomena, while he begins Part Four, titled "The Earth," by claiming that these false hypotheses are necessary to explain "the true nature of things." The treatise incorporates false assumptions so that the true nature of things might be exposed, but if any reader finds these false assumptions problematic, he or she is free to take them as hypothetical and fabular, as merely pedagogical tools to set the mind into motion. If that is the case, then the second half of the Principles apparently must be taken as a fable, just as The World or the Discourse, despite the appearance of operating in the traditional philosophical mode of a treatise, because the Principles, as a textbook, as an attempt to teach, is interested in setting the mind into motion over and above the proof of

\footnotetext{
${ }_{17}$ Daniel Garber notes that the Principles' form, where short paragraphs precede elaborations on those paragraphs, "is quite unlike any textbook then currently in use" (Daniel Garber, Descartes' Metaphysical Physics [Chicago: The University of Chicago Press, 1992], p. 316n. 95). However, in that it does "resemble theses posted for disputation, short statements, printed on a placard and posted, which were then defended in an oral disputation," the Principles would appear to resemble the announcement of Descartes' law thesis (ibid.). Marion notes that the number of the parts of the Principles_ “The Principles of Human Knowledge," "The Principles of Material Things," "The Visible Universe," and "The Earth"—matches the number of divisions of philosophy at La Flèche into logic, metaphysics, physics, and ethics (see The Jesuit Ratio Studiorum, pp. 40-45). Marion explains the lack of ethics in Descartes by claiming that "it shows up in the global opposition between what holds 'in Ethicis' and what holds 'in Metaphysicis”' (Marion, On Descartes' Metaphysical Prism, p. 13). For more detail on textbooks in Descartes' time, see Sister Patricia Reif, "The Textbook Tradition in Natural Philosophy, 1600-1650," Journal of the History of Ideas 30:1 (1969), pp. 17-32.
} 
its principles as such. Thus, treatise and hypothesis can be incorporated within the structure

of the Cartesian fable that, because hypothetical, obeys rules it generates. ${ }^{18}$ (CSM I, pp. 256-

257 and 267; AT VIII, pp. 100-101; pt. 3, arts. 45-46, and pt. 4, art. 1)

${ }^{18}$ In doing so, in incorporating hypothesis within the structure of fable, there is evidence not only of a
difference between Descartes and Galileo but also of what marks Descartes as thinker whose scope is wider
than what Galileo could have hoped to accomplish (see Garber, Descartes' Metaphysical Physics, p. 2), even if he
finds Galileo, according to a letter addressed to Mersenne, dated October 11, 1638, to philosophize "much
more ably than is usual, in that, so far as he can, he abandons the errors of the Schools and tries to use mathematical models in the investigation of physical questions" (CSM-K, p. 124; AT II, p. 380). When Cardinal Bellarmine writes his certificate for Paolo Foscarini on April 12, 1615, he writes that both Foscarini and Galileo "are proceeding prudently by limiting yourselves to speaking suppositionally and not absolutely [ex suppositione $e$ non assulutamente], as I have always believed that Copernicus spoke" (Cardinal Robert Bellarmine, "Cardinal Bellarmine's Letter to Foscarini," in Galileo Galilei, The Essential Galileo, ed. and tr. Maurice A. Finocchiaro [Indianaoplis, IN: Hackett Publishing Company, Inc., 2008], p. 146; "Bellarminus ad Foscarini 12.04.1615," http://apologia.sk/1615-04-12, accessed March 25, 2013). Galileo writes in the first part of his "Considerations on the Copernican Opinion" that the Copernican system is demonstratively persuasive and is therefore "worthy of being very carefully considered and pondered" whether it is true (Galileo Galilei, "Galileo's Considerations on the Copernican Opinion, Part I," in The Essential Galileo, p. 151). Thus, he explains in the preface to the Dialogue on the Two Cbief World Systems, addressed to "the Discerning Reader," that he is deploying the Copernican system "in the manner of a pure mathematical hypothesis [pura ipotesi matematica]" with the intent of showing it as superior to the geocentric system "though not absolutely [non . . a assolutamente]" (Galileo, "From Dialogue on the Two Chief World Systems (1632)," in The Essential Galileo, pp. 190-191; Dialogo sopra i due massimi sistemi [Turin: Giulio Einaudi editore, 1970], p. 3). In addition, throughout his depositions in 1632 and 1633, Galileo adheres to the position that he never assumed absolute superiority on the part of the Copernican system, but that it was merely an alternative to the geocentric system. Thus, for Galileo, supposition and hypothesis maintain themselves in a different relationship to truth than for Descartes. Hypothesis and supposition are laid out in Galileo for the purpose of demonstration to the persuadable, and thus are laid out for a rational mind in opposition to the irrational, or at least in opposition to the stubborn. Descartes' insight on this point exceeds Galileo's attempts to evade being placed on the Index in that what Descartes is always after is a generation of the rational mind itself. Galileo's claims always leave open the possibility of empirical support or refutation, but Descartes' claims are intended to generate the ground for the possibility of an empirical search in the first place. Whether Galileo ever muttered "but still it moves," what he does claim is that the movements themselves are to be witnessed in some fashion. What makes Descartes a philosopher, beyond the 'mere' scientificality of Galileo's research, is the recognition that, before the witnessing of given facts are possible, the mind itself needs to be moved. Hence the late portrait with "Mundus EST fabula": Before the world can be understood as moving, it must first be understood as fundamentally fabulistic, as a world to be engaged as open to varying degrees of interpretation. However, in order for this possibility to be opened up, the mind itself must first be moved, and this movement can only be inaugurated by engaging the world fabularly, by offering up not only a hypothesis, but also a hypothesis of the fabularity of the world as such. Such a dissimulation is not precisely dissimulating in that it does not present itself as a story or hypothesis that can be believed, but is rather the generation of a story that would allow for the world to be a world of hypothesis or fable. Hence the ostensibly serious look in Descartes' face in that portrait: It is not a lie to say that the world is a fable. "But still it moves" can be known as true if we can only get outside the world, or at least the earth, but the world as a fable can be known as true only if we first accept the fabularity of the world, only if the truth of the claim is accepted as a story that opens our minds to moving in some way, regardless of the alternatives, because it is these motions of the mind that will leave us in the position of being persuadable by the hypothetical attempts on the part of scientists like Galileo to demonstrate the motions of the heavens. To accept this fabularity is not an acceptance on the level of demonstration, nor can it be, which is the fundamental reason for accepting it qua fable. The demonstration is found within the fable itself, and is found in it as fable, as histoire and hypothesis. From that point, it is possible to discern other demonstrations. Thus, Descartes' fables are more difficult to place on the Index not because they are more persuasive or because he was more dissimulative, but because the fables tell the story of becoming persuadable, they persuade to 
Of course, the relationship between the Principles and The World is not merely

accidental. Descartes writes to Constantijn Huygens in 1642 that he is writing what will come to be titled the Principles that he wants to make The World learn (faire aprendre) "to speak Latin." 19 The Latin title he is considering at this point, "Summa Pbilosophiae," is specifically designed to "make it [i.e., The World] more welcome to the scholastics [il s'introduise plus aysement en la conuersation des gens de l'éschole." So the Principles is once again the fable of The World, only now shown to his readers, in particular his learned readers, as principia philosophiae rather than as les principes de la philosophie. Thus, the fable has been made to learn not only to speak Latin but also to appear not as a fable, which makes Descartes' appeal to reading the second half of the treatise as a hypothesis or fable all the more intriguing. ${ }^{20}$ That is, if the Principles, as principia, takes on the motivational role of a fable for the good sense of those who have spent too much time with uninterpretable books, then the form of presentation of this text qua treatise, qua principled and syllogistic, has not only expanded the Cartesian concept of fable to include hypothesis as well as treatise, but also shows that Descartes is always and primarily concerned with not merely showing his theories and proofs, but with doing so in a fashion, through a method of presentation that will most appeal to his readers,

persuasion, over and above persuading anyone about any particular claim. Thus, Descartes' fables find themselves on a more philosophical plane than Galilean hypotheses and suppositions. It is in constructing his fables, throughout his career, that Descartes is able to account for more than Galileo and his ilk, as Garber mentions.

${ }^{19}$ Cottingham translates "ie veux auparauant luy faire aprendre a parler latin" as "I want to teach it to speak Latin first" (CSM-K, p. 210; AT III, p. 523; my emph.). Though "made to learn" is far from perfect for similar reasons, it at least has the virtue of being more literal, as well as maintaining the importance of faire.

${ }^{20}$ Garber claims that "What is rhetoric in The World becomes the official argument in the period of the Principles," though he does not precisely clarify what he considers rhetoric in The World (Garber, Descartes' Metaphysical Physics, p. 216). This comment is made in the context of discussing the conservation principle and the three laws of motion as articulated between the two texts, and Garber does say that "what will later become Descartes' conservation principle in the Principles ... is supposed to support the first law of The World" but that Descartes' did not live up to a promise to demonstrate this principle in The World and that "it is not isolated as a principle" (ibid., pp. 215 and 204). It seems, then, that Garber's use of 'rhetoric' here is indicative of exaggeration rather than a particular technique in the text of The World. 
whether in Latin or in French, and that his attempts to do so always entail inaugurating the unlearning of what has been learned by said readers in such a way that each reader can find his or her own way to this unlearning and the subsequent learning that follows. (CSM-K, p. 210; AT III, p. 523)

The Principles is a hypothesis-fable-treatise, then, even while The $W$ orld is a fable, the Discourse a fable or histoire, and The Search is a treatise-fable-dialogue. But the Principles is even still more embedded in the fabular, since it was itself made to learn French, a translation by Abbé Claude Picot being published in 1647. The treatise that is the result of making the fable learn Latin itself turns back to the initial and initiatory language. And Descartes makes the Principles learn French in the hope that it will be "better understood" (CSM I, p. 179; AT IX-B, p. 1). He hopes, then, that translating the Principles will inaugurate that much more movement in that many more minds, though he is also concerned that the title, with its treatise-like tone and implication, will put off more people than otherwise would find it worthwhile, those who are either unlearned as well as those who find academic philosophy unsatisfactory. Indeed, when writing to Princess Elizabeth soon after the translation's publication, he explains that he has given up on writing a treatise on learning (Traité de l'Erudition) because, among other reasons, the preface to the French edition of the Principles touches on a number of the points he would have covered in that treatise. So, in making The World learn Latin and in making the Principles learn French, Descartes has written more or less how he considers learning in general. (CED, p. 168; AT V, pp. 111-112)

The fear he has that Les Principes will not be read by those who could better understand it involves its form and method of presentation, the residue of its apparent learnedness as principia. It is precisely not as principia, however, that Descartes wants his 
French readers to approach the text. ${ }^{21}$ On coming across the text, he writes, "I should like the reader first of all to go quickly through the whole book like a novel [Roman]."22 Only after having gone through the novelistic, cursory reading should the hoped-for reader read the text again, though only because certain issues therein deserve further investigation and curiosity is piqued. Thus his approach is to appear at first to encourage a light and unserious manner of reading, much like his appeals to fabulizing his physics and his biography. One

\footnotetext{
${ }^{21}$ How he would ask one to read the Principia remains, to some degree, unknown. However, if it was initially intended to be read by Scholastics as a replacement for his $W$ orld, then presumably they should have read it as non-Scholastic philosophy presented in Scholastic form. But we should bear in mind that such a way of reading is apparently a way that leads to less understanding, not more. Such a lack of understanding would certainly be in line with what he says numerous times about the capacities to learn and understand on the part of Scholastics, including here when he writes that "the more they have studied it [i.e., traditional philosophy] the less fitted they generally are to acquire a grasp of true philosophy" (CSM I, p. 185; AT IX-B, p. 11).
}

22 When Derrida discusses this moment in the Principles, he distinguishes it from every other use of roman in Descartes' corpus, in particular the letter to Mersenne on November 20,1629. In that letter, Descartes argues against hope for the use of a truly universal language because "the order of nature [l'ordre des choses] would have to change so that the world turned into a terrestrial paradise; and that is too much to suggest outside of fairyland [pays des romans]" (CSM-K, p. 13; AT I, p. 82). The moment at hand in the Principles, however, "does not have the same meaning" as this moment in the letter because the letter's meaning is of "a work of the imagination, the fabulous description of an unreal country, a fictitious paradise" while the Principles' meaning "insists on a certain mode of reading: to read a romance is to be taken up in a story [bistoire], to run through a narration without meditating, without reflecting, and without backtracking" (Jacques Derrida, "If There Is Cause to Translate II: Descartes' Romances, or The Economy of Words," tr. Rebecca Comay, in Eyes of the University: Right to Philosophy 2, tr. Jan Plug and Others [Stanford, CA: Stanford University Press, 2004], p. 30; "S’il ya lieur de traduire II: Les romans de Descartes ou l'économie des mots," in Du droit à la philosophie Paris: Éditions Galilée, 1990], p. 325). What unites both uses of roman is order, though the order at hand is different in each — an order of what should but cannot be in the letter and an order of reading in the Principles. Thus, when Derrida claims that "the romance is not to be confused with the fable," even if it can imply fable, the question remains which roman, which order cannot be confused with fable (Derrida, "Descartes' Romances," p. 30). In insisting that "The fable is a narrative, or récit, whose factual truth need not be verified," even if it can signify or bear truth, and that the end of the similarity between roman and fable is in avoiding tedium, in addition to noting that the Principles' use of roman is unique in the Cartesian corpus, it seems clear that the roman that Derrida is distinguishing from fable is precisely not the one used in the Principles (ibid., p. 31). Indeed, that Derrida never returns to the Principles in this essay and continuously makes reference to "the land of romance [le pays des romans]" would appear to insist that Derrida's insistence on the distinction between roman and fable is not applicable to this moment in the Principles (ibid, p. 41; p. 339). That to which I am trying to draw attention, that on which I am insisting, in the roman of the Principles would thus be, in Derridean terms, the order of reading at hand over and above the order of a world that should but cannot be. This order of reading, the 'order' to read in a certain order, with the hope of ordering the mind would appear to in fact change the world, the order of the world, even if it would not necessarily be of the universal order that Latin could hope to achieve. In such an ordering, then, this roman can be merged (not confused) with the fable, and not only because the Les Principes is The World's relearning French after a detour into Latin —and a detour into a Latin that would teach its readers how to unlearn a Scholastic Latin. Thus, Derrida remains correct when he writes that "History [histoire] cannot be written as a romance [roman]; the romance does not tell a true story [histoire]" but he only remains correct in reference to one of Descartes' uses of roman (ibid., p. 42; p. 341). In reference to the use found in the Principles, histoire can easily be written as a roman which tells a true bistoire, even an histoire of the truth, perhaps a true histoire that orders the ordering of the truth. 
can, one should approach Descartes without expecting the demands of a self-declared serious work of Scholastic philosophy. Only after such an unserious reading will curiosity be piqued so as to pick up the book a second time. But even this second reading is not meant to be serious, so as not to destroy the curiosity that has been piqued. Instead, on this second reading, the hoped-for reader should "mark with a pen the places where he finds the difficulties and continue to read on to the end without a break" (CSM I, p. 185; AT IX-B, p. 11; my emph.). Here, one should not linger over difficulties, but merely note them. Should curiosity remain piqued, should the reader want to dip back into the Principles a third time, Descartes predicts the difficulties will be solved, and if not on the third read, then by the fourth. It seems that only the third time is a more serious reading to be expected, but even then Descartes predicts that it need not be too serious because it will merely be to clarify lingering confusions. None of these proposed readings, though there are a number of them, are described as needing to be detailed or close. Rather, Descartes expects his readers, at least in French, to read quickly, barely marking the page. Despite all appearances, then, Principia Philosophiae or perhaps only Les Principes de la Philosophie is not a work for scholars who pore over every word, considering its import, weighing it against other texts both by the same author and by different authors. ${ }^{23}$ Only after multiple, quick reads will the importance

23 This description of the curious reader seems to ask for a comparison to Heidegger's critique of curiosity (Neugier). In Being and Time, he focuses on the prefix to the German word to explain that it "expresses the tendency towards a peculiar way of letting the world be encountered by us in perception" (Heidegger, Being and Time, p. 214). What is peculiar about curiosity is that it perceives, sees the world "not in order to understand what is seen (that is, to come into a Being towards it) but just in order to see. It seeks out novelty [Neue] only in order to leap from it to another [erneut] novelty [Neuem]" (Heidegger, Being and Time, p. 216; Sein und Zeit [Tübingen: Max Neimeyer Verlag, 1967], p. 172). Thus, curiosity, Nengier, the craving for the new does not linger with that about which it is curious, but always seeks after a new thing about which to be curious, and so never dwells anywhere. As a result, though curiosity has a futural relationship to what it seeks, it "is futural in a way which is altogether inauthentic, and in such a manner, moreover, that it does not await a possibility, but, in its craving, just desires such a possibility as something that is actual," constituted in its inauthenticity by a "making-present" that leaps away from a more authentic awaiting and dwelling in possibility and seeks out distraction, thereby forgetting what it has already sought out (Heidegger, Being and Time, pp. 397 and 398). Thus, the question would be whether this analysis of curiosity is applicable to the Cartesian use. In The Passions of the Soul, Descartes gives the closest definition of curiosity in his corpus, in the context of explaining how 
of this work wash over the reader-presumably because, if the reader's curiosity has

remained piqued throughout this process, he or she is learning to think along with Descartes.

It may be a novel, but it is a pedagogical novel—like a fable. And thus, like the dialogue of

The Search for Truth, this novel works to unwork, shows how to unlearn the problems

established by the learned. ${ }^{24}$ Like the fable of The $W$ orld, however, this novel does this

unworking by way of conjuring "false" principles. Also as in The World, Descartes claims it is

desires are differentiated based on the objects of their pursuits, curiosity pursuing knowledge (see CSM I, p. 359; AT XI, p. 394; art. 88). There is nothing here that would necessarily argue against Heidegger's analysis of curiosity, especially in the plurality of objects of the desire for knowledge found in curiosity. However, a glance at the etymology of curiosité may lead to a modification of the Heideggerean position as regards curiosity in this instance. Curiosité comes most directly from the very rare curiositas, which simply indicates "desire for knowledge," but it is also related to the more common curiosus and cura, both of which at least can indicate a care for, even an anxiety toward what is curious (Lewis and Short, s.vv. "curiositas," "curiosus," and "cura," accessed March 27, 2013, http://www.perseus.tufts.edu/hopper/text?doc=Perseus\%3Atext\%3A1999.04.0059 $\% 3$ Aentry $\% 3$ Dcuriositas, http://www.perseus.tufts.edu/hopper/text?doc $=$ Perseus $\% 3$ Atext $\% 3$ A 1999.04 .0059 $\% 3$ Aentry\%3Dcuriosus, and http://www.perseus.tufts.edu/hopper/text?doc $=$ Perseus $\% 3$ Atext $\% 3$ A1999.04 $.0059 \% 3$ Aentry $\% 3$ Dcura, respectively). Curiously, when Heidegger engages in his analysis of curiosity, he does not use the German cognate for the Latin word, Kuriosität, which in fact never appears in Sein und Zeit at all. The potential care-structure of curiosity seems to have been lost in the analysis of Neugier, then. To take this potential care-structure seriously in this moment of the Principles need not disregard Heidegger's analysis of curiosity, and it is clear that at least some of this analysis could remain applicable to the Principles. However, in that Descartes is addressing French readers, it may be worth asking after that about which he is asking them to care. Indeed, it does not appear that he is asking them to move from object to object, if only because he suggests reading the text three or more times. Even if such a reading is not careful at any given moment, it does demand attention and retention, perhaps even a dwelling in the principes at hand. Where the Heideggerean analysis of curiosity might have a foothold, however, could be in the fact that Descartes is asking his readers to read lightly, not to spend too much time in scholarly attention, but to find satisfaction in the repetition of a non-taxing reading. Yet such a critique should perhaps also bear in mind the context of this call to curiosity, a context not unlike the invocation of fable and histoire in the Discourse and the treatise-like beginning of The Search. That is, Descartes is calling on his French readers, his non-scholarly, non-Scholastic readers, to read this textbook like a novel, like a curious object, so that they not feel intimidated by the object in hand, so that their good sense, equally in potentia as forthose scholars, can begin to move. Such motion may require repetition, out of careful curiosity, out of care for the curious, but it need not be, in itself, overwhelming or tedious. Indeed, what Descartes may have in mind when he invites his French readers to read this textbook like a novel, like a new and curious object of the new and newly 'romantic' way of engaging the world, could be something closer to what Maurice Blanchot describes as the "infinite lightness" that a reader brings to a book without "add[ing] himself to the book" even while it tends toward "unburden[ing the book] of any author" (Maurice Blanchot, "Reading," tr. Lydia Davis, in The Gaze of Orpheus and Other Essays, in The Station Hill Blanchot Reader, ed. George Quasha [Barrrytown, NY: Station Hill Press, 1999], p. 431).

${ }^{24}$ Marion divides being in Descartes into ousia and sum, the latter of which is equal to esse. As a result of this equivalence, "the question of esse has neither the time nor the freedom to undo itself ... from the authority of the ego" (Marion, On Descartes' Metaphysical Prism, pp. 70-71). The question of being disappears with the self and being itself disappears into that self, according to Marion. However, the undoing which Marion references which esse does not do would seem to be accomplished in the very appearance of the self to which Marion claims esse amounts. If "esse amounts to the ego" as soon as the self appears, and if that self appears through an unworking and unlearning of what the self had learned, then it would seem as though esse does undo itself, if only through the unworking and unlearning of the self that allows for the appearance of the self (ibid., p. 71). 
the utility of "explanation" that makes these principles valuable, not their content per se (CSM I, p. 256; AT VIII, pp. 99-100; arts. 45 and 46). ${ }^{25}$

So the value and utility of the unserious novel of Les Principes is to be found in the explanatory power of its false principles. Meanwhile, the riskiest elements of the Principia, those very same false principles, can be excused if one reads them as merely hypothetical or fabular. ${ }^{26}$ And these false, hypothetical, fabular principles in the treatise-novel of the Principles

\footnotetext{
${ }^{25}$ Nancy also considers the suggestion to read the Principles like a novel as falling in line with similar moments in the Discourse and in The Search, specifically as indicating that Descartes "wanted to write a literary work with philosophical content," though also noting that deploying literary techniques in philosophical works was common in Descartes' era (Nancy, "Mundus Est Fabula," p. 638). Nancy's concern in this instance is with the fable "insofar as it must be believed," following out the fable of The World as a covering or ornament for the truth that the text will reveal or explain (ibid.). Taking the Rules" understanding of fable as "a story which someone has told us [fabulam nobis narraverit]" and which is compared to the imagination's unfaithful representations of objects, Nancy examines this supposed ornament as central to the Cartesian presentation of truth (CSM I, p. 47; AT X, p. 423). Indeed, for Nancy, "fiction enters into an intrinsic relation with explanation ... through its own invention of fiction," in essence making The World "the organ of an equivalent of creation" (Nancy, "Mundus Est Fabula," p. 639). If the Principles is the retelling of the fable of The World, and does so by means of conjuring false principles and/or operating like a novel, then not only does the Principles expand the fable to the novel and textbook (a textbook of false principles, no less), then its creation would be not only the false principles in the novel, but also the explanation that gives value to the principles, judged in terms of that explanation's utility, a utility that is judged according to and by the minds of readers, in Latin or French, set into motion by these fables, these novels. Fiction's intrinsic relation with explanation, then, is not is not simply the creation of a world that is to be explained, but of explanation and its utility.
}

${ }^{26}$ Ariew traces out the development of Descartes' conception of hypothesis. First, in the Discourse, Descartes writes that he will not prove some suppositions or hypotheses in the Optics and the Meteorology because "just as the last are proved by the first, which are their causes, so the first are proved by the last, which are their effects" because "the causes from which I deduce [effects] serve not so much to prove them as to explain them; indeed, quite to the contrary, it is the causes which are proved by the effects" (CSM I, p. 150; AT VI, p. 76). Ariew takes this moment as arguing for "a derivation of [Descartes'] hypothetical principles from his first truths" (Ariew, "Descartes's Fable and Scientific Methodology," p. 135). Second, in the Principles, he "believes he is free to assume whatever he wishes about the division of the parts and their motion, as long as what he deduces from this hypothesis 'agrees entirely with experience"' (ibid., p. 134; quoting CSM I, p. 256; AT VIIIA, p. 101; art. 46). Third, also in the Principles, Descartes "specifically warns his reader he is not claiming that his "hypothesis should be received as entirely in conformity with the truth"' (Ariew, "Descartes's Fable and Scientific Methodology," p. 133; quoting CSM I, p. 250; AT VIII-A, p. 85; art. 15). The difference between the conceptions of hypothesis in the Discourse and the Principles is that, "In the Principia, Descartes ... would have argued only for the coherence of the whole lot" (Ariew, "Descartes's Fable and Scientific Methodology," p. 135). It is for this reason that Ariew argues that, by the time he writes the Principles, Descartes believes he must accept some of his principles as inherently hypothetical, merely morally and not absolutely certain, and unable to be proven by demonstration or self-evident principles. Such an argument is fine as far as it goes. In tracing out a development in Descartes' thought, Ariew seems mostly correct. However, as in his claim about the change in the concept of fable, Ariew also appears to be overlooking that to which Nancy draws attentionthat the fable is no mere rhetorical ornament, even a "necessary" one, but is indicative of a fiction at the heart of the conception of what is to be explained and how it is to be explained, throughout Descartes' career (ibid., p. 138). 
are those which match up most neatly with The World, the fable that generates the rules that will set into motion the reason always already in potentia or en puissance, and always already in potentia precisely as following those rules that have been generated, which is the good sense of those who read what Descartes has to tell us, evaluated and judged, interpreted as useful by those readers according to the selfsame reason that the fable-histoire-treatise-dialoguehypothesis-novel which is the Cartesian corpus has set into motion. ${ }^{27}$

\section{Fable and Deception}

So the things called books can be deceptive, where what appears to be a treatise can be a

fable, a novel, a hypothesis, etc. And the content of these books frequently begins with an appeal to the deceptiveness of the things of nature whereby they are other than what is merely given to the senses. Finally, the use of a particular language to interpret the operations of the world, either Latin or French, can be deceptive insofar as what can appear

\footnotetext{
27 As a way to again argue against the idea that Descartes operates as a divine sovereign in the fabular foundations of his philosophy, even while he generates a motion in the minds of his readers through the fable as expanded to incorporate other literary forms, it may be useful to turn to Prendergast again. He explains that, in the Principles, the "tendency to persist in the state that it is in" on the part of a body is "the power of a body to act on another or to resist its action" and that this power "is measured according to the size of the body and of its surface and the velocity of its motion" (Prendergast, "Motion, Action, and Tendency in Descartes' Physics," p. 460). This power is of a constant measure throughout the universe thanks to god's concurrence and the tendency to persist is indistinct from the motion or resistance to motion itself. If the purpose of the Cartesian fable is to inaugurate a motion in the mind of his readers, the Cartesian fable is not of a divine creatio ex nibilo, but is an inauguration of motion in the sense of a counterforce generating a new motion, setting what had been dense, solid earth into the motions of liquid or light. The minds of Descartes' readers, dense and unmoving as they are, remain elements in the world. The fable he tells sets them into motion, but there was already motion in the world, thanks at least to the conceivable if uninterpretable language of Scholastic philosophy and other, everyday explanations of how the world operates. This fable is a counterforce to this force, a force which itself was already fabular in its explanations. The force of the syllogisms and quaestiones was a furthering of this force, but counterforces can develop, depending on the size, surface, and velocity of the minds already at work. What Descartes has noticed, however, in uniting fable and light and then in expanding fable beyond the mere ornament of literary rhetoric, is that the force of explanation is always motivated and set into motion by a fable, the element of thinking that maintains the overall motion of the mind of The World. Or, to use the language of the Principles, the force of explanation is always motivated and set into motion by a hypothesis, the supposition that some suppositions (some of which are false) sustain the playing out of the principles of the Principles.
} 
to be serious academic work is in fact not nearly as serious as it would appear and the content of the interpretation should be evaluated only on its utility through a judgment that has been newly accustomed to a particular form of judgment by the deceptively serious or unserious language of the books that themselves deceive as to their seriousness. Given the flexibility of the concept of the fable, then, and its intricate relationship to deception, it is time to focus more clearly on deception itself in order to connect it to the fable but also, and more importantly, to open a more serious understanding of the method that deploys it, especially in its construction and self-instruction of the self.

\section{Deception and Seriousness}

In the first Latin edition of the Meditations, Descartes introduces the text with three short pieces: the dedicatory letter to the faculty of the Sorbonne, the preface to the reader, and the synopsis. Between the letter and the preface, the seriousness, especially the academic seriousness of the text proper, is insisted upon. In the letter, he tells the faculty that he has just cause (justa causa) for offering the book up to their judgment and protection, so long as they understand the impetus that compelled him to write it. That impetus is the proof of the existence of god and of the soul solely through philosophy. He is concerned, first, that the circularity of argument by authority is unconvincing to the non-believers (infideles) and, second, that the Bible itself suggests the possibility of proving these things through philosophy alone and more certainly than the deceptive things of the world. Proving the existence of god and the soul through philosophy alone will thus be the most useful (utilissimus) service he can render to the Church. In doing so, he asks in particular for the faculty of the Sorbonne's approval of the Meditationes because its "reputation" in matters of 
faith is second only to the Sacred Councils and second to none in philosophical matters. Obtaining the endorsement of such a well-regarded faculty will, then, help him correct any errors and convince even the "atheists [Athei]" of the proofs. (CSM II, pp. 3-6; AT VII, pp. $1-6)$

Meanwhile, Descartes has also explained that he understands that not everyone will be able to follow his arguments in this book. He goes farther in the preface to the reader, saying, "I would not urge anyone to read this book except those who are able and willing [poterunt ac volent] to meditate seriously [serio] with me," and that such readers are rare. If such readers have the potestas to meditate, Descartes is clearly not writing to those with potentia or puissance. That is, he is not writing to those whose good sense remains in the potential of a chaos-like pre-motive density, but to those who have already begun a movement similar to his own, whose power or potestas is or has been exerted, whose will is or has been exerted through the serious task of meditation. This serious task of meditation will of course engage in a series of meditations along a particular order of interwoven doubt and proof, but this is getting ahead of this moment in the text. Here, the important point is Descartes' appeal to the seriousness of the task and of those who would follow him, if perhaps not in precisely the same sequence, because such followers are ostensibly only those who have been made to learn Latin. (CSM II, pp. 5 and 8; AT VII, pp. 4 and 9)

In the French translation of the Meditations, of course, Descartes does not include the preface to the reader, though he does include the letter to the faculty of the Sorbonne. This exclusion can be taken in at least three, interrelated ways. First, and most obviously, Descartes is attempting to be diplomatic if not deceptive toward his French readers. He does not want them to feel excluded from the possibility of meditating along with him, from feeling able to instruct themselves in the method that proves the existence of god and the 
soul, by implying that this task is too much for them. As with the first words of the Discourse, Descartes would here, in the exclusion, be telling his French readers that their good sense in its potentia is sufficient to follow the meditations, to be shown how to meditate. Even though he claims, in the letter, that not everyone can understand his proofs, he does not want to keep his French readers from at least trying, as is implied in the preface. Thus, he is perhaps deceiving his French readers as to the seriousness of the path on which he is about to send them.

Second, he is, by excluding this discussion of the seriousness of the Meditations, showing these meditations to be not as serious as he would have the faculty of the Sorbonne believe. The faculty, "those most learned and distinguished men, the Dean and Doctors""sapientissimis clarissimisque viris ... decano \& doctoribus," or "messieurs les doyens \& docteurs"- are of the honored order of the learned, who presumably would not waste their time reading frivolous books, let alone waste their reputations by deigning to lend their names and authority to them. They deserve to be treated with respect and thereby ought to be informed of the seriousness of the meditations being offered up to their judgment. In excluding the appeal to seriousness, Descartes would appear to be implying that these meditations are not as seriousness as the faculty would have believed in reading the Latin edition. ${ }^{28}$ In being diplomatic and deceptive toward the French readers, then, he is

\footnotetext{
${ }^{28}$ It should be made clear that much of the language in these moments is part of the language of literary dedications, and we should not, following Mary S. Lewis, be "deceived by standard phrases" but note how this language "may position the book for us socially, economically and culturally . . . to extract information that provides the keys to the text itself" (Mary S. Lewis, "Introduction: the Dedication as Paratext," in Cui Dono Lepidum Novum Libellum?: Dedicating Latin Works and Motets in the Sixteenth Century, ed. Ignace Bossuyt, Nele Gabriëls, and Demmy Verbeke [Leuven: Leuven University Press, 2008], p. 5). Descartes is of course engaged in the dedication as part of the honor and patronage code systems still very much alive in the seventeenth century. Though he does not discuss book dedications specifically, Becker's explanation of these systems is helpful. He notes
}

that personal bonds were vital for the cohesion of society and that they were frequently generated from gift-giving and reciprocation. Writing at the beginning of the seventeenth century, Eustache Du Refuge, in his Traité de la Cour (Paris, 1616), exhorted his readers to 
simultaneously showing a diplomatic deception toward the faculty as to the seriousness of Les Méditations, even if the Meditationes ought to have been taken seriously. ${ }^{29}$ (CSM II, p. 3; AT VII, p. 1; AT IX-A, p. 4)

Of course, third, the Meditationes was not taken seriously insofar as Descartes was never granted the endorsement of those most learned and distinguished men. And yet, the French translation keeps the dedicatory letter to them. However, the superlatives have been deleted. They may be docteurs but they are no longer sapientissimi, let alone sages. The extent to which this deletion can be placed at Descartes' feet is debatable, but it is safe to assume that the exclusion of the preface is an act that he approved, insofar as he reviewed the translation (see VMD II, p. 172). In deleting the superlatives and in excluding the preface, something more about the seriousness of the Meditations and of its readers would appear to be claimed. The Meditations may be serious, but not in the academic fashion to which its readers would like to believe. That Descartes requires "not a new method $[$ Methodum . . novam; methode ... nomuelle]" but a useful application of a method his friends had seen him deploy in other areas

study carefully the high art of giving and receiving gifts (bienfaits) and compliments in order to "induce into our confidence" figures of influence at court. This was to be achieved, in the author's view, "by a declaration or demonstration of honor and obligation." (Becker, The Emergence of Civil Society, p. 10)

At a minimum, of course, Descartes is interested in gaining the endorsement of the faculty of the Sorbonne and in not having the Meditations placed on the Index. Insofar as his interest involves a reciprocation, even if it is not precisely a patronage (of which he had almost no financial need), Descartes' standard dedicatory language is involved in the social, economic, and cultural dynamics of the honor and patronage code systems. It may be that I am taking the change in language too far-I am unaware of any differences in the code systems between the use of Latin and French, but there very well could be, and Descartes himself appears to have been unclear on the appropriate protocols in this vein (see CSM-K, p. 154; AT III, p. 185)—but the differences are themselves interesting in terms of the code systems. If Descartes removes superlatives from his letter to the faculty of the Sorbonne in the French translation after knowing he would not receive its endorsement, then why and in what fashion he writes or dedicates Les Méditations to this faculty is at the least an interesting question in terms of the honor and patronage code systems.

29 This reading could seem to be in conflict with Marion's claim that the Meditations is in essence responsorial. However, in that Marion's understanding of this responsorial status centers on the Meditations as responding to critiques made to the Discourse, it would not seem to be in conflict. Indeed, the very diplomatic deception toward the faculty of the Sorbonne could be seen as further evidence in favor of Marion's claim, if only because French readers would have been able to respond to the Discourse. See Jean-Luc Marion, "The Responsorial Status of the Meditations," in On the Ego and on God, esp. p. 38. 
means he cannot use the traditional, serious academic method of syllogisms and quaestiones

(CSM II, p. 4; AT VII, p. 3; AT IX-A, p. 6). ${ }^{30}$ In fact, by excluding the preface while keeping

the letter, he is mocking the faculty, engaged in a bit of raillerie concerning their supposed

wisdom and ability to engage in the serious task of metaphysical inquiry. In deleting the

superlatives, following the fact that the faculty did not take the Meditations seriously enough

to grant its endorsement, Descartes seems to be implying that the faculty is not serious

enough in its potestas or voluntas, its pouvoir or voluntaire, to read the Meditations, while those

unserious readers of French have good sense in potentia and en puissance enough that they can

take him seriously in this serious path that appears to be unserious. The French translation

was published in 1647, six years after the first Latin edition, and so the hope for the faculty's

\footnotetext{
30 As Sepper explains it, the Meditations as meditations could not itself be understood as a new method in general, insofar as it follows Hugh of St. Victor's standard definition of meditation: “"a repeated cogitation that investigates the mode and the cause and the reason of every single thing. Mode: what it is. Cause: why it is. Reason: in what way it is"' (Hugh of St. Victor, "De meditatione," in Six Opuscules Spiritules, ed. Roger Baron [Paris: Editions du Cerf, 1969], p. 44; translated by Sepper, Descartes's Imagination, p. 257). According to Sepper, meditation for Hugh and his student, Richard of St. Victor, is intermediate between cogitation and contemplation and is a discursive act between "image-induced cogitations" and intuitive contemplation (ibid., p. 258). Thus, cogitation begins from an image and meditation considers various cogitative images with the result that "the mind is blessed with a penetrating look that recognizes unity in the diversity of the meditated cogitations" (ibid., pp. 258-259). The Meditations of course deploys this method in reference the body, the paper, the fire, and it would seem to find the unity in the successive proofs of the self, god, and mathematical objects. And of course, the Meditations is not a metaphysics, and so does not operate according to a merely cogitative discourse, even if it is discursive within the self. However, the method referenced in this moment of the Meditations is not precisely a medieval method, which is of course the point. It may appear to be so, and may appear so in order to appeal to the faculty of the Sorbonne, but this appearance is deceptive. The non-new method at hand in the Meditations, insofar as it is one that Descartes' friends had seen him deploy in areas distinct from a discursive search for the unity of image-induced cogitations, is thereby a method distinct from the one that would discourse over said cogitations. To be sure, it is a meditation, and its method is not new, but it is not a meditation that follows the habits and methods of medieval meditation. As a result, it requires a method distinct from that of medieval meditation, and an understanding of the status of imagination distinct from that of medieval faculty psychology. These distinctions will be explored in more detail in chapters 3 and 4 below. For now, however, one more point of Sepper's should be brought to attention, where he follows this understanding of the medieval legacy of the Meditations as explaining why "Serious conversation and study ... appear to be a logical extension from the intellect's use of images to its use of words" (ibid., p. 260). At this moment, Sepper seems to elide the fact that the serious study at hand in the Meditations is serious in a deceptive fashion, is both seriously deceptive and deceptively serious, in terms of the conversation it would have with its author and its readers, whether in Latin or in French. Indeed, what in many ways seems to indicate the seriousness of the text is that it appears or might appear as unserious to those whose seriousness would lead them to understand serious meditations as operating according to Hugh's method, which Descartes' text does in only the least serious manner. Because seriousness is always interwoven with unseriousness, and is interwoven through deception and diplomacy, it may be that Sepper's not taking this interwoven aspect entirely seriously leads him to understand seriousness as overly connected to the medieval meditative methods.
} 
endorsement must have long since passed. In a 1642 letter to Guillaume Gibieuf, Descartes

claims that he never had any interest in gaining the approval of the faculty as a body or from

individuals within it. Rather, he hoped that meeting with its and their objections would

assure him of the truth of the proofs in the Meditations (see CSM-K, p. 201; AT III, pp. 473-

474). In keeping the letter asking for this endorsement, which he never expected, as part of

the French translation where he also excludes the preface, Descartes is playing up the very

lack of that endorsement on the part of a faculty that fails to take seriously what is of the

utmost seriousness, on both a philosophical and theological level, despite the fact that it

may, in the French translation, not appear to be exclusively serious because not exclusively

appropriate for those so-called most serious, learned, and distinguished teachers in the

academy with the highest philosophical and second-highest theological reputation. ${ }^{31}$

\footnotetext{
31 There may be, then, without announcing it, a similar theologico-political dynamics at work in turning the Meditationes into Les Méditations to what Derrida uncovers in looking at the Discourse's use of French. For Derrida, the Discourse's explanation of why it is written in French is part of the complex politics over language in the sixteenth and seventeenth centuries, where François I decreed legal proceedings to be conducted in the 'natural' language of France in 1539 as a way to establish a monarchical-state rule, the Protestant Reformation further insisted on the use of native languages that was then tied in with a rising nationalism, and a growing desire for a specifically French literature grew. All of these movements, especially in their relationship to the state as the primary political form, contribute to a situation where, "in order to be subjects of the law-and of the king-you will finally be able to speak your 'French mother tongue' (langaige maternel francois); as if they were being given back to the mother in order better to be subjugated to the father" (Jacques Derrida, "If There Is Cause to Translate I: Philosophy in its National Language (Toward a 'licterature en françois')," tr. Sylvia Söderlind, in Eyes of the University, p. 12). Bearing this history in mind along with its relationship to the text's internal operations and both of their relationships to the Cartesian corpus, Derrida considers the use of French in the Discours to indicate a foundering moment of translation within a language which indicates that translation "erases but also exposes that which it resists and which resists it. It offers up language to be read in its very erasure" (ibid., p. 19). To be sure, in that Les Méditations is not a translation within a single language, it does not operate in a precisely identical fashion as the Discours. However, if translation erases and exposes what it resists and what resists it, especially between Latin and French in the sixteenth and seventeenth centuries, then the analysis of the seriousness interwoven with unseriousness in the movement between Latin and French in the diplomatic deception and deceptive diplomacy to both sets of readers takes on a similar structure. The translation into French and that translation's excision of the preface is a movement to the mother (if perhaps not ultimately toward the father, insofar as Descartes will not return to France), but not without first appealing to the teachers. That these teachers reveal themselves, in their resistance to what diplomatically yet deceptively resists them, to be unserious, then a movement away from the seriousness of the academy and to the deceptively comforting unseriousness of the mother becomes necessary as a way to maintain the seriousness of the meditations that cannot operate as a scholarly metaphysics.
} 


\section{Deception and Self-deception}

There is deception in the Meditations, to be sure, but attentiveness to the fable-structure or logic consistent throughout Descartes' career can bring to light a further complication in these meditations that purport to prove the existence of god and the soul with the utmost clarity and distinctness. The first sentence of the First Meditation famously begins, "Some years ago I was struck by the large number of falsehoods that I had accepted as true in my childhood." These falsehoods will be conjured away once the book has done its work, but for some time, Descartes writes, he did not have time to deal with his recognition. There are already two layers of history at work in this beginning of the Meditations, then: the history of a youth of accepted falsehoods and the history of the time after the recognition of the falsehoods but before meditating on the meaning of the recognition and how to deal with it. In that secondary or second history, Descartes realized that conscious and comprehensive demolition of accepted falsehoods would be necessary to have a solid foundation, but awareness of his own immaturity and of the enormity of the task led him to procrastinate. In the interval between recognition and meditation, Descartes is pulled in multiple directions, between the exigencies of life, the desire for a solid foundation, and intimidation at the thought of throwing over every belief he had ever had. There is, then, a feeling of being caught between the different experiences of time: present exigencies, future foundations, past beliefs. (CSM II, p. 12; AT VII, p. 17)

This secondary or second history, especially its relationship to temporality, is necessary to understand the state of mind in which Descartes finds himself "today," when he has finally sat down to engage the recognition of his accepted falsehoods. 'Today' is the setting of the rest of the Meditations. For the next six days, Descartes will devote himself to 
the serious task that he had recognized in the secondary or second history concerning the primary or first history described in the beginning of the first paragraph to the First Meditation. These histories are thereby interwoven within the present and future as it presents itself to him over the course of his meditations. (CSM II, p. 12; AT VII, p. 17)

However, there is another issue to be taken account of concerning this shift to the present, over and above the use of the first person. That is, the present is a deception, on two levels. First, Descartes wrote the Meditations between 1638 and $1640 .^{32} \mathrm{He}$ did not, then, sit down and write out these meditations over the course of a week. Rather, even if he did initially sit down and write it in a week, he also rewrote, edited, deleted, arranged, rearranged, and engaged in all the other processes necessary to preparing a text for publication. The present is a fictional deception, a deception inherent to fiction, a deception concerning what was never written at the moment of declared writing. ${ }^{33}$

\footnotetext{
${ }^{32}$ See Stephen Gaukroger, Descartes: An Intellectual Biography (Oxford: Clarendon Press, 1995), p. 336.

${ }^{33}$ Nancy identifies a similar dynamic at work in the Rules, though what Nancy takes from it would be a more 'Cartesian' understanding of the fictional moment in Descartes' writing: "I measure the instant only by the letter. The instant is not a chronological measure: it is, quite evidently, the achronic limit of such a measure.... Reciprocally, the figure-the distinct and distinctive shape in which the individuality of something or someone is singled out, noted and presented—is what is given, sole and complete, in the instant" (Jean-Luc Nancy, "Dum Scribo," tr. Ian McLeod, Oxford Literary Review 3:2 [1978], pp. 8-9). Thus, at this instance of Nancy's reading of the Rules, when Descartes writes that he writes, he draws himself together in the instant of the writing, which itself can be broken down, analyzed, into its constituent parts, which are themselves instants that, in their summation of the whole, do not constitute a duration. But here, in the Meditations, a more deliberately 'literary' if not 'metaphorical' text, it is questionable whether the achronic temporality of the supposedly Cartesian instant is applicable. That is, because the present is deceptive, and is a deception that all or most of its readers know to be such, the instant of writing is never an instant, neither for the author or writer nor for the readers. Internally to the text, of course, the instant of writing only becomes an instant, a "today," in reference to the past experience of deception. However, in that the readers know the instant of writing to itself be a deception (and this is not properly external to the text because the experience of deception brings it within the text), the instant of writing is all the less instantaneous. There is then, of course, the deception inherent to fiction that no 'today' can ever be understood as meaning today, either for the author or for the reader. In the case of the Meditations, while it brings the external experience, deceptive and otherwise, of readers into the text on deception through a deception of the present tense, the text tells its readers that it is deceiving them, as all (fictive) texts do, in its very textuality, in the delay or duration between writing and reading - regardless of translation, editing, or printing issues. Insofar as it was "the first that I am truly writing as a book," the text of the Rules at the moment of writing "While I am writing" would not seem to escape the dynamic of duration inherent to texts, a dynamic that fictional texts can highlight (ibid., p. 6). In taking Descartes at his Cartesian word in the Rules, Nancy takes the achronic status of writing at its word, as though writing's claims to always be in the present tense, for writing to be alive, as it were, were not in themselves
} 
Second, even if readers who have only been made to learn French, do not know about the years of composition involved with the Meditations, there is a clue in the letter to the faculty of the Sorbonne, where Descartes writes, "I was strongly pressed to undertake this task by several people who knew that I developed a method for resolving certain difficulties in the sciences." Although there is no direct reference to the composition of the Meditations here, a sense that the method, which has developed over time according to the above claim, could contribute to the arguments laid out here could very easily be drawn from this claim, which remains in the French translation. In addition, if any of those French readers had read the Discours, published a decade before Les Méditations, then they would have encountered a more succinct version of these meditations in Part Four. However, Descartes explains in the Fourth Set of Replies, to Antoine Arnauld, that he did not want to engage in the hyperbolic doubt of the First Meditation in the Discourse because such doubts "are not suitable to be grasped by every mind," given that the French translation maintains the letter to the faculty of the Sorbonne while excluding the more elitist claims of the preface even as the French keeps the claim about suitable minds, what kind of mind is unsuitable to grasp hyperbolic doubt is uncertain. At any rate, it is clear that at least some French readers would know that the Meditations not only was not written in six days, but also that the concepts had

potentially deceptive. Here, in the non-instantaneous instant of the present in the Meditations, the death of the text, or at least of its duration — and thereby its potential mortality — is brought to light, not to examine as if it were a dead object, but as a dynamic that operates or moves between the various players in the 'living drama' between Descartes in his past, Descartes as 'present' writer, and reader removed from the 'action' of the endurational, enduring text, text enduring beyond the death of its author(s), the majority of its readers, and beyond itself insofar as it deceptively claims to be happening at the instant(s) of its composition and/or reading, and yet not beyond itself insofar as its deceptive claims are themselves the reinauguration of the nonpresent presence of the experience of deception, self-instilled or otherwise. Indeed, what appears to be the 'subjective' and 'instantaneous' dynamic at work in at least the Meditations is what Blanchot describes of writing: "To write is to enter into the affirmation of solitude where fascination threatens. It is to yield to the risk of the absence of time, where eternal recommencement holds sway. It is to pass from the I to the He, so that what happens to me happens to no one, is anonymous because of the fact that it is my business, repeats itself in an infinite dispersal" (Maurice Blanchot, "The Essential Solitude," in The Gaze of Orpheus and Other Essays, tr. Lydia Davis, in The Station Hill Blanchot Reader, p. 414). 
been thought through at least a decade before the translation of the Meditations. (CSM II, pp.

4 and 172; AT VII, pp. 3 and 247; AT IX-A, pp. 6 and 191)

Thus, readers of the Meditations in any language of which Descartes approved should

all know that this shift to the present is a deception of a fictional type, one that involves

complicity or a treaty between author and reader, and a deliberate self-deception on the part

of each. ${ }^{34}$ Descartes knew, more than anyone, that he was not writing the text in the manner

in which the words themselves appear. He is lying, deceiving, fictionalizing to himself as

much as his readers, and his readers as well as he himself must agree to this deception,

ostensibly with the goal of eliminating deception. But it is an open question whether

deception as such can or even should ever be eliminated from the Meditations. ${ }^{35}$

\begin{abstract}
34 This self-deception would thus appear to be of a different order from the self-deception, split self, bad faith, and false consciousness that Sissela Bok identifies as "compelling metaphors" that "point to internal conflicts and self-imposed defeats that we all recognize as debilitating" (Sissela Bok, Secrets: On the Ethics of Concealment and Revelation [New York: Vintage Books, 1984], p. 64). It is different from what Bok identifies here because this self-deception is not a metaphor. Bok understands 'self-deception' to be metaphorical because she relies on the psychoanalytic concept of a self with a conscious, unconscious, and so on that hides things from itself through the mechanisms of disavowal, denial, and so on. But that is not the psychological concept at work in Descartes. The self-deception at work in the Meditations is a deception not unlike the reading of most fictions, where the reader must pretend that actions at hand are in fact happening in the time of the reading. However, there is more to this self-deception, insofar as the Meditations begins as a search for the self itself. Because of the pedagogical, fabular goal of the Meditations to achieve a new way of thinking in its readers, the self-deception at hand for Descartes is a deception which founds the very meaning of self as something to be discovered. The self must deceive itself in following Descartes that it also must find itself, that it does not know whether it itself is, and so on. The self-deception of the Meditations, then, is not a self-deception of failing "to perceive and react," but, since it is founded from out of a recognition of failing to accurately perceive, becomes a selfdeception such that the self, and its perceptions and reactions, can be discovered in their essence and truth (ibid.).

35 Taking account of a chiaroscuro quality at work in The World, Cavaillé notes that "Shading [Ombrager] is a representative act aimed at exhaustively realizing an object (of painting or of science) by making use of an appropriated (pictoral or linguistic), fundamentally conjuring [fondamentalement illusioniste] technique" (Cavaillé, Descartes: La fable du monde, p. 188; my trans.). Descartes deploys a chiaroscuro effect in The World, then, when he, as a scientific writer, "exposes within his treatise an entire body of physics through the study of the luminous phenomenon alone" (ibid., p. 189; my trans.). In other words, in the fable of The World, the very premise to treat the world through a treatise on light is a way to shade all other objects under its illumination such that bodies can appear solid thanks to the reflection and refraction of light rays against solid and liquid objects which take on their apparent shape and solidity or liquidity insofar as light moves across and through them. This technique is as illusory as the shadings of chiaroscuro give the illusion of three-dimensionality on canvas because the rhetoric of light, insofar as light is always an element of the world which it would illuminate, functions as a "synecdoche of the world" (ibid., p. 190; my trans.). Thus, this fable of the world as explaining the world and its movements through light, takes on a chiaroscuro quality through the synecdochal function of light, which can necessarily only illuminate in an illusory fashion, only giving the appearance, and a deceptive
\end{abstract}


The question remains, then, why exactly Descartes wrote the text in this way. In taking up the most serious task he could ever take up, proving the existence of god and of the soul such that even atheists and non-believers are convinced, why begin the process that will eliminate deception with a deception, let alone a deception that nearly every reader knew to be a deception, thus making themselves and himself complicit in the deception and demanding a self-deception? It certainly seems odd for the man who wrote to Princess Elizabeth, on October 6, 1645, while discussing if it is better to be cheerful or knowledgeable, "I do not approve of trying to deceive oneself in going over false imaginings. On the contrary, great joys are ordinarily somber and serious" (CED, p. 116; AT IV, pp. 305-306). At least one answer can be found in considering the title itself. Descartes had initially thought of the Meditations as a metaphysics, and, even after sending it to the publisher, titled it “Metaphysics." He had changed his mind at least by November 11, 1640, when he tells Mersenne to give it the title of “René Descartes' Meditations on First Philosophy [Renati Descartes Meditationes de prima Philosophia] because I do not confine myself to God and the soul, but deal in general with all the first things to be discovered by philosophizing" (CSM-K, p. 157; AT III, p. 235). Thus, even if he had written in the deceptive, meditational fashion as we know the text, Descartes had initially thought of it as a metaphysics, and thus as a serious, academic work to be presented to philosophers (see also CSM II, p. 112; AT VII, p. 157).

appearance, of explaining the operations of the world in their objective totality. Such is of course partly why the objective and scientific treatise at hand here must take on the quality of a fable. But, what is more, it would seem that deception itself is the chiaroscuro element at hand in the Meditations. It is the inescapable shading to the whole text, its founding element, giving the appearance of having disappeared at various moments, but never being eliminated because the very rhetorical effect of its meditative procedure depends on the operation of deception. Thereby, deception is the synecdoche of knowledge, the part that stands in for the whole of the capacity to make the distinction between the false and the true. In operating as this synecdochal part, deception would appear to in fact become the whole, or at least would be inextricably woven into the fabric of the true because, at every turn on the path to truth, deception returns, even when, after the Second Meditation, the path seems clear and distinct, because the very uncovering of that path was made possible by a series of deceptions and self-deceptions. 
By the time of publication, because he does not deal only with abstruse proofs for the existence of god and the soul, he understands the text as using a literary form less syllogistic and associated with quaestiones. However, he is willing to engage in such exercises through the Objections and Replies. In connecting this text to the tradition of spiritual exercises and religious meditation, and so beyond the limits of metaphysics, he associates the text with exercises whereby one, novices in particular, can bring themselves to divine epiphany. ${ }^{36}$ The deception and self-deception interwoven and never escaped within the text qua meditative thus follows the fable-structure or -logic that has already been associated with histoire, treatise, hypothesis, and novel. ${ }^{37}$ The history of Descartes' experience with deception and

\footnotetext{
${ }^{36}$ Bradley Rubidge finds that the Meditations cannot be linked with traditional devotional meditations because the similarities it does have to this tradition "are few and fairly superficial" (Bradley Rubidge, "Descartes's Meditations and Devotional Meditations," Journal of the History of Ideas 51:1 [1990], p. 28). For Rubidge, these similarities are found in the "orderliness" of the Meditations, in the habit of reviewing the discoveries of the previous 'night', in rejecting the senses and imagination for knowledge, and in the distinction between soul and body (ibid., p. 45). However, the order at hand is different from devotional meditations insofar as Descartes "is trying to reach conclusions that are true for everyone," "approaches the question of God's existence in a speculative way," and is also different in that rejection of the senses is not necessary for devotional meditations (ibid., p. 46). For Rubidge, then, Descartes' use of the word 'meditation' merely indicates close attention and reflection. He speculates that Descartes uses this word to reinforce the idea of a cognitive exercise and the importance of meditations in the context of the Counterreformation.
}

${ }^{37}$ Donald Phillip Verene considers narration "The natural form of the meditation" (Verene, "Philosophy, Argument, and Narration," Pbilosophy \& Rhetoric 22:2 [1989], p. 144). Narration, in turn, gives form to the context within which philosophical arguments develop. However, that context "is not itself argued" because it establishes the ground for argumentation (ibid., p. 143). Thus, the Meditations takes up a narrative form, which "sets the tone of modern philosophy" because it identifies philosophy with argument, but does so while deploying rhetorical tropes "to accomplish the basis and communication of his philosophy" (ibid., p. 144). On my assessment, Verene is correct in a broad sense as to why Descartes takes up a narrative form consistently. However, Verene does not appear to have noticed that Descartes does in fact give an argumentation for the meditative, narrative form. The logic that justifies, even if retroactively, Scholastic philosophy is insufficient for what Descartes pursues, which is why he needs to take up a meditative, narrative form in the first place. The argument for the meditative, narrative form may not be given, but the argument against the Scholastic syllogistic form is reasonably clear (hence, the importance of attending to the historicized status of the Cartesian project). In this sense, then, the narration of the Cartesian meditation does not form the context within which arguments will develop, but the context also gives rise to a demand for narration as such. What is more, because the fundamental failure of Scholasticism is the failure of foundations, such narration must take on the fabular form, structure, or logic. That is, because the formal, structural, or logical context of Scholasticism makes Cartesian philosophy impossible, the new form, structure, or logic that Descartes is attempting to found and communicate could only be understood through a distinct form, structure, or logic. Such a distinction of the fundamental forms, structures, or logics of philosophy is not precisely reducible to the relatively innocuous concept of 'narration'. The distinction must take account of the fundamental status of the content of 'the narrated', which is why 'fable', the imaginary space or place of the fable, appears a more appropriate framework within which to understand the Cartesian project as a whole. 
falsehoods, recognized but not dealt with until "today," is incorporated into the meditationfable that is written to inaugurate a reasoning and method (if not a new or novel method) to exceed deception, even while the meditation-fable is itself deceptive and requires selfdeception on the part of author and reader.

Finally, however, a question about the seriousness and sincerity of this task appears necessary. It is serious and sincere, even if it is interwoven with deception and selfdeception. For whom is it a serious and sincere task, then? Insofar as it is written for academics and the most learned, it is serious and sincere in that it is written to prove the existence of god and the soul, along with other principal points of philosophy. However, at least by the French translation, these serious and sincere academics have already proven themselves to be lacking in true seriousness and in seriousness about the truth since he excludes the letter to the reader but keeps the preface to the faculty of the Sorbonne. The seriousness of the task, then, only seems possible for those who are able to sincerely think along with Descartes in his meditative investigation of these serious matters, rather than engage in what he considers the quibbling of so many of the objectors. That is, it is only possible given the proper inauguration of motion in the mind of the potential, the potentia, the puissance of those with good sense, the good sense to think in the same way as Descartes. ${ }^{38}$ And yet, this serious and sincere task is only inaugurated through a deception

\footnotetext{
${ }^{38}$ In his analysis of the twelve appearances of 'natural light' in the Meditations, Stephen H, Daniel indicates that one's own nature is deployed as a "basis for relating my natural light to concerns which are pointed to, though not directly included within, the compass of that light" (Stephen H. Daniel, "Descartes' Treatment of 'lumen naturale,", Studia Leibnitiana 10:1 [1978], p. 93). Natural light in this sense becomes a vector where different concepts of nature meet the concept of the self such that it "serves as the expression of the essential tendency of the self to understand itself in terms of the source of its power and the reasons for the limitations of that power in itself," limitations which are determined "by determining the structure of the laws of nature" (ibid., pp. 96 and 99). However, there would seem to be an additional complexity to this vectoral status of the natural light, if it can be associated with the potential good sense to which Descartes appeals throughout his corpus. This additional complexity, which would transform the vector of natural light into something more like a node or a knot, rests on the necessity for this good sense, this natural light, to be set into a proper motion, whether by oneself or by the Cartesian fabulator. That is, the limitations of the natural light would not be determined solely by determining the structure of the laws of nature, though it does depend on that determination. In
} 
and self-deception on the part of the reader by an author who must deceive himself into

thinking in the present beyond the precise presence of the thoughts that are articulated. ${ }^{39}$

What is more, this deception leads Descartes to the method understood precisely as doubt, a

doubt that appears sincere, but which remains interwoven with the deception that

inaugurates the meditations proper. And it is doubtful whether doubt can ever be sincere,

even if it is serious, as Descartes himself intimates when he expresses his concern about and

distinction from skepticism and academic quibbling in, for instance, the Second Set of

Replies, mostly to Mersenne. The question of whether and how this doubt can ever exceed

addition, the mind whose natural light is being set into motion must itself be already 'known' qua limited in the same way that the imaginary space of The World is already understood as finite to some extent. This good sense, based in the experience of having been wrong, must turn in on itself as something limited in order to find itself in the state of requiring being set into motion. The natural light's potential would otherwise remain only potential, and thereby could easily think of itself as infinite since it would not have reflected on the fact of its limitations. That Scholasticism's attempts to reflect on this have resulted in uninterpretable explanations of error is only an indication of the need to reflect more carefully on the limitations of the mind, a reflection that happens ahead of the determination of the laws of nature, as the very order of the Meditations indicates, even if this reflection only needs to happen once.

${ }^{39}$ Because of the necessity of self-deception for the seriousness and sincerity of the meditative task, it is difficult to adhere to Merleau-Ponty's claim that Descartes is involved in a "bypothesis of the Nichtgkeit of the world" (Merleau-Ponty, The Visible and the Invisible, p. 172). Descartes does not intend to negate the world or to make it null, but to deceive himself, and to have his readers deceive themselves, such that the deceptions from the world are taken up qua deceptive, rather than through naïve or Scholastic ingenuousness such that the world's deceptions are passively believed. Merleau-Ponty goes so far as to say that "Every negation of the world, but also every neutrality with regard to the existence of the world, has as its immediate consequence that one misses the transcendental" (ibid.). However, it certainly seems a stretch to consider the Meditations neutral as to the world's existence if only for the fact that the terror over that possibility is the source of the drama of the First Meditation and the beginning of the Second. In the deceptions and self-deceptions that are interwoven into every element of the Meditations, the world as such is neither negated nor ignored, but recognized as that which can deceive. If it is that which can deceive, then the self-deceptions that inaugurate so many of the moments of the Meditations, especially early moments, is a repetition of the world, something imagined. To be sure, the exteriority of the world, what about it that escapes the 'bracketing' of the Cartesian fabulation, is not brought into the fabular world. However, this exteriority's remaining exterior is an indication of neither a negation nor a neutrality on the part of the Cartesian world, especially in consideration of the Sixth Meditation's demands for habituation to account for the deceptions that the world presents to the meditator. What is exterior about the world as such could very well remain exterior, as unignorable and generative of deceptions, which is why one must habituate oneself to trust the world even while engaging it as deceptive. Self-deception is a bringing of the exterority of the world into meditation, but, because it remains deception, it will always also remain exterior to the meditation, even while it is interwoven and incorporated into the meditative method. The world deceives and, to account for this, the deceptiveness of the world must be repeated by oneself to oneself, to make oneself the world and to repeat the world's exterior 'worldliness' within oneself. Such a process does not negate the world's exteriority any more than it ignores that exteriority. It is founded on that exteriority, maintains its distance from that exteriority while simultaneously repeating it within itself. 
the realm of unseriousness, especially since it is persistently interwoven with deception and self-deception, thus requires looking into his discussions of it with those possibly unserious objectors. (CSM II, p. 94; AT VII, p. 130)

Hyperbole and Seriousness

Despite the fact that Descartes decided he did not want his meditations to be considered a metaphysics in the strict academic sense, based on his interchangeable use of 'metaphysical' and 'hyperbolic' to describe the doubt that is the operation of the method, he clearly considers the Meditations to be consistently engaged in metaphysical operations even when they are not considering the metaphysical concepts of god and the soul. ${ }^{40}$ The connection between hyperbole and metaphysics can be most clearly seen in the impracticality of the doubt that Descartes considers both hyperbolic and metaphysical. Its impracticality is not, just because impractical, an argument against the doubt. Rather, Descartes wants to divide hyperbolic doubt into foolish and appropriate. Foolish hyperbolic doubt occurs, according to the Fifth Set of Replies, to Gassendi, "when it is a question of organizing [regenda] our life." That is, just as the mark of academic, metaphysical questions and syllogisms can be found in the impracticality, the uselessness of the endeavors, to engage in hyperbolic doubt in the attempt to organize, regulate, or rule over life on the pragmatic or practical level is foolish, a joke. Indeed, anyone who did such a thing, who attempted to organize his or her life grounded in hyperbolic doubt would "deserve to be laughed at." So, on the practical level, hyperbolic doubt is a joke, is comic, foolish, and unserious. However, that selfsame

\footnotetext{
40 "But I said this at this point because I was dealing merely with the kind of extreme doubt which, as I frequently stressed, is metaphysical [metaphysicam] and exaggerated [byperbolicam] and in no way to be transferred to practical life" (CSM II, p. 308; AT VII, p. 460).
} 
laughability, comedy, and unseriousness is "crucial" for philosophy, according to the Fourth Set of Replies. It is crucial for those whose minds are properly attuned or accustomed to understand the seriousness interwoven with the unseriousness of the hyperbolic quality of the doubt. If and when unsuitable minds — careless people, children, and the like-take up hyperbolic doubt, they make it a foolish joke because they do not understand how to use it, how to make it useful, just as a knife will be misused by a child despite its utility (utilis). But the unseriousness of hyperbolic doubt does not demand that it remain foolish if and when a serious mind takes it up. A serious mind can understand and laugh at the joke with appropriate seriousness because it understands the necessity and seriousness of exaggeration when in search of "what can be known," according to the Fifth Set of Replies, "with complete certainty." (CSM II, pp. 243 and 172; AT VII, pp. 351 and 247; my emph.)

On this note of exaggeration, I would make the argument that the hyperbolic quality of the doubt in fact exceeds its metaphysical quality. Insofar as 'hyper-bole' indicates 'throwing beyond' or 'thrown beyond', the doubt that is hyperbolic would seem to exceed what is merely metaphysical because 'meta-physics' concerns merely what is before, behind, or beyond the physical, while hyperbole, as hyper-bolic, throws the content of its doubt beyond itself, beyond all practicality, and beyond what is beyond the physical. ${ }^{41}$ Hyperbolic doubt, then, is beyond metaphysics precisely in its 'hyperbolicity', in the fact that it throws the content of the doubt beyond and in that it itself is thrown beyond even the limits of

\footnotetext{
${ }^{41}$ Marion considers the tradition that claims metaphysics as surpassing physics, through the link that 'meta-' indicates a beyond, to be "disputable" (Marion, On Descartes' Metaphysical Prism, p. 22). Tracing the history of this tradition from Aristotle to Fonseca to Suàrez, he acknowledges that Descartes acknowledges this tradition, however, and thus must acknowledge that the question of metaphysics in Descartes will always be whether it transgresses all other sciences such that physics and even "prote philosophia could . . . be abolished in a metaphysica that encompasses or replaces it" (ibid., p. 23).
} 
metaphysics. ${ }^{42}$ This hyperbolicity is what allows the Meditations not to be merely a

metaphysics, but to exceed or throw itself beyond metaphysical concerns of god and the soul into all the first principles of philosophy, into being meditations on first philosophy.

However, especially in arguing with academically trained philosophers and other learned objectors, Descartes does not seem to acknowledge the distinction between hyperbolic and metaphysical doubt (see, for instance, ibid., p. 308; p. 460), so I will follow his nondistinction here, until looking more explicitly at method and its relationship to substance, though I do insist on consistently using 'hyperbolic' to describe the doubt rather than 'metaphysical'.

So the exaggeration at hand in hyperbolic doubt is an attempt to come to know what can be known with complete certainty, and this requires a doubt that matches the completeness of the attempted knowledge. In the hands of the foolish, such doubts deserve to be laughed at because such people would only engage such doubt on the level of practical utility. However, "The philosopher knows that it is often useful [utiliter] to assume falsehoods instead of truths in this way in order to shed light on the truth.” Philosophical utility is of a different order than practical utility, then. ${ }^{43}$ What makes the philosopher able to

42 As D. Graham Burnett points out, the rhetorical use of byperbole predates and is borrowed by the mathematical use (see D. Graham Burnett, Descartes and the Hyperbolic Quest: Lens Making Machines and Their Significance in the Seventeenth Century [Philadelphia: American Philosophical Society, 2005], p. 129n. 11). Burnett's focus, however, is on the ability of a hyperboloid lens to bring light into focus so that the eye could see clear and distinct images. The possible analogy to hyperbolic doubt thereby hinges on the doubt as "another hyperbolic focusing device" (ibid., p. 129). However, another analogy internal to the Cartesian use of byperbole could focus not so much on the conic aspect of hyperboloid lenses, but on the two-dimensional geometric aspect of the hyperbola as a line, an arc. On such an analogy, the double movement of the hyperbola's curves, infinitely distancing themselves from their vertices, could open up an understanding of the hyperbolic doubt as initiating a double movement—on the reader's as well as Descartes' parts — whereby the arcs move away from each other, individually so, but along mathematically parallel paths. It is this analogy that is the focus of my discussion of hyperbolicity, that structure of infinite, open curvature away from a given point or set of points and that finds its 'parallel' in another arc.

${ }^{43}$ Because of this difference in order, Marion claims that "the initial hypothesis of the Meditationes appears to be not only hyperbolic, but also incoherent” (Marion, On Descartes' Metaphysical Prism, p. 215). It is incoherent for Marion because it operates "by confusing two contradictory characteristics," that of an omnipotent authority 
understand the seriousness of the unserious or exaggerative quality of the hyperbole of Cartesian doubt is that philosophical utility is involved in the search for a certainty beyond that of practical utility. Ultimately, this philosophical utility will of course help shore up the practical utility with which Descartes is concerned to help those with good sense apply, but the completeness of the certainty born of the complete doubt that would give rise to a certainty of practical utility is precisely what careless people do not understand about hyperbolic doubt, thereby making the doubt deserving of laughter. That completeness of doubt and certainty, beyond the practical, in its very apparent unseriousness, is however what makes the doubt serious. (CSM II, p. 242; AT VII, p. 349)

It is also the completeness, the exaggerative and apparently unserious quality of the doubt, beyond any practical usefulness, that throws the hyperbole of it beyond rhetoric for Descartes (see DCB pp. 30-31; AT V, p. 165). For him, Gassendi fails to understand this thrown-beyond-rhetoric quality of the hyperbole when he asks Descartes, in the Fifth Set of Objections, why he insists on the "apparatus [apparatu]" of hyperbole, especially that of the evil genius. For Gassendi, a brief note to the reader explaining that the doubts are doubted in order to be resolved would be helpful, if only so that his Latin readers would not think he is fully serious in these doubts. For Descartes, to object to hyperbole in this fashion is to "employ rhetorical tricks instead of reasoning." Instead, Gassendi should be focused on the

which annihilates mathematics and logic and that of the same authority being identified as god (ibid.). These characteristics are contradictory because they result in the paradoxes of the evil genius or of the god "who created the conditions of my self-deception" (ibid.). Marion appears here not to take the unseriousness of hyperbolicity seriously enough. If the order of the philosophical or the order of reason allows us to imagine what is exaggerated, false, impossible, contradictory, or incoherent, then the attempt to demand an adherence to a logic that has not yet established itself within the philosophical order is not a serious demand. Indeed, much of the point of hyperbolic doubt is to establish what will allow for logic to establish itself through establishing a self that can establish itself even in the face of an unestablished logic. The self, after all, survives even the mad logic of the evil genius. In other words, Marion here appears to be playing a similar role as Gassendi, of assuming that the order of philosophical utility, whereby even logic can be jettisoned, requires references back to the 'sane' world of practical order such that a 'serious' reader will not be alarmed by the exaggerated, unserious 'disutility' of the hyperbole. 
preparatory quality of the apparatus of hyperbole, a preparation for serious minds to think

about what is beyond practical utility such that both practical and philosophical utility will be given the complete certainty for which philosophical certainty searches. It may be that, for

\section{Descartes, as he explains in a letter to Mersenne, "there is nothing in Mr Gassendi's}

objections with which I have problems; the only thing I shall have to attend to is the style

[eloquution]." ${ }^{44}$ However, it is clear that the question of style is not merely a question of style,

of eloquence, of rhetorical technique. ${ }^{45}$ The seriousness of the doubt, in its very exaggerative

\footnotetext{
${ }^{44}$ René Descartes, "Descartes to Marin Mersenne, [Endegeest castle] 27 May 1641,” tr. Erik-Jan Bos, Charles Roberts Autograph Collection, Haverford College, Haverford, PA, http://www.phil.uu.nl/ bos/transcript .shtml, accessed August 2, 2012. There is a similar, though inverted tension in Husserl in response to the style of philosophy that preceded and surrounded him. At the end of the Fourth Cartesian Meditation, he explains that his style of philosophy, as transcendental-phenomenological, is shown as a "necessary style [Stil" because it is the only possible style for the "sense-interpretation" of "the universe of what exists for us actually or possibly" since the transcendental-phenomenological style understands the importance of "a genuine intentional psychology" and avoids the psychologism of thinking that transcendental philosophy ever leaves the "natural realm" (Husserl, Cartesian Meditations, pp. 87 and 86; Cartesianische Meditationen: Eine Einleitung in die Phänomenologie und Pariser Vorträge, in Husserliana, vol. 1, ed. Stephan Strasser [The Hague: Martinus Nijhoff, 1963], p. 119). However, in the Introduction, Husserl also proposes that "The splintering of present-day philosophy" resembles the state of philosophy in Descartes' time, which suggests that the early twentieth century is an appropriate moment to repeat the radical Cartesian gesture against the contemporaneous state of philosophy "with its medley of great traditions, of comparatively serious new beginnings, of stylish [modischem] literary activity (which counts on 'making an effect' but not on being studied)" (ibid., p. 5; p. 47). Even if the difference between Stil and modisch indicates a distinction between the form of approaching a philosophical method as opposed to a trendy appeal to rhetorical techniques over content, a more appropriate distinction to be noticed in this context is in fact the distinction between philosophy and literature. Husserl's critique of that literary style of philosophy is that it generates effects, while the transcendental-phenomenological style produces fundamental insights into the natural world as it exists for us because its intentional psychological perspective allows it to do so. What is at stake in the debate between Descartes and Gassendi, however, is that the style that Gassendi implores Descartes to use is one that would announce something of the intentionality of the intentional psychology that Descartes is establishing. Descartes' response, that doing so is in fact more of an appeal to rhetoric than Descartes himself is making in the hyperbole, shows that his concern with style is on the side of literary activity that makes effects. Indeed, its focus on making effects is precisely why Cartesian philosophy should be studied. Husserl's recognition of the radicality of the "Cartesian overthrow [Umstury]" actually comes too late in the Cartesian text (ibid.). What makes the hyperbole hyperbolic, what allows the Umstury to make its effects, is not precisely, for Descartes, the intentional psychology involved in the hyperbolic structure of the doubt, but the deceptively quality of that intentional psychology that the hyperbole is. That is, the intentional psychology of the hyperbolic doubt makes its effects possible thanks to precisely not announcing itself as intentional, thanks to not explaining to the readers that the doubt is merely hyperbolic for the sake of demonstrating truth all the more clearly. Such a deceptive intentional psychology, in the very fact that an aspect of its intentionality is deception, is a literary style, trendy though it might be.

45 In this way, it Descartes' understanding and deployment of rhetorical and stylistic techniques goes beyond Marjorie Grene's claim when she says “one uses one's reader's language when one can. Descartes is neither a liar nor a hypocrite, but a superb philosophical rhetorician” (Marjorie Grene, Descartes among the Scholastics [Milwaukee, WI: Marquette University Press, 1991], pp. 6-7). It is true that Descartes is a superb philosophical rhetorician in the sense that he periodically tries to adopt the language of Scholasticism in order to make
} 
and unserious fashion, throws it beyond 'mere' rhetorical gamesmanship and into the realm of completeness — complete certainty, complete doubt — that is the hallmark of metaphysics, a hallmark precisely because not practical, since the practical is always at the mercy of the deceptions of things of the world as they are given to the senses. (CSM II, pp. 180 and 243; AT VII, pp. 259 and 350)

The apparatus of hyperbole serves the purpose, beyond rhetorical technique, of preparing the mind of the serious reader for a doubt interwoven with the unseriousness of exaggeration such that these minds can be engaged in the most serious task of complete certainty. This preparation shows that there is a fable-structure or -logic to the very hyperbole of hyperbolic Cartesian doubt in the sense that Descartes intends to inaugurate a new kind of motion on the part of these learned and serious minds, a motion of unlearning what they have already learned such that they can instruct themselves. That this motion toward complete doubt that will lead to complete certainty despite the deceptions of things of the world is inaugurated by a move to deceive the reader or at least to demand that the reader deceive him- or herself shows that deception and self-deception are necessarily interwoven with the hyperbole of the doubt such that deception can never be clearly and distinctly eradicated from the certainty that purports to be complete. Interweaving doubt into certainty in this way leads to questions of a possible supplementarity inherent to the completeness and seriousness of the method. That the translation of the Meditations into French, along with some of its strategic changes, makes doubtful who exactly is to be considered serious and for what reasons, a question is raised concerning the precise line of demarcation between unserious and serious hyperbolic doubt, which would at first

himself better understood by those critics — the Objections and Replies and the Principles are prime examples of this effort. However, at this point on the question of rhetoric and philosophy, Descartes is making a claim for his rhetoric not as a mere 'rhetoric of philosophy', as not a rhetoric as a mere addendum to his philosophy, but as in itself crucial for the philosophical concepts, for the philosophizing itself. 
appearance seem to be drawn on traditional education and its concomitant customs and habits, as is a question of the difference between philosophical and practical utility, which would seem to be drawn on the potential for understanding the importance of certainty beyond what is necessary for average everyday experience and use. These issues are best addressed, however, by turning away from the question of hyperbole itself and turning back to the Meditations, specifically to the evil genius.

Excursus: The Evil Genius and the Self

Descartes begins the Second Meditation by reminding himself of the great or "serious [tantas]" doubts "into which I have been thrown [conjectus sum]" the day before. His doubts are so hyperbolic that they throw him into doubt of even their resolution. He can only conjecture, can only be a conjector, an interpreter of dreams, if he is to recover the stability of the 'real' world beyond this hyperbolic world. ${ }^{46}$ If he is to recover the physical world, his hyperbolic doubt that has made it all seem or appear as if a dream must be satisfied through the conjecture of nothing less than the imaginary evil genius. This hyperbolic doubt that inaugurates the inability to distinguish reality from dreamworld requires a hyperbolic and imaginative figure to satisfy itself. ${ }^{47}$ Thus, the arc of a hyperbole is met with another

${ }^{46}$ Lewis and Short, s.vv. "conjector," accessed April 25, 2013, http://www.perseus.tufts.edu/hopper/text?doc $=$ Perseus $\% 3$ Atext $\% 3$ A $1999.04 .0059 \% 3$ Aentry $\% 3$ Dconjector.

47 As mentioned above, Zarka's assessment is that the evil genius is the Cartesian moment closest to the Hobbesian annibilatio mundi in that both bring us to first truths or principles, though they are not parallel. The two differences between these moments for Zarka is that Hobbes's annihilatory fiction is posed as a fiction from the beginning, while the evil genius requires god to establish its fictionality, and that the cogito is not a first principle of philosophy for Hobbes. That is, the Hobbesian fiction establishes the principles of space and time from out of a presupposed subject, but a subject that is not a first truth because it itself is inferred from the world or as subject to the forces of the world, insofar as it represents the forces of the world, which themselves are established as first truths thanks to the annihilatory fiction (see Zarka, La Décision Métaphysique de Hobbes, pp. 39-44). It is clearly true that the subject is not a first principle for Hobbes in the same way that it is for Descartes, and that this is so because the subject is inferred from out of the forces of the world, which are 
hyperbole, another throw beyond all reasonable, practical doubt such that the initially

impractical, unreasonable doubt may be satisfied and some substance established. ${ }^{48}$ (CSM II,

p. 16; AT VII, p. 23; my emph.)

Substance, that which, according to the Fourth Set of Replies, "can exist by itself, that is without the aid of any other substance," is of course what is proven by the end of the third paragraph of the Second Meditation in that even the hyperbolic image of the evil

genius cannot take away the thinking of the thinking thing insofar as thinking is equatable

with the selfsame hyperbolic doubt which itself doubted substance as such to begin with. In

something like a tautological relationship or a virtuous circle of Archimedean foundations,

the substance that doubts, doubts substance itself and thereby proves itself as substance.

And yet the doubt, in order to find itself resting upon itself qua solid foundation, needs to

themselves first principles. However, I am not convinced that the fictionality of either the evil genius in particular or the Meditations in general is established only at the proof of god. The fictionality of the Meditations is established from the beginning, even from before the beginning, in that any reader would know that the meditations are not sheer representations of six nights of thinking, but that they took years to compose. The first-person account is in itself a fiction, and a fiction that everyone knows, and this is the source of much of its power as a philosophical, metaphysical text. It establishes its first principles or first truths by way of its fictionality As a consequence of this fictionality, the principality of the subject, at least the subject as it is frequently taken — the subject as a thing with certain faculties always already at work — can be called into question. This question and consequence will be pursued in chapter 4, below, but for the moment let it be said that the fictionality of the Meditations is clear from the beginning, as it is clear from the beginning of numerous Cartesian texts. Indeed, the hyperbolic doubt is dependent on being taken as a fiction if it is to be properly hyperbolic, a properly metaphysical thought process or thought experiment that will allow for certain truths to emerge, one of which is the subject, but not necessarily the subject as it has been taken. The hyperbolicity of the hyperbolic doubt, in turn, demands reaching the telos of such doubt as found in the evil genius, where space, time, and mathematical truths can all be taken as dubitable. Without such a level of doubt, the Cartesian fiction qua hyperbolic, qua metaphysical, would not be a hyperbole worthy of the name.

${ }^{48}$ For Cottingham, there is no special metaphysical role for the evil genius. It rather reinforces the dreamworld thesis, the evidence for which he finds in the fact that, when Descartes introduces the evil genius, "he specifically refers back to the dreaming argument" (J. G. Cottingham, "The Role of the Malignant Demon," Studiana Leibnitiana 8:2 [1976], p. 264). However, he does not seem to consider that the reference to the dreamworld might indicate not merely a reinforcement of that world, but also an intensification of what is shown to be at stake in the dreamworld. Most of Cottingham's argument in this vein centers on the question whether the evil genius is "designed to pose a new and distinct epistemological threat" (ibid., p. 261). But if the evil genius is an intensification, a repetitive and reinforcing intensification to be sure, then it is not so much an epistemological figure as it is a metaphysical one, an unimaginable figure who is figured thanks to the hyperbolicity of the doubt which had begun in the possibility of the dreamworld. It would seem, then, that Cottingham's claim that there is no special metaphysical role for the evil genius is centered more on a confusion of the epistemological with the metaphysical. The evil genius may not be a unique epistemological threat, but it is a serious metaphysical question, not to say possibility, if only because it is a question figured from out of the hyperbolic, metaphysical doubt that inaugurates the Meditations. 
doubt itself as foundational, needs to conjecture the evil genius as the final guarantor against dreamworld. The doubt, then, qua hyperbolic, the hyperbolicity of the doubt demands that the doubt throw itself beyond itself qua substance in order to find itself resting upon itself in the selfsame action of its self. The adjective does more than describe or supplement the noun here-it demonstrates the excessiveness that is the internal structure of the method such that substance itself can be given ground. It is not precisely that the method qua doubt grounds the substantiality of substance and thereby opens Descartes onto the conflation of extension with being. ${ }^{49}$ Rather, the hyperbolicity of the doubt qua method necessarily supplements or substantiates itself such that substance as that which needs nothing else can

\footnotetext{
49 That Descartes conflates extension with being is Heidegger's critique. For him, the Cartesian concept of extension "makes up the real Being of that corporeal substance which we call the "world" because Descartes does not engage the question of the substantiality of substance since "substance as such — that is to say, its substantiality-is in and for itself inaccessible from the outset" (Heidegger, Being and Time, pp. 123 and 126). In ignoring the question of substantiality, the Cartesian Interpretation, the theoretical application of the phenomena of entities of the world, creates a situation where "The only genuine access to them [i.e., to entities of the world] lies in knowing, intellectio, in the sense of the kind of knowledge we get in mathematics and physics" such that being is reduced to "constant presence at hand, which mathematical knowledge is exceptionally well suited to grasp" (ibid., pp. 128 and 129). Further, because "Descartes knows very well that entities do not proximally show themselves in their real Being," he cannot "let what shows itself in sensation present itself in its own kind of Being" when he reduces substantiality to extension (ibid., pp. 129 and 130). To extend this critique to method, the intellectual knowledge of the self that would be the moment of the cogito is the result of a method of knowing entities through an intellectual or a mathematical methodology. But since the substantiality of substance, whether of the substance of the self or of the substance of any other entity, has not been adequately considered, Descartes' method cannot "[uncover] the meaning of Being” (ibid., p. 62). But it may be questionable whether method precedes substance and/or substantiality for Descartes, at least in the Meditations. The tautological or Archimedean foundation of the self as the point from which he will be able to move the world is that the activity that would call the world, including methods of engaging it, into question is both the method through which the world will be engaged and simultaneously the self that uses this very same method. The substance for Descartes is the method, but the method is always in need of a substantiation provided by that selfsame method. The substance of the self makes itself through a method that cannot be differentiated from the self itself. Thus, at least in the case of the substance of the self, that this entity does not show itself in its real being, that it is always in need of supplementation and a supplementation that it provides through itself, is in fact its real being, and this being is thereby uncovered in a method that operates as self-supplementing. If this method develops as a reduction of the phenomena of entities to simple mathematico-extensive attributes insofar as it is a theoretical Interpretation of the phenomena of entities of the world, this may be more a result of Descartes' not recognizing the complexity of his seemingly simple methodology than it is a result of some lack of substantiation of substance or substantiality on his part. This question will be pursued in more detail in chapter 3 below.
} 
be uncovered in that same method-doubt-cognition-substance..$^{50}$ (CSM II, p. 159; AT VII, p.

Despite the preparatory self-pedagogical work of deception's utility, the rigor demanded in the self-deception of exaggerated, hyperbolic doubt overwhelms Descartes. The fear or the worry that he cannot maintain the rigor leads to another self-deception. In the final paragraphs of the First Meditation, after he has reiterated the standing rule of doubt that he must maintain "if I want to discover any certainty," Descartes worries about his

\footnotetext{
${ }^{50}$ The definition of substance at hand here is consistent with what Marion identifies as the first definition of substance in article 51 of the Principles. As Marion points out, however, article 52 introduces a second definition of substance, "as the substrate known by its attribute(s)" (Jean-Luc Marion, "Substance and Subsistence: Suàrez and the Treatise on Substantia in the Principles of Philosophy 1, \$51-\$54," in On the Ego and on God, p. 89). Marion defends this second definition because, without it, all substance would be radically distinct from every other substance, and thereby unknowable since, following the statement on method in Rule Six, some things are only known in relation to others. Marion's point here is thus that some substances are known by themselves alone, without supplement, while others are known via supplements, in relation to other substances, which themselves may be known either by themselves alone or in relation to other substances. With the understanding of the self at hand here, however, neither of these definitions would precisely apply because the doubt, the doubting substance, supplements itself. This is not to say that the doubting substance stands alone, but that doubt itself stands in need of supplement-if only because something, some substance must be doubted - and that the hyperbolicity of the doubt, as hyperbolic, is excessive, beyond what is necessary (practically or otherwise) to supplement that which requires supplementation. That this doubt is what will establish the self, necessarily through the most hyperbolic moment of the evil genius, through another possible substance that itself is the result of a self-deception, establishes the substance of the self as in relation to itself, in relation to itself as another, and in relation to another that is only in relation to the self that made it come to be as a fiction but a fiction for and of the self. Thus, the self in the Meditations must be understood as falling under both definitions of substance simultaneously.

Marion uses his defense of Descartes' two definitions of substance to critique the Heideggerean critique of this point in Descartes. For Heidegger, Descartes needs two definitions of substance because the meaning of being is "something incapable of clarification," leaving substance defined through substantial entities, such that "something ontical is made to underlie the ontological" and substantia can mean something ontical or something ontological (Heidegger, Being and Time, p. 127). For Marion, if the two definitions of substance refer to kinds of substance that can be known on their own (like the self) or kinds of substance that can only be known in reference to other things (like most external objects), this means that Descartes recognizes that "only substance," and only according to the first definition of substance at that, as opposed to "substance in general," affects us (Marion, "Substance and Subsistence," p. 94). More, in that Descartes' second definition emerges from recognizing a problem with his first definition being the exclusive definition of substance and in that this recognition does not result in denying that access to substance in general indicates that Descartes does not in fact think of being as incapable of clarification. But perhaps Marion's critique of Heidegger can be pushed further. That is, if the self is, as one of the substances that can be known through themselves, is always also known through something else insofar as the structure of hyperbolic doubt operates as something else such that the self's falling under the first definition of substance is also a falling under the second definition because it is known through itself and known through its relation to itself, then it begins to appear as if the affect that a substance known through itself (i.e., the self) has on us can give us an indication of an affect of substance in general insofar as that substance known through itself is also known through the selfsubstantiating relationality to itself that is the hyperbolicity of the doubt qua method.
} 
ability to maintain this rigor since "My habitual [consuetae] opinions keep coming back

[recurrunt]." Hence, the importance of establishing a new habit or custom through the useful showing of self-deception's use established in the first paragraph with the fiction that

Descartes is sitting in a room, writing his meditations as the thoughts come to him. Hence, the importance of the continued present tense, the continual showing and making seen, in the moment of declaring the return of bad habits for maintaining and sustaining the deception necessary to find the truth. Thus, what Descartes will do, since "I shall never get out of the habit [desuescam] of confidently assenting to these opinions," is "turn my will in completely the opposite direction [versa] and deceive myself [me ipsum fallam]." ${ }^{51}$ The result of this self-deception, this artifice or stratagem of the self by the self is to "suppose [Supposonam] therefore that not God [non optimum Deum], who is supremely good and the source of truth, but rather some malicious demon of the utmost power [potentem] and cunning has employed all his energies to deceive me [me falleret]. ${ }^{, 52}$ Of course, neither god

\footnotetext{
${ }^{51}$ It is moments like this that will lead me to conclude that Brann, along with most, including Descartes himself at points, cannot be entirely right that Descartes "excludes the imagination from the human essence" (Eva T. H. Brann, The World of the Imagination: Sum and Substance [Lanham, MD: Rowman \& Littlefield Publishers, Inc., 1991], p. 70). This is not to say that the imagination in Descartes is not something distinct from what it was in ancient and medieval philosophy, but rather that the way the imagination changes is not what the tradition has told us it is. At the heart of this change will be a way of addressing whether the claim that the self "can know itself by itself, without the mediation of the imagination" is a fully correct one, and the question of its full correctness will rest on the question of whether the self can know itself without the imagination at all or if it can know itself without the imagination as a mediator between itself and its knowledge (ibid., p. 72). To make sense of this final question, how knowledge comes about for Descartes, or what his method in fact is, must be addressed before addressing whether the imagination is a mediator or something else entirely.
}

${ }^{52}$ Marion attempts to find otherness inscribed into the assertion of the knowledge of the self's existence as well. However, Marion does not precisely find it in the self-deception involved in supposing the evil genius, but in the otherness that is the being of god on which the self ultimately depends. He does this by showing that (1) the other, god and/or the evil genius, is supposed or hypothesized before the self; (2) the self that is proven as existing and the self that is persuaded of its existence serve different illocutionary functions; (3) there is thus a difference between the First and Second Meditations in that the First Meditation involves an implicit dialogue between the self that must be persuaded of its existence, while the Second involves an implicit dialogue between the self and the evil genius whose existence precedes but does not prevent the existence of the self; and (4) the confirmation of the self involves a speech-act concerning the self that results in a self that is always outside itself (see Jean-Luc Marion, “The Originary Otherness of the Ego: A Rereading of Descartes' Second Meditation," in On the Ego and on God, pp. 13-19). I am in full agreement with Marion on the last three points, but I question an element of the argument involved in the first point. For him, that the evil genius is supposed before the self is evidence of "the interlocution whereby an other than itself establishes [the ego] prior to every 
himself nor god as supremely good and the source of truth has been shown yet, and so must remain a residue of the habitual thoughts he is trying to eradicate but cannot, at least until he has established the self that deceives itself in strategically supposing the evil genius at this moment of faltering rigor and recurring bad habits. Thus, the self is shown and proven in deceiving itself as having substance through the doubt that doubts substance. (CSM II, p. 15; AT VII, p. 22)

Again, the self-deception that creates the evil genius allows for the self to be established. This self-deception has precedent in the opening paragraph of the work proper, when the author deceives people who know that he is doing so, thereby setting the tone of deception as the mode of rehabituating, reeducating bad habits that have deceived in the past. ${ }^{53}$ And it is the self-deception as a self-deception that will fully establish and secure, in

self-positing. This other is exercised first under the mask of an omnipotent God, at one time confused (against all coherence) with the evil genius who deceives, and, in any case, maintained in anonymity with a nescio quis" (ibid., p. 26). The evil genius is never confused with god, even if it may have all the power that god has. This non-confusion would be at least in part because the evil genius would be a deceiver, but it is also in part because the existence of the evil genius could just as easily imply the non-existence of god because god would be an idea the self thinks it has but about which it is deceived. Indeed, it is for this reason that the disproving of the existence of the evil genius must come before the proof of the existence of god. Without the separation of the evil genius and god, the hyperbolic proof of the existence of the self despite the deceptions of the evil genius could return in the proof of the existence of god insofar as the only reason the self could have to believe the proof of the existence of god would be the self's insistence on the non-deceptiveness of god. The mere fact that the evil genius and god could have all the same power is not enough to claim them as confused or conflated. The deceptiveness of the evil genius must be eradicated, and it is done through the understanding that the self deceives itself in supposing the evil genius, thereby undermining the potential power of the evil genius as compared to god. That is, the self must show itself to itself as potentially more deceptive than the evil genius in that the self deceives itself by supposing an interlocutor beside itself. That this proof of the existence of the self against the potential deceptions of the evil genius emerges because it overpowers the deceptiveness of the evil genius becomes the model for the proof of everything else, including god since the proof of god must be believed despite any attempts to deceive oneself into believing there not to be a god, is further evidence for the claim that the evil genius is never confused with god and that the originary otherness of the ego is not found by an 'incorporation' of god into the self, but by an othering of the self such that the self demonstrates itself in the kind of ecstatic auto-affection that Marion shows in the last three points of his argument.

${ }^{53}$ Here, then, the problems with both Foucault's and Derrida's readings of the Meditations come to light. Foucault first, if only because the flaw in his reading is related to the critique Derrida gives of it. In the preface to the 1961 edition of the book, titled Folie et déraison at the time, Foucault famously defines madness "in its most general but most concrete form" as "the absence of an oewvre" (Michel Foucault, History of Madness, ed. Jean Khalfa, tr. Jonathon Murphy and Jean Khalfa [New York: Routledge, 2009], p. xxxi). Marking his work as distinct from a history of knowledge or psychiatry, he explains that he will study the structures that hold 
madness captive such that, "in the absence of that inaccessible primitive purity" of madness, "the obscure common root, the originary confrontation" that unites madness and sanity can be found (Foucault, History of Madness, p. xxxiii). It is this goal, of letting madness speak for, by, and/or through itself, that brings Derrida's critique to the fore, because "To say madness without expelling it into objectivity is to let it say itself. But madness is what by essence cannot be said: it is the 'absence of the work,' as Foucault profoundly says," thereby leaving Foucault's history or archeology in the realm of "a logic, that is, an organized language, a project, an order, a sentence, a syntax, a work" (Jacques Derrida, "Cogito and the History of Madness," in Writing and Difference, tr. Alan Bass [Chicago: The University of Chicago Press, 1978], pp. 43 and 35). And so the debate begins.

In the midst of one of his replies to Derrida, Foucault focuses on criticizing Derrida's conception of the meditation at hand in the Meditations. Specifically, he distinguishes meditations from " "rhetorical' or 'pedagogical' fiction" as well as deduction because, in meditations, "the speaking subject ceaselessly moves, changes, modifies his convictions, and advances in his certainties, taking risks and constantly trying new things" (Foucault, "Reply to Derrida ['Michel Foucault Derrida e no kaino'. Paideia [Tokyo] February 1972]," in History of Madness, p. 579). This is in response to Derrida's claim that "The pedagogical and rhetorical sense of the sed forte [at CSM II, p. 12; AT VII, p. 18, in the paragraph where Descartes proposes the hypothesis that he is mad] which governs this paragraph is clear. It is the 'but perhaps' of the feigned objection" (Derrida, "Cogito and the History of Madness," p. 50). Focusing as he does in the passage that started the debate between them, where Descartes dismisses the possibility of his madness (CSM II, p. 13; AT VII, p. 19), Foucault critiques Derrida's reading of the dismissal of madness as finding a more universal deception in dreaming by claiming that the importance of dreaming here "is so that the experience of dreaming can take its [i.e., madness's] place in the effective movement carried out by the meditating subject" (Foucault, "Reply to Derrida," p. 581). As a result, the moment when Descartes finds the locus of his meditations in the possibility of it all being a dreamregardless of the meditations' rhetorical, pedagogical, or fictional status - is for Foucault "not simply a logical inference" but "is inscribed at this precise moment of the meditation" such that there is an "immediate effect on the subject who is meditating" and "genuinely places him inside the possibility that he is actually asleep" (ibid., p. 582), because it leaves Descartes "dazed [obstupescam], and this feeling [stupor] only reinforces the notion that I may be asleep" (CSM II, p. 13; AT VII, p. 19). For Foucault, this sentence of stupefaction "is not there for stylistic effect: it is neither 'rhetorical' nor 'pedagogical"' because it allows for the Second Meditation to emerge on the supposition of dreaming and because it is in response to the dismissal of the possibility of his own madness (Foucault, "Reply to Derrida," p. 582). Foucault does not define what he means by rhetorical or pedagogical fictions, but neither does Derrida (at least not beyond describing it as a "feigned objection"). Given the lack of definition as to what would be precisely meant by 'rhetoric' or 'pedagogy' here, the only recourse may be to return to Descartes. As is clear from the debate with Gassendi over the rhetoric of the Meditationswhether the hyperbolic doubt requires some introductory explanation that it is not to be taken seriously-it is hard to take seriously any claim that there is no rhetorical purpose at any moment of the Meditations. Foucault wants to claim that there is no rhetorical purpose to the stupefaction Descartes feels at the possibility that he might be dreaming. However, Foucault also claims that the thought of the possibility of dreaming has an effect on Descartes. In that Descartes' critique of Gassendi is that the latter wants to play rhetorical games instead of getting down to the serious business of philosophy precisely through the latter's request for a disclaimer against the effects that hyperbolic doubt can muster, it is already difficult to understand what Foucault would mean by a rhetoric that does not generate an effect on the meditating subject. In terms of pedagogy, there is always an interweaving between it and rhetoric for Descartes. To clarify, in the Second Set of Replies, Descartes explains why he refuses to use the synthetic method of philosophizing preferred by Scholastics, with its "long series of definitions, postulates, axioms, theorems, and problems": Descartes finds that synthesis fails to "engage the minds of those who are eager to learn [discere]" (CSM II, p. 111; AT VII, p. 156). Instead, he prefers analysis, and used only this approach in the Meditations. So learning, discernment, is best encouraged through the method that Descartes deploys in the Meditations, a text that is deliberately established as fictional and as deploying a specific understanding of rhetoric such that the mind of the reader is engaged. Synthesis and analysis will be engaged more directly in chapter 3 below, but here, with all this in mind, it is quite difficult to take Foucault's claim seriously that the point of confusion between real world and dreamworld is not rhetorical, stylized, pedagogical, or fictional in favor of a definition of meditation that hardly seems to eliminate rhetoric and/or style. Indeed, there is no moment in the Meditations that can be considered lacking in rhetoric, style, pedagogy, or fiction. It is necessarily all of these things, as is so much of Descartes, precisely because of the failures not only of Scholastic pedagogy, but also of its comprehension of what constitutes the real over and against the fictional. The Meditations is a pedagogical text through its rhetoric, its rhetorical fiction and fictional rhetoric, 
and to claim otherwise about any of its moments can truly only be understood as, at a minimum, a problematic understanding of the text's movements and effects, perhaps even an understanding overly determined by that very same assumption of knowledge that the Cartesian rhetorico-pedagogical fiction inaugurates.

None of this, however, lets Derrida off the hook for his own misreading of the Cartesian text.

Though Derrida may have an "ever-sharp sense for texts," as Foucault sarcastically puts it, he does not appear sharp enough in his reading of the Meditations here (Foucault, "Reply to Derrida," p. 581). Derrida exposes a dullness, then, on his understanding of the deception at work in Descartes. On Derrida's reading, in the midst of showing that the move to dreams as beginning the road to the evil genius, he explains that, with dreams, "madness, insanity, will spare nothing, neither bodily nor purely intellectual perceptions," which the possibility of madness still spares because it fails to attain "the byperbolical moment within natural doubt" that dreams can attain (Derrida, "Cogito and the History of Madness," pp. 53 and 52). As a result, the cogito becomes "the starting point from which the history of the determined forms of this opposition [between reason and unreason], this opened or broken-off dialogue, can appear as such and be stated" because the self of the cogito survives even in the face of the unnatural doubt of hyperbole or metaphysics that would encompass the totality or infinity of the world (ibid., p. 56). Insofar as the turn to the unsparing doubt inaugurated by the possibility of dreamworld is such a starting point, "this project is mad, and acknowledges madness as its liberty and its very possibility. This is why it is not human, in the sense of anthropological factuality, but is rather metaphysical and demonic: it first awakens itself in its war with the demon, the evil genius of nonmeaning" (ibid.). In this war, the cogito is always at risk of remaining a "silent madness," which is why god is required to assure meaning, making the cogito "a work [oenvre] as soon as it is assured of what it says. But before it is a work [oeuvre], it is madness. If the madman could rebuff the evil genius, he could not tell himself so. He therefore cannot say so" (ibid., pp. 58 and 59; "Cogito et histoire de la folie," in L'écriture et la difference [Paris: Éditions du Seuil, 1967], pp. 90-91 and 92). God is able to assure the making-work, the working-out of the work that is the cogito because "God is the other name of the absolute of reason itself, of reason and meaning in general," which is the only thing that could either exclude or embrace madness since it is there, at the absolute or in the infinite, that the borderlines between reason and madness appear (Derrida, "Cogito and the History of Madness," p. 310n. 28). Mere mortals can only assure themselves from the silent terror of madness "by construing this shelter as a finite one, by making God a third party or finite power, that is, . . by deceiving oneself" (ibid.). Thus, there is an "only apparently indirect" light that illuminates the difference between god and the evil genius, a seeming reflection that is in fact directly shone from historicity (ibid.). For Derrida, it would appear that Foucault has taken the direct light from historicity as a reflection such that he believes he can reflect it back to the reflection in order to shine a historical light on the historical and historicized difference between reason and madness, even while that light from historicity is itself the illumination of the difference, leaving Foucault's reflection shining on nothing but light and making itself indirect because he forgets that the activity of historicizing is already itself a participation in the differentiation between reason and madness. All this is well and good, but not germane to a slip that Derrida makes here. For him, the shelter that protects oneself from madness is the deception that makes finite the infinite or absolute god that would cleave the difference between them. Such a protection is, again, a deception, and a self-deception at that. It is the deception that tells oneself that one is not mad because one can tell oneself anything at all. And yet, the self-deception at work in the Meditations is precisely not a deception of this sort, if only because it offers no real assurance, at least not in the sense that Derrida implies. The self-deception of the Meditations begins long before the reader encounters the possibility of madness, dreamworld, or the evil genius, let alone god. It might begin before the reader opens the book, but certainly when the reader encounters the letter to the faculty of the Sorbonne. The whole operation, the whole meditative exercise, as an exercise, is one of self-deception, which is the only way the hyperbole-which is indeed pedagogical and metaphysical, beyond the finite boundaries of the world-can set itself to work, on the part of both Descartes and the reader, but all the more so in the reader. To deploy the rhetorical technique of warning the reader that these hyperbolic doubts should not be taken seriously would ruin the effect that would establish the god who grants assurance of meaning, but before the hyperbolic doubts and before god, selfdeception is engaged, and done so knowingly, even without, especially without the rhetoric of warning and of unseriousness. That Derrida seems to disregard the 'self' of 'self-deception', the consciously generated operation of the fiction or fabularity would seem to be an indication that he is himself caught up in that very fiction as if it were real, forgetting the unstated Cartesian warning that the exercises, as meditative and metaphysical, are not to be taken too seriously, and are all the more serious for that.

This is not to suggest that the self is in the sense that the cogito has been taken (at least by Foucault and Heidegger) as an object established prior to the dynamics of the fiction at work in the Meditations or other Cartesian works. Rather, it is to suggest that, like so many of Descartes' other works, the rhetorical and 
two ways, the apodeictic truth of the self as a thinking substance. First, in acknowledgement of the possible authorship of the evil genius, Descartes knows he exists as "the author [author] of these thoughts." Second, if the deceiver truly exists, it remains that "I too undoubtedly exist, if he is deceiving me [me fallit]." Finally, then, the self has been indubitably established, through doubt, because one cannot doubt that one doubts when one is doubting, even if one is doubting one's own existence, one's self, oneself. However, this doubt that secures the self, especially as it maintains its rigor in the turn to the self-deception of the evil genius, is itself made possible, given a habitual principle in the deception of the opening paragraph. (CSM II, pp. 16 and 17; AT VII, pp. 24 and 25)

pedagogical techniques serve to unwork whatever self might have already been established, insofar as it is a self that itself and whose meaning cannot be interpreted. It is possible to claim, then, that what Descartes is trying to do in the Meditations is to deliberately make himself go mad. He can only be insane, at least by the standards of Scholasticism, to have such doubts as these, and he is doing so on purpose, with the fiction of six days at work throughout. It is not that 'Descartes' or 'the meditator' or whatever other differentiation between author and narrator may be used is making himself go mad. Descartes is, and is doing so through the use of a selfdeception that sets the whole narrative to work, and sets it to work on the reader, such that the reader goes mad along with him, by following him, and not by being taught by him. In reading the Meditations in this way, there is perhaps something of a weave or path between Foucault and Derrida shown: The work of the Meditations, like so much of the Cartesian corpus, is an unworking, a désoeuvrement. When Blanchot identifies in writing the passage "from the I to the He," he does not eliminate the author in its entirety, which is why, for him, "The act of writing is ... related to the absence of the work [l'absence de l'oeuvre], but is invested with the Work [l'Oeuvre] as book" (Maurice Blanchot, The Infinite Conversation, tr. Susan Hanson [Minneapolis, MN: The University of Minnesota Press, 1993], p. 424; L'Entretien Infini [Paris: Éditions Gallimard, 1969], p. 622). The act of writing is related to madness, to the silence and absence that madness is, then, and is, following Mallarmé, a game as well. And yet the act of this mad game is always also a production, insofar as it is an act, making the mad game, the absence of the work, the silence of writing "the absence of the work as it produces itself," an unworking-désoeuvrement (ibid.). The movement between writing as act and as désoeuvrement is, for Blanchot, "infinite," though, at least in the case of Descartes, because the self-deception that inaugurates the motion of the mind through the mad game of writing into an unworking of the self is deliberate and because it is deliberate because it is both rhetorical and pedagogical, 'infinite' may be a problematic word insofar as this self that deceives itself is not infinite, and cannot be for Descartes. 'Transfinite' might be a more helpful word, about which more will be said in chapter 4 below. This contestation aside, however, Blanchot's désouevrement that is the act of writing, the madness that writing entails, would seem to be a more appropriate way to understand the dynamics at work in the Meditations, and indeed in almost all of Descartes' works. Both Foucault and Derrida, because they are so caught up in the drama of the meditations as they present themselves within the fiction appear to forget about the deception that is the necessary inaugural point from which the fiction can itself emerge as something deceptive. As a result, they both appear to forget that what is at stake in the moment of madness and dreamworld in the First Meditation is not so much a decision against one or the other, made possible by a belief in (one's own) reason, but that this moment is one of the early, but not the earliest stage of unworking reason as such, or at least as understood by Scholastics, such that reason can again emerge, but in a possibly more mad form. 
The fable serves a pedagogical purpose for Descartes, as it has since at least Aesop. This purpose is not, however, merely to inscribe and reinscribe the importance of certain rules that have already been established. Rather, the fable inaugurates the motions by which these rules are to be written, even as it simultaneously obeys them, since the fable is not and cannot be entirely outside the world its fabulates. As an inaugural form for Descartes, the fable can be expanded beyond the precise positive mentions of it into other moments where he inaugurates his readers onto the path of his thinking. Thus, the fable is to be taken not so much as a literary technique as a structure or even logic of inauguration whereby the reader begins to think along with Descartes. It is that by which thinking and logical investigations of the world begin to take shape, to be formed. To bear this structure or logic in mind or to attend to it will have an effect on other aspects of Descartes' philosophy. Because the fable has begun to show itself as a structure or logic that runs to the very heart of this philosophy from its beginnings and because this remains a pedagogico-literary form, the question of Descartes' understanding of logic, the order and/or structure of thinking, and its relationship to other, less exalted philosophical concerns like rhetoric and history is the appropriate direction in which to turn next. This understanding comes to light in Descartes' discussions of method. Attending to the effect that attending to the fable has on method will, in turn, make it easier to turn to the effect that attending to the fable has on another crucial aspect of Descartes' philosophy— the status of the imagination — because deducing the mind's faculties through an analytic reduction to its simplest components would appear to be achieved through the method that will show itself as affected by the fable. 
Part II 
... recurrat saepe memoria judicii ante facti, cum non amplius attend ad rationes propter quas tale quid judicavi ....

—René Descartes, Meditationes 


\section{Chapter Three}

\section{Method}

Coming out of an investigation of the fable, where it is shown to hold a crucial pedagogical role in terms of both how the world is to be interpreted as well as how the self can construct itself, it is now possible to examine what effect this fabular structure has on our understanding of the Cartesian method in general. The traditional understanding of the method is, roughly, an intellectual reduction of the complexities of the way the things of the world present themselves to the simple essences of those things, whether they be oneself, god, or things like a piece of wax. Of the material objects of the world, in their materiality, a reduction to their geometric essences, especially expressed in algebraic notation, is the clearest and most distinct expression of their truths, and will be an expression of eternal truths.

However, having attended to the use and mention of fables throughout the trajectory of Descartes' career, especially insofar as they relate to a consideration of the deceptiveness of things in the world and the self-deception required to assure oneself against deception, the Cartesian method changes tack. It can no longer be considered a simple, straightforward path to clear and distinct ideas, nor are the truths expressed in these ideas necessarily eternal in the sense of being removed from history, be it personal, political, religious, or literary. Instead, what will hopefully become clear over the course of this chapter, is that (A) what appears to be simple in the method is in fact complex, especially insofar as the analytic method is always interwoven with or supplemented by the synthetic method; (B) the 
relationship of literary and politico-religious history to this method shows it, even in its supposed analytic structure, to be less an unknotting of what is complex than itself a knot of what is exact (science proper) and of what is inexact (history and etymology); and (C) the relationship between the ordering of the life of the metaphysician and that of practical lifewhether in the crafts or in ethico-political decision making-is one of mutual imitation and/or supplementation, which in turn exposes a supplementation between rule-obedience and rule-generation in general for Descartes, a dilemma that was already at work in the earliest discussion of fable.

\section{Simplicity and Complexity}

In case it is not already clear, I take the hyperbolicity of the doubt found at heart of the Cartesian method as exceeding the limitations not only of metaphysics but also of rhetoric. The link between this hyperbolicity and other rhetorical and literary forms of presentation, fable being the form most structurally important for my argument, shows that there is a thread of inaugurating motion in the minds of his readers throughout Descartes' career that persistently requires deployments of deceptive forms of presentation that the reader may or may not take as deceptive. The interweaving of deception within the very forms of presenting his way of thinking places Descartes in an interesting position with regard to the method that is supposed to develop from the inaugurated motion. That method, inspired by geometry, by and large is supposed to follow the steps of analysis. These steps that guide the 
method, then, are the method in the sense of being the methodos, the path before, beyond, behind the path of applying the method. ${ }^{1}$

\section{Analysis and Synthesis}

For Descartes, method comes in two (duplex) opposed (oppositam) methods, analysis and synthesis. To begin, as he puts it in the Second Set of Replies, "Analysis shows the true way by means of which the thing in question was discovered methodically and as it were a priori [Analysis veram viam ostendit per quam res methodice \& tanquam a priori inventa est]," allowing a reader to come to understand the truth discovered "as if he had discovered it for himself [quam si ipsemet illam invenisset]," though it cannot guarantee compulsion on the part of readers unwilling to take on the method for themselves and it does not always mention truths that

\footnotetext{
${ }^{1}$ As Heidegger explains it, the etymological source of 'method' is methodos, which did not mean the same thing for the Greeks as it does for us, since it was a combination of meta and hodos, such that methodos meant "to-beon-the-way, namely on a way not thought of as a 'method' man devises but a way that already exists, arising from the things themselves, as they show themselves through and through," with the 'already existing' element showing method's "perspective and prospective essence” (Heidegger, Parmenides, tr. André Schuwer and Richard Rojcewicz [Bloomington, IN: Indiana University Press, 1992], p. 59). A detour, an apate, which is also a deception, is an acceptable form of method for him in that it "[makes] available another prospect and supporting it in such a manner that, as way, it might indeed be the one going 'straightaway' toward the unconcealed" (ibid.). Apate is distinct from the deceptions of both pseudos and sphallein in that pseudos is a "counter-essence" while sphallein means " to mislead" and thereby do not lead one on a path to unconcealedness insofar as they are false and dissembling, even opposed to the truth (ibid., p. 58). The deceptive method of hyperbolic doubt, then, would seem to be in line with apate's detour, an arc away from traditional methods that unconceals the essence of the self, god, and other things. All the more, insofar as the hyperbole follows the fable-logic or -method, insofar as it interweaves its deception within the revealing of truth, the Cartesian method qua hyperbolic and fabular reveals in a concealed, deceptive manner, leaving the essences it unconceals to emerge in their lack of showing, at least a lack of straightforward showing, even if the ideas of them show themselves clearly and distinctly, because the showing is always a chiaroscuro showing. Methodologically, Descartes' path might be able to mislead, as any path can, especially if the one following it desires, like Gassendi, a disclaimer of its falsehood, but this does not make the hyperbolicity of the hyperbole, the structure of what allows the method to emerge as it does, a pseudos or sphallein. The hyperbolicity of the hyperbole is an apate, a detour from the supposed straightforward interest in straightforward truth and essence, which neither Descartes nor Heidegger think is possible, at least not through the dominant methods of their times, Scholasticism and empirical science (or at least scientism), respectively.
} 
are clear if given more attention. ${ }^{2}$ Synthesis, however, "employs a directly opposite method

where the search is, as it were, a posteriori (though the proof is more often a priori than it is in

the analytic method)" through definitions, postulates, axioms, theorems, and problems to

demonstrate a conclusion such that even the most stubborn reader will be compelled to

agree with the truth discovered. What Descartes is indicating here is that, for him, analysis

operates through a reduction of the complications of the world as it appears to first

principles and a simplification of the process of that reduction such that a reader may take

on the reduction for him- or herself. ${ }^{3}$ Synthesis, in bringing its theses and claims together,

\begin{abstract}
${ }^{2}$ As Cicero points out, inventio is one of the principal parts of the art of rhetoric. Specifically, it is "the discovery [excogitatio] of seemingly valid arguments to render one's case plausible" (Cicero, De Inventione, in De Inventione, De Optimum Genere Oratorum, and Topica, tr. H. M. Hubbell [Cambridge, MA: Harvard University Press, 2006], 1.7.9). The inventa of inventio, then, lay out the terms of an argument. Thus, analysis shows the way by which a thing's discovery was made plausible a priori. For Cicero, the character of invention always revolves around a constitutio (an issue), which can be of a conjectural, definitional, qualitative, or translative sort. A conjectural issue, the terms of which an invention must lay out, concerns facts (see ibid., 1.8.10). For a definitional issue, the issue concerns definitions; for a qualitative issue, "the value of the act and its class or quality"; and, for a translative issue, the issue concerns the right person bringing the right charge against the right person to the right tribunal at the right time under the right statute with the right penalty (ibid.). To turn back to the conjecture of the evil genius, this would mean that said conjecture lays out not just the facts of the case concerning the existence of the self, but also the foundational fact of facts, the fact from which all other facts, all other arguments or inventa, can be made.
\end{abstract}

${ }^{3}$ Here I am contesting to some degree Ricoeur's argument concerning the Cartesian cogito as opposed to the Lockean self. Ricoeur claims that Locke's self is the true invention of the modern subject insofar as "it is truly an invention," while "the grammatical subject of the Cartesian cogito is not a self, but an exemplary ego whose gesture the reader is invited to repeat" (Ricoeur, Memory, History, Forgetting, pp. 102 and 103). Because the Cartesian ego is not conscious, does not invent consciousness in the way that Locke's self does, even "the multiple operations of thought enumerated in the Second Meditation" do not allow the cogito to develop a person "defined by his or her memory and the capacity to give an accounting of himself or herself" since "Always thinking does not imply remembering having thought." Meanwhile, Locke's conscious self lays out "the diversity of the places and moments by means of which the Lockean self maintains its personal identity" (ibid., p. 103). One way to critique Ricoeur's position is to say that his reading of Locke's self disregards the fact that the "empty cabinet" of the mind, which precedes the memories that would give the self the consciousness Ricoeur desires, suggests that the supposed construction of consciousness is, on some level, established prior to experience, and thus prior to memory, and thus the self is hardly invented here, but is a result of pulling memories from their appropriate draws in the psyche (John Locke, An Essay concerning Human Understanding, abridged and ed. John W. Yolton [London: J. M. Dent, 1996], p. 23). This is a critique that can be developed from Deleuze's reading of Hume, but also from my reading of Descartes in chapter 4 below (see Gilles Deleuze, Empiricism and Subjectivity: An Essay on Hume's Theory of Human Nature, tr. Constantin V. Boundas [New York: Columbia University Press, 1991], esp. pp. 126-127). Another, related way to critique Ricoeur's position is to ask him what precisely he understands as happening in the course of the analytic reduction to the cogito. Ricoeur's claim is that there is no memory in the cogito, but this seems to assume that the "lightning flash of an instant" that is the discovery of the cogito can only be understood within the flash, within some parameters of the event of discovery, and it fails to take account of how the cogito is discovered, the procedure of hyperbolic doubt which is always in necessary reference to the experience of having been deceived and of having been 
would be a more complicated process, even if it compels stubborn readers to accept its

\author{
conclusions. ${ }^{4}$ (CSM II, p. 110; AT VII, pp. 155 and 156)
}

wrong thanks to the problematic expectations that are a result of synthesis (Ricoeur, Memory, History, Forgetting, p. 103). The instant of the cogito is never merely an instant, and could not be insofar as it is the result of an analytic reduction, a finding of simples from what there already is: complexity. The Cartesian cogito is at least as much the result of memory as the Lockean self, it would seem, and may even be more inventive than Locke's self if, borrowing from Deleuze on Hume, "the mind...transcends itself" when it deploys itself in the discovery of itself from out of the deceptions it has experienced through a deception of its own making (Deleuze, Empiricism and Subjectivity, p, 127).

${ }^{4}$ See also The Port-Royal Logic, tr. Thomas Spencer Baynes (1861), pp. 308-316. As Sepper describes it, ancient analysis is distinct from the Cartesian version. Though both engaged analysis as a method of "taking the unknowns as known and schematically working out what would be true if they were known" such that the reversal of the reduction, the synthetic constructive deduction, can be carried out (Sepper, Descartes's Imagination, p. 190). However, while ancient analysis was complex, involved multiple simultaneous considerations, and demanded "a sophisticated geometrical insight," Cartesian analysis simplified the method, reduced analytic reduction "to a progressive linear sequence requiring attention to no more than two things at once," thereby making it more accessible to all human ingenium (ibid.). For Sepper, this leads to a state where, even in the early work of the Rules, where the imagination is active in a way it does not appear to be in the later work, "imagination is a necessary and sufficient cognitive tool when a quite restricted, local analysis is needed," but in more general analyses, the intellect is the necessary faculty because the imagination cannot take up the original synthesis the simples of which must be found through analytic reduction: "for imagination synthesis must be given, either in a particular thing that appears to it or in a pattern of appearances ... ; but it is only intellect that can understand the character and necessity of synthesis as such" (ibid., p. 228). Such analyses generate "a way of arriving at an experience of the synthesis of the aspects in realities (not in fictions made up by cogitation), and these syntheses...lead in turn to new aspects that point to the ultimate synthesis of all, God" (ibid., p. 252). As a result, Sepper will claim that "the intellect is serving not just as a cognitive power but also as a lawgiver or, better, a rule giver" (ibid., p. 229). Clearly, the givens of the world ought to be considered synthetic. However, it is not clear that the imagination is precisely limited to local analyses, even if the intellect is required to take up the character and necessity of synthesis as such, or even if the intellect is a rule giver. If the givens of the world are synthetic, and if the imagination can analyze their syntheses on a local level, then it would appear the initial foray into analysis is possible because of the imagination, whether passive or otherwise. The synthetic givens appear as synthetic, as having parts. The world does not appear in an undifferentiated form-such would be the pre-motive chaos of The World. Thus, the very possibility of engaging in a more 'global' analysis or in synthesis as such, the work of the intellect, finds its origin in the imagination, even in its most passive state. That the intellect, in generating the rules for analysis and synthesis, lays out the limitations of the imagination does not mean that the imagination does not exceed those limitations. Indeed, this excess or exceeding is precisely what occurs, for instance, in the Meditations, when the fiction of 'six days, six meditations' establishes the grounds on which the analysis will play out — an analysis that sets precise limits to the imagination. It is also what occurs in The World, where the synthesis of the given world, the world as it appears, is re-synthesized in the fabular creation story that begins with the pre-motive chaos of an undifferentiated, solid world, a re-synthesis that is, itself, an imaginary and global analysis of synthetic givens back to their original (even pre-original) state. In both these cases, it would seem that the imagination is exceeding the limits that the intellect would set for it in such a way that the very possibility of the intellect giving rules for the imagination to obey has been made by the imagination. Sepper's contrast of "realities" and "fictions made up by cogitation" does not precisely apply here because the context is one aspect of essences and/or corporeal reality, while the imaginative moments to which I am appealing in the Meditations and The World are more foundational to the method as such, to the methodology of the method (analytic or synthetic). Thus, it would seem as though Sepper's appeal to the "intrinsically biplanar" quality of the imagination, while clearly true to a certain extent, still enters the question of the imagination too late in the Cartesian corpus because it assumes a pre-formed faculty psychology where, though the imagination may exist in two different realms, those realms are separated and static and because it assumes that the analysis and synthesis are applied without context, save the context of a given synthesis of the world. To attend to the fundamental status of fabular moments in the Meditations and The World should not only 


\section{Ancient mathematicians, such as Pappus of Alexandria and Diophantus of}

Alexandria, employed primarily synthesis over analysis Descartes believes, because they kept analysis to themselves as a part of their sacred mystery cults (see CSM II, p. 5 and 111; AT VII, pp. 4-5 and 156 and CSM I, pp. 18-19; AT X, pp. 376-377). ${ }^{5}$ The result of emphasizing synthesis over analysis in the public writings is twofold. First, it "is so closely tied to the examination of figures that it cannot exercise the intellect without greatly tiring the imagination" (CSM I, p. 119; AT VI, pp. 17-18). ${ }^{6}$ Second, in addition to boring or exhausting the reader, synthesis "does not show [docet] how the thing in question was discovered" according to the Second Set of Replies (CSM II, p. 111; AT VII, p. 156). ${ }^{7}$ Ancient

undermine the notion of a pre-formed faculty psychology (see, again, chapter 4 below), but also call into question the assumption that the method can be so simply understood as a global analysis.

5 When Marion addresses the concern with Pappus and Diophantus in the Rules, he points out that Pappus "explicitly developed the topos analuomenos" in the seventh book of his Collection and that, in Diophantus, "the theory of determinate equations is coupled with a theory of the reduction of indeterminate equations from higher [supérieur] degrees to others of the first or second degree" (Jean-Luc Marion, "Annotations,” p. 152; my trans.). As Marion points out, then, there are some public displays of what would be considered Descartes' analytic reductive method that should condition the Cartesian assessment of ancient secrecy, displays that Descartes himself knew. However, as Pappus explains, analysis for the ancients was not considered a general or perhaps generalizable approach to mathematics, but was "a special resource that was prepared ... for those who want to acquire a power in geometry that is capable of solving problems set to them; and it is useful for this alone" (Pappus of Alexandria, Book 7, p. 82). Moreover, this publicity of analysis would not address the boredom of reading synthesis, nor synthesis' failure to demonstrate how it arrived at its definitions.

${ }^{6}$ It should be noted that in the Discourse, Descartes refers to ancient mathematics as an analysis. Gilson observes, however, that Pappus and Diophantus "only codified the results" of analysis in its earliest stages of development, results which were "obscured" by their commentators (Gilson, "Commentaire Historique," p. 188; my trans.).

7 That synthesis is boring and does not show how it makes its discoveries would lend credence to what Nancy says about Cartesian mathematics: "beginning with the Regulae, the truth of Cartesian science is precisely such that it requires a covering [vêtement] (that of 'common mathematics') in order to show itself" (Nancy, "Mundus Est Fabula," p. 639; Ego Sum, p. 102). Showing (docere), for Nancy and for myself, is distinct from teaching: "I do not teach [Je n'enseigne pas], (which invalidates the fable's function as defined by the adage fabula docet), I show [je fais voir]. . . . There is no 'hidden instruction' here; the instruction itself, the motif or the subject of instructing is as if withdrawn from the fable. Here authority, truth as authority, withdraws itself. It is thus that fabula docet: I teach above all that I am not teaching" (ibid., p. 643; p. 108). (This use of docere is rather unique in the Cartesian corpus, of course, insofar as the Latin word is usually translated as 'teach'. Indeed, it is translated in just such a way in the Conversation with Burman, where Descartes distinguishes between the Meditations and the Principles, where the former is associated with "discovery [inveniendi]" and the former with "exposition [docendi]" as well as synthesis [DCB, p. 12; AT V, p. 153]. However, the structure of Nancy's claims still stand.) The covering of mathematics that allows the truth of Cartesian science to show itself is then the showing of the withdrawal of authority, of the authority in the hidden truths of the hidden methods, or at least those methods 
mathematics, then, in its synthetic approach, bores its readers with endless definitions, axioms, etc. that still fail to show how the conclusion was reached, perhaps because the lack of proof of those definitions, axioms, etc. leaves the reader with a sense that the conclusion is based on unproven assertions (DCB, pp. 19-20; AT V, p. 156). ${ }^{8}$ Definitions, after all, only show how a given writer will use a given word.

The lack of utility found in synthesis can also be found in the academic syllogistic reasoning Descartes was taught. All syllogism does, in the words of the Discourse, is "[explain] to others the things one already knows" (CSM I, p. 119; AT VI, p. 17). Syllogism is not, then, following the Second Set of Replies, how "we should search for the truth" because it begins too late in the process, which should always begin from the analytic reduction and simplification such that the syntheses of syllogisms are built on simple notions (CSM II, p. 271; AT IX-A, pp. 205-206). Now, like academic logic, Cartesian analysis also begins from a presupposition of an understanding of the problem. However, as he explains in Rule Thirteen of the Rules for the Direction of the Mind, Descartes does not "distinguish . . . a middle term and two extreme terms" (CSM I, p. 51; AT X, p. 430). ${ }^{9}$ That is, Descartes does not

hidden from those who are not authorized to be shown them or those who are not interested enough to authorize themselves for the "special resource" of certain methods. In addition, to give the truth of Cartesian science the covering, veil, patina, or vestment of analytic mathematics for the common because it is not boring is to show to those who would not otherwise authorize themselves that they need no authority, that authority withdraws in the face of the vestments enrobing Cartesian truth, that they are hereby authorized to authorize themselves not to be bored, thanks to analysis.

8 This approach is, then, arguing from ends for Descartes, insofar as it is typically Aristotelian and begins from the purpose of a thing rather than from the thing itself, which is especially problematic when discussing god's purpose. In his commentary on the Conversation with Burman, where this argument against arguing from ends appears, John Cottingham points to the Fifth Set of Replies, where "conjecture [conjecturis]" is allowed if piety would require guessing (conjicere) god's purpose, but that it is of no use in physics (CSM II, p. 258; AT VII, p. 375). Cottingham further points out, however, that there is a deeper purpose to Descartes' argument against an argument from ends that Scholastic synthesis would seem to deploy, insofar as it reaches conclusions from out of unproven, assumed assertions: "to understand $X$ fully is necessarily to have a full mechanical account of its workings in terms of efficient causality" (Cottingham, "Commentary," p. 86).

9 This point seems as appropriate as any to note that a new manuscript of the Rules has been discovered recently. To my knowledge, nothing about this manuscript has been published by those who maintain possession of it, Richard Serjeantson and Michael Edwards, though they have given a few public talks. The 
distinguish between the term shared by the major and minor premises and the terms used in only either the major or major premise. Rather, he understands three elements to every problem: the unknown, the delineation of the unknown, and the known by way of which the unknown is to be delineated. In its algebraicization of logic, he brings together syllogism and analysis thanks to an emphasis on self-instruction, while also distinguishing what would appear to link them to an academic approach, the presupposition of understanding. ${ }^{10}$ When

Descartes writes, in the Geometry, that the first step of his method is to "assume the problem to be already solved," he is not placing his method in the same position as academic syllogism's explaining to others what is already known. Rather, he is operating on the presumption that the unknown element can be known through a delineation via what is

manuscript itself has not been made public, either. As a result, it can have no bearing on what is presented concerning the Rules here.

10 As Michael S. Mahoney points out, Descartes is in this way following the example of Petrus Ramus, whose simplifications of ancient mathematical treatises "represents the beginnings of the writing of textbooks" (Michael S. Mahoney, “The Beginnings of Algebraic Thought in the Seventeenth Century," in Descartes: Philosophy, Mathematics, and Physics, ed. Stephen Gaukroger [Totowa, NJ: Barnes \& Noble Books, 1980], p. 149). As a result, for Mahoney, "Analysis ... is not logically rigorous but does have its own sort of rigour," the rigor that an "attentive student" will deploy in learning how to teach him- or herself (ibid.). This shift in the conception of logic and pedagogy is part of what allows for mathematics to shift from being an episteme, as it was for the ancients, to being an ars or techne, as it became from at least François Vieta on, according to Mahoney. As he explains it, "Only what had been proved by strict synthetic deductions by means of Aristotelian logic counted as episteme, as science" because analysis necessarily assumes as solved the theorems it analyzes by investigating the consequences of its assumed solution (ibid., p. 147). (To be clear, at this point, Mahoney seems to be conflating theorematic and problematic analysis, which at least Pappus distinguishes, even if not very clearly. For the distinction, see Pappus, Book 7, pp. 82-84, and Alexander Jones,

"Introduction," in Pappus, Book 7, pp. 66-68.) The return from analysis to synthesis is required for the proof to be given the stamp of rigor, and thereby episteme. This new kind of rigor found in an exclusively analytic approach, the rigor of the attentive student learning on his or her own through a simplified textbook of techniques is possible because the algebraicization of mathematics and of logic, the deploying of universal symbols, operates on the assumption not only that "an algebraic derivation can always be reversed to yield a strict synthetic proof," but also that this synthesis is unnecessary in the showing of the analysis (Mahoney, "The Beginnings of Algebraic Thought," p. 147). It is something the attentive student can do on his or her own time, in his or her own way, should he or she desire to show him- or herself this 'more rigorous' proof. Indeed, it would be for this very reason, this synthetic operation that an attentive student can do on his or her own time and in his or her own way, that demonstrating a synthesis is both boring and explains to a student what is already known. However, in a certain way, it does appear as though Mahoney is discounting some of Descartes' fears of boring his readers. This fear leads Descartes to frequently leave certain portions of his texts or proofs incomplete, which is not something Mahoney notes about the Cartesian expression of analytic method in general. Descartes' pedagogical interest extended beyond a simplistic analytic rivalry with synthesis, it seems. He was concerned that even analysis could be boring, and wanted to allow even that method to demonstrate its rigor precisely through not explaining every step or every problem of an analysis, so that these attentive students could take up the method on their own even in the very learning of his method. 
already known, a delineation and reduction set up so that his readers can have "the pleasure of learning it [i.e., the method of delineation and reduction] for [themselves], as well as the advantage of cultivating [their] mind[s] by training [themselves] in it" (E, pp. 186 and 180; AT VI, pp. 383 and 374). Through such a process, those simple known notions can build together to show what is heretofore unknown. Thus, even if there is a pedagogical benefit to the process of dialectical quaestiones and syllogisms in what he calls, in Rule Two, the "certain rivalry" formed, the self-instruction opened up by a more analytic, algebraicized approach to logic and problems in general is preferable (CSM I, p. 11; AT X, p. 363).

Syllogisms in themselves are not the problem, and, as he writes in the Seventh Set of Objections with Replies, to Bourdin, "indeed, I used syllogisms throughout my writings, when I needed to," specifically citing the end of the Second Set of Replies (CSM II, p. 371; AT IX-A, p. 544). The problem is that they cannot be formed without already knowing the conclusion rather than an algebraicized logic's reduction and simplification allowing previously unknown truths to emerge. ${ }^{11}$ The conclusion is known ahead of the investigation

\footnotetext{
11 In calling this aspect of Descartes' project an 'algebraicized logic', I am building on certain claims made by Gaukroger. At La Flèche, Descartes’ exposure to logic would have involved Pedro Fonseca and Francisco Toledo's commentary on Aristotle's logic (see The Jesuit Ratio Studiorum of 1599, tr. Allan P. Farrell, S. J. [Washington, DC: Conference of Major Superiors of Jesuits, 1970], p. 41). As Gaukroger explains them, these commentaries provided two things: (1) "an account of the difference between syllogisms which, while formally identical, nevertheless differed in that some of them yielded conclusions that were merely descriptive, while others ('demonstrative' syllogisms) yielded conclusions that were genuinely explanatory" and (2) "a normative theory of thought, a set of rules for thinking correctly" (Gaukroger, Descartes: An Intellectual Biography, p. 54). In addition, syllogism is associated with synthesis in that each is "a form of deductive demonstration (ibid., p. 125). Since Descartes rejects syllogism "at quite an early stage of his career" as well as prefers "analysis at the expense of synthesis," the rejection of medieval logic and mathematics would seem to be intertwined (ibid., pp. 54 and 124). He also rejects attempts at 'algebra' like that of Christoph Clavius, which makes "analysis ... little more than a preparation for synthesis; it is simply an exercise in translating geometrical propositions into syllogistic form so that the deductive structure of geometrical demonstrations can be shown for what it really is, namely Aristotelian logic" (ibid., p. 125). As Descartes develops his algebraicization of geometry in the Geometry-by which geometrical problems can be solved through mathematical symbols, notations, and formulae without the need for tracing lines - he is developing an algebraicization of logic such that it is not a handmaiden to an already rejected Aristotelian logic (see E, p. 178; AT VI, p. 371). Logic is no longer a syllogistic building up "from something [i.e., the premises] taken as understood" (Aristotle, Posterior Analytics, 71a) but a procedure or method whereby, "if we wish to solve some problem, we should first of all consider it solved [on doit d'abord le considerer comme desia fait], and give names to all the lines-the unknown ones as well as the others-which seem necessary in order to construct it. Then, without considering any difference between
} 
because, as he explains in Rule Ten, academic syllogism "can nevertheless draw a conclusion which is true simply in virtue of the form" of the syllogism. As a result, Descartes wants to place it in the realm of rhetoric. If the hyperbolicity and fable-structure or -logic of the Meditations throws its technical apparatus of methodical doubt beyond the realm of rhetoric, then the technique of memorizing syllogistic forms is thrust into the realm of rhetoric because it gives its answers ahead of any content. The technical apparatus of hyperbolic doubt, like that of an algebraicized logic of analytic reduction and simplification, allows its students to instruct themselves and determines the truth and discovery of unknowns through knowns without predetermining the conclusion of the unknowns because the knowns, not the form of reasoning itself, give the content to the unknowns. (CSM I, pp. 36 and 37; AT X, p. 406)

Thus, to return to the Second Set of Replies, "analysis ... is the best and truest method of instruction," while "synthesis . . is a method which it may be very suitable to deploy in geometry as a follow-up to [aptissime post] analysis, but it cannot so conveniently be applied to these metaphysical subjects." However, Descartes does perform a synthesis at the

the known and unknown lines, we should go through the problem in the order which most naturally shows the mutually dependency between these lines, until we have found a means of expressing a single quantity in two ways" (E, p. 179; AT VI, p. 372). Between the known and the unknown, then, there also appears to be no middle term for the logic that this algebraicized geometry shows itself to be. Thus, I call this an algebraicized logic.

It is this potential of an algebraicized analytic logic to allow previously unknown truths to emerge that Gilson would seem to have identified in the third meaning of puissance in Descartes as being "related to the logical potential [la puissance logique]; this potential is confused with the logical possible [le possible logique] since it consists only in the non repugnantia extremorum" (Gilson, Index, p. 248; my trans.). However, if the potential to allow previously unknown truths to emerge is the puissance of the analytic method, and if the potential of this puissance should not be confused with the possibility of the possible, as Gilson implies, where would the difference enter? Following from the note on Gilson in chapter 1 above, it would seem that the potential of what is not yet at work, the potentially non-contradictory showing of what is unknown that analysis sets to work in the minds of its attentive readers, would be the non repugnantia extremorum of the logical potential, while the logical possible would seem to align itself more with syntheses' going over ground that analyses would have already covered, like the power of a mind that has already been set into motion, and here set into motion by analyses, such that the possibly non-contradictory reversal of an analysis would be the non repugnantia extremorum of the logical possible. 
end of these Replies as well as in the Principles. ${ }^{12}$ So synthesis is best understood as a

rhetorical technique to follow analysis, if necessary. In their opposing, antistrophic

relationship, they form the duplex of demonstration, the latter reducing problems to simple

notions that can subsequently be brought back together through the former. ${ }^{13}$ If the

syntheses of syllogisms are considered rhetorical because of their formal overdetermination

of possible conclusions, this overdetermination would be permissible and possible on the

\begin{abstract}
12 Daniel Garber denies that the Principles is a synthetic approach to the same issues brought up analytically in the Meditations, though he also emphasizes that the former is not necessarily analytic. Indeed, he finds that "the distinction between analysis and synthesis may be entirely irrelevant to understanding the true relations between the metaphysical arguments of the Meditations and the Principles" (Daniel Garber, "A Point of Order: Analysis, Synthesis, and Descartes' Principles," in Descartes Embodied: Reading Cartesian Philosophy through Cartesian Science [Cambridge: Cambridge University Press, 2001], p. 62). He suggests that the differences between the two books might be reconciled by thinking of the metaphysics in the Principles as conceived as prefatory, like the metaphysical Part Four of the Discourse (see ibid., p. 62n. 11), or that Descartes' interest in having the Principles used as a textbook might have driven him to write in a more typical fashion for that approach, or even that Descartes initially thought that what we have of the Principles would be a portion of a larger work (see ibid., p. 63). In the end, though, Garber's main point is that the notion that the Principles is a synthetic presentation of the Meditations' analysis must be abandoned as unhelpful for understanding what is at stake in either work. The precise details of this debate are not particularly relevant to my own argument, as far as I can tell. We do not have to take Descartes at his word on this point, except to note that he claimed it. In fact, it seems to me that accepting Garber's position on the matter, and following his suggestions for what the metaphysical arguments of the Principles are - whether prefatory to the work proper, taking on a traditional textbook form, or as a portion of a larger work-only lends credence to my own claims about the fable-logic or -structure to the Principles, once the appeal to its novelistic status has been taken seriously. Let it be any of the suggestions Garber suggests, and the Principles, especially its metaphysical arguments, can still be understood as operating on the theme of setting the reader's mind into motion, of unlearning what he or she has already learned in order to teach him- or herself. Whether that unlearning and learning begins in a prefatory, textbook, or partial manner would not affect the structure at hand.
\end{abstract}

13 In the opening sentence of the Rhetoric, Aristotle describes rhetoric as a "counterpart [antistrophos]" to dialectic (Aristotle, Rhetoric, tr. W. Rhys Roberts, in The Rhetoric and the Poetics of Aristotle, tr. W. Rhys Roberts and Ingram Bywater [New York: Random House, Inc., 1984], 1354a). If rhetoric and dialectic are antistrophes to each other, facing and correlating with each other, winding around each other, as the stanzas in a choral ode, without being precise copies of each other, and if one of the constant dilemmas concerning the relationship between analysis and synthesis is which in fact holds a rhetorical position and which a more properly philosophical one, then it would seem that a perhaps more generous understanding of analysis and synthesis would be to consider them in an antistrophic relationship. This would indicate, among other things, that the Cartesian concept of analysis and synthesis is distinct from the counterpart relationship indicated in ancient mathematics, where synthesis is a "reversal [hypostrophes]" of analysis (Pappus, Book 7, pp. 82 and 83). For Pappus, synthesis was a reversal, even a relapse, of analysis, the method reserved for those who sought a deeper understanding of geometry and which therefore must be kept relatively secret. For Descartes, it could be that synthesis is the antistrophe to the strophe of analysis, existing in an interwoven harmony, even if they neither replicate nor precisely depend on each other. Such an understanding of the relationship between Cartesian analysis and synthesis could very well go a long way to answering Garber's dilemma described in the previous note while still allowing for the fable-logic or -structure to operate and inaugurate motions as necessary, whether in the minds of francophone craftspeople or in those of university students. 
Cartesian schema thanks to analysis's having pulled apart the apparent duplicities of a given problem such that a synthesis can be understood as legitimate and already proven, which is why he can engage in the syllogistic synthesis at the end of the Second Set of Replies and repeat both The World and the Meditations in the Principles. (CSM II, pp. 111 and 113-120; AT VII, pp. 156 and 160-170; DCB, p. 12; AT V, p. 153)

Now, in that Descartes ignores the syllogistic process of premise-conclusion in his algebraicization of logic, he cannot be considered as laying out an enthymematic structure to his method. However, in the appeal to content over form thanks to the analytic algebraicization of logic, whereby knowns give rise to the delineation of unknowns, there is something of an appeal to the rhetorically inductive technique of example in that the two forms of example are understood as historical facts and fables. ${ }^{14}$ Descartes' attempts to inaugurate motion on the part of his readers through his various forms of fable-structure or -logic can thus be understood as operating rhetorically in an Aristotelian sense, even if Descartes understands this structure or logic as being thrown beyond rhetoric thanks to its hyperbolicity. The relationship between rhetoric and logic, synthesis and analysis, and all four together is thereby significantly more complicated than the appeal to the simplicity of

14 As Aristotle explains it, "syllogism proceeds from something [from premises] taken as understood, whereas in the case of induction, the universal is proved because [its truth] is clear in each particular" (Aristotle, Posterior Analytics, 71a). In rhetoric, induction's particulars take on the form of examples for the purpose of persuasion, while the terms of a syllogism take on the form of an enthymeme. Though there is some contention as to the precise accuracy of this claim, especially in the relation to other claims made late in the Prior Analytics (see Hippocrates G. Apostle, "Commentaries," in Aristotle, Posterior Analytics, p. 77), the claim here is consistent with what Aristotle claims in the Rhetoric: "for it [i.e., example] has the nature of induction" and "the Enthymeme is a syllogism" (Aristotle, Rhetoric, 1393a and 1395b). Aristotle divides examples into two categories, (1) historical and (2) invented (poieo). Invented examples are further divided into (a) illustrative parallels and (b) fables. He divides enthymemes into two categories as well, (1) demonstrative and (2) refutative, the difference between which "is the same as that between syllogistic proof and disproof in dialectic," with demonstrative enthymemes drawing conclusions from premises and refutative enthymemes contesting another's conclusion (ibid., 1396b). Maxims (gnomai) can be either premises or conclusions for the enthymeme's syllogistic form, depending on the context (see ibid., 1394a). From this perspective, at least elements of Aristotelian rhetoric seem to be at work within Descartes. Descartes of course was educated in the Rhetoric, as indicated by The Jesuit Ratio Studiorum of 1599, pp. 72-79, esp. pp. 72-73, which was the official guideline at La Flèche. Indeed, perhaps this link with rhetoric could even be seen as a missing chapter of René Le Bossu, Parallele des Principes de la Physique d'Aristote et de celle de René Des Cartes (1674). 
analysis would appear to make it. ${ }^{15}$ It is not merely a realignment of the relationship between, on the one hand, rhetoric and logic, and, on the other, synthesis and analysis. Rather, in its deployment of a deliberately and acknowledged rhetorical technique to inaugurate a different form of logic while simultaneously making clear the rhetorical dependence of traditional logic (and pedagogy), how and why logic, the logic of the Cartesian analytic method but also the logic of the uninterpretable old world of synthesizing and syllogizing academics, can be distinguished from rhetoric with any simplicity is made more complex, if impossible. ${ }^{16}$

\footnotetext{
${ }^{15}$ According to Deleuze, Spinoza achieves a synthesis of sorts, "not without a certain irony," of Aristotelian synthesis and Cartesian analysis insofar as both of these approaches "come to the same thing, more or less, to abstract a universal from a confused knowledge of an effect, and to infer a cause from a clear knowledge of its effect" (Deleuze, Expressionism in Philosophy, p. 160). Spinoza's 'synthesis' of these two approaches does not merely put them together, however, since both are inadequate on their own. Ancient synthesis failed to conceive of the soul "as a sort of spiritual automaton, that is, of thought as determined by its own laws," while Cartesian analysis is premised on the problematic conception of synthesis as presented in the ancients, such that he failed to see that synthesis "gives us knowledge of our power [puissance] of knowledge" (ibid., pp. 160 and 161). The Spinozistic method for Deleuze, in going beyond Cartesianism and Aristotelianism, has three aspects: reflection, genesis, and deduction. The reflexive aspect is the one where knowledge of the puissance of knowledge emerges. The genetic aspect "invents or feigns [forge ou feint] a cause on the basis of an effect" in order to quickly "reach the idea of God as the source of all other ideas" (ibid., p. 161; Gilles Deleuze, Spinoza et le probleme de l'expression [Paris: Les Editions de Minuit, 1968], p. 146). Finally, the deductive aspect follows the ideas which follow or are produced from the idea of god as real beings and so deductions of reality. However, in the very laying out of the Spinozistic method which he claims goes beyond the Cartesian and Aristotelian methods, Deleuze appears to have inadvertently linked Spinoza and Descartes more intimately than he would want. If the Spinozistic method begins from knowledge of a puissance, especially one of knowledge itself, and then moves into a feint of causes, this method looks not unlike that of Descartes, at least in fables like The World and the Discourse, where, in the former, a feigned chaos is caused to move by god, and, in the latter, the puissance of good sense is the inaugural appeal to enter into the method. Between this situation and that where synthesis shows itself as never fully extractable from analysis in Descartes, Deleuze's Spinoza and the Descartes presented here would seem to be less at odds than Deleuze wants them to be. It may simply be that Deleuze accepts too much at face value as concerns the meaning of Descartes, too much based on what became Cartesianism, though this would seem to be unfair to Deleuze, who reads Descartes closely. Whatever the cause, it would seem that attending to the Cartesian fable and its effects on how the Cartesian method is to be understood makes Descartes not merely one of the major figures whose method Spinoza overcame.
}

${ }^{16}$ This may very well be an explanation to a consequence Brann lays out of the "great baring of bones of reason" (Brann, The World of the Imagination: Sum and Substance, p. 69). She does not make a broad claim as to the modern move from a paring down of logic and metaphysics to "metaphysical systems every bit as abstruse and as deep as were the classical philosophical developments," but if the paring down of logic by Descartes is done in the interest of maintaining readers' interests, this would indicate that there is necessarily a link or an enmeshing between logic and rhetoric which itself betrays the appeal to simplicity as a metaphysical and logical premise to begin with (ibid.). Brann's focus is on the imagination, and so she is concerned with how the imagination becomes worked back into a metaphysical system that becomes as complex as what it rejected, and this will be addressed below, in chapter 4, but for the moment it is worth noting that the complexity of the new Cartesian metaphysical system is indicated in the very interest in developing that new system, enmeshed as that interest is in rhetorical goals. 
Indeed, the complexity of what appears to be simple, for and in all practical engagement, may show itself as the necessary (rhetorical) duplicity, perhaps even a necessary double supplementarity, inherent to the method..$^{17}$

\footnotetext{
${ }^{17}$ Husserl appears to assume that the Cartesian analytic reduction that operates through the algebraicization of logic is in fact the simple procedure that Descartes himself assumes it is. Husserl claims that Descartes fell into an inconsistency concerning the claims of clear and distinct ideas as being anything "more than a characteristic of consciousness within me," as a result of which, Descartes "missed the genuine sense of his reduction to the indubitable" (Husserl, Cartesian Meditations, p. 83). In its place, Husserl would substitute the transcendental reduction of the epoché that would come to terms with fact that, even if what is external to the world of sense for the transcendental subject is nonsense, "even nonsense is always a mode of sense and has its nonsensicalness within the sphere of possible insight" such that the ego can explain itself as both selfconstituting and "constitutes in himself something 'other', something 'Objective', and thus constitutes everything without exception that ever has for him, in the Ego, existential status as non-Ego" (ibid., pp. 84 and 85). Fink continues this critique in the only mention of Descartes in the Sixth Cartesian Meditation, when he criticizes possible misunderstandings of the epoché as having "a 'simple straightforward aim,' namely, that it is nothing but a method of confirmation, an 'exaggerated methodism"' such that phenomenology would presume to operate from a position without presuppositions, "a fateful prejudice to demand for the beginning of philosophy-since Descartes" (Eugen Fink, Sixth Cartesian Meditation: The Idea of a Transcendental Theory of Method, tr. Ronald Bruzina [Bloomington, IN: Indiana University Press, 1988], pp. 45 and 46). (He names Heidegger as one of those who misunderstand the epoché.) Fink's response is that these objections are irrelevant because the epoché "puts into question what all 'existential' philosophies of this kind presuppose: buman being itself (the natural attitude)" (ibid., p. 46). Even more, the reduction of phenomenology is not to be confused, for Fink, with "the mundane cognitive antecedency of consciousness before the objects of experience for a mudane-ontic antecedency in being on the part of experiential life before that which is experienced" because the phenomenological reduction "interrogates [the antecedent consciousness as well as man in the world and makes] them the theme of a transcendental clarification," without turning an apodeictic inner experience into "'absolute being"' (ibid., pp. 47-48). Thus, in these passages, the critique of the Cartesian method of analytic reduction seems to be grounded in an idea of analysis, or at least reduction, and the bracketing off of the world that this analysis requires in seeking out the apodeictically certain self, is too simple, straightforward, and presumptively without presuppositions, leaving Descartes open to the charge that he misses the genuine meaning of this procedure. However, because both Husserl and Fink ignore the fable-logic or -structure that is always at hand in Cartesian analytic reduction, especially insofar as that structure or logic, qua fabular, can be aligned with syllogism and synthesis, they would thereby seem to begin their critiques from what may itself be a misunderstanding of Cartesian logic and method. If analysis and synthesis are, in Descartes, in an antistrophic relationship thanks to the fable-structure or -logic which inaugurates the movement down the path of the method, such that it is difficult if not impossible to specify at which point the analysis ends and the synthesis begins, if the common notion that would serve as a 'premise'-maxim for the analytic method is established thanks to a fable, an invented example, a gnomic story, a whole new potential world of sense, then the Cartesian relationship between analysis and synthesis would seem much closer to the relationship between passive and active synthesis that Husserl describes, without the presupposition that activity "necessarily" makes concerning passivity (Husserl, Cartesian Meditations, p. 78). And perhaps the fable-structure or -logic that sets this antistrophic relationship to work is more fundamental, without being transcendental because not simply a condition for the possibility of the method but interwoven within it even while it grounds the method, than Fink's understanding of science as the synthetic unity of antithetic demonstrations which is the "working within the phenomenological concept of truth" (Fink, Sixth Cartesian Meditation, p. 134).
} 


\section{The Whole Method}

What is the whole method, if it is whole?

The whole method [Tota methodus] consists entirely in the ordering and arranging of the objects on which we must concentrate our mind's eye [mentis acies] if we are to discover some truth. We shall be following this method exactly if we first reduce [reducamus] complicated [involutas] and obscure propositions step by step [gradatim] to simpler [simpliciores] ones, and then, starting with the intuition of the simplest ones of all [simplicissimarum intuitu], try to ascend through the same steps [per eosdem gradus] to a knowledge of all the rest.

For Descartes, Rule Five covers almost the whole of human industry, though keeping to it carefully and closely appears to be rare and difficult. This rarity of following the method is a result of a failure to reflect upon it (reflectere), a failure of ignoring it, or a failure of presuming it to be unnecessary. ${ }^{18}$ Committing these errors results in a disorderly (inordinate) approach to problems (quaestiones), driven in particular by a desire to leap ahead by too many steps (scalae gradibus) and make claims that have not been earned by the proofs at hand. Studies that are specifically named as committing these errors are astrology, mechanics without physics, and philosophy that fails to take account of experience (see CSM I, pp. 20-21; AT X, pp. 379380).

\footnotetext{
18 As with Murdoch's translation to 'reflect', in his French translation of the Regulae, Marion also translates reflectunt to réfléchissent, which is clearly correct (see Descartes, Règles, p. 16). However, using reflectere as a synonym for thinking seems somewhat an unusual choice on Descartes' part, though it is hardly a hapax in his corpus. Following Lewis and Short, s.v. "reflecto," http://www.perseus.tufts.edu/hopper/text?doc=Perseus \%3Atext \%3A1999.04.0059\%3Aentry \%3Dreflecto, accessed May 24, 2013, the closest to a connection to thinking is a reference to Seneca's Agammemnon ("animum reflexi") but otherwise all definitions and nuances center on the physical act of bending, turning back, or yielding. In addition, in Robert Estienne's 1594 FrenchLatin dictionary, reflechir simply refers to flechir, and the latter does not appear to refer to any act of thinking, except perhaps the entry "Iuger sans flechir," but that merely translates to "Incorrupte iudicare," and so does not maintain the etymological link to flectere (Robert Estienne, Dictionnaire françois-latin [1594], s.vv. "reflechir" and "flechir"). In addition, reflectere does not appear at all in Rudolph Goclenius, Lexicon philosophicum (1613), nor does "reflect" appear in Roger Ariew, et al., Historical Dictionary of Descartes and Cartesian Philosophy (Lanham, MD: The Scarecrow Press, 2003). Finally, the earliest citation of "reflect" used as a synonym for thinking in the Oxford English Dictionary is from 1605 (Oxford English Dictionary, 2 ed., s.v. "reflect"). Thus, it does not seem likely that Descartes, in using reflecto as a synonym for thinking, is doing so in an entirely unique fashion, but what the origin of that use is, is difficult to identify, especially insofar as, between Estienne and Goclenius, there seems to be no mention of this use, even though the use of cognate for reflecto in English appears in the years between them and Descartes is using it in his Latin a decade after Goclenius.
} 
However, Descartes recognizes the difficulty of following the whole method, in particular because "the order [ordo] that is required here is often so obscure and complicated [intricatus] that not everyone can make out what it is," which is why Rule Six is required to supplement the whole method of Rule Five. Rule Six claims that,

In order to distinguish the simplest things [res simplicissimas] from those that are complicated [involutis] and to set them out in an orderly manner [ordine], we should attend to what is most simple in each series of things [rerum serie] in which we have directly deduced some truths from others, and should observe how all the rest are more, or less, or equally removed from the simplest [maxime simplex].

This rule, even if not new or unique (novum), is considered the most useful (utilissimus) in or of the Rules. It is more useful than the whole method of Rule Five, then, because it shows how to arrange things into groups according to previously known things such that difficulties can be regularly, serially, usefully resolved through comparison of knowns and unknowns grounded in their relative or absolute utility. Those of absolute utility are "whatever has within it the pure and simple nature [naturam puram \& simplicem]" of independence, causality, simplicity (simplex), universality (vniversal), singularity (vnum), equality, similarity, straightness (rectum), etc., while those of relative utility share at least something of the nature of those of absolute utility like dependence, and so on. What is most important in Rule Six is the emphasized attention to the most absolute, and thus what has the simplest nature, of which there are only a few and these can be immediately intuited (intuer) by experience or by the natural light, allowing the numerous relatives to be deduced immediately or with a few inferences. However, since Descartes' interest is not in retaining all these intuitions and deductions in memory and since maintaining these deductions is difficult, becoming accustomed to reflecting (reflectere) on details of what has already been determined will be the wisest approach, even if the reflective process can seem childish at times, as with reflection on mathematical relationality. It is the wisest approach because such 
attentiveness will steadily and serially give rise to coming to terms with more complex problems and because it will show that, while there may be diverse paths (diversae viae) to the same solution, one will be clearer and more direct than another. (CSM I, pp. 21 and 22-24; AT X, pp. 381 and 382-387)

Here, I want to focus on the necessary supplementation of Rule Five by Rule Six, and the latter's superiority to the former. At first it appears as though Rule Six is a guideline for ordering and arranging things upon which the mind's eye, the acumen, the mental power of Rule Five must focus. However, to know how to order what appears before the mind's eye requires attending to things that have already allowed some truth to emerge. That is, for the mind's eye to properly observe and deduce truths, some observations and deductions of truths must have already occurred. This deduction may very well be the result of an analysis, a pulling apart of the complicated, involved, and relatively simple truths bound or rolled up within the complex of the world as given, so that an intricate or complicated synthesis of steadily more complex and relative truths can be brought together from out of the analysis's reduction to absolutely simple truths. Yet this would mean that the absoluteness of the absolute and simple truths that are the ground for arranging and ordering the relationality of relative truths can itself only be relative to relative truths, since they emerge qua absolute only in comparison with the relativity experienced by the remainder of the things of the world as given. Thus, the simplicity of the truths being pursued in the whole method of Rule Five has itself already been given to us, if in a complicated and involved manner, according to Rule Six. ${ }^{19}$ This thus means that Rule Six supplements Rule Five in a deconstructive sense

\footnotetext{
${ }^{19}$ Nancy makes much of the fact that Descartes wrote the Rules in notebooks, rather than on a scroll: the Ancients wrote on the scroll, the volumen, the Moderns on the cabier, i.e., according to some, the codicarium, the small codex, and according to others, more learned, on the quaternum, the codex of four leaves. I write on the codex, whose paper does not close up on
} 
since it not only adds onto Rule Five the necessary guidelines for the whole method but also indicates what is necessary to have noticed before beginning the process of determining a need for method. ${ }^{20}$ More than the luck that contributes to a curious person's hitting on a truth that otherwise results in deception that inaugurates Rule Four's explanation why “ $W e$ need a method," Rule Six's double supplementation of Rule Five indicates a method before or for the method, a method for identifying what is simple as opposed to what is complex, such that the method can be applied in its useful and simple manner. The whole method would itself in a process of involution, as is the case with the volume, but offers its plane surfaces
always ready in advance for writing as for reading; its leaves turn one after the other, can be
numbered, making reading and writing more practical [pratique] in all respects, as befits the
epoch which I will inaugurate [inaugure] and which will be that of a 'practical philosophy'
intended to 'make us like masters and possessors of nature'. The codex is made of wood--
from the stump or trunk—of that very wood of which the liber, between the bark and the
sap-wood, will be used to make the book [livre]; the codex consists of leaves of wood joined
at the back and articulated upon one another. It is a writing machine suitable for connecting
up all the monstrative and demonstrative principles of knowing in the clearest, simplest, and
most rigorous manner possible. I am writing its rules, drawing up its code; I am making a
book, codifying the Truth, making it inseparable, indissociable and indiscernible from the
operation which here and now inscribes its rules. I am making the first book, with the
knowledge that knows itself in the act and manner of inscribing itself. (Nancy, "Dum
Scribo," p. 7)

And yet, though it is true that Descartes writes in a codex, it is perhaps too much to say that he is not involved with scrolls and rolling. According to Rules Five and Six, the method is intended to be an unrolling, an evolution of simples from out of complicated, involved things, but these Rules are involved with each other insofar as Rule Six gives to Rule Five what was necessary to have noticed before the whole method of Rule Five could have been applied. In the very serial laying out of the rules for the method in the codex of the Regulae, these rules fold back on each other and into each other, making a scroll of the codex, perhaps even a scroll within the codex. This would seem to complicate the code of the truth in the book even as this truth is "inseparable, indisocciable and indiscernible from the operation which here and now inscribes the rules" since even a simple truth is necessarily more complicated and involved than a simplex of laid-out truths would appear to be, and is more complicated precisely because of the seriality involved in that laying out.

${ }^{20}$ The deconstructive sense of supplementation emerges from the dual meaning of the word 'supplement' as that which completes something which has a lack and that which is an unnecessary addition to what is already complete. Its most famous deployment is found in Jacques Derrida, Of Grammatology, tr. Gayatri Chakravorty Spivak (Baltimore, MD: The Johns Hopkins University Press, 1997), pp. 141-164. There, Derrida points out that Rousseau's use of supplement to describe masturbation's relationship to copulation means, at first glance, the latter understanding of 'supplement', that masturbation is an unnecessary, even unnatural addition to copulation, like writing to speech. However, in that there is no specific demand for the word to be attributed this meaning, masturbation can also be read as the completion of copulation. That there is no absolute demand for either reading to gain precedence over the other, no reading more natural than the other, the supplement of masturbation to copulation can be both. Here, then, I am claiming that Rule Six's supplementation of Rule Five operates in a similar fashion, if inverted in its priority. Rule Six may appear as if it supplements Rule Five in that the former completes what is lacking in the latter, but simultaneously, Rule Six adds more onto Rule Five than would appear necessary in terms of the wholeness of Rule Five. 
appear not to be whole at all, then. Rather, it requires a method to identify how and why it is to come to be. (CSM I, p. 15; AT X, p. 371)

In its supplementation of Rule Five, however, Rule Six is itself supplemented by Rule Five. Rule Six, in indicating the method necessary for the whole method through the identification of the absolutely simple relative to the relative and complex from within the complex of the world as it is given, gives rise to the whole method qua whole, total, complete, pure, and simple. It is this very totality and simplicity, even if it is an intricate simplicity, that gives credence to the necessity of the supplementation of Rule Six as laying out a guideline for the simple procedures inherent to Rule Six. Thus, the totality indicated by Rule Five supplements the procedures of Rule Six by indicating the absoluteness and simplicity to be pursued by those selfsame procedures, procedures that themselves derive their seriality and utility from out of the clarification of absolute and relative. In short, then, the very simplicity of the method, a method that opens a less obscure and more direct path to truth, is justified by its procedures for identifying the simple truths it pursues, but its procedures are themselves derived from out of its absoluteness, totality, and intricate simplicity. Rules Five and Six are interwoven within and involved with each other, supplement and justify each other, which, even in their ostensibly superficial separation into two rules, indicates a lack of wholeness on the part of the method presented as whole, and thereby a complexity to it that it otherwise would deny. ${ }^{21}$

${ }^{21}$ Cavaille points out that "Simple corporeal natures form the a priori frame for sensible perception, not as things of the world, but inasmuch as they constitute the look that we bring to [portons sur] the world. The great book of the world is legible only because the mind furnishes its reading principles which allow for bringing its grammar and glossary to light" (Cavaillé, Descartes: La fable du monde, p. 104; my trans.). For Cavaillé, though, this situation, insofar as it turns the mind toward decoding the book of the world, which is a task the arbitrariness of which could only be mediated by "leaving it to the arbitration of the Author," which would seem to undermine the primacy of the decoding, thinking subject (ibid.; my trans.). What Cavaillé does not emphasize here is the doubly supplemental relationship between the method of decoding and the relationality of simple and complex natures at hand in Rules Five and Six. That is, these simple corporeal nature may very well form an a priori frame for perception, but such corporeal natures are simple only to the extent that they 
The fable-structure or -logic that gives rise to a deployment of analysis that thereby

interweaves analysis and synthesis within rhetoric and logic, thus has an effect on the conceptualization of the whole method qua whole, in the conceptual connection between

wholeness, purity, and simplicity. The intricate and complicated totality of the method, which needs to be unknotted in a supplemental rule that simultaneously gives the justification for the whole method as a pure and simple analysis in search of simple truths, as an effect of the fable-structure or -logic that interweaves analysis and synthesis within rhetoric and logic, thereby complicates that totality by involving it within the relativity of

are not complex natures that are to be decoded, and the complexity of complex natures remains such only in relation to the simplicity of the natures which will be brought to light in the decoding. In this way, the appeal to the great author of the great book of the world as an appeal to arbitrate the decoding of the book is not necessarily an appeal to anything other than the grammar and glossary of reading itself, not necessarily to its author-by which we could refer to either the author of the book or the author of the grammar and glossary. The grammar and the glossary of the book of the world are coherent insofar as they expose and explain the frame for a comprehension of the book, but the book itself requires the frame of a glossary and grammar into order to be coherent and comprehensible. We are not discussing just any book, after all. We are discussing the book of the world, the world as something that can be comprehended and/or decoded, and the grammar and glossary of such a book can never be fully external to the content therein because they are themselves already involved in that content. However, the impossibility of externality between the grammar and glossary and the content of the book of the world does not indicate that there is a wholeness to the 'bound' book at hand. Rather, this book's 'supplementary' material becomes, by turns, more central than the content, even while its content establishes the grammar and glossary itself.

It is in this way that Stephen H. Daniel offers a response both to this concern in Cavaillé, perhaps unwittingly in this case, and to Nancy's claim that the truth of Cartesian science requires a vestment of mathematics. In describing Descartes' response to Baconian claims that "True invention . . . brings into our experience new objects, meanings, or ways of viewing the world in order to attain the truth by means of expanding our comprehension of the world," Daniel explains that Cartesian invention has a "need of a prior criterion for determining true inventive insights" (Stephen H. Daniel, "Descartes on Myth and Ingenuity/Ingenium," pp. 160 and 161). Thus, according to Daniel, "The value of mathematics does not lie in its of figures to provide an imaginary covering (integumentum) of objects or truths inaccessible to sensible description. Its value lies in its procedures which accustom ingenium to distinguish valid arguments and truths known with certainty from those which are unsound, false or only probable" (ibid., p. 161). Daniel's claim that mathematics establishes the frame for decoding the book of the world is fair enough, and it could seem that this would give credence to Cavaillé's claim that this frame is a priori. However, Daniel goes on to explain that "the activity of ingenium is simply that of attending to ideas which are already formed in order to detect the correctness of their interconnectedness," which is why, "at the very outset of the description of his physics ..., Descartes acknowledges in The World ... that he is sensitive to the imaginative or poetic character of such a description" (ibid., pp. 161 and 162). The precedent interconnectedness of ideas is the frame or glossary and grammar of the book of the world, but, as Daniel points out here, that very interconnectedness is itself the result of an imaginative and/or poetic moment, a moment not established by the great author of the great book of the world, but by the reader of that book. In this way, the glossary and grammar and the content of the book, the interconnectedness of the ideas and the methodical description of that interconnectedness, are never separate from each other. Rule Five and Rule Six involve, complicate, and supplement each other. The rules are generated by what would follow them, and rule-obedience is the generation of the rules themselves. 
effects rather than being purely an absolute as much as the structural relativity of the

absolute's relationship to relatives does the same. That fable-structure or -logic, then, has an affect on the whole of the Cartesian corpus. ${ }^{22}$

\section{The Self and God}

As a supplemental example to the above claim, I would like to turn attention to the first proof for the existence of god in the Meditations. In chapter 2, I had tried to establish that the fable-like hyperbolicity of the doubt at hand, in its giving rise to the self-deception of the evil genius who deceives, opens on to the proof of the self as a thinking, because doubting, substance. Following the clarification in the Seventh Set of Objections with Replies, doubt is in "our thoughts [nostra cogitationes]" and not "in the objects." This means, then, that the doubt that inaugurates the need for the deception and self-deception that proves the self is

22 As to the question of wholeness, Verene places fable under the category of narration, which "holds the individual arguments of a total philosophy together" (Verene, "Philosophy, Argument, and Narration," p. 143; my emph.). A total philosophy, for him, is the fashion in which various elements of a philosophical argument are held together, since "A philosophy cannot be simply a collection of arguments found in one place" and arguments "are only interesting for the role they play in some narrative" (ibid.). This seems to me true almost to the point of obviousness (though perhaps for that very reason worth stating and restating). Yet, what is in question in this particular element of the whole of Descartes' philosophy, the element concerning the whole of the method, is whether that part of the whole, which purports to be whole itself, is in fact whole. The method is not wholly analytic, nor is it wholly contained in the Rule that claims to contain it. And all the more, if Descartes' appeals, through the appeal to analysis, to readers taking up the method in their own ways are to be believed, then it is at least questionable whether the method should be referred to in the singular. What is more, it would appear that the interwoven, doubly supplemental, and never fully complete method at hand is a result of the fable-logic or -structure that brings the method to the fore in the first place. These narrative momentstelling an histoire or fable, meditating for 'six days', giving a new account of creation ex nihilo-are what establish the logics or structures by and through which the method can emerge. That those fabular or narrative moments do not operate according to the method that emerges from them even as they deny the foundations of that against which they orient themselves is not an indictment of the moments. Rather, this disruption of the structure that allows for the wholeness of the Cartesian system to appear demands an attention to its very fact because what this fact says about the method, about the total philosophy that Descartes develops through that method, is something like a claim to being both inside and outside that total philosophy. The fable allows the total philosophy to become whole, and the fable is both inside and outside that philosophy, is the generating of the rules which it itself is supposed to obey, is the field within which the method that will even go so far as to critique it comes to play. The narrative qua narrative, the fable-structure or -logic, here holds the individual arguments together, to be sure, and in doing so it is both part of and not part of those individual arguments. 
itself in the self that it proves. ${ }^{23}$ But since the object being doubted, in the doubt inaugurated

by the self-deception that conjectures the evil genius, is that same self, then this doubt is in

the object being doubted. Such is the virtuous circle of the Archimedean foundation for the

rest of the Meditations, the hyperbolicity of the proof of the self. (CSM II, p. 319; AT VII, p.

This Archimedean ground, this hyperbolicity and virtuousness not to say the intricate

virtuosity of the proof of the self, is never merely proven, however. Because it is the

Archimedean ground for all other proofs, it is, even if only formally, but not just formally, reproven with every other proof of every other thing. That is, the proof of everything that

\footnotetext{
${ }^{23}$ It is here that at least an aspect of Marion's understanding of a Cartesian gray ontology can perhaps become clear. As Marion explains it, "Being known always conveys a way, exactly, of Being. The way of Being that leads beings back to their status as pure beings is put forth in what Descartes inaugurated-Being in the mode of objectum" (Marion, On Descartes' Metaphysical Prism, p. 91). As a result, Descartes can be distinguished from Aristotle in that "physics does not reach the ens" since beings are not defined through their relationship to physics, "but uniquely and sufficiently according to objectivity" such that the objects of mathematics, i.e., the things of the world as these objects, are beings, have their ways of being in a mathematical, objectively known being which remains at a distance from the physics of the world of these things (ibid., p. 92). Objects, then, are "led back" to their being as beings known in mathesis, which is why "The mind is known better than and before the body, the mathematical essence of material things ... before these same things" (ibid.). This leading back to the being of things as being known is what Marion calls Descartes' gray ontology, and it "would remain impossible without the intervention of another authority," that authority being that of the self, which knows beings as beings which have a way of being in being known (ibid.). In terms of the self, the operation of this gray ontology shows that the cogitatio "comes back to itself. It comes down to coming back to itself, to the point of knowing itself first (. . me cogitare), to the point of constituting itself as a being (ego), because, more originally, it bends back over itself" (ibid., p. 93). In this bending or leading back to itself, the cogitatio makes itself an object which is insofar as it is known, and this "implies a reflecting appropriation, the ultimate implication of which is named-ego," making the operation of the cogitatio which leads objects back to their gray ontological status as known beings a "curve of thought" which can be called "the "logic' in Cartesian thought" (ibid., p. 94). This curve of thought of a gray ontology might also be called the fable-logic or -structure identified in the previous chapter, whereby a new world is imagined or a self establishes itself in a hyperbolic logic of doubt and self-deception. Marion anticipates two objections to this position, the first that it is in contradiction with "the Cartesian way of thinking" whereby "analysis arrives at the existence of the ego without passing through doubt, or ... admitting that a new operation of thought ... is required for this effect," and the second is that it "leads one to identify the being par excellence with the ego, thus with a finite being and not with God" (ibid., pp. 95 and 96). Marion's response to the first point is that the analysis of the piece of wax "extracts the ego (cogitans) directly from the cogitatum, or rather from the interpretation of the objectum as a cogitatum," meaning that the analysis of the piece of wax involves a "reduction ... to the actually operative cogitatio" just as much as the self's proving of its own existence to itself (ibid., pp. 97 and 98). To the second point, he replies that "The cogitatio sui offers too little to be able to designate God. A finite res cogitans is enough to accomplish the gaze focused on objectness" (ibid., p. 102). I would contest only this last reply, and only to the extent that the res cogitans is precisely finite, but this contestation emerges from the question of what allows, in Marion's language, the cogitatio to lead itself back to itself as a known being known to itself called the ego, to inaugurate this operation at all. Fabulation accomplishes this, and accomplishes it thanks to what I will call, in chapter 4 below, the transfinite status of the imagination as distinct from other faculties.
} 
follows after the proof of the self moves through the operation of intellectual perception of presenting ideas for judgment to determine their clarity and distinctness. This is the same operation by which the self is proven to itself, and the idea of the self is the model of clarity and distinctness against which all other ideas will be judged. But what is more, because the operation of judgment whereby the self proves itself to itself is simultaneously all that is known of the self, this operation itself is also all that the self is at the moment of the Archimedean foundation for all other proofs of clear and distinct ideas. As a result, all other proofs are always also proofs once again of that self both in that they expand the knowledge which constitutes that self and in that all knowledge moves through the operation which is always also the proof of the self's existence (i.e., the intellectual presentation of ideas for judgment concerning their clarity and distinctness). The self is the model of proof, and is thereby proven again and again with every consequential proof (see CSM II, p. 24; AT VII, p. 35), just as Descartes describes the mathematical example as a model of the whole method in Rule Six (see CSM I, pp. 23-24; AT X, pp. 384-387). What is more, insofar as the object and cognizer in this proof are identical, there is a coincidence of subject and object. As a result, there can be no middle term from which a syllogism can form, no logical demonstration of the self. It is this identity that demands a different form of proof in order to prove the self, not only because the self is an object unlike any other, but also and all the more precisely because it is the foundational model, reproven with every subsequent proof, for all other proofs. Thus, the hyperbolicity of the proof of the self is indeed hyper-bolic in that it throws itself beyond itself and the self that it proves as object and cognizer of the doubt, a relationship between object and cognizer that itself is hyperbolic in throwing the self beyond itself in ob-jectifying itself, in throwing itself up against itself, via doubt. ${ }^{24}$

\footnotetext{
${ }^{24}$ Merleau-Ponty seems to be touching on this point when he claims that the claim to "auto-apparition," or the
} 
However, this cognitive substance, which proves itself in doubt thanks to the selfsupplemental relationship between object and cognizer in this particular proof that is then reproven with every new proof insofar as it is the model for proof itself, remains not fully proven. It remains unproven because the cognitive substance, which proves itself as a substance itself via doubt, cannot derive itself from itself, despite the coincidence of object and cognizer in the proof. If doing so were possible, "I should neither doubt nor want, nor lack anything at all; for I should have given myself all the perfections of which I have any idea." Thus, even the substance that is proven in a self-supplemental proof, is proven not to be derived from itself with the selfsame certainty as the proof of itself, following its model of proof. $^{25}$ (CSM II, p. 33; AT VII, p. 49)

pure Cartesian thinking associated with the appearing of the self to the self, "presupposes the idea of the for itself and in the end cannot explain transcendence" (Merleau-Ponty, The Visible and the Invisible, p. 191). For Merleau-Ponty, the for-itself is derived from "differentiation," the differentiation that is the world, and from out of which the presence of the self presents itself to the self (ibid.). For him, this perceptual differentiation operates and encloses being through "language as differentiation," leaving consciousness as the differentiation of a figure from the ground on which the figure appears (ibid.). That is, the linguistic moment of "this, not that" between the figure and the ground is the moment of consciousness, from out of which the supposedly foundational moment of recognizing the self as a self for itself, as a thing of which the self is conscious, can occur. Perhaps I can be forgiven, however, for insisting on doubt as the operative element for the autoapparition at hand rather than language as differentiation, if only because, while language might allow for the moment of identifying one thing against another, doubt is what drives the particular moment where language as differentiation folds back on the one who uses language to differentiate. It is doubt, and especially hyperbolic doubt, the doubt that doubts the existence of the doubter, that allows for the self to become objectified in such a way as to differentiate itself from any and all other things, all those other things which are dubitable. While this might not explain transcendence, it is at least a performance of transcendence, insofar as the self must doubt itself in order to present itself to itself as an object. Thus, the self must exceed itself, rend itself from itself to see itself qua figure, even if the ground against which the self is identified is nothing, or at least dubitable. The transcendence, the making-oneself-mad of the hyperbolicity of the doubt may not be able to explain, to put into language, the transcendence it experiences in the appearing to itself as an object (which is already an odd demand on Merleau-Ponty's part considering the role he give to language), but that does not mean that the performance or experience of the doubt is not a performance or experience of transcendence.

${ }^{25}$ James Blizman distinguishes between models and analogies insofar as an analogy is "the vanishing point of the image" (James Blizman, "Models, Analogies, and Degrees of Certainty in Descartes," The Modern Schoolman, 50 [1973], p. 183). He establishes a spectrum or hierarchy with images and concepts at the poles, models falling between them, analogies falling between models and concepts, and symbols falling between models and analogies. As a result "analogy would be the vanishing point of the image," though "The use of analogy does not preclude the use of images but only imposes special conditions on their use" (ibid., pp. 183 and 184). This is especially the case when "immaterial concepts" like 'purpose' are being transferred, which should occur "When the mind is comfortable in a domain and knows its ability to read off the actual structure of reality in this domain" (ibid., pp. 184 and 196). On this reading, the proof of the existence of the self would appear to be the model for the proof of the existence of god. The proof of the self is the most familiar structure Descartes 
Because of the need for some other form of proof in order to prove the self to itself, and because the substance of what is proven in this proof cannot derive itself from itself, it appears that the substance of the self is a relative and dependent truth, caused and preserved by the being that can derive itself from itself, that is an absolute and independent truth: god. ${ }^{26}$ The analytic method that proves this independent and absolute god does so by modeling its proof on the Archimedean proof of the self, which has already thrown itself beyond itself in objectifying itself in the proof. ${ }^{27}$ That Archimedean proof of the self appears

has - in fact, the only structure for proof at this point in the text-but it remains an incomplete proof, one that must reach out to something else in order to fulfill itself as a proof. Thus, the proof of the self must prove something beyond itself, something that has not yet been proven on the model for proof that is the proof of the self, in order to fully prove itself. It would seem that, under no circumstances, could the structure of the proofs of either the self or god be complete in themselves enough for an analogy to condition the use of the 'images', abstract as they are, between the proofs. It is for this reason that I would contest Blizman's claim that the evil genius is a mere "heuristic device" and that "there is no question of trying to imagine a real item" there (ibid., pp. 204-205; my emph.). If the proof of the self is a model for the proof of god, which itself requires the supplement of the proof of god, such that the proofs of the self and of god would appear to reflect and supplement each other, interweaving themselves into each other, and if the evil genius is the apotheosis of the hyperbolic doubt that finally brings the proof of the self into clarity and distinctness, even if this proof requires supplementation, then there is no analogy between god and the self which could condition the use of imagery in either proof. Indeed, this relationship would make much more sense of Desacrtes" claim that "it is no surprise that God, in creating me, should have placed this idea [of a being with all perfections] in me to be, as it were the mark of the craftsman stamped upon the work- not that the mark need be anything distinct from the work itself. But the mere fact that God created me is a very strong basis for believing that I am somehow [quodammodo] made in his image [imaginem]" (CSM II, p. 35; AT VII, p. 51; my emphs.). There is some mode by which the self is the image of god, some way in which the self is modeled on god, some mode of being that makes the self a minor mode, a modulus, of god, through an unconditioned imagery-unconditioned because there are no other models than the self and god, and the structure of the proof of the self remains a model, a modulus, of the proof of god as much as the structure of the self itself is modeled on the image of the structure of god.

${ }^{26} \mathrm{It}$ is on this point that Husserl finds his two main critiques of Descartes. That god is the self-caused being on which the self depends is evidence of "how much scholasticism lies hidden, as unclarified prejudice, in Descartes' Meditations," in addition to the prejudice that the self is "an apodictic 'axiom', which, in conjunction with other axioms and, perhaps, inductively grounded hypotheses, is to serve as the foundation for a deductively 'explanatory' world-science” (Husserl, Cartesian Meditations, p. 24). To replace the Cartesian psychological ego which depends on the self-caused god, Husserl offers the transcendental-phenomenological ego as "the Ego who comes to the fore only with transcendental-phenomenological epoché" and "who bears within him the world as an accepted sense and who, in turn, is necessarily presupposed by this sense" (ibid., p. 26).

${ }^{27}$ When Marion addresses the idea of god as expressed in the ontological proof, he follows Kant's argument that the crucial decision made by Descartes in this context is that, "from now on, the 'ontological' argument relies on the (first) presupposition that a concept...can match the divine essence" (Jean-Luc Marion, "Is the Ontological Argument Ontological? The Argument According to Anselm and Its Metaphysical Interpretation According to Kant," Journal of the History of Philosopby 30:2 [1992], p. 204). Thus, god becomes a concept. Insofar as god is perfect being, a gap thus opens between essence and existence that, for Descartes, is emphasized 
rather than bridged by the supreme perfections that are god's essence, one of which is existence. Malebranche closes this gap by introducing the ontological argument proper in that "he re-establishes, at least tentatively the Thomistic identity of the divine essence with Being as such, i.e., in actu. God exists by the immediate consequence of his essence, which amounts solely to being," while Leibniz perfects it in that "he identifies the divine essence not only with the concept of being in general, but also definitively with the concept of the necessary being" (ibid., pp. 205 and 206). Four years later, when he takes up the question of the Cartesian god as self-caused, Marion finds that Descartes "shoulders the patent logical contradiction of the causa sui," which is a contradiction because, from Anselm to Aquinas to Scotus to Ockham to Suàrez, god as first thing is simply uncaused since nothing can bring itself into being, "because the onto-theological accomplishment of his metaphysics implies for him incommensurably more than a polemic even with the greatest medieval thinkers" (Jean-Luc Marion, "The Causa Sui: First and Fourth Replies” in On the Ego and on God, p. 148). Descartes attempts to mollify Scholastic concerns as to the contradictoriness of the claim that god can be self-caused by explaining that the causation at hand is not an efficient causation; that he is simply saying it is not impossible (non impossibile) for something to be its own efficient cause, or quodammodo or quasi self-caused; or even by "introducing a distance between the causality of the causa sui and strict efficiency ... as an analogy of the causa sui with efficient causality," an analogy that is necessary to guide the natural light (ibid., p. 156). Marion finds that the analogical mollification fails because the analogy to efficient causation fails to account for any of the contradictions that caused divine self-causedness to be rejected in the first place, especially the inherent anteriority of either a thing or a principle to god, and because the analogy to efficient causation either goes back to god "and all other beings would exercise it only analogically" or efficient causation only applies to finite beings (ibid.). Descartes' solution, that "God (the infinite) is said by analogy and by reference to finite being, while, according to theological analogy, the finite is said with reference to God" results in a number of tensions with other Cartesian texts, the most important of which here is that, "From a divine attribute, causality has become the divine essence” (ibid., pp. 157-158). Between these two essays, then, Marion's concern seems to be that, in making god a concept in the ontological proof, the gap between essence and existence would only seem to have been bridged by divine self-causation. That is, if efficient causation is to be thought in two analogical ways, where either, non-theologically, god is said to be self-caused by analogy to finite and efficient causation or, theologically, the finite is said to efficiently cause by analogy to divine causation, then there remains a gap between the conceptualizable essence of god and god's existence insofar as that existence is caused by the divine self because that essence of god could only be conceived by an analogy to efficient causation, which itself is supposed to be only an analogy to finite efficient causation. Thus, nothing has been conceived, but at best only analogized with itself. (For this reason, Marion is willing to concede Descartes as the founder of the ontotheological tradition of Heidegger's critiques even while Marion potentially excludes the medievals who deny divine self-causation from that tradition.)

A solution to Marion's dilemma is perhaps found in two separate essays: Blizman's article cited above, and Richard A. Lee, Jr., "The Scholastic Resources for Descartes's Concept of God as Causa Sui," in Oxford Studies in Early Modern Philosophy, vol. 3, ed. Daniel Garber and Steven Nadler (Oxford: Clarendon Press, 2006), pp. 91-118. Having already discussed Blizman, I will do so with Lee now. Like Marion, he addresses the Scholastic concerns with the argument for god as self-caused. Unlike Marion, Lee claims that "those concepts that Descartes mobilizes in making sense of causa sui were developed not in proofs for the existence of God based on causation, but with reference to God's infinity, power, and perfection," and that this argument is not posited against the medievals, but through them, or at least through Scotus and Suàrez (ibid., p. 92). (It should be noted that Lee cites neither of these Marion essays.) From the division of ideas into innate, adventitious, and invented by me arises the question of whence the idea of such a perfect being as god could come, which leads to the argument, using "terms ... familiar from our discussion of Scotus and Suàrez," that a thing's objective reality must be caused through the formal reality of its cause, a formal reality which must have at least as much perfection as the objective reality of what it causes (ibid., p. 113). Thus, the objective reality of the principle and most important ideas - i.e., those involving perfection and thereby god as the sum of all perfections-must come from something with at least that much formal reality-i.e., god as the being with all perfections. Replying to Caterus' concern that this means god is self-caused, Descartes' argument that it is not impossible for something to be self-caused develops into a claim that "the notion of cause, even efficient cause, does not demand that the cause be temporally prior to the effect" and that, since "the notion of causation is bound up with the notion of power, ... a being of infinite power would have to be cause of itself, otherwise it would be, to a certain extent, impotent" (ibid., p. 115). The power in question here is potentia (see CSM II, p. 78; AT VII, pp. 109), and for Lee "the immense and incomprehensible power that is contained in the idea of God" demands a positive sense of self-causation that itself builds from Scotus' "joining of efficient causation with 
significantly less Archimedean, then, because it requires a supplement to give ground to the

ground. Yet the ground for the ground requires that selfsame Archimedean proof in order to

give credence to the form of the proof for the ground of the ground. In other words, the

that of eminence" and Suàrez' linking "power to perfection and perfection to eminence" such that "we are allowed to think God in a certain way with respect to Godself as an efficient cause with respect to itself, and thus to be from itself positively" (Lee, “The Scholastic Resources,” pp. 115 and 116; my emph.). Having been pushed by Arnauld on the contradictoriness of self-causedness, Descartes says that the 'certain way', the quodammodo in which god relates to efficient causation is "the inexhaustible power [potentia] of God is the cause or reason for his not needing a cause" (CSM II, p. 165; AT VII, p. 236). For Lee, this means that "we can ask why God does not need a cause, and the proper answer to that is not Arnauld's 'because God is God', but rather 'on account of the immensity of God's power,", thus placing "the power of God . . between the essence of God and the existence of God" since, "Without this middle, the existence of God cannot be demonstrated at all" (Lee, "The Scholastic Resources," p. 116). Further, because essence and existence are only formally distinct in god and the divine potentia is deployed as a middle term between their distinctions in order to prove divine existence, "that power must be related to God in some way like an efficient cause is related to its effect" (ibid., p. 117).

With this attention to power, it seems as though Marion's concern is addressed. Making god a concept may very well separate essence and existence, but analogy between the theological and non-theological causations does not simply move between those causations alone. Rather, the analogy is itself possible thanks to the concept of power, or potentia. God's essence and god's existence are bridged through power, a concept which shows that this essence and existence are only formally distinct, and a concept which is also able to be analogized between efficient and divine causation without reducing divine causation to the contradictory position of efficient self-causation. In addition, by turning to Blizman's distinction between models and analogies, this concept of power is analogized "at the vanishing point of the image" such that the model between the proofs of the self and god are given conditions and structures and the self can imagine in what way, by what mode, quodammodo, it is an image of god insofar as the proof of the self is a model, a modulus for the proof of god: insofar as the self can cause, even if only efficiently, the power of causation, or at least the concept, idea, or notion of that potentia is analogizable with the concept, idea, or notion of the divine potentia which bridges god's essence and existence. In this way, Marion's concern about the double 'analogy' between finite efficient causation and divine self-causation is merely a concern for a double modeling between them, made possible and conditioned by the actual analogy of power. (That, as Marion points out, Descartes himself thinks he is making an analogy is more or less irrelevant here since it is the structure of the investigation and argument rather than its precise language that is the concern at the moment [see Marion, "The Causa Sui," p. 154]).

Finally, if power is the concept that guides the natural light in its analogical investigations of both divine self-causation and finite efficient causation, then it would seem that power is the concept that allows the method of those investigations to operate, and the capacity for analogy that the concept of power, of potentia brings about would in turn make possible the interwovenness, double-supplementarity, and non-wholeness between analysis and synthesis, logic and rhetoric, the proof of the self and the proof of god. The concept of potentia that would guide the natural light, however, would itself seem to need to be innate, adventitious, or invented by me. If this concept would be what makes possible the analogy between finite efficient causation and divine self-causation, then it seems as though this concept makes possible the analogy between the element of light and the motions of the mind. This concept, then, would seem to emerge from out of the fable, from out of the fable-logic or -structure at the heart of the Cartesian corpus. Insofar as the fable of light is a fable of an element that both causes and obeys rules, however, it is unclear whether the concept that emerges from it is precisely categorizable as invented by me, but no more can it necessarily be adventitious since the light of the fable would still generate rules, and it cannot precisely be categorized as innate insofar as it is a story told in order to set the mind into motion as a motion analogized onto the observed physical motion. If potentia is the concept that makes possible the analogies operative between the proof of the self as the model for the proof of god, this concept would seem to be conceivable only within the structure or logic of a fable because there is no ground for the concept without some story, some fable at hand to give it referential as well as reverential meaning. 
method whereby the existence of the self is proven gives credence to the proof of the

existence of god, but the proof of the existence of the self requires the proof of the existence of god insofar as the substance of the proven self depends on the substance of an otherwise unproven god. Thus the proof of the self and the proof of god supplement each other. This double supplementation need not be considered circular, at least not viciously so, but rather as a complication, an involution of the most simple and straightforward proof that gives ground to all other proofs, even while it is itself reproven in all other proofs. ${ }^{28}$ The point

\footnotetext{
${ }^{28}$ Samuel C. Rickless argues against the charge that Descartes committed the fallacy of circularity by focusing on what he calls the Natural Light Strategy (NL-Strategy) over and above the argument against circularity that relies on what he calls the Conditions of Doubt Strategy (CD-Strategy). The CD-Strategy claims that "the class of statements Descartes considered certain from the outset includes all and only those that serve as conditions or presuppositions of his use of the method of doubt in the First Meditation" (Samuel C. Rickless, "The Cartesian Fallacy Fallacy," Noûs 39:2 [2005], p. 310). Among such certain statements are the claim that the self exists because "it is a condition of using the method of doubt" and that everything has a cause, because "it is a presupposition of "the imperfection argument"' which argues that god could not have been created by something less perfect than god (ibid., p. 330). The NL-Strategy claims that "Descartes considered indubitable ab initio all and only those principles that he perceived clearly and distinctly (and non-demonstratively) by means of the natural light" (ibid.). The natural light being equated with the understanding, it is distinct from clear and distinct perception, with the result that, "although everything that is known by the natural light is clearly and distinctly perceived, not everything that is clearly and distinctly perceived is known by the natural light" (ibid., p. 310). As a result, to appeal to the natural light avoids the reasons for the hyperbolic doubt because the reasons for doubting come from perceptions, "whether clear or obscure, distinct or confused, that derive from the senses or from the imagination," and the senses, imagination, and understanding are distinct faculties with distinct perceptions (ibid.). Thus, "all that is required to validate these doubtful perceptions is an argument for the Truth Rule [i.e., the Fourth Meditation's claim that all clear and distinct perceptions are true] the validity and premises of which are distinctly perceived by the understanding (i.e., known by the natural light). Descartes takes himself to have provided exactly such an argument in the Third and Fourth Meditations" (ibid., p. 318). The advantage of the NL-Strategy is that it does not suffer from two critiques from which the CD-Strategy seems to suffer: (1) The NL-Strategy does not relativize "the epistemic status of a principle (as doubtful or certain) to the particular reasons for doubt offered in the First Meditation" because "what the natural light (i.e., the understanding) perceives clearly and distinctly does not depend on the kinds of reasons offered for doubting the perceptions of the senses and the imagination" (ibid., p. 331). (2) The NL-Strategy can explain the text of the Meditations better than the CD-Strategy, specifically "why Descartes grounds the indubitability of the 3M-Premises [i.e., the Third Meditation's argument for god's existence and truthfulness] in the fact that they are perceived by means of a special faculty (to which he gives the name "natural light')" (ibid.). I am, to an extent, sympathetic to this interpretation, if only because the charge of circularity is worth arguing against and because the CD-Strategy appears problematic, at least as Rickless presents it. However, both strategies seem to suffer from similar flaws, flaws which perhaps find their source in an assumption that all circles are vicious ("It is one of the most devastating of philosophical criticisms to be told that one has argued in a circle" [ibid.]), an assumption itself made possible by looking at the Meditations too late, by not attending to the structure that allows the text to emerge in the way it does. First, the NL-Strategy certainly and the CD-Strategy possibly ground their arguments in the belief that the faculties are established prior to the engagement with method. If the CD-Strategy grounds its argument in this belief, it is because the doubt which is conditioned is itself a mode of thinking and, if it is conditioned by the assumption of a self which thinks, then at least the faculty of thinking would appear to have been established as distinct from other faculties of the self. Again, this belief in a preformed faculty psychology will be argued against in chapter 4, below, but if it is an inappropriate belief, then
} 
from which Descartes would be able to prove the whole of the world, to escape the

conjecture of the dreamworld, is in fact no point at all. It is closer to a knot, a tight wrapping

together and interweaving of a series of at least one line or thread, but seemingly more than

one, concerning the most serious proofs and doubts that one can ever encounter if one is to

engage the world seriously, practically, and methodically. ${ }^{29}$

both the CD- and NL-Strategies would seem to have entered the Cartesian argument too late, and what they take as fundamental may be derived from something else. Second, this something else can perhaps be seen by focusing on the other name for the supposedly pre-established faculty of understanding: the natural light. If light, whether physical or mental, is the element that generates the rules which all elements obey and emerges from out of the potentia of chaos set into motion, then the natural light, and the methodo-logical rules which it obeys are also generated by it from out of the chaotic potentia of even the densest minds. This relationship to rules, to method and to logic, on the part of the natural light might be circular, but such a circle is only vicious to the extent that one assumes that all circles are vicious. Once again, both the CD- and NL-Strategies engage the Meditations too late in that they do not attend to the fabular structure that sets the potential method and logic for minds into motion. If that movement appears circular, it is not a vicious circularity for the very reasons that the NL-Strategy lays out. Indeed, the better geometric metaphor for the movement of the argument that the natural light generates and obeys its own rules is the one Descartes himself uses: hyperbole, the double arc that throws the line of doubt beyond itself.

29 Thus, here I mostly agree with Marion that "the 'I' does not become worthy of being put into question until it pretends to attain or to posit [itself as] a foundation... Y Yet in coming about, by the same gesture this pretension exposes the 'I,' which henceforth is inasmuch as it thinks, to two aporias—a scission and a closure" (Jean-Luc Marion, "The Originary Otherness of the Ego: A Rereading of Descartes' Second Meditation,” p. 4). I am not entirely convinced, however, that the self ever closes even in the loose sense Marion seems to mean here if only because I am not convinced that the self is ever transcendental, and this would be because I am not convinced the method that would allow the self to emerge can be considered the straightforward method that the transcendental closure of the self would require. For Marion, the scission occurs because, insofar as the self is the transcendental condition for the possibility of experience, it is excluded from experience in a strict sense only by objectifying itself. Thus, the scission is between "a first transcendental (hence abstract) ' $I$ ' and an empirical (real, but second) 'me." (ibid.). The closure occurs because the transcendental "I" remains transcendental and treats all other egos as objects so that "the ego is hence closed in on itself, without door or window, in the aporia of solipsism" (ibid., p. 5). As a result of this movement between scission and solipsism, Marion claims, correctly in my opinion, that "Transcendental idealism does nothing but simplify and ask this originary dialogical intrigue" (ibid., p. 27). Marion then asks if there might be "a figure of subjectivity other than the transcendental one" that could render the division between the scission and solipsism "joined' such that there could be "a primacy instituted by the event itself of experiencing itself originarily thought," suggesting that "Descartes also — and throughout — [might] have anticipated without knowing it, or at least without having signified it explicitly to us, that which comes after the [transcendental] subject and which we have not ceased to sketch and to await" (ibid., pp. 28-29). My disagreement with Marion is, in the end, perhaps minor, but I believe it worth mentioning. I believe he is correct that Descartes anticipates without necessarily realizing it, something beyond or other than what the tradition has thought him to have claimed in that the Cartesian subject is never the atomized figure of solipsism it is frequently taken to be. However, where Marion slips is in the source of what he calls the originary dialogical intrigue that transcendental idealism simplifies. For him, the originary dialogue occurs when the ego qua transcendental emerges through "the interlocution whereby an other than itself establishes it prior to every self-positing," which occurs through, first, an omnipotent god and, second, through the confusion and anonymity of the evil genius (ibid., p. 26). First, of course, the evil genius is never confused with god. The introduction of the evil genius is as follows: "I will suppose therefore that not God [non... Deum], who is supremely good and the source of truth, but rather [sed] some malicious demon of the utmost power and cunning has employed all his energies in order to deceive me" 


\section{Error and Inexact Science}

I must now turn back to the Rules, to those Rules that precede the whole method as well as what shows the need for a method at all. If the whole method is complicated by its relationship to what lays out the intricate procedure involved with following the method, complicating the already complicated relationship between analysis and synthesis, then attending to what precedes the whole method will show this method as not necessarily maintaining the foundational status it would otherwise claim for itself. Thus, I here want to turn to the first three Rules.

Before the Whole Method

The Rules begins with the claim that "The aim of our studies should be to direct the mind [ingenii] with a view to forming true and sound judgements about whatever comes before it." Thus, the end of the

(CSM II, p. 15; AT VII, p. 22; my emphs.). The very point of introducing the evil genius is to distinguish it from god. Insofar as this is the case-and insofar as the evil genius is a supposition, a speculation, a conjecture, or a conjured dream - the interlocution is always an interlocution with the self and therefore would not precisely escape the solipsism Marion thinks it does here. However, in the interlocution with god, some originary otherness does occur, though I am not convinced that it occurs in the way, along the methodology Marion claims it does. For him, naming god as infinite establishes "an unconditional otherness that precedes the ego of the cogito first chronologically and finally right to the point where this ego reveals itself first as a cogitatum, persuaded, deceived, brought about" (Marion, “The Originary Otherness of the Ego," p. 26). The fundamental issue I take with this reading is that is assumes the chronology of the precedent infinite god over and above the logic that allows that chronology to present itself. This logic allows the self to present itself to the self, then supplements this self with the presentation of god, a presentation which repeats the presentation of the self in its logical form. The infinity of god can only be logically prior to the self if the logic of chronology were the primary logic of the Meditations, which it is not. The primary logic of the Meditations is fabular, which allows Descartes the freedom to analytically present himself to himself before presenting god, a logic that shows the self in excess of itself via its repetition of its proof of itself in the proof of god. Marion seems to be working on the assumption that the primary method of the Meditations is a straight path, but this does not take the scission of the self seriously enough. The method is schismatic, especially so in the Meditations, and moves in more than one direction simultaneously, through an analysis that depends on synthesis, and vice-versa, through a whole method that is never fully whole, and through a presentational logic where what would appear to be chronologically second is presented first, and vice-versa. Marion's solipsistic transcendental ego can never fully close for the very reasons he gives for its closure: the interlocution between self and god. 
Rules is a directing of ingenium. ${ }^{30}$ Insofar as Rule One begins with a description of the ends

for the other Rules, it cannot be considered, in itself, a rule for the direction of ingenium. It is, rather, something of a preface or prelude to these Rules. The Rules here appear to need to be told not merely in what direction they are to direct ingenium, but that they need to direct it at all. By implication, then, ingenium needs to be told not only how to form true and sound judgments, but to do so at all. Descartes' claim concerning ingenium seems to be more radical than even similar claims concerning good sense in the Discourse and The Search. In those later texts, good sense in its potential is ready to be placed on the path to true and sound judgments, requiring only doubt to inaugurate that process. In the Rules, it appears that both ingenium and its potential for rule-obedience require a rule for the rules to be obeyed, a meta-

${ }^{30}$ Following Gilson, Sepper identifies Descartes' use of ingenium in the Rules, though mostly with Gilson's second sense of esprit for the Discours, as connoting "memory and imagination, as distinct from reason in its proper sense," though ingenium also incorporates aspects of the other two senses of esprit, which are "thought as substantial and personal" and "spirit as distinct from 'soul”" (Sepper, Descartes's Imagination, p. 87; see Gilson, "Commentaire Historique," p. 86). Most generally through history, ingenium "has clearly to do with the natural powers of things and, in human beings, with the natural powers associated with the rationality that differentiates them from animals, but that also includes the corporeal basis attendant on their being rational animals" (Sepper, Descartes's Imagination, p. 90). As Sepper traces it, ingenium develops from classical Latin's use of the word as "something inborn or innate .... With regard to the intellect, it could be used generally of the powers of the mind and be extended metonymically to the whole human being"; to the Scholastic nontechnical, though common, use in Aquinas to "indicate ingenuity or cleverness" or to "[suggest] the properly human powers of knowing that therefore fall short of reaching the things of revelation," and in Hugh of St. Victor as paired with memoria "as the two natural powers . . . that are necessary to prolonged study or meditation"; to the Italian Renaissance use "as the human power of understanding and invention that in its flexibility and adaptability underlies the effective use of words and that contrasts with reason"; to Goclenius' breakdown of its general, specific proper, and specific improper meanings in his Lexicon, where the most proper use is " the constitution of the rational faculty of the rational soul for understanding something or discovering or teaching”" (ibid., pp. 88-90; see Goclenius, Lexicon, p. 241). When Descartes was a student at La Flèche, ingenium was used as a category of assessment, roughly equivalent to "what we would today call 'natural ability,' talent,' or 'aptitude”' (ibid., p. 91). For Sepper, this history is important for understanding precisely what the Rules was to direct. Finding support for his reading in letters from 1619 and 1628 and the Early Writings, he ultimately defines the ingenium of the Regulae ad Directionem Ingenii as "the native endowment of the human being who is composed of body and soul (thus it would not be relevant to the soul that has been liberated from the body after death) ... ., in particular its cognitively relevant aspects" (ibid., pp. 96-97).

Stephen H. Daniel, in associating ingenium with 'mind', finds that the Rules maintains the sense of the mind's making new connections, not unlike what he calls the mythopoetic imagination of the Cogitationes, but that the Rules "shifts the focus away from cognitive invention and discovery toward the determination of the means by which ingenium can be directed or trained to attain certainty" (Daniel, "Descartes on Myth and Ingenuity/Ingenium," p. 160). In doing so, and finding particular evidence in the Conversation with Burman, Daniel argues that "mathematics in particular accustoms ingenium to the habit of recognizing the truth. ... In order to argue that mathematics trains the mind (ingenium) to make new discoveries, Descartes posits mathematical reasoning as that type of reasoning which serves in every domain of discourse to enable the detection of truth in those discoveries" (ibid., p. 161; see DCB, pp. 47-49; AT V, pp. 176-177). 
or proto-rule, if ingenium is to even make sense of the rules that will direct it toward true and sound judgment. ${ }^{31}$ (CSM I, p. 9; AT X, p. 359)

To be sure, it also appears that Descartes pulls back from the radicality of this claim in the text of the rule, when he claims that "what makes us stray [nos abducit] from the correct way of seeking the truth is chiefly our ignoring the general end of universal wisdom and directing our studies towards some particular ends." We stray from the path of true and sound judgment because of the bad custom of faulty comparison between the arts and sciences (artes and scientiae) so that we assume that the difficulties of one playing the harp well and farming well apply to the sciences as well. ${ }^{32}$ As a result, the sciences are studied separately when they should be studied in relation to each other with an eye "to good sense-to wisdom [de bona mente, sive de hac vniversali Sapientia]." The separation of the study of the sciences leads to a focus on discoveries that are either overly interested in increasing worldly comfort or in impractical contemplation of the truth such that we might overlook important truths which appear uninteresting or useless. Thus, for Descartes, one should study the sciences together with a focus only on "how to increase [angendo] the natural light of his reason ... in order that his intellect should show his will what decision it ought to make in each of life's contingencies." Descartes has not, at this point in the text, actually

\footnotetext{
${ }^{31}$ Marion sees in this moment a "radical reversal" of Ignatian vocabulary (Marion, "Annotations," p. 88; my trans.). Whereas Ignatius lays out a course of study with the transcendence of knowledge (cognitio, connaissance) through theology as an aim, Descartes "situates the aim of studies within knowledge [connaissance] itself" so that, following Bacon, "the finis of knowledge [connaissance] depends on principia which precede it, without in any way being confused with the very practice of knowing [savoir]" (ibid., p. 89; my trans.). Marion and I appear to agree, then, on the strange status of Rule One: It is a principle for the operation in which it simultaneously claims to participate, that operation being the directing of the mind, at least if Rule One is a rule for directing the mindif it is to be considered as participating in the practice of knowing even while it identifies the principia by which this practice is to be practiced.

${ }^{32}$ Cf. Plato, Republic, 397e-398b.
} 
begun the process of inaugurating that increase of the natural light (lumen naturale). ${ }^{33}$ Instead,

Rule One remains a rule for the Rules, removed from the actual operation of their

inauguration and regulation of ingenium, but regulating the Rules themselves in this inaugural

gesture. (CSM I, pp. 9-10; AT X, pp. 360 and 361)

However, Rules Two and Three still do not give the method itself, while Rule Four

only establishes why a method will be needed. They are also removed from the Rules that

direct ingenium, and thus are rules for those Rules. Rule Two explains that "We should attend

only to those objects of which our minds seem capable [videntur sufficere] of having certain and indubitable

cognition," while Rule Three clarifies what is meant by objects of which ingenium could have

certain and indubitable cognition: "what we can clearly and evidently intuit [intueri] or deduce with

certainty, and not what other people have thought [senserint] or what we ourselves conjecture

[suspicemur]." 34 Thus, the objects to which we can attend are only those that we can intuit or

33 When Stephen H. Daniel discusses the natural light, he acknowledges some serious difficulties in untangling its different meanings, potential and otherwise. Though his focus is primarily on the Meditations, what he says about the Rules is, as it were, illuminating. As a general rule, he identifies a "dialectic" between lumen and naturale such that lumen naturale could mean "Nature-as-light and nature-as-illuminated" or "light-as-nature and light-asnatured" such that "a discussion of the light of nature would demand a discussion of the nature of lightindicating the possibility for not only a physics of light but also a metaphysics of light" (Stephen H. Daniel, "Descartes' Treatment of 'lumen naturale,", p. 93). In the context of this moment in the Rules, the "natural light of reason' "indicates how the ideas which I have are to be judged as true or false, and that such judging activity can be used as the basis upon which to speak about matters of faith or morals," though Descartes does tend to hesitate on the latter (ibid., p. 96). The lumen naturale in this moment, then, would be the light by which the order of nature is illuminated, and thus in the first portion of the dialectic. However, to the extent that Daniel is correct about the dialectical relationship between the potential uses of lumen naturale, then the light of reason should be understood as natured, as itself emerging from the order of the nature the order of which is

illuminated by that selfsame light. Daniel himself does not seem to take this position, in that he concludes that "The reflective thinker specifies the 'natural' in his attitudes toward self, God, and the world" but not that this thinker would specify light (or reason) in those same attitudes, though it does seem an at least possible reading from what he does claim (ibid., p. 100).

34 While Murdoch translates intueri with 'intuit', Marion translates it with regarder. Save for a footnote where he writes, "Lat. intueri, literally, 'to look, gaze at'; used by Descartes as a technical term for immediate mental apprehension” (CSM II, p. 13n. 1), Murdoch never explains his translation of this term. However, though there is no cognate in French for 'intuit', Marion gives several negative and positive reasons for not translating intueri with some circumlocution of intuitif or intuition. The four negative reasons first: (1) Descartes never allows his translators to translate intuitus with intuition and Marion feels that a circumlocution like intuition intellectuelle is anachronistic. (2) Marion finds a neologism like intuitionner indecorous and circumlocutions cumbersome. (3) Even the seeming parallel between intuitus and lumen naturale fails because "Intuitus constitutes, more than its equivalent, the completion of the "natural light" (Marion, "Annexes," in Règles, p. 295; my trans.). (4) Descartes 
deduce with certainty, rather than any which others put before us or what we suspect

without clear evidence. ${ }^{35}$ The problem with the education system of syllogism and quaestiones

is reserved when applying the godlike or supernatural characteristics of cognitio intuitive or connaissance intuitive to the knowledge achieved by the natural light. The five positive reasons all hinge on a risked "equivalence between intuitus/intueri and regard/regarder" (ibid., p. 298; my trans.), and are as follows: (1) The substantive makes the use of a verb possible. (2) Following from the first reason, regard/regarder will not hide the original association with vision that intuition/intuitionner would. (3) The principle of retroversion is satisfied because Descartes uses regard or regarder in several other works and letters in contexts similar to that of the Rules. (4) Other translators, including especially Descartes' friend Étienne de Courcelles, use regard/ regarder to translate intuitus/intueri. (5) "Intuitus keeps [garde] under its sight [vue] the thing that it highlights; it takes it under its view [regard]; the composition in-tueri keeps quite effectively the surveillance and vigilance of tueri; re-garder maintains [maintient] exactly this very same second sense, of a look [regard] which keeps [garde], in a word, of a sight [vue] which holds [tient] under its look [regard] the thing which it 'has very much in sight [" a bien à l'oeil »]" (ibid., p. 302; my trans.).

In addition, the writers of the Historical Dictionary of Descartes and Cartesian Philosopby point out that, in the Rules, Descartes "explicitly denies that intuition can be our trust in the senses (which is fluctuating) or a judgment of the imagination (which is deceptive)" (Roger Ariew, et al., Historical Dictionary of Descartes and Cartesian Philosophy, [Lanham, MD: The Scarecrow Press, 2003], s.v. “intuition”). Meanwhile, they also claim that Descartes knows he is changing the definition of intuitus from the traditional Scholastic use and that, in his later work, it "seems to be replaced by [the term] of natural light" (ibid.). The writers of the Historical Dictionary do not acknowledge an explicit connection between intuitus as receiving the sensation of light and intuitus as replaced by lumen naturale, but such a connection seems difficult to pass over without comment. It would indicate that Marion is correct to be hesitant to translate intuitus with 'intuition' because the latter would appear to be more of a false friend than a cognate. For all of these reasons, in particular Marion's second and fifth positive reasons, Murdoch's translation of 'intuit' seems problematic, though I am unsure what would be a better word in English. Perhaps 'insight' could serve this purpose, but the traditional translation is 'intuition' and it would be cumbersome to challenge it beyond this note here.

${ }^{35}$ Nancy writes that "Intuition is a pure vision, a pure vision of the mind. I want here, without taking away any of its purity, to show it (la faire voir: to make it seen, to make it see)" (Nancy, "Dum Scribo," p. 10). Shifting between Rules Three and Twelve, he draws a connection between intuition and the intellect where the intellect perceives truth, but putting the general principles of true knowledge to work occurs by intuition. Thus, within the laying out of the Rules, to show the pure vision of intuition will require something other than the intellect, namely the imagination, sense perception, and memory. This intuition takes place in "the natural light of the mind," and so would appear to operate in the way Marion considers the relationship between intueri and lumen naturale, where the former completes the latter insofar as the natural light may shed light on objects, but its activity is not complete until the object is perceived. It would also work with the dialectical ambiguity of lumen naturale that Daniel analyzes, where nature is illuminated by the natural light and intuition perceives what is illuminated in nature. Having both these references in mind, Nancy's claim that the intellect requires help from the imagination, sense perception, and memory in order for the natural light to itself be illuminated is all the more interesting, and also makes all the more sense, especially when we consider that, insofar as the intellect would perceive objects seen by intuition in the illumination of the natural light, such perception demands that this faculty be "a receptacle," and thereby incapable of the showing that Nancy claims is the goal of at least Rule Three (ibid.). However, Nancy's position that the intellect is a receptacle could be problematic in that there are no vacua in the Cartesian schema, objects do not occupy space as though it were empty, and the movement that light would inaugurate begins from the movement of a solid chaos. If Nancy is suggesting that the intellect is always a receptacle to the truths of what the natural light would illuminate for intuition, this would seem to suggest a pre-established faculty psychology that cannot truly be the case.

Fòti identifies intellect with ingenium, and claims that intellect/ingenium "alone is now considered capable of the cognitive acts of intuitus and deductio" (Fòti, "The Cartesian Imagination,” p. 634). For her, intuition oversees imagination and abstraction. It would seem that this understanding is the reason why she does not see, as Marion does, a continuation of the earlier works in the Rules. Though she is willing to concede that ingenium "now exhibits the spontaneity and autonomy characteristic of a creative or poetic imagination," 
is not, of course, that it fails to give exercise and "a certain rivalry" to the mind and prevents some from falling off a cliff. Rather, the problem is that this system tends to ignore the simpler steps and heads straight for the most difficult issues such that its practitioners "ingeniously [ingeniose] construct the most subtle conjectures [conjecturas] and plausible arguments on the most difficult questions, but after all their efforts they come to realize, too late, rather than acquiring any knowledge, they have merely increased the number of their doubts." If Descartes' self-instruction is to avoid this problem, he must focus only on what he can intuit and deduce clearly. (CSM I, pp. 10, 13, and 12; AT X, pp. 362, 366, and 364)

This multiplication of doubt is a result of the faith in one's masters and in books of the past, a faith established by a non-rigorous attention to method. Descartes defines method in general in Rule Four as "reliable rules which are easy to apply, and such that if one follows them exactly, one will never take what is false to be true or fruitlessly expend one’s mental efforts, but will gradually and constantly increase one’s knowledge [scientiam] till one arrives at a true understanding [cognitiam] of everything within one's capacity [capax]."36

because she equates it with the intellect, such spontaneity and autonomy on the part of ingenium is not associated with imagination, even though imagination "supplies to the intellect the criteria for possible experience in extended nature" and "can be at the behest of the intellect and serve as both the medium and the limit marker of representation because it is not bound by the order of experience" (ibid., pp. 634-635 and 636). This reading seems to be in conflict with Marion's and perhaps with Nancy and Daniel's. However, something of a reconciliation may still be possible. In identifying the imagination as a limit marker that is not bound by the order of experience while it supplies possible criteria for experience to the intellect, Fòti hints at the importance of the imagination's relationship with the natural light that would inaugurate mental motion such that the natural light's illuminations that are seen by intuition and perceived in their truth by the intellect. Thus, the imagination would exceed whatever order and truth that intuition and the intellect/ingenium could see or perceive within the horizon of the natural light in the action of offering up criteria by which intuitive seeing or intellectual/'ingenius' (or even, following Sepper, 'endowed') perception could see or perceive. Moreover, it places abstraction and deduction, where abstraction "isolates "simple natures" so that they can be "intuited by the intellect and recomposed by means of deductio," in an interesting position with regard to the imagination because, if the imagination is offering up potential criteria for experience, then it would seem it is offering up said criteria for the abstraction (or analysis) to do its isolating work (ibid., p. 634).

${ }^{36}$ Like Murdoch, Marion translates capax as 'capability'. Marion justifies this choice by pointing to two moments in the Discourse as conforming to this moment in the Rules (see Marion, "Annotations," p. 132). The first occurs in Part Two, where Descartes explains that he decided not to reject any of his old opinions "until I had first spent enough time in planning the work I was undertaking and in seeking the true method of attaining the knowledge of everything within my mental capabilities [la connoissance de toutes les choses dont mon esprit serait 
The syllogistic, academic approach, which does not see the interwoven quality of the sciences but treats them as distinct, has a tendency to go straight to the most difficult questions of the particular study of the queen of the sciences rather than seeing its relationality not to say relativity to other sciences. Thus, this approach does not lead to the slow, methodical building of simple and simply deduced scientia toward the more general cognitio. As a result, students of this non-methodical method become reliant on their masters, whether present before them or as found in books, for guidance in these most difficult matters, faithful in the belief that these masters and that the educational methods presented by them are true. But what is required for method as Descartes understands it is a faith that the false can be taken for the true, a faith in skepticism and deception. ${ }^{37}$ (CSM I, p. 16; AT X, pp. 371-372)

A faith in skepticism and deception would lead students who free themselves from their masters to recognize that "even if all writers were sincere and open [ingenui \& aperti], capable]" (CSM I, p. 119; AT VI, p. 17). The second occurs in Part Three, where he explains that one of the benefits of adhering to the fourth moral rule he laid out for himself, to choose the best occupation after some review, is that "I could not have limited my desires, or been happy, had I not been following a path by which I thought I was sure to acquire all the knowledge of which I was capable [toutes les connoissances dont ie serois capable]" (ibid., p. 125; p. 28). The relationship between capability and knowledge as laid out here, insofar as Marion links it to capax, and insofar as Marion also refuses to connect intuitus with connaisance, would seem to be that 'capability' ought to be connected with pouvoir and possibilitas, as a faculty for knowledge, as a possibility that is opened only once the motions of the mind have been inaugurated, rather than the puissance or potentia or the faculty for thinking that all minds have, whether or not they have engaged in an appropriate cognitive method, a method for understanding and/or cognition (or, in Marion's translation, connaissance).

37 It is in this faith that Cavaillé finds Descartes' argument against skepticism. However, Descartes also argues against Scholasticism because "he turns away from the problem of being in the service of the establishment of a truth which is no longer adequatio rei et intellectus" (Cavaillé, Descartes: La Fable du Monde, p. 44; my trans.). Such turning away from truth as adequatio is in fact a "precellence of the problem of truth above that of being" and is thereby nihilistic for Cavaillé, a nihilism confirmed by the bias or angle of Descartes' fable insofar as it "lays claim to the truth" (ibid.; my trans.). It is unclear to me exactly why Cavaillé would consider this turning from adequatio on Descartes' part to be nihilistic. Descartes' arguments against such understandings of truth are grounded in the idea that the methods of inquiry have skipped over the sciences themselves in favor of inquiry into being, to which things and the study of them must adequate themselves. It would certainly seem, from a Cartesian perspective, that adequatio is more nihilistic than he is because adequatio encourages a disregard for the world as such, the things of the world insofar as they are things. It does so because the methodology of its approach to the world sees the sciences not as interrelated, which in turn encourages moving 'past' the sciences to what unites or rules over them. The fable, in its bias or angle, would not be nihilistic from a Cartesian perspective, but would be restoring a respect for things that was lost in both Scholasticism and skepticism. 
and never tried to palm off doubtful matters as true, but instead put forward everything in good faith [bona fides], we would always be uncertain which of them to believe, for hardly anything is said by one writer the contrary of which is not asserted by some other." The good faith of those who work in a non-methodical, un-skeptical method that fails to begin with an understanding of the interwoven quality of the sciences in order to build to scientia is, ultimately, bad faith. The contradictions, counterclaims, the disputiones and quaestiones of the academic, syllogistic methodology are a result of leaping into the most difficult matters ahead of the simpler, scientific knowledge, especially algebra and geometry, that can be acquired thanks to a faith in the interwoven quality of the sciences that can be, so Descartes believes, brought together in an understanding. By having leapt straight into the most difficult matters, students' reliance on masters leaves them unable to be sure of the ground from which they make inferences. While the inferences themselves are not faulty, the judgments they make with them are, because groundless, "rash." As a result, it is doubtful and unclear whether any knowledge claim has ever actually been made. Instead, in the end, "what we would seem to have learnt would not be science but history [non scientias videremur didicisse, sed historias]." It is learning history, which can only be doubtful, that leads academic, syllogistic studies astray. ${ }^{38}$ However, history is to be distinguished from memory, because the synthetic deduction to follow the analytic reduction is grounded in the certainty of intution's direct

\footnotetext{
38 As Foucault lays it out, this is the fifth consequence of Descartes' shift of the fundamental categories of knowledge away from resemblance to measure and order, and follows from the fourth consequence, that the activity of the mind is no longer in synthesis, but "in discriminating, that is, in establishing their identities, then the inevitability of the connections with all the successive degrees of a series" (Foucault, The Order of Things, p. 55). History becomes an erudite awareness of authors" opinions that can "possess an indicative value, not so much because of the agreement it produces as because of the disagreement" because only a few will have grasped the truth in such cases (ibid., p. 56). However, "intuition and their serial connection [enchainement]" can give us truth (ibid.; Les mots et les choses, p. 70). The final result of all of this is, then, for Foucault, that "the written word ceases to be included among the signs and forms of truth" (Foucault, The Order of Things, p. 56). At best, the written word translates the truth. Foucault does not mention here, however, the written words that allow for the shift from resemblance to measure and order in the first place.
} 
impact on ingenium. ${ }^{39}$ Such, then, is the necessary prelude or propaedeutic to method. ${ }^{40}$ These first four Rules are distinct from the Rules that direct ingenium because they prepare ingenium for coming to grips with the whole method itself. They do not themselves direct ingenium, but prepare it for the importance of analysis, for what will not lead it astray. (CSM I, pp. 13, 12, and 15; AT X, pp. 367, 365, and 370)

Error

Before turning to Descartes' understanding of history more directly, it is important to become clearer on what he means by error, the going astray to which academic nonmethodical methods lead. This error-prone quality of academic synthesis will hopefully be made clear by turning to the 'synthetization' of the Meditations as found in the Principles. What Descartes means by the Principles being synthetic while the Meditations is analytic is not precisely clear in itself (except to say that the second proof of god comes later in the Meditations than it does in the Principles because the former operates a priori and the latter from effects) since the first seven articles of the former are a reduction to the cogito, unless he merely means that he runs through the analysis so quickly that the bulk of the book is a synthesis from that fundamentally simple truth. However, I can take Descartes at his word

39 This would seem to be at least implied in Ricoeur's point about Descartes, where he writes that there is a methodical forgetting through the doubt that rejects the pedagogy of memorization, or the ars memoriae. What follows from this strategic forgetting is "a methodical use of memory, but of a natural memory freed from mnemotechnics" (Ricoeur, Memory, History, Forgetting, p. 68). If this forgetting and remembering is put into the language of method (and Ricoeur understands the age of method inaugurated by Bacon and Descartes to be that which closes the age of memory [see ibid., p. 65]), it would perhaps be as follows: Doubt allows for the analytic reduction to simples, to what cannot be denied, against what we have been told by and remember from our masters. Using memory from out of the analytic reduction thanks to doubt, using what cannot be denied, we can synthetically deduce other truths.

${ }^{40}$ Marion names the first four Rules as the construction of an "originary primacy" of a universality of science which the rest of the Rules will "practice," even while this primacy is itself also a science because "Primacy simply collapses the universality of science back into itself" in that there is not yet any god or self which could claim itself as primary (Marion, On Descartes' Metaphysical Prism, p. 63). 
that the Principles is synthetic and can thus show, from out of a method closer to the academic one, how error occurs and what can be done to prevent it. (DCB, p. 12; AT V, p.

Now, if the Principles is a combination or even synthesis of the Meditations and The World, it is interesting to notice how it begins and ends. It begins with doubt and ends with submission to the Church, perhaps even to faith, especially in those judges of prudence (prudentiorem judiciis). He is appealing, then, to those with judiciousness, cleverness, and sensibility to the practical and pragmatic. However, the truths under discussion here are absolutely, and thereby "more than just morally, certain." 41 They are grounded in an impractical, extraordinary doubt. Whether the prudent judges in fact have ground for judging these truths is uncertain, since they may have, as Descartes claims repeatedly in the Objections and Replies as well as in the Rules, already begun from an erroneous ground. Thus, the appeal to the prudent authority of the Church, as with the letter to the faculty of the Sorbonne, would seem to belie an irrelevance on the part of that selfsame authority, all the more so if the methods that have defended that authority qua prudent judgment are grounded in an erroneous, overly faithful starting point. At any rate, the Principles travels from an unconditioned faith in doubt to a conditioned faith in the authority of prudence, an authority

\footnotetext{
${ }^{41}$ As Ariew explains it, "Moral certainty accrues to physical principles about particular things that cannot be perceived. We do not have real doubts about these principles, but they fail the test of hyperbolic doubt, because we understand that God could have brought about things in some other way" (Ariew, "Descartes's Fable and Scientific Methodology," pp. 137-138). As Ariew reads it, Parts One and Two of the Principles (respectively titled "The Principles of Human Knowledge" and "The Principles of Material Things) contain the general physical principles about which Descartes can be absolutely certain because derived from the absolutely certain metaphysical principles and self-evident truths, but Parts Three and Four (respectively titled "The Visible Universe" and "The Earth") are morally certain and hypothetical. The claim to Parts Three and Four being more than morally certain is grounded in their connection with the absolute certainty of Parts One and Two, though Descartes is unwilling to fully commit himself to the absolute certainty of Parts Three and Four because he recognizes that their connection to Parts One and Two must be accepted first (see CSM I, p. 290; AT VIII-A, p. 328; pt. 4, art. 206). Such acceptance is what he seeks in the appeal to the prudent in the Church. So it would seem that their prudence would bring what is now morally certain into the realm of absolute certainty. The appeal to prudence for this task would, again following Ariew, not necessarily seem to bring this certainty outside the realm of 'morals'.
} 
that the book itself exceeds. However, doubt needs a raison d'être, which is why Descartes always feels the need to give a rational account of its necessity. The reasons for doubting are always, of course, error and deception, which are countered by the faith in doubt, by skepticism. Thus, in discussing error and how it comes about, Descartes will give an account of how it is that we are deceived and make seen the reason for doubt, thereby conditioning or relativizing the faith in the doubt even while absolutizing the truths to which that doubt gives rise. $^{42}$ (CSM I, p. 290; AT X, p. 328; pt. 4, arts. 206-207, and pt. 1, art. 3)

Doubt, at least the hyperbolicity of doubt, has been fairly well covered above, so a clarification of error remains. Error can be avoided primarily thanks to the freedom of our arbitration (liberum arbitrium), which can rein in our tendency to believe in the world as it is given. However, error occurs "when we make judgements about things we have not sufficiently perceived [percepta]." Judgments are made through a combination of the perception of the intellect (intellectum) and the operation of the will (voluntatas), which are the only two modes of thinking (modos cogitandi) according to article 32. Because the will has a wider scope than the intellect, because we want to judge to have knowledge of more than we can clearly perceive intellectually insofar as the intellect can only perceive a few objects offered before it, error occurs when the will is allowed to extend beyond the intellect's perception. The intellect's

\footnotetext{
42 In a letter to Clerselier, from June or July, 1646, Descartes clarifies on Clerselier's request what he means by 'principle'. For Descartes, there are two ways of using this word, as "a common notion [vne notion commune] so clear and so general that it can serve as a principle for proving the existence of all the beings, or entities, to be discovered later" or as "a being whose existence is known to us better than that of any other, so that it can serve as a principle for discovering them” (CSM-K, p. 290; AT IV, p, 444). By way of illustration, he offers the impossibility of a thing to be and not to be simultaneously as a common notion in that it does not "properly speaking make known the existence of anything, but simply to confirm its truth once known," and the existence of the soul as an ontological principle in that "there is nothing whose existence is better known to us" (ibid.). Common notions are, however, not of much use because they add nothing to the knowledge of that which is reduced to them. For this reason, Descartes explains that it is unnecessary to demand that a first principle be that to which all others reduce and by which all others are proven, "For it may be that there is no principle at all to which alone all things can be reduced," and that the manner (façon) in which one could reduce everything to the common notion of the impossibility of being and not being simultaneously is "superfluous and useless" (ibid., p. 290; p. 445). The more useful principle is the ontological principle of one's own existence, since the existence of god and of other things can be proven through (par) it.
} 
perception is found in "Sensory perception, imagination and pure understanding [sentire, imaginari, \& pure intelligere]," while the will's operation is found in "desire, aversion, assertion, denial and doubt [cupere, aversari, affirmare, negare, dubitare]." There are, then, four causes of error: (1) prejudices (prajudiciis) from childhood that trust the world as given to the senses; (2) not forgetting those prejudices; (3) exhaustion from attending to what is other than the world as given; and (4) attributing concepts to words, which do not correspond (respondent) to things of the world. Thus, insofar as doubt is an element of the will, we have to want to doubt the world as it is given in order to counter the prejudices of childhood and the exhaustion and linguistic laziness that can maintain those prejudices even in the face of the will to doubt and of doubting. Such a will can only be inaugurated from the development of reason that, first, distinguishes between sensations and things and, second, recognizes and remembers the inherited prejudices that the failure to distinguish between sensations and things developed (CSM I, p. 204; AT VIII-A, p. 17; pt. 1, arts. 6, 32-35, 1, and 71-74). In other words, it is only through what the histoire of the Discourse calls "the great book of the world," which is so "soon to punish the man if he judges wrongly [mal juge]," that Descartes or anyone of reason will be able to experience the failures of childhood prejudices as errors and maintain the will to doubt and of doubting them in the face of exhaustion and linguistic laziness. Such experience, especially the memory of this experience, is why, in the Rules, memory is distinguished from history. ${ }^{43}$ (CSM I, p. 115; AT VI, p. 10)

\footnotetext{
${ }^{43}$ It is for this reason that I cannot fully agree with Flynn when he equates history and memory. For him, Descartes' expressed preference for, in the Discourse, "cities which architecturally have no history" and "societies which have no constitutional history" links hyperbolic doubt and Ricouerian strategic to a desire on Descartes' part “to be a man without a personal history. ... Methodological doubt is his strategy for annulling the effects of his inheritance in history-natural, educational, and personal—namely, his opinions" (Flynn, "Descartes and the Ontology of Subjectivity," pp. 17-18). This argument rests on the assumption that the forgetting involved would be not so much strategic as totalizing that, methodologically, it is not. Descartes cannot eliminate memory because it is an assurance against the otherwise total, Pyrrhonic skepticism against which he consistently argues. Memory is an assurance against this total, Pyrrhonic skepticism in a double fashion: first, as a bulwark against sliding back into the bad habits of one's inherited prejudices (in that one
} 
However, it remains the case that past events remain the impetus for the inauguration both of the will to doubt and of the doubting that will, eventually, give rise to the method, whether in the Rules or the Principles. That the method of doubt needs a raison d'etre, which develops from an appeal to the past, in particular to the experience of error in the great book of the world, is thus evidence of the need for a pre- or proto- or metamethod, a path before the path that opens onto the path to the proper interpretation of the things of the world. That this appeal to experience is made, when addressing lenscrafters, through Descartes' own bistoires and, when addressing students of philosophy, to their experience (i.e., their histoires) in that the Principles is written in the first person plural, complicates the relationship between reason and history or histoire or historia. That we know error qua overextension of the will thanks to the will to doubt and of doubting things of the world as given, a will that is itself inaugurated thanks to our own bistoire, shows that the unlearning to which experience and memory should give rise if we have an appropriate, analytic method to find the foundational point from which we can begin a more appropriate synthesis is grounded in historia at least in the broadest sense. Thus, a more careful examination of the distinction between history and memory, and whether they in fact can be distinguished on Descartes' on grounds, is necessary.

remembers the errors into which those prejudices led oneself) and, second, as the storehouse from out of which the building up of truths from first principles is possible. Descartes would in fact seem to want to extricate himself from the formal study of history, though how successful he is in the attempt remains to be seen, but he certainly does not want to extricate himself from memory. 


\section{Etymology and History}

Descartes' denigration of history, even if he simultaneously lauds histoire, leaves a reader in a strange position when reading his texts. ${ }^{44}$ How are those reading him, especially those doing so almost four centuries after his death, to take this denigration? What is there to learn from a historically important writer who denigrates history as a scientific enterprise? Descartes' claims on history would appear to exceed throwing away a Wittgensteinian ladder in that his interest in methodology seems to specify the approach to learning beyond what Wittgenstein does, even if the crucially important step of unlearning is up to each reader and his or her bistoire. ${ }^{45}$ It is not that history in itself is to be eliminated, of course, in particular for its ability

${ }^{44}$ It is probably important to bear in mind that "from 1640 on there was a gradual substitution of the Cartesian and atomistic philosophies of nature for the traditional natural philosophy taught in the school" (Reif, "The Textbook Tradition," p. 18). However, "the textbook as we know it" started to become an important pedagogical tool beginning in the sixteenth century (ibid.). To whatever extent that the Principles, which was published in 1644, would have been considered a textbook in Descartes' time, the form it does take and especially the approach to history gives it the appearance of the textbook tradition that follows from it. Following Kuhn, modern (and contemporary) textbooks, as the primary pedagogical tools in the sciences, are "pedagogical vehicles for the perpetuation of normal science" and "begin by truncating the scientist's sense of his discipline's history and then proceed to supply a substitute for what they have eliminated" insofar as those substitutions "refer to that part of the work of past scientists that can easily be viewed as contributions to the statement and solution of the texts' paradigm problems" (Thomas S. Kuhn, The Structure of Scientific Revolutions, 3 ed. [Chicago: The University of Chicago Press, 1996], pp. 137-138). That these textbooks "have to be rewritten after each scientific revolution" places them in a similar position as the Principles, though not precisely (ibid., p. 138). The difference emerges in the gap between normal science and the scientific and conceptual revolution inaugurated by Descartes in his text. That is, because Part One, article 1, begins with an appeal to doubting "semel in vita," the course of one's life, the bistoire is incorporated into the very structure of the text (AT VIII-A, p. 5). Even more, the experience of that life is understood as ruptured and rupturable because of the deceptions that lead to doubt. Such a pedagogical approach could not be much more different than the one that, following each rupture, seeks to make "science once again seem largely cumulative" (Kuhn, The Structure of Scientific Revolutions, p. 138). In other words, even while Descartes may have a disregard for history, he is attuned to its breakages, at least on the personal level, in a way that the more contemporary textbook tradition Kuhn describes is interested in covering over. As a result, the strangeness of reading an old textbook of the contemporary sort is the strangeness that wonders how one's predecessors could have made so many of what are now considered errors — a strangeness that normalizes the contemporary engagement with the worldwhile the strangeness of reading Descartes is the unsettling, possibly even unbeimlich position of being criticized by an author for taking his text seriously simultaneous to recognizing that disruptions of the normal engagement with the world is the serious task which this same author wants to instill in the reader.

45 It should never be forgotten that the reason Wittgenstein's ladder can be thrown away is that "anyone who understands [versteht] me eventually recognizes them [i.e., his propositions] as nonsensical [unsinnig]" (Ludwig Wittgenstein, Tractatus Logico-Philosophicus, tr. D. F. Pears and B. F. McGuinness [London: Routledge \& Kegan Paul, 1966], 6.54). By contrast, Descartes' explanations in the Principles have absolute or at least more than 
to broaden awareness of customs (Discourse) or to offer up the useful labors of others (Rules), but that it is not to be understood as a rigorous science since it displays so many omissions and contradictions. ${ }^{46}$ At any rate, the difficulty of coming to terms with Descartes' conception of history from such a temporal distance remains.

This difficulty can perhaps be engaged, if not eliminated, by first attending to his critique of etymology. In the Principles, the fourth and final cause of error is attaching concepts to words that do not correspond to things of the world, and is the one cause of error which is not directly related to childhood prejudices. Memory holds both the thing and the word, but words are easier to recall than things, though they are conceptually distinct and so not modally or really distinct. Modal distinctions are either "between a mode $\ldots$ and the substance of which it is a mode" or "between two modes of the same substance." Real distinctions are distinctions between two substances. Conceptual distinctions are between a substance and an attribute of the substance, marked by the "inability to form a clear and distinct idea of the substance if we exclude from it the attribute in question, or, alternatively, by our inability to perceive clearly the idea of one of the two attributes if we separate it from

moral certainty. Even if Parts Three and Four are ultimately shown to have only moral certainty, they certainly would not be senseless. Thus, the history or bistoire that is to be thrown away precedes the principles demonstrated in the Principles to whatever degree of certainty, while the reader of the Tractatus is to exceed or transcend the propositions contained therein. What is to be thrown away in the Principles is then that which allows for its principles appear at all, so it appears that what is to be transcended in Descartes is that which is the condition for the possibility of that which allows for the transcendence.

${ }^{46}$ Following Jean Wahl, Du rôle de l'idée de l'instinct dans la philosophie de Descartes (Paris: Alcan, 1920), Dalia Judovitz claims that, because the succession of time for Descartes is "the negation of all the possibilities which have not been realized ...., history itself destroys its own representation as a legitimate discipline" (Judovitz, "Autobiographical Discourse," p. 101). However, there remains for Judowitz a qualification on the nonscientificity of history in that history "involves discovering the science by oneself, or self-sufficiently" with the result that "Descartes ... presents himself as the most singular figure in the history of philosophy because his method warrants his refusal of every past discovery as the domain of history" and this refusal is justified through "reading other authors" (ibid., pp. 101 and 103). None of this, of course, makes history a rigorous science, even if it is the source or starting point or condition for rigorous science. 
the other" (CSM I, pp. 213-214; AT X, pp. 29 and 30; pt. 1, arts. 74 and 60-62). ${ }^{47}$ The

conceptual distinction between word and thing in memory rests on the inability to form a

clear and distinct idea of the thing without the attributed, corresponding word, at least within a given language. ${ }^{48}$ Error would occur when we assume that the distinction between words and things is an inability of the second kind, such that we think we cannot clearly perceive the idea of the thing without the idea of the word. Because words, as human inventions, merely signify things, regardless of the language, and thus many words can signify the same thing, the idea of the thing remains distinct from the idea of the word (see CSM II, p. 126 and CSM-K, p. 187; AT VII, pp. 178-179 and AT III, pp. 417-418). Thus, the overextension of the will in this fourth kind of error is involved with the mistaken faith in a one-to-one correspondence between words and things, which then gives rise to "people [giving] their assent to words they do not understand [intellectis], thinking they once understood them, or that they got them from others who did understand them correctly" (CSM I, pp. 220-221; AT VIII-A, pp. 37-38; pt. 1, art. 74). Thus, in asking what the word 'mathematics' means in Rule Four, Descartes does not want to depend on others' understanding, and he wants to

\footnotetext{
${ }^{47}$ For Descartes, these are the only kinds of distinction. In the First Set of Objections, Caterus claims that the distinction between soul and body should be considered formal, which falls between conceptual and real distinctions. He claims this because the distinction between soul and body is grounded in "the fact that the two can be conceived apart from each other" and, following Scotus, "in order for one object to be distinctly conceived apart from each other, there need only be what he calls a formal and objective distinction between them" (CSM II, p. 72; AT VII, p. 100). Descartes' reply is that "this kind of distinction does not differ from a modal distinction; moreover, it applies only to incomplete entities," which the soul and body decidedly are not (ibid., p. 85; p. 120). In that he recognizes only real, modal, and mental distinctions (distinctiones modalem, realem, and rationis), Descartes is similar to Suàrez, though the latter considers formal distinctions to be types of mental distinctions, and mental distinctions also distinguish between a substance and the attributes we consider to be of the substances qua ideas (see Francisco Suàrez, On the Various Kinds of Distinction, tr. Cyril Vollert, S. J. [Milwaukee, WI: Marquette University Press, 2007], pp. 32-33 and 18; Disputationes Metaphysicae VII, I.21 and 4, http://homepage.ruhr-uni-bochum.de/michael.renemann/suarez/suarez dm7.html, accessed June 4, 2013).

48 In the Principles, 'attribute' is deployed "when we are simply thinking in more general way of what is in a substance" (CSM I, p. 211; AT VIII-A, p. 26; pt. 1, art. 56). That is, an 'attribute' is more general than both 'mode', used "when we are thinking of a substance as being affected or modified," and 'quality', used "when the modification enables the substance to be designated as a substance of such and such a kind" (ibid.). For a discussion of Descartes' relationship to Suàrez on the question of substance, see Jean-Luc Marion, "Substance and Subsistence," in On the Ego and on God, pp. 80-99.
} 
know he has a clear understanding of the word. Hence, "it is not enough to look at the etymology of the word, for, since the word 'mathematics' has the same meaning as 'discipline' [disciplina],' studies like optics and mechanics, sometimes considered dependent on arithmetic and geometry, can equally be considered mathematics (CSM I, p. 19; AT X, p. 377).

In coming to terms with what mathesis might mean on its own, what distinguishes it from disciplina, and doing so independent of the etymological connection between the Greek and Latin words, Descartes concludes that mathesis is concerned with order and measure (ordo and mensura) in general, regardless of the material being ordered and measured. ${ }^{49}$ The disciplines that come under its sway are those that deploy mathesis in terms of number, light, movement, and so on. This recognition leads him to the conclusion that there must be a mathesis universalis, the ordering principle as such, the order for ordering. The analytic reduction to mathesis, the name of which "everyone knows... and without even studying it understands what its subject-matter is [circa quid versetur]," will lead him, in the next two Rules, to show the method. ${ }^{50}$ Thus, there would seem to be no need to engage the

\footnotetext{
49 On the relationship between mathesis and mathematics, in particular the reduction of the former to the latter in neo-Platonism as regrettable for Aristotle, which informs Descartes' understanding of the question and its responses, see Jean-Luc Marion, “Annexe II,” in Regles, pp. 302-309. Through this mathesis, Marion also shows the difference between Descartes' first philosophy and the tradition of that term. He investigates the origin of 'first philosophy' in a debate between Suàrez and Bruno Pereira (Pererius). For the latter, “metaphysics is well and truly divided into, on the one hand, a metaphysics restricted to theology (God and the intelligences), as in Descartes, and, on the other hand, a 'pars ... universalissima,' constituted of the transcendentals" (Marion, On Descartes' Metaphysical Prism, p. 45). Pererius' 'first philosophy' is in contrast with Descartes' in that, for the former, it "deals with the ens in quantum ens" and so is a forerunner of what will come to be called ontology, while, for the latter, first philosophy "is concerned with the Mathesis universalis, which investigates all beings as knowable according to the order and measure," meaning that Descartes in fact wanted to "eliminate the very thing that Pererius wanted to consecrate: the question of being as such" (ibid., pp. 47 and 48).

${ }^{50}$ For Buchdahl, the question of this subject-matter of method leads to the contention that the mathesis universalis opens Descartes to the charge that he does not have "any very positive grounds for his metaphysics" (Buchdahl, Metaphysics and the Philosophy of Science, p. 94). There are a few reasons for this. The first reason is that the simplest model by which to analyze and understand all the relations between the interrelated sciences "is the geometrical model," which quickly itself turns to algebra as the symbolic representation of the relations between imagined and sensed lines (ibid., p. 84). Second, in the move to geometry and algebra, "all the objects of scientific knowledge should be considered under the aspect of extension-perhaps even, as it were,
} 
etymological debate over the relationship between mathesis and disciplina, and thus not to

engage the historical contingencies involved in that relationship, because analytic reduction,

which has itself not been presented yet and which is an unlearning of childhood prejudices,

can expose the mathesis universalis that gives rise to the method according to which we will

build knowledge in persistent reference to the individual experience of deduction, or at least

the experience of taking note of another's deductions, in persistent reference to

fundamental, simple truths. ${ }^{51}$ (CSM I, p. 219; AT X, p. 378)

Taking note of another's deductions is why it is sometimes useful to read the

ancients, to engage with history, with books of the past. Such utility is limited, in Rule Three,

'reduced' to extension" (ibid., p. 89). Finally, the reduction to extension operates through an abstraction from sensory experience to the unchanging aspects of what is sensed, leaving what remains after the abstraction to take on "an additional 'ontological' existence" because what is understood of the geometrico-algebraic aspects of what is sensed truly is (ibid., p. 91). For Buchdahl, that Descartes is open to the Berkeleyan charge of claiming to have perceived extension in general, though Descartes would deny such a claim because he is trying to move us away from perception, and that the defense for this is possible thanks to the via negativa defense for the ontological significance of the unchanging aspects of what is sensed, there is not much positive in the metaphysics on which the Cartesian argument depends and the argument which leads to the metaphysics. Of course, in identifying this non-positive form of a chiaroscuro quality to Descartes' methodology "from theoretical principles to laws and from laws to the observations 'colligated' by such laws," Buchdahl ignores the chiaroscuro effect that Cavaille observes, where the fabulation of a new or other world becomes the shading by and through which the objects and/or subject-matter of the study of that world come to appear (ibid., p. 83). In ignoring this chiaroscuro, which certainly appears to be positive, or at least positing, Buchahl is all the more bound to find his chiaroscuro to be negative.

51 In the appeal to the ancientness of the term 'mathesis universalis', Nancy points out that, between Descartes' appeal to the ancients and his critique of their covering over of geometric methodologies, this mathesis universalis is "to be discovered anew by Descartes, and to be covered up once again by him" (Nancy, "Larvatus Pro Deo," p. 23) since Descartes will "clothe and adorn [the mathesis universalis] so as to make it easier to present to the human mind" (CSM I, p. 17; AT X, p. 374). Thus, following Nancy, it appears that, for Descartes, "Mathesis could be seen only in the guise of Mimesis" (Nancy, "Larvatus Pro Deo," p. 23). Derrida builds on this point by noting that, in the economic principle of the Cartesian mathesis, utility and ease for the mind are of paramount importance. Hence, the importance of the turn to algebraic symbols that assist in the reduction of what is sensed to extension in Buchdahl's excessive ontological significance of what remains from the reduction. As Derrida points out, though, the introduction of the algebraic symbol, in its connection to the economic principle, means that "We will designate by a single sign everything that must be regarded as one for the purposes of resolving a difficulty. This sign itself will be forged, feigned, invented, arbitrary-whence the recourse to a certain fabulating, if not Romanesque or novelistic, fiction, in the invention of this artificial writing" (Derrida, "If There Is Cause to Translate II," p. 34). Thus, it would seem that the fabulation at hand, the fabulation that feigns the symbol to reduce what is sensed to what is insofar as it is understood by the geometrico-algebraic mind, is, again, a positive moment in Descartes' metaphysics. However, this positive moment, this positing of the fabular, is also negative in that it covers up in the same gesture that it exposes the ancient methods that develop from the mathesis universalis. In doing so, Cavaillés chiaroscuro effect of shading via a fable once again appears as a more comprehensive understanding of what is going on in Descartes than Buchdahl's chiaroscuro of movement between principle and law. 
by the "considerable danger that if we study these works too closely traces of their errors [errorum] will infect us and cling to us against our will [invitis]" (CSM I, p. 13; AT X, p. 366). However, these errors could only come to be seen as errors later in life. Just as with childhood prejudices, the limitations of books that make the mistake of assuming a one-toone relationship between things and words, of assuming that the conceptual distinction between them is of the second kind described in the Principles, are seen only to the extent that the interpretability of the words and the consequential utility of the knowledge claims reaches a saturation point or a point of exhaustion. Whereas there are at least two stages to the rejection of childhood prejudices, both of which depend on awareness "of the difference between things and sensations," the rejection of non-Cartesian knowledge claims depends on awareness of the precise form of conceptual distinction between ideas of things and ideas of words, an awareness that can only come with the method of analysis. Yet analysis, which hinges on the faith in doubt based on the experience of deception, engages in a deliberate process of unlearning prejudices, prejudices which favor synthesis. In other words, to show the superiority of analysis, to learn why we should unlearn, an engagement with history, with books of the past, is not only assumed but structurally necessary to the Cartesian method. History as well as histoire is interwoven within the process of unlearning that is analysis. (CSM I, p. 219; AT VIII-A, p. 35)

It is because of this structural necessity and interweaving of history and bistoire within analysis that Descartes deliberately begins so many texts with the rhetoric of a fable-structure or -logic. This structure or logic is what allows the reader to begin to see, on his or her own terms through the story Descartes tells, whether of his own life or in formal analysis or synthesis, that the childhood prejudices he or she has inherited, not only from individual experience but from the accumulation of habitual and customary or accustomed conceptual 
errors as to the form and possibility of knowledge claims, are erroneous, misleading, have led him or her astray. History is crucial to Cartesian knowledge claims, if only as that which is to be rejected. ${ }^{52}$ This is not to say that history and science exist in a kind of dialectical relationship whereby the negation of the former is included in the supersession of the latter. There is no supersession for Descartes, no progressive movement of historically embedded truth, "for nothing is older than the truth." There is rather the analysis toward simple, fundamental, and eternal truths that can be utilized in syntheses to deduce more complex truths. But this analysis, qua analysis, is embedded in both memory and history and can never, as a method, a meta-hodos, a path before or beyond or behind the path of utilization of analysis, escape the unlearning of childhood prejudices that are themselves inherited from individual experiences of underdeveloped reasons and from erroneous habits and customs that articulate claims to truth. Analysis always requires a knot to untie, whether that knot is born of oneself or of the historical circumstances within which the analyst finds him- or herself. (CSM II, p. 4; AT VII, p. 3)

It is with this understanding of the relationship to history that one must read Descartes nearly four hundred years after his death. Here are books of the past, which present a knot to the reader, a knot inherited in one's own engagement with the world. That knot is not merely that of the self, which shows itself to be interwoven with the knot of god through the double supplementation they have between themselves. It is also the knot of analysis itself, the knot of that which leads to the knot of the self, and so a knot of

\footnotetext{
${ }^{52}$ Ricoeur hints at but does not develop such a point. He describes the concept of historical criticism in Marc Bloch, The Historian's Craft, tr. Peter Putnam (New York: Vintage Books, 1964), where history can become scientific, as emerging from "the testing of written testimony, joined with that of those other traces" which are outside juridical procedures (Ricoeur, Memory, History, Forgetting, p. 171). Ricoeur further explains that "Historical criticism has had to blaze a difficult trail between spontaneous credulity and Pyrrhonian skepticism" (ibid., p. 172). Descartes is included in Ricoeur's list of progenitors of historical criticism only in terms of doubt, as opposed to mathematics and presumably its assuredness, insofar as “we link historians' doubt with Cartesian methodic doubt" (ibid.).
} 
unknotting, as an intricate interweaving with things of the world, synthesis, rhetoric, and history. Analysis of things of the world already begins with the argued-for interpretation of things of the world as other than merely given, as syntheses of simples. The argument for an engagement with things of the world in this way hinges on the failure, limitation, or exhaustion of the interpretation of things as matching up well with words. It hinges on this failure, limitation, or exhaustion in that a rhetorical appeal to what I am calling the fablestructure or -logic that extends throughout Descartes' personal history and corpus is necessary to begin the unknotting of historico-cultural and individual prejudices such that analysis in itself can be seen, on the reader's terms, as a superior method. The knot of analysis, then, is its structural inability to escape from what it would consider inexact, possibly even disordered and ill-measured-i.e., history — at the point immediately before it shows itself as a method.

\section{Histoire and Rule Obedience and Rule Generation}

Along with the question of supplementation and the knots it exposes comes the question of rule-obedience and rule-generation. Through an analysis of the fable-structure or -logic at work throughout the Cartesian corpus, I hope that I have shown that the pedagogical role that fables and their ilk, in its precedent status over discovery of any thinking proper, leads to an intricate and complex relationship between the fables or histoires each of us tells ourselves on the way to the discovering the method for ourselves. In addition, the effect of attending to this fable-structure or -logic, I claim, leads to an internally complicated and doubly supplemental structure to the method itself in its relationship to and justification of itself as well as to both etymology and history, both of which the method claims it ought to 
be able to regard as inexact and, overall, useless. Here, then, I would like to press on this effect a little more to see what effect attending to the fable-structure or -logic has on practical life, both for craftspeople and in ethico-political life, in order to gain a wider understanding of the supplemental relationship between rule-obedience and rule-generation at work throughout Descartes' works.

\section{Obedience, Habit, and Imitation}

The method is not intended for practical life any more than the hyperbolic doubt that both deploys and discovers the method is. As he explains in the Principles, hyperbolic doubt is supposed to be taken up, at most, "once in the course of [a person's] life," while the explanations deduced from the deployment of the method "possess more than moral certainty." Practical life ought to be ordered on obedience to one form of rule or another. The remaining questions center on what kind of practical life is under discussion and what kind of rule that life ought to obey. To address those questions, it seems appropriate to turn, first, to what moral philosophy is for Descartes. To be clear, Descartes does not appear to distinguish very carefully, if at all, between moral and political philosophy, ethics, and a virtuous life. Thus, these terms will be investigated as roughly synonymous. (CSM I, pp. 193 and 290; AT VIIIA, pp. 5 and 328; pt. 1, art. 1, and pt. 4, art. 206)

The preface to the French edition of the Principles, where he exhorts the reader to approach his textbook as a novel, contains the famous section where he describes philosophy as a tree. Metaphysics is the roots; physics the trunk; and other, practical sciences (sciences) the branches. Those other sciences are reducible to the principal ones of medicine, mechanics, and morals. The last of these is the only one Descartes describes: "the highest 
and most perfect moral system [la plus baute \& la plus parfaite Morale], which presupposes a complete knowledge [entiere connoissance] of the other sciences and is the ultimate level of wisdom" (CSM I, p. 186; AT IX-B, p. 14)..$^{33}$ Thus, morality is not a pursuit that appears to interest Descartes much, at least not until metaphysics and physics have been known entirely, with totality, and thereby absolutely. In other contexts, it is not merely a lack of interest in the name of intellectual priority that leads to Descartes' attempts to do his best to avoid moral philosophy, but perhaps even a moral imperative. For instance, in a letter, dated June 15, 1646, to his close friend, the diplomat Hector-Pierre Chanut, whose "principal study" was moral philosophy,

Of course, I agree with you that the safest [le plus assure] way to find out how to live is to discover first what we are, what kind of world we live in, and who is the creator of this world, or the master of the house we live in. ... [A]nd so I must say in confidence that what little knowledge of physics I have tried to acquire has been a great help to me in establishing sure foundations in moral philosophy.

The most assured and safest, the clearest and most preserving path to take in discovering the right way to live is to begin from questions of metaphysics and physics, even if this path leads one not necessarily to "preserve life" through medicine, but to take "another, much easier and surer [plus sur] way, which is not to fear death." The irony that Descartes caught the infection that killed him from Chanut notwithstanding, what is important here is that moral philosophy most assuredly gains its importance through metaphysics and especially physics. Thus, even if moral philosophy is the last and most important science and can only

\footnotetext{
${ }^{53}$ Richard Kennington finds the tree simile to be deceptive because the more overarching simile for Cartesian political and moral thinking is, following Bacon, architecture. He claims this is the case because "Political science, the architectonic or master art according to Aristotle, is replaced by philosophy understood as theoretical mastery, or 'architecture"” (Richard Kennington, "René Descartes," in History of Political Philosophy, ed. Leo Strauss and Joseph Cropsey, 3 ed. [Chicago: The University of Chicago Press, 1987], p. 425). Kennington implies, but does not explicitly state, that Descartes thus lays the groundwork for the technocratic ideal of an anti-political, in the Schmittian sense, liberalism whereby discoveries could reform civil society without violence, all the more so in that, "By a scientific 'fable of the world,' or by what purported to be a scientific account of the genesis of the heavens and the earth, of the visible universe and all its phenomena, he established the belief that science is master of the whole" (ibid., p. 437). This Schmittian theme will be explored more below.
} 
be established from out of an absolute knowledge of metaphysics and physics, it appears to be the case that metaphysics and physics, and of course the right direction of the mind that the method gives for their pursuit, have a moral quality to them in that pursuing them with absolute clarity and distinctness are of a piece with the pursuit of having clear and distinct moral ideas. (CSM-K, pp. 289 and 386; AT IV, pp. 441 and 442)

With this relationship between moral philosophy and the more intellectual pursuits in mind, Descartes writes, in a letter to Princess Elizabeth, dated August 4, 1645, that, while reason does not need to be completely free of error (ne se trompe point) in order to lead a virtuous and thus content life, “virtue unenlightened by intellect can be false [lorsqu'elle n'est pas esclairée par l'entendement, elle peut estre fausse]" (CED, p. 99; AT IV, p. 267). If the intellect fails to clarify for the will (volontê), the will can, as it can with non-moral pursuits, take what is false to be true. ${ }^{54}$ The source of error or of being deceived, the overextension of the will, is precisely the desire for a good, honest life as well as the thoughts associated with that life produced by virtue. ${ }^{55}$ It produces this desire because, as Descartes claims in the Passions of the

\footnotetext{
${ }^{54}$ It seems that this moral risk is what Rosen points out when he claims that "The activity of the soul is willing to think rather than simply thinking" (Stanley Rosen, "A Central Ambiguity in Descartes," in Cartesian Essays: A Collection of Critical Studies, eds. Bernd Magnus and James B. Wilbur [The Hague: Martinus Nijhoff, 1969], p. 31). The result of this active quality of the will marks for Rosen the fundamental break Descartes makes from the ancients because "Nothing truly affects man but the free disposition of his will or desires .... Man may will himself to love God, but he is also free to ignore, or perhaps to hate him" (ibid.). Thus, the intellect's proof of a god as a non-deceptive, all-creating being can contribute as much to the clarification of moral ideas as it can to non-moral ideas, or even help clarify what would otherwise be an ignorant, unenlightened love of god.

${ }^{55}$ Sepper agrees with Rosen that the relationship between the intellect and the will in the Passions is such that the thinking is passive to the activity of willing to think. However, Sepper, in turning to this letter to Elisabeth, pushes a bit further than Rosen to claim that "The essence of the soul in conceived preeminently in its actions rather than in its passions, and the actions of the soul are properly speaking acts of will' (Sepper, Descartes's Imagination, p. 276). The intellect remains passive because it cannot do anything to what it perceives unless directed to do so by the will. There are two aspects of the will, as Sepper follows the argument, which are active: "imagining and applying our mind to immaterial things" (ibid.). Thus, the imagination is closer to the essence of the thinking thing than passive intellectual perception. Much of Sepper's argument here depends on his biplanar understanding of the structure of the imagination, which I will contest in chapter 4, below. However, his analysis of the importance of the will over and above the intellect, coupled with Rosen's implication of this relationship for moral ideas, is helpful for remembering that the source of moral error is the same source as that of a virtuous life, that is, the will. This common source, then, makes the order of priority all the more difficult to disentangle, if it can be disentangled, between metaphysics and morals.
} 
Soul, virtues are passions and passions produce desires as well as thoughts (pensées) (see arts.

160, 144, and 161). In that, according to the Principles, ideas (ideae, idées) are modes of

thoughts (cogitandi, pensées), the passions that are virtues can be considered as indirectly

productive of ideas via being productive of thoughts, so if virtuous desires are not clarified

by the intellect, the ideas produced will not be clear or distinct (see CSM I, p. 198; AT VIII-

A, p. 11; AT IX-B, p. 32; pt. 1, art. 17). As a result, to return to the letter to Elizabeth, false

virtues "can carry us toward bad courses [choses manuaises], even though we think them

good," while "the right use of reason [raison], giving us a true knowledge of the good,

prevents virtue from being false. In making virtue accord with licit pleasures, reason makes

practicing virtue quite easy; and in giving us knowledge of the condition of our nature [nostre

nature], it restrains our desires” (CED, p. 99; AT IV, p. 267). So reason must temper the

desire to be good in order to be truly good through reason's power, its puissance, to discern

between the false and the true. ${ }^{56}$ Otherwise, this desire, as with all other operations of the

will, will produce a thought the mode of which is not a clear and distinct idea as perceived by

\footnotetext{
${ }^{56}$ In another letter to Princess Elizabeth, Descartes responds to questions from the princess as to the Senecan concept of the supreme good, which she describes as a "joy and satisfaction of the mind" (CED, p. 106). Descartes' response, dated September 15, 1645, explains his own thoughts on the matter, which is that judging well depends on "knowledge [connoissance] of the truth" and "practice [habitude] in remembering and assenting to this knowledge" (CED, p. 111; AT IV, p. 291). The four general truths to be known for good practical judgment are the perfect and infinite god, as "we will find ourselves naturally so inclined to love him that we will draw joy even from our afflictions" (CED, p. 111; AT IV, p. 292); the immortality of the soul, which "prevents us from fearing death and detaches our affections from the things of the world so much that we regard all that is in the power [pounoir] of fortune only with contempt" (CED, p. 112; AT IV, p. 292); the immensity of the universe, to stop ourselves from "want[ing] to be counsel to God" (ibid.); and the interdependence each has on others in the world, which should help us "to prefer the interests of the whole, of which each of us is a part, to those of one's person in particular” (CED, p. 266; AT IV, p. 293). Two other truths to know, "which relate more particularly to each" action, are that "all our passions represent to us the goods they incite us to seek as much greater than they actually are, and that the pleasures of the body are never as lasting as those of the mind" (CED, p. 113; AT IV, pp. 294-295). In addition, local customs will guide us in the deployment of each of these known truths. Yet, practice is crucial for the activity of judging well "since we cannot always be attentive to the same thing-even though we have been convinced of some truth by reason of some clear and evident perceptions - we will be able to be turned, afterward, to believing false appearances, if we do not, through a long and frequent meditation, imprint it sufficiently in our mind so that it turns into a habit" (CED, p. 113; AT IV, pp. 295-296). This habituation, though, results in a knowledge, a connaissance, and is a practice informed by constant engagement by reason's theoretical knowledge with the practical world. This theoretical knowledge would thus seem to produce practical knowledge such that reason tempers the desire to be good so that one becomes truly good.
} 
the intellect and, in the name of the good, evil will be done. All of this is in line with much of what Descartes wants to claim about the pedagogical element of a new habituation of thought through the method generated by his fable-structure or -logic.

However, at this point of reason's tempering of the desire for a good, honest life, I want to turn back to the Passions, to articles 161 and 144 in particular, while bearing in mind this pedagogical habituation. In article 161, centered on generosity, Descartes writes, "what we commonly call 'virtues' are habits in the soul which dispose it to have certain thoughts: though different from the thoughts, these habits can produce them and in turn be produced by them." This movement of production between habits and thoughts, especially in the relationship between the habits called virtues, means that the relationship between the false and the true in morality is more complicated than it might otherwise appear. That is, insofar as reason can clarify what are clearly perceived ideas as modes of thought and unclearly perceived ideas that the will to and of desire to lead a good, honest life would direct the mind in a method that habituates the self in the direction of clarity, everything seems clear, simple, and straightforward, but if habits produce thoughts that themselves produce habits of clarification, it is unclear how or why the discernment of reason is to be trusted or at least considered not to be deceptive. The habit of thinking as oriented to clearly perceived ideas is a virtue, and a virtue that will lead the self to the complete system of morals after the complete cognizance of other sciences. But if the habit of thinking, as a virtuous habit, is itself produced by a thought of clarification, as opposed to a clearly perceived thought or idea, what would be the source of this habit is not, cannot itself be clear. It cannot itself be clear because the thought of clarification cannot rest on clarity. Such would come down to claiming that clarity itself can be clearly perceived, which is akin to claiming that the 
condition for the possibility of seeing can be seen. ${ }^{57}$ A claim that the condition for the

possibility of seeing can be seen is possible only in the guise of a fable, however, and so only

by an inauguration of perception or thinking that initiates a habituation of self-instruction

through a method, thus opening the thought of clarity that could produce the habit of

thinking in terms of an intellect focused on clearly and distinctly perceived ideas that will in

turn produce virtuous thoughts to a circle that can never be clearly and distinctly perceived

as either virtuous or vicious. ${ }^{58}$ (CSM I, p. 387; AT XI, p. 453)

\begin{abstract}
${ }^{57}$ For Carl Page, "Certainty in all its forms entails a meta-reflection" (Carl Page, "Symbolic Mathematics and the Intellect Militant," Journal of the History of Ideas 57:2 [1996], p. 237). This meta-reflection is necessarily retroactive and depends on the evidentiary standards for the context (i.e., mathematical reasoning has a higher standard for evidence than other forms of reasoning). The satisfaction that comes from properly defined and established mathematical proofs arises "because reason has determined the specifications in accord with its own design, what reason thus begins with is to that extent clear. Clear means, in this context, that the identification of the object is exact" (ibid., p. 238). Reason cannot err in the identification of a mathematical object, even if it can mistake reality for that identified object. Such a meta-reflection is fine as far as the practices, the habits, or the virtues of mathematical reasoning go, or any practice of reasoning, for that matter. However, what is at stake here is not so much the meta-reflection that makes sense of the clarity of the objects of reasoning, but the clarity of the habit to clarify, whether methodically rigorous or not. The clarity involved here would demand, to manipulate Page's language, a meta-meta-reflection. To be sure, the practice of metareflection, what we could perhaps simply call 'philosophy', remains a habit, practiced to a better or worse degree by practitioners, but, just as the practitioners of mathematics do not need to concern themselves with why the practice of mathematical clarity is satisfying, neither do all practitioners of meta-reflection, the metareflection on the satisfaction derived from mathematical clarity, neither do the practitioners of this form of reasoning need to concern themselves with the satisfaction derived from the certainty and clarity of their own proofs. But to such reflection on meta-reflection is what the investigation of article 161 and the relationship between habit and thought has led.
\end{abstract}

${ }^{58}$ Husserl reaches a similar point in $\$ \$ 34$ and 35 of the Cartesian Meditations. There, he writes that "By the method of transcendental reduction each of us, as Cartesian meditator, was led back to his transcendental ego" (Husserl, Cartesian Meditations, p. 69). Though the French translation replaces 'Cartesian' with 'transcendental', the point remains (see ibid., p. 69n. 2). Continuing the meditations led to "the intentional uncovering of my 'monad' along the fundamental lines that offer themselves," meaning that each of the intentional processes of perception, recollection, etc. has itself been "explicated and described in respect of its sort of intentional performance" (ibid., pp. 69 and 70). Explicating and describing the intentional processes give an "'empirical' significance" to those explications and descriptions, although "from the very start we might have taken as our initial example a phantasying ourselves into a perceiving, with no relation to the rest of our de facto life," which risk shows "the pure 'eidos' perception, whose 'ideal extension is made up of all ideally possible perceptions, as purely phantasiable processes" (ibid., p. 70). The eidos of, for instance, perception, the phantasiable process that has been explicated and described to give it an empirical significance, insofar as it would be prior to perceptual concepts that would emerge from perception itself, is what concepts "must be made to fit" (ibid., p. 71). That each intentional process of the transcendental ego can be explicated and described as an eidos does not, however, expose the connection between the eide as such. Rather, the horizon of the connections "itself becomes eidetic," giving rise to an eidos ego (ibid.). As a result, "a purely eidetic phenomenology" is necessary in order to take account of this eidos ego and thereby "explores the universal Apriori without which neither I nor any transcendental Ego whatever is 'imaginable' [erdenklich]" (ibid., p. 72; Cartesianische Meditationen, p. 106). The attempt to explore the horizon of the eidos ego in an eidetic phenomenology would seem to be an attempt to 
It is here that article 144 may be helpful, where Descartes claims that "the chief utility [utilite] of morality" is found in the "control [regler]" it exerts over "Desires whose attainment depends only on us" and that are produced by the passions of joy, love, sadness, and hatred. In that joy and love (and wonder) produce virtuous passions and habits while sadness and hatred (and wonder) produce vicious passions and habits, morality itself would appear to regulate the will to and of desire that produces virtue. Here, then, if morality regulates the distinction between what depends only on us and what is independent from us, even if only in terms of virtuous and vicious passions, it would appear to regulate the virtuous habit of thinking as clear and distinct perception, and thereby is productive of the sciences, the complete knowledge of which will lead to moral philosophy (CSM I, p. 379; AT XI, p. 436; arts. 144, 142, and 160). This is not merely to say that reason need not be fully developed to lead a good, honest, virtuous life, nor to say that the pursuit of the sciences is in itself a contribution to moral philosophy and inherently moral and virtuous. ${ }^{59}$ Rather, it is to claim

clarify the clarifications of perception and other intentional processes, to explicate and describe the processes by which processes are themselves explicated and described such that the processes of explication and description are themselves given empirical significance. It is an attempt, then, to perceive perception, to clarify clarification. For Husserl, such an attempt would result in an absolute phenomenology, but it is somewhat unclear why explicating and describing explication and description as intentional processes to explicate and describe the intentional processes of perception, etc., would not itself at least possibly be subject to yet another explication and description to give empirical significance to the process of explicating and describing the eidos ego of eidetic phenomenology, and so on ad infinitum if not ad deo. Descartes' recourse to fable in the face of such a possibility thus appears somewhat more straightforward, or at least not as consistently reductive to 'objectivity' in the fashion that Husserl lays out.

${ }^{59}$ The sciences are not in and of themselves virtuous because, as Richard B. Carter describes it, "Ethics involves the will for Descartes, but the will only realized through that passion of the soul which he calls 'desire"' (Richard B. Carter, "Ethics as Drawn from the Method," Pbilosopbica 46:2 [1990], p. 113). Desire is a particular passion or emotion resulting from the body preparing to transform an imaginative fantasy into an accomplished volition. Without desire, there would be no mathematics or engineering on Carter's reading, but without the regulation of desire—not the regulation of the will, which would "strip it [i.e., the will] of its freedom"- there would be no ethical mathematical or engineering pursuits (ibid.). The content of this regulation is, according to Carter, an intellectual assessment of the achievability of the desire and a cost-benefit analysis of the pursuit of its achievement. Thus, intellectual pursuits without desire, but no pursuit of those desires without ethics, and ethics as drawn from the intellectual methodology of utility. What Carter does not seem to recognize here, though, is that it is not only the case that ethics or morals is built from out of the intellect's calculations, but also that these calculations are themselves built out of morals. If a moral system is represented in the top branches of the tree of knowledge, physics and metaphysics still seem to remain 
that morality, in its very usefulness, is the regulation of what will regulate morality's clearly

and distinctly perceived pursuits (i.e., reason or thinking), pursuits which will in turn be

determined as virtuous in terms of their pedagogical and/or practical utility as the

application of the good use of the puissance of reason, to return to the Discourse (see CSM I, p.

112; AT VI, p. 3). ${ }^{60}$

There appears to be yet another knot here, a complex and involved point of

difficulty. This difficulty, in a fabular structure similar to the double supplementation of

analysis and synthesis, self and god, etc., here operates through the questions of obedience,

habituation, and imitation. Does reason imitate morality, or vice-versa? Does morality

produce the habit of virtuous thinking? What element of the mind produces the rules

obeyed, the rules that regulate the mind's thinking and the self's living, whether in the

practical or hyperbolic realm? Is this element discernible, analyzable, without imitating, and

therefore obeying, that which it would discern, analyze, or clarify? To further clarify these

dependent on morality insofar as morality's calculations will tell the intellect whether a given desire is worth pursuing, whether it is a useful pursuit.

60 To see more clearly what is at stake here, Foucault could again be helpful. When he identifies in the Rules a critique of resemblance as adequation and an offer of a relational comparison as the source of knowledge, Foucault shows that knowledge becomes dependent on the comparative techniques of measure and order. In measure, the comparison operates through "the arithmetical relations of equality and inequality," while, in order, it operates through "a simple act which enables us to pass from one term to another, then to a third, etc., by means of an 'absolutely uninterrupted' movement" (Foucault, The Order of Things, p. 53). But when we arrive at this relationship between reason and morality, the comparison seems significantly more difficult because what would be compared would not be things to be measured and ordered but that which would itself order and measure. Insofar as it is unclear whether morality orders reason through regulation, or whether reason gives the measure of morality through utility, the comparative techniques that would become the new Cartesian ground for knowledge are less useful than they at first appear. Again, it becomes a question of whether the condition for the possibility of intellectual perception can itself be seen: how to rationally assess the relationship between reason and morality, how to make a moral judgment of this relationship? If morality's utility is its regulative abilities over reason's desires, where does the determination of the utility of morality find its source, since the desire to make a moral judgment would be a rational one and this desire should itself be regulated by morality? What is the common measure between reason and morality except for utility, which is itself already at work in the ordering of their internal mechanisms as well as in their interrelationality, and therefore itself can be neither "merely conventional or 'borrowed'," as Foucault describes the units of measuring (ibid.)? If this utility, as the ordering principle of both morality and reason, is the order by which such comparison could operate, insofar as utility is not "an exterior unit," then utility would appear to be the order of order, whether moral or rational, but then it would be all the more difficult to identify whether moral utility orders reason's desires or if rational utility regulates what would be considered moral (ibid.). 
questions, which may in fact result in a further confusion or complication of them, a turn back to Parts Two and Three of the Discourse, which is a turn to the relationship between the epistemo-logical and the moral and thereby a turn to the relationship between the metaphysical and the political as well as the mind and the external world, appears necessary.

\section{Eight Simple Rules}

Descartes does not always appear to be comfortable in the realm of virtue, moral, ethical, political philosophy, and would prefer not to write on it if possible. When he does elaborate on this realm, he writes to Chanut in 1647 that it is for two reasons: "One is that there is no other subject in which malicious people can so readily find pretexts for vilifying me; and the other is that I believe only sovereigns, or those authorized [sont authorisez] by them, have the right to concern themselves with regulating [se meler de regler] the morals of other people" (CSM-K, p. 326; AT V, p. 87). The second reason for his reticence on moral philosophy will be addressed below. The first reason, however, is related to the general problem of the potential lack of regulation or clarification of the desire to lead a good, honest life by the intellect. That is, the desire to be good, to be thought good, to appear good, is a genuine desire on the part of many of Descartes' critics. However, in that it is not restrained or clarified by the intellect, this desire becomes a false virtue, leading to malicious slander of his positions as challenging Aristotelian-Church authority. In the structure of the Passions, this malice is the result of indignation, which is "observed much more in those who wish to appear [paroistre] virtuous than in those who really [veritablement] are virtuous" and results in becoming enraged over relatively trivial matters (CSM I, p. 398; AT XI, p. 476; art. 198). The relatively trivial matter that leads to slander thanks to the lack of clarification as to what is 
dependent and what independent of us on the part of Descartes' critics, then, is that nothing he writes challenges divine or Church authority, only Aristotelian authority. Thus he periodically feels compelled to address moral problems or issues so that the slanders can be addressed.

Parts Two and Three of the Discourse is one of the places where he feels compelled to address such moral problems. He tells Burman that he wrote what he did "because of people like the Schoolmen; otherwise, they would have said that he was a man without any religion or faith [religion, fide] and that he intended to use his method [methodum] to subvert them." However, this question, whether the Cartesian method subverts Catholicism or faith, turns them on their heads, is not the issue for me. The question here is rather, having questioned whether morality or reason produces the habit of thinking, in questioning and analyzing the fabular structure of the knot of obedience, habituation, and imitation, whether morality turns the method on its head, whether morality subverts the method. (DCB, p. 49; AT V, p. 178)

In the Discourse, Descartes lays out eight rules, four epistemological and four moral, though not without a rule for these rules, a rule which itself is given a prelude in the telling of his histoire or fable. As he tells it, he was not immediately prepared to totally reject his inherited opinions, not until he had "first spent enough time in planning [faire le proiet] the work I was undertaking and in seeking the true method [Methode] of attaining the knowledge of everything within my mental capacities [capable]." ${ }^{62}$ Thus, as was discussed above, he looks

\footnotetext{
${ }^{61}$ Cottingham seems correct when noting that Gilson's commentary on this moment in the Conversation may be a little too strong. Gilson claims that "It is not absolutely certain that this later remark exactly represents the state of mind within which Descartes found himself at the moment when he wrote this part of the Discourse in 1648, since, in 1648, Descartes had become extremely distrustful following the attacks of which he had been the object on the part of the Jesuits in France and on the part of some Protestant ministers in Holland" (Gilson, "Commentaire Historique," p. 234). As Cottingham explains, citing The World, Descartes was no stranger to suppression and calumny in the 1630s (see Cottingham, "Commentary," p. 119).

62 Citing Geneviève Rodis-Lewis, L’oeuvre de Descartes, 2 vols. (Paris: Librarie Philosophique J. Vrin, 1971), Garber considers that, at the time of his famous dreams in the poêle on November 10, 1619, when Descartes
} 
to logic, geometry, and algebra, discovering that syllogisms are useless and confuse (meslez)

false and true precepts and that mathematics has been overly concerned with abstract

problems. These problems lead him to conclude that he would like to find another method

that will maintain the advantages of logic, geometry, and algebra, while discarding their

disadvantages. Doing so leads him to the proto- or pre-rule that will guide his rule-finding:

a multiplicity of laws often provides an excuse for vices, so that a state is much better governed when it has but few laws which are strictly observed; in the same way [ainsi], I thought, in place of the large number of rules that make up logic, I would find the following four to be sufficient, provided that I made a strong and unswerving resolution never to fail to observe them.

Two interwoven issues must be noted concerning this proto- or pre-rule. ${ }^{63}$ The first

concerns the evidence for Descartes' conclusion for the proto- or pre-rule for his logical

rules, which is political and concerns the maintenance of order. This evidence of political

rule is the evidence from which he concludes that his self-rule, his self-instruction would

best be grounded in simulation, imitation of political order. The second issue concerns the

claims to have formulated these rules, "It is highly unlikely that Descartes formulated his provisional morality at that time. But it is highly likely that the idea of the interconnectedness of the sciences and the idea that there is some method for constructing them date from that period" (Garber, Descartes' Metaphysical Physics, pp. 12-13). When precisely Descartes formulated these morals rules is fairly irrelevant for the point here, which is that they have the conceptual relationship to the epistemological rules and the pre- or proto-rule they happen to have.

${ }^{63}$ For Cavaillé, politics for Descartes is not foreign to morality, but "resists and becomes a problem" within morality (Jean-Pierre Cavaillé, "Politics Disavowed: Remarks on the Status of Politics in the Philosophy of Descartes," tr. R. Scott Walker, Diogenes 35:118 [1987], p. 120). This is because science seeks to "supplant politics" to the extent that politics is necessarily "destined...to an unmitigated indetermination, both ontological and epistemological" since it is embedded in the world of the inexact science of history and depends on an assessment of contingencies (ibid., pp. 123 and 126). Thus, for Cavaillé, Descartes does not try to change the world, but one's own desires, leading to "a moralization of politics" (ibid., p. 130). What Cavaillé does not notice, in his assessment of Descartes' refusal to try to change the world, is that the very changing of one's desires depends on the individual fabulation of what and how the world is, how the world is to be interpreted and taken up. Insofar as this fabulation accomplishes its task, the world is changed, it is a new and fabular world, one where morality can find itself displacing politics. However, insofar as the changing of the self and the world begins from out of a proto- or pre-rule imitative of political rule, the changing of one's own desires is a making of oneself a political agent or subject, even if only of oneself. Such a task is, of course, not merely moral any more than it is merely political, and it is a moralization of politics to the same extent that it is a politicization of morality. Such may be the technocratic utopia of an apolitical liberalism, but it does not supplant politics and it does not "subordinate [politics] to moral ends" (ibid., p. 138). It is a politics and an imitation of the political, the ordering of oneself as a political act. Hence, perhaps, the disavowal at work in Cavaille's title, though this would seem to $b$ a disavowal on the part of Cartesians more than on that of Descartes himself. 
indication of this conclusion, the ainsi, the 'and so', the 'thus'. With this word, Descartes indicates that there is already a logic at work in the conclusion that leads to the proto- or pre-rule for the four epistemological rules, a logic that is in part an imitation, by way of imitation of the advantageous elements of traditional and inherited syllogistic logic. Thus, the imitation of the political, moral, ethical, and virtuous as found in the proto- or pre-rule for the four epistemological rules is also an imitation of what is advantageous from logic. So the rule for the rules of the logic of knowledge interweaves itself within the political and the logical, the sciences most explicitly concerned with order in and for itself. The rule for the rules of epistemology is itself neither logical nor political, though it imitates both in the appeal to order in and for itself as that which ought to be obeyed. (CSM I, p. 119 and 120; AT VI, pp. 17 and 18)

From the Passions, the Principles, and some letters, it is shown that the reason for the appeal to order in and for itself is argued for on the grounds of clarifying desire for the will, but here there is none of that. The Discourse moves seamlessly, except for the ainsi, from maintaining the advantages of logic, geometry, and algebra to political order to imitation of political order. In a letter to Princess Elizabeth, dated September 15, 1645, however, Descartes perhaps clarifies this transition. There, he discusses three useful truths to acknowledge—god's goodness, the soul's immortality, and the universe's immensity—which leads him to a fourth such truth: the relationship between individual and community. ${ }^{64}$ In

\footnotetext{
${ }^{64}$ In Descartes' making âme and esprit interchangeable, James M. Edie finds the fundamental break from preCartesian concepts of the soul. Whereas, in Plotinus and Augustine, "the soul (anima) is primarily a principle of life which animates a body" (James M. Edie, "Descartes and the Phenomenological Problem of the Embodiment of Consciousness," in Cartesian Essays, p. 104), when Descartes declares mind and soul to be roughly equivalent in the Second Meditation (see AT VII, p. 27 [note I do not cite the CSM here, because Cottingham takes makes what seems to me an overly interpretive decision to translate animus with 'intellect']), even if he prefers to refer to the mind, the mind is no longer a principle of the organization of life, and is therefore no longer "an anima" because life and consciousness are separate, despite Descartes' word choice in the Second Meditation, and he can thereby reject the Aristotelian theory of the soul as the substantial form of the body because the thinking thing is not technically "a 'substance' at all" (Edie, "Descartes and the
} 
that each person's interest is distinct from that of all other things in the world, "one must [doit], all the same, think that one does not know how to subsist [subsister] alone." As a result of being parts of the whole of the universe, planet, state (Estat), society (societê), and family, each of us must calculate, measure, order our lives with this insubstantiality, if only physical, in mind. However, this calculation, measurement, or ordering is to be done "with measure [mesure] and discretion" because one should not rush into danger if it will not benefit family, state, community, etc. to a greater extent than the sacrifice. Descartes maintains that knowing and loving god will naturally lead to such measurement because such a person will abandon him- or herself to god's will (volonté) and will direct his or her passions toward god's pleasure. (CED, pp. 112-113; AT IV, p. 293-294).

If this letter can be applied to the Discourse, then it would appear that the appeal to political order as the proto- or pre-rule for his four epistemological rules is explained through the experience of measuring that is the individual's relationship to the state and community. Politico-ethical life is, it would appear, a persistent state of measurement and comparison. Politico-ethical life, community life, moral life, the virtuous life is best, or at least most easily, measured by an individual against him- or herself if and when there are fewer laws. As with the simplification and reduction of the analytic method, the best-ordered state allows the individual to measure his or her interests against that of the state, which is easiest, simplest when there are as few rules as possible. The imitation of this experience, in

Phenomenological Problem," pp. 104 and 105; see Aristotle, De Anima, 414a). For Edie, this places Descartes in a similar dilemma as Husserl in that both must confront "the problem of the embodiment of consciousness with its own method and its own resources," which may be an impossible task (Edie, "Descartes and the Phenomenological Problem," p. 113). Edie's concern about Merleau-Ponty's solution, which refuses a conscious ego as distinct from bodily life, is that it may not be sufficiently phenomenological because it rejects transcendental reduction, but Edie also does not himself have a solution to the problem of dualism and only turns to Descartes as the originator of the problem. 
concluding in proto-logical fashion, is Descartes' proto- or pre-rule which rules over the epistemological rules. ${ }^{65}$

To turn to the four epistemological rules, then, also requires turning to the four moral rules. The epistemological rules that Descartes will follow are familiar: (1) not to accept anything as true without clear and distinct knowledge of its truth, (2) to divide what is difficult into as many parts as possible (pourroit), (3) to conduct (conduire) his thoughts (pensées) from simple to complex, and (4) to list or count off (denombremens) the discovered truths completely. The four moral rules are as follows, formed with his move to Holland in mind: (1) "to obey the laws and customs of my country [païs]" in terms of religious faith "and governing myself in all other matters according to...the opinions commonly accepted in practice [pratique] by the most sensible of those with whom I should have to live," (2) "to be as firm and decisive in my actions as I could, and to follow even the most doubtful opinions, once I had adopted them, with no less constancy than if they had been quite certain," (3) "to try always to master myself rather than fortune, and change my desires rather than the order of the world," and (4) "to review the various occupations which men have in this life, in order to try to choose the best" (CSM I, pp. 120 and 122-124; AT VI, pp. 18-19 and 22-27). Though much of the Seventh Set of Objections with Replies centers on the apparent contradiction between epistemological rule 1 and moral rule 2, the apparent distinction between hyperbolic and practical doubt as Descartes understands it has already been

\footnotetext{
${ }^{65}$ It may be an important aside to note that Aristotle is not necessarily the best reference point for the target of Descartes' politico-ethical reformation, if only because the Nicomachean Ethics and the Politics were unavailable until medieval moral and political thought had already been developing for several hundred years (see Cary J. Nederman, “The Meaning of 'Aristotelianism' in Medieval Moral and Political Thought," Journal of the History of Ideas 57:4 [1996], pp. 563-585). Rather, Aristotelian moral and political thought was "but one among a diverse array of approaches," even if an extremely important one (ibid., p. 584). Other important resources that were available throughout the medieval period include Augustine's City of God and Isidore of Seville's Etymologies, which stress a narrow sense of moral philosophy as "knowledge of about the appropriate end of individual action, personal virtue" and do not discuss politics. By the twelfth century, still prior to the appearance of the Nicomachean Ethics and the Politics, there was also "the recovery of Roman law," Aristotelian logic, and Aristotelian intermediaries like Boethius, Cassiodorus, and Hugh of St. Victor (ibid.).
} 
discussed (see CSM II, pp. 302-383; AT VII, pp. 451-561). However, there is a more complex overlap between these two rules, stemming from the pre- or proto-rule, drawn from experience, to make as few laws as possible. If in fact the rule not to accept what is doubtful is drawn, insofar as it is the first rule of an intentionally short list, from a pre- or proto-rule which is clearly practical not to say political, then the epistemological claim that generates the extremes of hyperbolic doubt would seem to be drawn from a practical decision made on moral grounds that would appear to replicate, imitate, or even 'simply' be an application of moral rule 2, which itself is the second in an intentionally short but separate list. If this point is true, then neither Bourdin's complaints nor Descartes' frustrated responses in the Seventh Set of Objections with Replies get to the heart of the difficulties here: Descartes is fabulating a world, a milieu, a culture of clear and distinct judgment, grounded on a handful of rules that themselves are determined in at least their paucity of number by a pre- or proto-rule grounded on the ethical, moral, political behavior of people in the world, but this handful of rules is split between the purely rational and the moral or practical, and claims that the difference between the two realms (epistemological and moral) should be clear and distinct insofar as the moral rules are geared toward Descartes leading a happy life, a claim of differentiation which itself is necessarily, on Descartes' reasoning, already epistemological, an epistemological claim which girds the moral claim that establishes the pre- or proto-rule that itself appears in reference to worldly travel and moral judgment made possible by the education the fabulator has had such that he can tell his unique story in such a way that he can faire voir his readers to replicate, imitate this same story in their own way, with their own (limited) rules that determine yet are simultaneously determined by the rational, and so epistemological, judgment which makes them human. The fable of the 
Discourse, then, is a fable of rule generation that tells itself its histoire of rule obedience, and it is a rule obedience that is an histoire of rule generation. ${ }^{66}$

Thus, the relationship between the metaphysico-epistemologico-hyperbolic and the moral-practical seems to be an interweaving between them. It is persistently unclear to what extent the moral obeys rules generated by the epistemological or vice-versa. In that even the generation of the proto- or pre-rule that rules on the value, virtue, and utility of a small number of epistemological and moral rules seems to turn itself into a knot of the politicomoral and the logical, the unclear and indistinguishable relationship of rule-generation and rule-obedience that emerges between the four epistemological and moral laws is made all the more unclear and indistinguishable because the rule for the rules already itself appears to be imitating another rule — that is, the experience, the practice of order and rule itself. ${ }^{67}$

\footnotetext{
${ }^{66}$ Debra B. Bergoffen focuses on moral rule 2's delimiting quality on the "the scope of doubt" (Debra B. Bergoffen, "Cartesian Doubt as Methodology: Reflective Imagination and Philosophical Freedom," Proceedings of the American Catholic Philosophical Association 50 [1976], p. 187). For her, reading Descartes as he would appear to prefer to be read, this moral rule indicates the difference between thought and action, the difference between metaphysical and moral certainty. In turn, the extravagance or madness of hyperbolic doubt places a limit on the philosophical freedom of the imagination, and further marks the difference between reflective and nonreflective imagination. However, she never again returns to the Discourse and, like Descartes, never seems to acknowledge the pre- or proto-rule of having few rules, least of all the moral certainty and politico-experiential source for this rule. This elision implies, as Edie explicitly states, that Bergoffen believes Descartes' pursuit of "the elusive goal of establishing a philosophy of experience, a philosophy which would accept no metaphysical postulate and make no metaphysical hypothesis which could not be founded on and verified in the evidence of experience" is a failure (Edie, "Descartes and the Phenomenological Problem," p. 103). But if the pre-or protorule that demands few rules is in fact a rule for lists of both metaphysical and moral rules, then there would seem to be an experiential background to the these lists, especially insofar as the paucity of the number of rules within them coincides well with the metaphysical background that would inform analytic reduction to simples. Here is a small number of simple rules by which to live in both epistemologically and morally, the simplicity and smallness of said lists being in agreement with the three of the epistemological rules themselves and also being grounded in a moral and/or political conclusion drawn from practical experience. The range of the reflective imagination's freedom in developing this pre- or proto-rule thus seems, at the least, more open to discussion than the question of its range in the operation of what follows from the epistemological rules.

${ }^{67}$ In drawing the line of "The age of method" from Descartes to Hegel, Derrida notes that, in this age, "the path [chemin] of thought, the path-character of thought is restrictively determined as a technological process of modernity, in the reign [regne] of representation, of the subject-object relation, of the mastery and of the inspecting [arraisonnement] of nature" (Jacques Derrida, "La langue et le discours de la méthode," Recherches sur la philosophie et le langage: Cabiers du Groupe de recherches sur la philosophie le langage 3 [1983], p. 44; my trans.). Following out some of Heidegger's thoughts in Der Febl beiliger Namen, Derrida finds that, because 'process' is a foreign concept for the path, "method is a reign, an adjustment [réglage] which disrupts [dérègle] and disguises the path around the distinctive feature of the path [le chemin vers le propre du chemin], it disappropriates [désapproprie] the
} 
None of this, however, indicates that Descartes himself is taking up a sovereign role

\author{
here in the fable or histoire of the Discourse. ${ }^{68}$ To return to the second reason for Descartes'
}

path in its essence" (ibid., p. 45; my trans.). It is perhaps by attending to the pre- or proto-rule and to the knot made from the paths of the epistemological and moral rules which follow from this rule, the way this pre- or proto-rule shows how the epistemological is interwoven with the moral and vice-versa, that we can see how Descartes himself recognizes the perversion of the path that method engages, but this perversion is not imposed on the path from outside the path. It is itself part of the path, insofar as what would pervert the path-i.e., the technological and methodical application of rules, whether epistemological or moral-is interwoven into the path itself, the pre- or proto-rule for rule-generating, whether epistemological or moral. The path for the method perverts itself, disrupts and disguises itself in obeying what it would generate. In such self-perverting and disguising, it also seems to multiply itself, even in its attempt to rein itself in from overt multiplication via the content of pre- or proto-rule.

${ }^{68}$ Cavaillé and Nancy believe the fable or histoire is exactly how Descartes gives himself, as a self, a sovereign role. For Cavaillé, in the conclusion, subtitled "Le Je Souverain,"

The autobiographical feint, like the feint of science, the fable of the Discourse like that of The $W$ orld are hatched by an $I$ which exceeds or rather precedes the diverse statuses - narrative, rhetorical, psychological, epistemological—successively assumed within the text as so many avatars: subject of the story [récit] (fabulist of 'a new world,' portraitist of his 'life' and of his 'thoughts'); subject of the passions which, according to the author or despite him, appear within the text; subject finally of the science which comprehends all the others; audacious and chimerical hero of imaginary spaces, geometer and poet of the new world. (Cavaillé, Descartes: La Fable du Monde, p. 304; my trans.)

For Nancy, it is precisely the unusual anonymity of the Discourse that speaks to the sovereignty being exerted by Descartes. Whereas a normal anonymity hides or disguises its author, this anonymity

proclaims that the dissimulated name is the most proper of proper names: the name of the one who alone gave himself the method of certitude, and hence of the one who gives bimself out as the method of certitude and the certitude of method. But the identity of this subject is valid only on the condition that it be identity itself, stripped entirely of the accidental, the empirical (the name René Descartes, for example), and presented in its substance as subject. (Nancy, "Larvatus Pro Deo," p. 28)

For both Cavaille and Nancy, then, the anonymity of the presentation of the fable or histoire of the Discourse gives Descartes a sovereign role over his readers such that the author, as the authorizer of this histoire, is everywhere and nowhere in the text-nowhere specific, especially insofar as the bistoire is a fable written anonymously, and everywhere because of the autobiographical nature of the text. However, both Cavaillé and Nancy, again, operate from the assumption that the self who authors this fable or histoire is a fully formed self in the writing, before the writing, that the method is generated by a self which asserts itself in the autobiography. But if the pre- or proto-rule is any guide, the self is not sovereign insofar as it is not a rule-giving entity, at least not wholly. In addition, this self, this anonymous self, would not be sovereign so much as an exemplar, an example, a paradigm of the anonymous, modern, rationally democratic experience of the self, whether we want to take this example as an example proper (i.e., historical) or as a fable. Indeed, Nancy hints at this, though he still operates on the assumption that this self is always already itself before its fabulation of itself, when, in a footnote to the first sentence cited above, he explains that the self which is given as the method of certitude and the certitude of method "will later have to be extended by analyzing the special exemplariness set in play by the fable in Descartes" (ibid., p. 36n. 26). Yet, because the role of the self is assumed as sovereign, an assumption grounded in the further assumption that the faculties of the mind are formed prior to the fables at hand, and thus that the imagination can only be a passive or at most have a biplanar structure, Nancy and Cavaillé both miss the more complicated relationship to sovereignty at hand in the self which authors itself into existence through the authority of the fable, a form which itself has less authority than bistoire or at least history 
reticence on morals, sovereigns alone have the right to "concern themselves with regulating the morals of other people." Sovereigns, nobles, rulers are able to do this because, as he writes in another letter to Chanut, dated November 1, 1646, "persons of high birth, whether men or women, do not need to be very old in order to be able [pounoir] to go far beyond other people in learning and virtue." Descartes was born to a noble family, but he does not consider himself beyond others in learning or virtue except in having discovered a method that democratizes the power, the potentia, the puissance of good sense to everyone, which is precisely why he tells his fable or histoire, even to those who may be incapable of following its intricacies. ${ }^{69}$ This point of his fable or bistoire is the story of the generation of the rules that he obeys, rules generated in imitation of and obedience to a proto- or pre-rule that itself imitates and obeys an interwoven combination or relationship between the logical and the

and which, in its pedagogical status, authorizes others to author themselves as equally sovereign as the fabularly paradigmatic or paradigmatically fabular self.

${ }^{69} \mathrm{It}$ is in the democratization of the power of good sense that perhaps Schmitt is somewhat off when he claims that "The protego ergo obligo is the cogito ergo sum of the state" (Carl Schmitt, The Concept of the Political, tr. George Schwab [Chicago: The University of Chicago Press, 1996], p. 52). Schmitt claims this because all order depends on protection and obedience. Schmitt may very well be correct that the protego and the cogito run parallel to each other, but this is as much to say that the moral-political runs parallel to the epistemologico-metaphysical. Such a parallel would certainly explain Descartes' specific political positions and consistent appeals to the authority of sovereigns to shape a moral and political order, as well as his praise for De Cive even while lambasting Hobbes's metaphysics (see CSM-K, pp. 230-231; AT IV, p. 67). Yet these parallels for Descartes operate on the order of the pre- or proto-rule of few rules, which is an ordering principle that does not precisely follow the logic of protection and obedience insofar as it is the order from out of which that logic would emerge on both the epistemologico-metaphysical and on the moral-political planes. Such a relationship between the pre- or proto-rule and the epistemological and moral rules does not, however, make the pre- or proto-rule sovereign over the ordering principles of those eight simple rules for at least two reasons. One, the pre- or proto-rule is not separated from the eight simple rules but is formed by them in the difficult and knotty logic of comparative ordering at hand between the epistemological and the moral insofar as that comparison would operate through utility, which is also the justification of the pre- or proto-rule. Two, it is not sovereign even in the sense of a Hobbesian-Schmittian Leviathan born from the individuals formed qua individuals in the formulation of the Leviathan because there is no obligation on the part of the reader to become Descartes, let alone Cartesian. Descartes, because he does not teach, allows his readers to tell their own stories, without any forced obligation to repeat his own. The epistemological and moral rules, and even the pre- or proto-rule that opens up the possibility of formulating those rules, are part of Descartes' own, individual, even if anonymous, histoire. It is his experience which had contributed to the formulation of the pre- or proto-rule, and his experience alone. In the telling of his exemplary and paradigmatic story, he is showing what came from that histoire, but readers must tell their own stories to themselves, even if this book of the past itself becomes part of the story of the reader. It may be a persuasive story, but it is neither a sovereign demand nor a command, even if all the more persuasive for it. 
political. The moral of this fable, then, is already its telling. ${ }^{70}$ And this telling is the telling of

the generation of rules to obey from out of obedience to and imitation of rules generated in

the surrounding milieux, intellectual, political, social, or otherwise. ${ }^{71}$ (CSM-K, p. 299; AT IV,

p. 536)

${ }^{70}$ Thus, again, this moral is unlike other morals for other fables. It is not separate from its story. Unlike La Fontaine's moral for The Wolf and the Lamb, which promises what the fable will show such that "The demonstration has already taken place, in the very promise and in the differance, the act of deferring the demonstration" (Derrida, The Beast and the Sovereign, p. 79). That is, when the fable is introduced by the nonliterary moral that proposes what the fable will show, it in fact demonstrates ahead of the demonstration and monstration, all the more so in this fable, which ends "Sans autre forme de procès" (Jean de la Fontaine, Selected Fables/Fables Choisies, p. 10). This is the logic of sovereignty, to attempt to show before the showing what will be shown, to speak in the future anterior such that what is is what will have been, and so on. This sovereign logic of moral and fable is perhaps repeated in the The Concept of the Political, in the dedication, which reads, "In memory of my friend, August Schaetz. of Munich, who fell on August 28, 1917, in the assault on Moncelul," with Moncelul being the last major battle on the Romanian front before Romania sued for peace in 1918 (Schmitt, The Concept of the Political, p. 19). This would be, following something of a Straussian critique of Schmitt, the moral, the liberal 'apolitical' heart of the fabular Concept's understanding of sovereignty. None of that relationship between moral and fable is at hand in Descartes' fables and histories. The fable follows the logic of light, the method of being the rule that obeys and generates itself, and therefore does not show ahead of the showing because it is the showing. Such a logic may be political, but it does not appear to be sovereign.

${ }^{71}$ On the intellectual, religious, and political mileux in which Descartes chooses to write the Discourse in French, which of course is not an apolitical decision, see Derrida, "If There Is Cause to Translate I," pp. 6-16. As Derrida explains it, this choice "is not simply revolutionary, even if it seems relatively singular in the order of philosophy and if it looks something like a rupture" because the choice to write in French remains a choice in favor of the language of the state over the church (ibid., p. 17). This seems correct, and bears in mind the balance between the non-sovereign self who declares the cogito and the individuality of the event of the Cartesian moment, a balance that is frequently lost in assessments of Descartes. 


\section{Chapter Four}

\section{Imagination}

Following from the complication of the method that attending to the fable inaugurates, the next concern is the faculty psychology of that self that generates and obeys the rules of the method. Once again, attending to the fable has an effect on this concept, not only on the concept of the faculty psychology of the self, but on the concept of a faculty psychology as it pertains to Descartes at all. Attending to the fable has this effect on the concept of a Cartesian faculty psychology, however, only after having attended to the fable's complicating effect on the method because the method is that by which a mind will achieve its logic. This remains the case even though the method remains an application of logic, regardless how complicated this logic may be. Thus, even though the self, as that which is constituted by a psychology, is the thing which applies a method, the effect of the fable on the method exposes something about this self and its psychology which attending to the fable's effects without having attended to its effects on the method would be unable to expose. In particular, because the fable affects the concept of the method such that it becomes selfsupplemental, knotted, and interwoven with what it would exclude, the self that both applies and is discovered by the method now comes into question as to its psychological constitution.

The usual, most straightforward understanding of the Cartesian faculty psychology is that the mind is divided into the faculties of intellect, will, passions, sensation, memory, and imagination. The intellect takes in ideas and, combining with the will, determines whether 
said ideas are clearly and distinctly perceived. The will is an infinitely free faculty the volitions of which are limited by intellectual perception and physical limitation. The passions are reactions to experiences in the world. Sensation is the faculty to experience the world. Finally, memory and the imagination are the faculties that store and recombine ideas, volitions, passions, and sensations. Yet, if we attend to the foundational quality of the fable in Descartes' work, this structure, especially the presumption that it is pre-formed, must be called into question. By the end of this chapter, I hope to have shown that (A) there is no faculty psychology which is formed prior to the fabulation of the world for Descartes; (B) the imagination does not exist even in a biplanar, parallel fashion between mind and world, not even in the sense of imaginary space; $(C)$ the imagination's relationship to the infinite will and to the finite passion of wonder show that the imagination in fact exists as a transfinite faculty, moving across the border between the infinite and the finite; and (D) this relationship should be taken seriously for the comic, laughable quality in Descartes' philosophy that it is.

\section{Pedagogy and Imagination}

If attention to the fable affects the method in the way laid out above, such that the latter cannot sustain itself in the simplicity and precision distinct from history that Descartes or at least Cartesians would believe, the next question centers on the effect attention to the fable has on Descartes' faculty psychology, on the divisions of the mind that would be put to use in the appropriate methodical search for simple truths. ${ }^{1}$ Insofar as fables, novels, dialogues,

\footnotetext{
1 There are different ways of taking the concept of a faculty psychology. It can be understood as descriptive of a hard and fixed delineation of physical loci in the brain where specific mental activities occur, à la phrenology or, in a different fashion, cognitive science. It can also be understood as descriptive of different regions of the
} 
etc. are imaginative works, attention to the faculty of the imagination will be the focus here, beginning from a work that may be early or late (The Search for Truth; see CSM II, p. 399), then turning to an early piece (the 1619-1621 notebook) before a later one (Meditations).

\section{The Form of the Imagination}

As he does so many times, Descartes begins The Search with what a "good man [honneste homme]" can or should do, with what is required of him. Here, one is not required to read what the schools would have one read because such reading could in fact be a detriment to one's education. Instead, because of the exigencies of life, a good, honest man would do better to focus on performing "good actions [bonnes actions]." Such actions are those that one's reason would teach (enseigner) oneself were reason the only teacher one had. The problem, as is so frequently the case, is the combination of innate ignorance, trust in the senses, and the authority granted to one's teachers (précepteurs). Thus, reason is a more effective enseignant than academic précepteurs, but the ignorance with which we enter the world leads us to trust both the senses and our précepteurs over and above reason, which must be

immaterial substance of mind where distinct mental activities do their respective jobs. In that Descartes' texts do not tend to feature maps of the brain like phrenology, it is difficult to consider him in the former camp, even if he does consider the pineal gland to be the seat of the imagination. However, it is commonly understood that Descartes, like many of his contemporaries, "believed that the human mind has a fixed cognitive structure" (Gary Hatfield, "The Workings of the Intellect: Mind and Psychology," in Logic and the Workings of the Mind: The Logic of Ideas and Faculty Psychology in Early Modern Philosophy, ed. Patricia A. Easton, North American Kant Society Studies in Philosophy 5 [1997], p. 34). Hence, this common understanding goes, as Descartes develops his considerations of the intellect, the imagination, the will, and the passions, these regions of the immaterial substance of mind are to be understood as fixed in their roles and relationships to each other. As Sepper puts it, "As soon as one allows even a small degree of independence to a function, one has in fact taken the first step into a psychology of the faculties" (Sepper, Descartes's Imagination, p. 13n. 1). Sepper perhaps takes this first step too far, leading him into an assumption of hard and fast delineations of the faculties which Descartes himself might not endorse, but he is hardly alone in his thinking that the Cartesian faculties have distinctions from each other which cannot be crossed by the others-see, for instance, the schema of the faculty classifications Robert Stoothoff gives in a note in his translation of the Passions (CSM I, p. 338n. 1). That Sepper's is, to my knowledge, the only sustained investigation of the Cartesian imagination in English for about one hundred years, his is the understanding which frames my reference to a Cartesian faculty psychology, even if only as that against which I will argue. 
trained, given a method for practical application. Indeed, it may even be the case that précepteurs are neither teachers nor tutors at all, but rather something closer to the word's Latin root as one who takes or captures someone, in particular someone's reason, before he or she has a chance to develop it in the fashion that would lead to an appropriate use. (CSM II, p. 400; AT X, p. 495)

It would be for this reason that Descartes explains that these précepteurs are able to fill (remplir) the imagination "before reason could guide [entreprendre] his conduct." That is, academic teachers fill the empty vessel of the imagination such that the false thoughts that filled it guide one's conduct, preventing reason from doing so. ${ }^{2}$ To be able to do so, such academics must have had access to a pre-existing vessel that could be filled with thoughts as found in books. In addition, this pre-existing vessel must also be precisely a vessel, an empty container that takes in, enfolds within its contours and borders, whatever is poured into it. Such an imagination would, of course, benefit from books if it in fact was formed, even if empty, prior to contact with the thoughts, false or otherwise, that were poured into it. For Descartes, it is not merely the case that the thoughts that would fill the imagination are false, but that their filling of the imagination de-forms the imagination, warps it and gives it a strange shape. The imagination is deformed in the filling by too much reading, however, not because it is a pre-existing vessel made into a warped shape, but because the imagination, the faculties themselves, the mind itself, is not a vessel at all. ${ }^{3}$ Like space as articulated in The

\footnotetext{
${ }^{2}$ Remplir means not only filling a container, but also fulfilling a capacity. To the extent that both of these are in play in this context, it would indicate that the very consideration of the mind as a container to be filled gives rise to a concept of education where one can only fulfill a capacity, rather than inaugurate a potential. Nonetheless, I will favor the use of filling a container here, as the context demands it.

${ }^{3}$ Nancy seems indicate something close to this issue when he claims that the instant of the appropriation of the self that is Descartes' discourse is an appropriation of "only the sans-fond of the still surfaceless substance, or the formlessness of the support that has not taken pictorial form" (Nancy, "Larvatus Pro Deo," p. 30). On his analysis, any portrait requires a fictive viewer for its very concept. Since the subject or concept of the Cartesian painting is "the auto-conception of this subject, or the auto-conception that is this subject," there is no
} 
World, the ignorant mind of a newborn is not something yet to be filled, but is closer to the

pre-motive solid matter of chaos, where the forming of the faculties occurs in the

procedures of motion. ${ }^{4}$ (CSM II, p. 400; AT X, p. 496)

Now, in that the experience of learning for most good and honest men is that of

having their minds filled, Descartes is concerned that his readers will be intimidated by the

plan he has for them in this dialogue to search for truth. Such a concern is the mark of the

difference between his approach to pedagogy and the Scholastic approach. He recognizes

interiority to the subject even while the auto-conception or self-apprehending of the subject or self is impossible because "the ontology of the thinking substance stands as a matter of principle in contradiction with the exhibition of the surface covered with signs" that would be the subject without interiority (ibid.; trans. modified). As a result, the surface of the apprehended subject is itself the depth of that subject and the fictive viewer of that subject is the selfsame self that appropriates itself in the impossible auto-conception of a thinking subject that is only surface. Without seeming to acknowledge the effect it would have on his conceptions of the Cartesian faculty psychology, Nancy even goes so far as to claim that what is indicated in the fictive viewer is that "the 'fictive' is not the 'imaginary,' or rather that it is, in the sense that the imaginary itself, the order of the image, is henceforth the order of thought" (ibid., p. 31; my emph.). Whether the imaginary is identical to the order of the image is contestable, however, because the imaginary, or at least the imagination, may be that which brings the order of the image into being, even if it is not the condition for the possibility of that order.

${ }^{4}$ As Cavaille points out, “Imaginary spaces' thus offer the point of narrative departure for the fable at the same time that they inaugurate the Cartesian reflection on the conditions and principles of physics" (Cavaillé, Descartes: La Fable du Monde, p. 215; my trans.). Garber's explanation of imaginary space is helpful here. In Aristotelian philosophy, there can be no nothing, but such a possibility is worrisome in Christian theology because "not even God could create an empty space" (Daniel Garber, Descartes' Metaphysical Physics, p. 127). In 1277, Bishop Ėtienne Tempier of Paris condemned this possibility, forcing Aristotelians to think about the possibility of empty space. This rethinking resulted in "the possibility, in some sense, of an empty space beyond the world, what came to be called 'imaginary space,' space that would allow God to move the finite world as a whole" such that, in Descartes' time, "it was by no means uncommon to hold that space is in some sense independent of the bodies that occupy it, and that there can be or actually are portions of this space unoccupied by body" (ibid., pp. 127-128). Returning to Cavaillé, he points out that "Descartes adroitly exploits a simultaneous linguistic and doctrinal ambiguity" by implying that the concept of imaginary space is a fiction and also that the Aristotelians admit that space is infinite such that "the negative infinity recognized in extraworldly spaces become in Descartes' eyes the camouflaged expression of an imperative of the imagination itself" (Cavaillé, Descartes: La fable du monde, pp. 213 and 216, my trans.). This is the case because "the imagination indefinitely exceeds the limits that we want to fasten to it" to such a point that, even though it cannot have an image of infinity, "the narrative fiction of a voyage within the imaginary spaces of the philosophers is, from a theoretical point of view, a passage to the limit, the crossing of an interworld which is already no longer Aristotelian ... and which becomes a Cartesian space only with the enunciation of the first supposition, that of the filling of the imagined vacuum" (ibid., pp. 216-218). In other words, since the imagination imagines empty, imaginary space, it can also imagine that space as filled. The imagination is able to imagine a filled, heretofore empty, space because that space was already imaginary since, insofar as it is a space imagined as empty of all matter, it is unimaginable, but the imagination is able to imagine what is unimaginable. Since Descartes begins by imagining imaginary space as filled, then a connection between matter and mind would demand imagining the mind as without any empty space either, as an imaginary space that is not separate from what occupies it. The mind, like space, is not a vessel filled with objects, but must be imagined as, at least at first, solid. 
that it would take an extraordinary amount of talent or the luck to have an appropriate teacher (sage) to re-form or unmake (defaire) one's deformed imagination filled with the false thoughts of the précepteurs, but he will have to play this sage role, having himself an extraordinary nature. In playing this role, he will be "opening [ouvrant] to each of us the means whereby we can find within ourselves ... all the knowledge [science] we may need for the conduct of life, and the means of using it in order to acquire all the most abstruse items of knowledge [connoissance] that human reason is capable [capable] of possessing." Thus, he does not understand himself as a preceptor, as a capturer of all knowledge ahead of the capturing, but as one who opens up, sets into motion the solid and ignorant mind by exploiting the cracks in the solid matter that are not themselves vacuous, whatever it is that reason can capture of its own ability. (CSM II, p. 400; AT X, p. 496)

But his concern about readers' intimidation is well founded in that he is concerned that the unmaking, the unlearning of what has been learned through the preceptive filling of the empty vessel of the imagination could very easily overwhelm the reader. It could, as he puts it, "fill [remplisse] your minds with so much wonder [estonnement] as to leave no room [place] for belief' (CSM II, p. 400; AT X, p. 496). He is concerned that his readers will not believe they can learn after learning to unlearn, that their minds are so used to passively taking in thoughts that the thought of thinking, of learning on their own, overwhelms and intimidates them with the wonder of it all. In one way, this means that the mind has become synonymous with a passive imagination, while in another it means that wonder itself has been eradicated from the form of learning insofar as wonder, or at least astonishment, generates an incapacity for belief. Descartes' position on the eradication of wonder can be seen in two moments that critique the syntheses of syllogistic formulae as well as the disputations and quaestiones of academic philosophy. First, in Rule Ten of the Rules, 
dialecticians are unable to formulate a syllogism with a true conclusion unless they are already in possession of the substance of the conclusion, i.e. unless they have previous knowledge of the very truth deduced in the syllogism. It is obvious therefore that they themselves can learn nothing new from such forms of reasoning .... It should therefore be transferred from philosophy to rhetoric. (CSM I, pp. 3637; AT X, p. 406)

Second, in the Second Set of Replies, “I wrote 'Meditations' rather than 'Disputations' ... .

In doing so I wanted to make it clear that I would have nothing to do with anyone who was not willing to join me in meditating and in giving the subject attentive consideration" (CSM II, p. 112; AT VII, p. 158). In these two places, the very form of argumentation as practiced in the academy precludes learning as such, learning in the sense of discovering new truths based not on preconceived or pre-existing formulae of truth but on reason's teaching. Reason's teaching is grounded in wonder, but if wonder has been eradicated because of preconceived or pre-existing formulae, the wonder to which one is exposed in unlearning or unmaking the imagination could be overwhelming for the mind as formed by a pedagogy that thinks it fills an empty vessel. The wonder from reforming, unmaking, or unlearning in order to learn how to teach oneself could fill an imagination already deformed by academic education with an incapacity for belief in the capabilities of the mind. However, to return to The Search for Truth, "what I am undertaking is not so difficult as one might imagine [pourroit imaginer]" (CSM II, p. 496; AT X, p. 496). The possibility, the pouvoir for the imagination has been, thanks to the filling of the mind by books, disputations, and syllogistic formulae, severely limited such that it is unaware of its potential, its puissance. The faculty of the imagination remains potential here not only because facultas is always associated in Descartes with potentia, but also because it was not merely deformed but malformed by the pedagogy which considers the imagination to be an empty vessel. This malformation of the imagination leaves it incapable of imagining and believing its own power, its possibility, which is why it must be reformed by unmaking, unlearning the forms of learning that 
malformed the faculties such that it can imagine this possibility, can become a faculty proper as opposed to the empty vessel filled and being filled with false thoughts. ${ }^{5}$

To begin this search for truth, then, Descartes must begin with the reformation of the imagination as one that can reform itself in reforming its possibilities, and not an imagination understood as an empty vessel, which is why he asks his readers to, along with him, “imagine [suppose] that Eudoxus, a man of moderate intellect [esprit] but possessing a judgement which is not corrupted [perverti] by false beliefs [creance] and a reason which retains all the purity of its nature, is visited in his country home by two friends." What is more, he will leave "to your imagination [imaginer] their other conversations as well as their surroundings (from which, however, I shall frequently have them take examples in order to make their thoughts clearer)." Descartes is not satisfied with asking his readers to imagine along with him the conversation that he will show them, but he also asks them to imagine 'extraneous' content that may suit them. Even in taking examples from the imagined surroundings, he is telling his readers that he will show them ways in which the imagination can put itself to work. This approach is distinct from that of academics who would fill readers' minds with the appropriate information and instead sets the mind to work on its own. In setting itself to work on its own, the mind, the imagination forms itself, and shows itself how it can work. It is, then, establishing the rules that it will obey in its search for a truth that it does not already know thanks to the formulae it has been taught. The mind is

\footnotetext{
${ }^{5}$ It is for this reason that I contest Flynn's claims that "Descartes would prefer to be a man without history," even if such a desire is impossible, and that "Methodical doubt is his strategy for annulling the effects of his inherence in history" (Flynn, "Descartes and the Ontology of Subjectivity," p. 18). It is not that Descartes is after the eradication or nullification of history, personal or otherwise. Rather, he is after an unlearning, a deformation of what has been malformed, which is different than forgetting, nullification, or destruction. Indeed, Harald Weinrich seems to be somewhat closer by noticing that the 'forgetting' at hand here is "a willed forgetting," representative of a first stage of the Cartesian method, where the second stage is a "methodically controlled remembering," which also requires the will (Harald Weinrich, Lethe: The Art and Critique of Forgetting, tr. Steven Rendall [Ithaca, NY: Cornell University Press, 2004], pp. 59 and 60). Acknowledging and remembering this non-annulling aspect of Descartes is key, for Weinrich, for attending to the difference between Descartes and Cartesians.
} 
forming itself, forming its rules for its search for itself and for truth, in the process of imagining what forms the surroundings of the conversation that it will witness. In doing so, in imagining in this way, the minds of the readers will reform their relationship with wonder such that it may be the passion that prompts learning while still leaving place for belief in the mind that wonders and imagines because, in the very wondering and imagining, that place is being formed. (CSM II, p. 401; AT X, pp. 498 and 499)

The Force of the Imagination

Insofar as there is debate over the period when Descartes wrote The Search, it seems appropriate to turn to an early discussion of imagination, to see whether the conception of the imagination in each piece fits with the other. What will be shown in doing so is not only that there is a consistency between these earlier and the possibly later works, but also that the content of these works relates to each other in such a way that the form of the imagination in The Search has a similar form as the force of the imagination in the early work. This early discussion is found in what Cottingham calls the Early Writings and what Adams and Tannery call Cogitationes privatae, a notebook Descartes kept between 1619 and 1621. The specific note to which I want to draw attention is, to my knowledge, the earliest consideration by Descartes as to the function and status of the imagination. There is some use of it in the treatises he wrote for Beekman in 1618, the Physico-mathematica and the Compendium musicae, but by and large Descartes limits himself to noting what is imaginable and in asking Beekman to imagine certain physical activities. ${ }^{6}$

\footnotetext{
${ }^{6}$ The one possible exception would be in the Compendium musicae, where Descartes indicates that we note musical division into two times by calling it percussion, beat, or singing for the aid of the imagination (see AT
} 
This note, which Cottingham places under the heading "Olympian matters," following a suggestion by Baillet, begins by making a claim as to the function of the imagination: It "employs figures in order to conceive of bodies [vtitur figuris ad corpora concipienda]." Here, then, the imagination is at work, utilizing figures, such that conception of bodies is possible. This conceiving of bodies also appears to be the work of the imagination, so it would seem that the imagination both utilizes and conceives. That figures are utilized in order that bodies be conceived indicates that figures precede bodies for the imagination, which is consistent with much of what Descartes will claim throughout his career, but what is most important here is that the imagination is at work in utilization and in conception. This imaginative work is favorably compared with the work of the intellect, which, "in order to frame ideas of spiritual things, makes use of certain bodies which are perceived through the senses, such as wind and light [vtitur quibusdam corporibus sensibilibus ad spiritualia figuranda, vt vento, lumine]." The intellect also performs two kinds of work, utilization and framing or figuring, in such a way that certain sensible bodies are utilized in order to figure spiritual things. That is, the intellect employs sensible bodies to give shape to what is otherwise without figure. The imagination thus has a function that involves utilizing figures and conceiving bodies, while the intellect's function involves utilizing bodies and figuring spiritual things. Through the utilizing and conceiving imagination and the utilizing and

\footnotetext{
X, pp. 93-94). However, he still does not consider the function or status of the imagination here, so I believe myself justified in considering the note in the Early Writings as the earliest consideration of the imagination.

Timothy J. Reiss considers the Compendium to have solidified the reliability of music as a mathematical practice "for future assumptions about the relation between 'mathematical' reason and imagination" insofar as the imagination is related to sense and the passions (Timothy J. Reiss, Knowledge, Discovery, and Imagination in Early Modern Europe: The Rise of Aesthetic Rationalism [Cambridge: Cambridge University Press, 1997], p. 189). If the division of music into mathematically proportional beats aids the imagination as well as comprehension such that a listener can remember and apprehend a beat from the beginning of a piece at its end, it is because "nostra imaginatio easily combines the simple successive proportions marked by bars" (ibid., p. 193). This is the closest to a description of the function and status of the imagination in the Compendium. It would seem to be, as is traditional, the faculty where memories are stored and possibly toyed with. That this assumption of the function and status of imagination does not fit very well with the discussion of imagination in the Early Writings is interesting, but Reiss does not discuss these notebooks in this book.
} 
figuring intellect, Descartes believes we are able (possumus) to philosophize in a more sublime fashion. (CSM I, p. 4; AT X, p. 217)

Presumably, the lack of a more sublime fashion of philosophizing leads to poets having serious judgments, over and above those of philosophers. The specific reason Descartes gives for this situation is that "the poets were driven to write by enthusiasm and the force of imagination [poetae per enthusiasmum \& vim imaginationis scripsere]." That is, there is a strength, force, or energy in the imagination that forces poets to write at all. This force in the imagination would seem to be in its utilization of figures, its conceiving of bodies, or both. At any rate, there is a force at hand in the imagination that drives its function, a force with which poets appear to be more in touch than philosophers. (CSM I, p. 4; AT X, p. 217) There remain, however, the seeds (semina) of knowledge within everyone, poets as well as philosophers, and knowledge is as potential within the mind as sparks are within flint. The difference is found in the methods by which philosophers and poets come to know. Philosophers, according to Descartes, "extract them [i.e., the seeds of knowledge] through reason [per rationem a philosophis educuntur]." That is, the philosopher leads knowledge out thanks to reason. The philosophical education involved in developing reason draws or leads knowledge, or the seeds of it, out of its hidden place. Poets, however, "force them out through the sharp blows of the imagination [per imaginationem a poetis excutiuntur magisque elucent]." That is, the seeds or sparks of knowledge shine forth thanks to the force that the imagination sends forth, rather than the rational drawing out of those seeds or sparks by the philosophically educated and educating. ${ }^{7}$ (CSM I, p. 4; AT X, p. 217)

\footnotetext{
${ }^{7}$ In commenting on this same passage, Fóti points out the connection to another note in the Early Writings, on Lambert Schenkel's De memoria. There, Descartes writes that the "good-for-nothing" Schenkel "does not depend on the right order... [, which is] that images be determined by mutual dependence" (AT X, p. 230; my trans.). As Fóti describes it, Descartes wants to replace Schenkel's art with "the institution of intellectual order among series of memory images or phantsmata elapsa. Such institution of intellectual order requires, Descartes
} 
Perhaps there are two imaginations at work, one which operates through bodies and is of a lower order than the intellect, and a second which operates through the intellect such that spiritual things can be figured, in some imitation of the utilization of figures through which the first kind of imagination operates. ${ }^{8}$ This second imagination would then be figuring, giving shape to spiritual things, which would not seem to have matter of any sort. This imagination would thus be imagining that which has no image, would in fact be imagining what cannot be imagined, or figured. It makes what has no figure into figura. Even if true, however, not only is it the case that the imagination remains active, and so is not an empty vessel, but a faculty psychology has been established that does not involve a preformed structure insofar as the imagination would involve multiple roles, one on the level of bodies and the other moving within the realm of the intellect and spiritual things. It is no more radical, in other words, to suggest that the faculty of the imagination does not remain in its place but moves into the faculty of the intellect than it is to suggest that there are two

notes, recourse to new images” (Fóti, “The Cartesian Imagination,” pp. 632-633). As a result, the intellect still depends here on the imagination. For Fóti, this early relationship between the imagination and the intellect is dropped later in Descartes' career because he worries about the unruliness of the imagination and its capacity to generate illusions, which is why he eventually "relegate[s] it to the body" (ibid., p. 641). Whether such relegation ultimately happens, or whether the relationship between the imagination, the body, and the intellect is more complex than she suggests, is what is sought in this chapter.

8 This note is the basis for Sepper's understanding of the imagination as biplanar. He calls it " "the two imaginations note" and sees in it a distinction between the intellectual and poetic imaginations (Sepper, Descartes's Imagination, p. 47). By the time Descartes writes the Rules, then, "The philosopher or savant ... learns to discipline the imaginative leaps that the poet makes; guided by the spark of truth poetic imagination reveals, the philosopher fills in, item by item, through step-by-step imaginative discursion, the logical space that the poet typically overleaps" (ibid., p. 118). Even the Principles, insofar as there a substance is only known through attributes, "retains the biplanarity characteristic of the early period" (ibid., p. 185n. 22). While I agree with Sepper that frequently "our impressions of the later Descartes mislead us," especially so when it comes to the function and status of the imagination throughout his work, and am even willing to extend this misleading beyond Descartes himself and claim that we sometimes confuse Descartes for a Cartesian, the structure of biplanarity seems problematic insofar as it assumes a kind of separation between intellectual and poetic imagination (ibid., p. 184n. 20). Such a separation appears to be most clear in the Passions, an appearance which is enhanced and endorsed by the taxinomic schema at CSM I, p. 338n. 1, but it is unclear to me that that separation is appropriate as a full or even Sepperian mitigated separation, especially if Foucault's distinction between mathesis and taxinomia is to be taken seriously (see Foucault, The Order of Things, pp. 71-77, esp. p. 72). What will hopefully be revealed over the course of this chapter is not so much a biplanarity but a movement at work in the Cartesian imagination. 
distinct faculties of imagination at work in this note. Indeed, if the faculty of the imagination in fact does not remain in its place in this note, then it would appear to have a similar approach to the faculties of the treatise-like preface to The Search because the faculties would be more complicated than a pre-formed structure would presumably give them. If it is no more radical, in terms of making sense of or in terms of figuring out this note, to suggest that the imagination does not remain in its place in a given faculty psychology than it is to suggest that there are two imaginations at work within the faculty psychology which operate in a biplanar relationship with each other, then we find ourselves at the limit or bound of faculty psychology as an applicable concept. The independence of function necessary for even a minimal faculty psychology begins to look less strictly delineated by attending to the form and the force of the imagination.

Imagination in the Meditations

Thus far, much of what has been claimed about the imagination is in contrast with what Descartes claims in the Sixth Meditation. There, he writes that the imagination "is not a necessary constituent of my own existence, that is, of the essence of my mind" because it requires an "additional effort $[$ nova ... contentio $]$ " of the mind and "depends on something distinct from myself' which is the body. As a result, it would seem as though the imagination is a passive faculty, one that depends on the appearance of bodies to be sensed by the body so that it can do its work, because sense perception itself is "a passive faculty [passiva ... facultas]." Thus, in the faculty psychology laid out over the course of the Meditations, it should be clear that the understanding is the active faculty which intellectually perceives itself and other objects on its own terms, perceiving their essences, while the 
imagination is passive, requiring passive sensory perception to report what it receives before it can do any work, and never able to properly discern between how an object appears and what its essence is, but merely operating on the level of reportage. The understanding engages the world as though it were other than it appears, but the imagination is incapable of such active engagement and so can only imagine a world, imagine the world as though its essence is reported in its appearance. (CSM II, pp. 51 and 55; AT VII, pp. 73 and 79)

However, as is so frequently the case with Descartes, it is at least problematic not to say dangerous if not un-Cartesian to take things at face value, as they appear. Words need not resemble the things that they signify, but words are themselves things, as are books, pages, etc. More than that, words can resemble each other, as Descartes explains to Mersenne: "Words [paroles] are human inventions, so one can always use one or several to express the same thing" (CSM-K, p. 187; AT III, p. 417). Thus, following the synonymic relationship between 'imagine' and 'suppose' that persists in several Cartesian texts, it is important to turn back to the end of the First Meditation, to look at precisely what happens in the development from the supposition of the evil genius through the wax example. As has already been noted, in chapter 2, self-deception is at the heart of the Meditations. However, self-deception in its relationship to the imagination is especially potent when Descartes is about to posit the evil genius. While looking at this passage above, the focus was on the relationship to doubt. Here, the focus will be on the imagination. ${ }^{9}$ In the last two paragraphs

\footnotetext{
${ }^{9}$ World as text, text as world is Merleau-Ponty's focus when he claims that "philosophy for its part is more and less than a translation" (Merleau-Ponty, The Visible and the Invisible, p. 36). This is because, for him, there is a naive seeing and feeling and a seeing and feeling of the understanding, the latter of which requires a suspension of seeing and feeling because "to understand is to translate into disposable significations a meaning first held captive in the thing and in the world itself. But this translation aims to convey the text; or rather the visible and the philosophical explications of the visible are not side by side as two sets of signs, as a text and its version in another tongue" (ibid.). Thus, the philosophical translation of the text of the world into a text proper is the presentation, the making visible of the world as such insofar as the philosophical translation "suspends the brute vision" (ibid.). Now, it is true that this suspension and translation "will never restore to us the "there is' of the world" and it is true that, perhaps having forgotten the impossibility of this restoration, Descartes or at
} 
of the First Meditation, he notes that he has become tired and that his customary opinions of accepting the world as it presents itself keep recurring, but he also notes that, because these customary opinions remain probable, "it is still much more reasonable [rationi] to believe than to deny" them. Thus, he must "turn [his] will in completely the opposite direction and deceive [himself], by pretending for a time that these former opinions are utterly false and imaginary [voluntate plane in contrarium versa, me ipsum fallam, illasque aliquandiu omino falsas imaginariasque esse fingam]." The pretending here is a figuring of the former opinions as false and imaginary. As a figuring, it is a fictio (fingo is the verbal form of fictio), it is an imagining, but what is figured and imagined is opinions now figured as imaginary. If the opinions are imaginary, it is the imagination that tells him this, so the imagination is what forms both the opinions and the opinion that these opinions are imaginary. (CSM II, p. 15; AT VII, pp. 22)

To prevent the problems generated from his customary opinions, now imagined and figured as imaginary, he supposes the evil genius, a supposition he cannot maintain in the face of the exhaustion of maintaining the rigor of the doubts that this supposition entails. This exhaustion leads him back to the "imaginary freedom [imaginaria libertate]" of accepting the world as it presents itself. So what occurs in the moment of supposing the evil genius is that, despite the rationality of passively accepting the world as it presents itself, supposition and imagination is necessary to generate and maintain the belief, the will to believe, that the

least Cartesians operate from the "very naïve postulate" that the world "is always the same thing I think when the gaze of attention is displaced and looks back from itself to what conditions it" (ibid., pp. 36 and 37 ). However, insofar as the translation-text (not 'the translated text') of philosophical engagement with the world is the text of the world, then this translation-text remains a thing, a thing as possibly deceptive as any other thing. Words are things, and can be treated with as much metaphysical, hyperbolic doubt as other things. Descartes' words, as they are words of deception and doubt, all the more ought to be doubted, if only to hold Descartes' translation-text up to its own standard. What is more, such doubt as to the goodness and honesty of words reminds us of the worldliness Descartes had about the possibility of a universal natural language à la Claude Hardy: "I do not hope ever to see such a language in use. For that, the order of nature would have to change so that the world turned into a terrestrial paradise" (CSM-K, p. 13; AT I, p. 82; see also Derrida, "If There Is Cause to Translate II," pp. 31-33). 
world is other than how it appears. ${ }^{10}$ But, what is more, the pressure to believe that the world is as it presents itself leads one to a freedom only found in the imagination, an imaginary freedom like that of the dreamworld. Thus, the imagination is necessary to be able to maintain the recognition of the imagination's flaws. (CSM II, p. 15; AT VII, pp. 23)

This structure, in a way, repeats itself in the Second Meditation, when Descartes investigates what it means to be a thinking thing. In fact, the question is not even quite framed as an elaboration of the meaning of thinking, at least not at first. After identifying himself as a thinking thing, he asks "What else am I [Quid praeterea]?" It is not until the next paragraph that he identifies the other elements of the self as modes of thinking. Thus, it seems as though, initially, the faculties are potentially distinct from thinking, and thus that the self might be composed of modes other than thinking. And yet, in asking after what else the self might be other than thinking, Descartes' movement into this investigation is to "use my imagination [Imaginabor]” (CSM II, p. 18; AT VII, p. 27). In the French translation, he even goes so far as to say that he will use his imagination to see if this I is "more [plus]" than thinking (CSM II, p. 18n2; AT IX-A, p. 21). What he first imagines is what he is not: a body, even in the most vaporous form. Rather, the I, the known I, is independent of what the imagination can invent "for imagining is simply contemplating the shape or image [figurram, seu imaginem] of a corporeal thing" (CSM II, p. 19; AT VII, p. 28). Thus, using the imagination to further determine what the self is will necessarily fail because knowledge is not gained through the imagination. This structure is a repetition of the evil genius structure

\footnotetext{
${ }^{10}$ For Bergoffen, this moment represents "the ultimate hypothesis of the reflective imagination" (Bergoffen, "Cartesian Doubt as Methodology," p. 193). As such, again, it does not give a ground for positive philosophical thinking, but it does mark the distinction, in its methodological aspect, between reflective and non-reflective imagination. It still seems worth pointing out, against this tacitly biplanar understanding of the imagination that Bergoffen (as well as Foucault) presents, that this limit to reflective imagination is not rational, is a kind of madness, and so the distinction between what Descartes calls the imaginary freedom, which remains rational, of accepting the world as it presents itself and what Bergoffen calls "The rational limit of imaginative freedom" in the evil genius becomes blurrier (ibid., p. 194).
} 
in that Descartes begins to use the imagination to demonstrate the imagination's passivity and irrelevance for knowledge, whether of the self as a thinking thing or of the elaboration of thinking.

However, in another way, this structure is not a repetition of the evil genius structure. The structure of the elaboration of thinking, for one thing, is dependent on the evil genius since it gives rise to the self that is elaborated in thinking. In this structure, the imagination's "fictitious invention [fingerem]" is exposed as irrelevant for knowledge. Yet, the move to the supposition of the evil genius is precisely such an invention, a work of the imagination, and the structure of the elaboration of thinking remains dependent on the evil genius. The evil genius is the product of turning the will away from what is reasonable such that a new custom, a new habit of doubt can be cultivated. In the proof of the self even in the face of the evil genius, Descartes explains that it is irrelevant whether the evil genius exists or is invented by him to prove the self because thinking survives the evil genius as truth or fictitious invention. However, the Third Meditation proves that god both exists and is no deceiver-exists because all the divine attributes necessitate existence and cannot come from the self, is no deceiver because it is beneath the dignity of a divine being to deceive. The Third Meditation thus eliminates the possibility that the idea of the evil genius is not innate because the only possible innate ideas are that of the self and of god—of the self because it proves itself in doubting itself, of god because sensory perception suggests no such being as god and because "I am plainly unable either to take away anything from it or to add anything to it." The idea of the evil genius is also not an idea that is suggested by sensory perception, and thus cannot be an adventitious idea, but Descartes can add something to it, namely, the perfection of non-deception. As a result, the only option remaining for the possibility of the evil genius is that it is a fictitious idea, an idea invented 
("factae") by Descartes. ${ }^{11}$ Thus, through the hyperbolic moment of imaginary, fictitious

invention that is the evil genius, Descartes not only doubts the existence of the self, but also comes to prove that self as a self with a passive imagination, an imagination dependent on sense perceptions which themselves are passive receptors of the world. An imagination activated in order to demonstrate its passivity is an indication not only that the imagination cannot be considered purely passive, not only that it does not necessarily depend on sense perception and corporeal bodies to do its work (the evil genius is just like god, and thus needs no corporeality or figurality even while it can be imagined, at the same that a chiliagon is decidedly figural, but cannot be imagined), but also that a pre-formed structure of a faculty psychology, where the self's faculties are delineated ahead of their use, cannot be the case. The active imagination inaugurates the movements that will establish the structure of the mind. The imagination sets thinking into motion, forms the self and its faculties. (CSM II, pp. 19, 31, and 35; AT VII, pp. 28, 45, 52, 51, and 38)

This quality to the imagination, where it generates the mental movements that will structure the rules of passivity that it must obey, is seen once again in the movement into the wax example. The wax example begins because Descartes continues to doubt his doubt, his

11 On this reading, it would seem that the evil genius is a "study model" in Blizman's categorization, "allowing us free variations at will to gain conceptual control by deliberately imagining not only limit situations but even unreal situations" (Blizman, "Models, Analogies, and Degrees of Certainty in Descartes," p. 201). However, in that the evil genius remains a model, it is not an analogy, and so is not at "the vanishing point of the image" (ibid., p. 183). Yet the evil genius, like god, would not be imaginable in this strict sense because it would be omniscient, omnipotent, and so on. So what is imagined in this turning of the will toward the imagination? What is the image of the study model for god? Thus, what would be the image of god? Descartes of course claims that the will is that whereby "I understand myself to bear in some way the image and likeness of God [imaginem quondam \& similitudinem Dei; l'image \& la ressemblance de Dieu]" (CSM II, p. 40; AT VII, p. 57; AT IX-A, p. 45). But this will is turned toward imagining the unimaginable as a study model for conceptual control over the most unimaginable figure of god. Thus, that which bears the most resemblance to that which is most unimaginable is what brings forth the imagining of the unimaginable study model for the conception of what is most unimaginable. As Marion puts it, "the idea of God, to which the imago Dei amounts, is far from constituting the ego as its prior, immeasurable, and unrepresentable horizon; rather, the imago Dei is itself also constituted by the cogitatio, which, in 'cogito, sum,' reflexively secures its autarkic existence for itself. By a prodigious reversal, the imago Dei follows from the ego, far from transporting it outside itself into God" (Marion, On Descartes' Metaphysical Prism, p. 137). And yet, in the reflexive securitization of the autarkic existence of the cogitatio, the self also exceeds itself, takes itself outside of itself insofar as it makes of itself an object for itself. Even if this does not transport the ego into god, it does transport it outside itself. 
customary opinions return, and he begins to think once again that he knows corporeal things qua corporeal. This doubt of doubt occurs because "my mind enjoys wandering off [aberrare]," enjoys drifting into the realm of unrestrained belief, reasonable though it may be. Thus, Descartes decides "just this once [semel]" to relax the rigors of knowledge and take up the question of corporeal knowledge through the image of the wax. There, the unimaginably varied changeability of the wax shows him that it is not the image of the wax that gives him knowledge of its essence, but the judgment of the wax. Here, once again, the imagination is unleashed to show that the imagination does not do the work that it appears to do. ${ }^{12}$ This is neither the first nor the second time he has unleashed the imagination to perform this action. The evil genius and elaboration of thinking also relied on an unleashing of the imagination. Indeed, the very conjecture of the evil genius forced the will to imagine what would otherwise be unimaginable. Even the will is subsumed under the imagination in the evil genius, and both the elaboration of thinking and the wax example depend on the 'selfdestructive' movement of the imagination as found in the evil genius. What is more, this unrestrained will in the wax example, where the will to believe that the wax as it appears is in fact how the wax is known, thereby remains dependent on the imagination's subsumption of the will in the evil genius. ${ }^{13}$ That is, the will, by the point Descartes reaches the wax example,

\footnotetext{
12 For Rosen, the wax example is actually a bad example because it is not "a fair and sufficient basis for the conclusion which Descartes draws" (Rosen, "A Central Ambiguity in Descartes,” p. 26). He explains that many other physical objects - apples, trees, and cats are his examples_-would not be recognizable given the same experiments. He writes, "we need merely ask ourselves ...," but here he seems to be missing a crucial point (ibid.; my emph.). Descartes, in asking us to ask ourselves what would happen given these experiments with wax, is asking us to imagine for ourselves. It is for this reason that Rosen finds the dilemma of intuitions to be that they are dependent on either the imagination or on god and that, "If the former, then intuition is always of bodies," while, "If the latter, then, since God is primarily free will, natural order . . . is an arbitrary divine creation, subject to equally arbitrary change" (ibid., pp. 26-27). However, it only needs to be the case that the intuition would always be of bodies insofar as it depends on the will if the imagination itself is limited to the body, which it is not. Following Cavaillé, the imagination exceeds the limits imposed upon it, as the imagining of the evil genius attests.

13 The will thus finds itself within a Husserlian horizon, a predelineation within which "the potentialities of conscious life at a particular time" are uncovered, giving a "determinate structure" to the otherwise indeterminate
} 
has already been conditioned and formed by the imagination's generation of the evil genius. (CSM II, p. 20; AT VII, p. 29)

To the extent any of this can be taken as accurate, that the imagination inaugurates the movements of the mind such that the mind's faculties are generated and do so in such a way that the imagination finds itself relegated to the realm of passivity and dependence on sense perception, then it cannot be the case that the faculties are formed before the inauguration of mental motion that the imagination performs. The imagination, like the mind, is not an empty vessel to be filled for Descartes. Such an understanding of the imagination is a mark of non-Cartesian, Scholastic, academic faculty psychology. This academic understanding of the imagination as passive is what resulted in an approach to the world as though it presented itself as it is, rather than coming to grips with the fact that the senses can lead to "falsehoods." In other words, hyperbolic Cartesian doubt is neither simply a willing suspension of belief in the world as it appears nor the willing suspension of disbelief of a fictional story that Descartes tells in order to inaugurate in his readers a more rigorous habituation toward knowledge and clear and distinct ideas. It is, rather, an activation of the imagination as such and in such a way that it can form, or reform, the malformed mind of academic training that itself treats the imagination as passive. Mental space, the division of the faculties, is carved out by the imagination that inaugurates the motion necessary for this carving to occur. The academic and everyday approach to the world, to the images of the world, has been too passive. The imagination must set this right, through the actions of fictionalization and doubting. (CSM II, p. 12; AT VII, p. 17)

will (Husserl, Cartesian Meditations, p. 45). Like all Husserlian horizon structures, the horizon structure that the imagination gives to the will demands and even "prescribes" a new method, which is the method of hyperbolic doubt born of a hyperbolic imagination and imagining (ibid., p. 48). 


\section{Space and Fable}

If the imagination is not part of a pre-formed faculty psychology, the question remains what it is, 'where' it is located. The what and the where are the same question not only because the imagination is locatable in the mind only to the extent that its function exposes said location, but also because, insofar as the imagination inaugurates the mental movements that establish the faculties, its location is not to be understood as spatial even in the sense of an imaginary space. That is, the imagination's ability to inaugurate motion is what allows for mental and/or imaginary space to emerge qua space, qua ordered and orderly motion of mental matter. Because of this ability, the imagination is distinct from the mental or imaginary space that it carves out in its inauguration of motion. To better understand what the imagination is and where it is located, then, a turn to the Cartesian understanding of external space is necessary. It is not necessarily because of a biplanarity between mental and external space, a parallel structure between mind and world, but because the structuring of space comes to be understood thanks to the inaugurating motion of the imagination. To that end, and especially to clarify how this position on the imagination in Descartes is not an example of the interpretive caviling that Descartes detests, a turn to the Optics is necessary, followed by a return to The World and a turn to the Treatise of Man, and finally to the Rules.

Space and Sensation

There are four moments to which one should pay attention in the Optics in order to understand Descartes' understanding of space, but also to understand the relationship of external and mental space. Much of the discussion of space repeats what Descartes claims in 
The World, but the additional discussion of animal spirits is particularly helpful here. The other three moments are the discussion of the instantaneous transmission of motion, the discussion of the imagination's deployment in perceiving location and distance, and the role of the imagination in the whole of the essay. The order in which it is most helpful to investigate these discussions is the transmission of motion, animal spirits, the perception of location and distance, and the role of the imagination in the essay.

Descartes first addresses the instantaneity of motion early in the First Discourse, through his typical stick analogy. He introduces this analogy by explaining that, because his intended readers are craftsfolk who have little formal education, he wants to be "intelligible to everyone, and to omit nothing, nor to assume [supposer] anything that might have been learned in the other sciences." His goal in this text is simply to explain how vision works and how it can be supplemented, which is why he wants to begin with a description of light before discussing the eye and how light enters the eye. However, in the first sentence of the next paragraph, Descartes does explain that he will omit something: the "true nature [vray quelle est sa nature]" of light, the truth that is the nature of light. Instead, having recourse to a few examples will "help to conceive [concenoir]" light's properties. The first example is that of the stick. As an analogy, he reminds readers of possibly having found themselves at night in an unlit place and using a stick to guide themselves through the landscape because "the medium of this stick" gave a "confused and rather obscure" sensation that reported the existence of objects in their path. Where someone who has been blind from birth would be comparatively efficient in determining what objects appear to him or her via the stick, to the extent that "one might almost say that they see with their hands... or that their stick is the organ of some sixth sense," sighted people caught in the countryside at night are less efficient, but still extend their senses through the stick. The analogy, then, moves into light 
because "light can extend its rays in an instant from the sun to us." Sensing light is like

feeling one's surroundings with a stick because light, insofar as it is a ray like the stick, extends motion from one end to the other instantaneously. ${ }^{14}$ (E, pp. 66 and 67; AT VI, pp.

83 and 84$)$

In the Fourth Discourse, Descartes explains why the analogy works: first, because the mind senses, not the body; second, because the mind proper is found in the common sense in the brain, not because the mind is found in the sensory organs; third, because the nerves serve as media through which sensation is transmitted to the mind. Thus, there is a commonality to all sensation in that the transmission from external world to sensory organ is identical in itself and only gains distinction in the mind. What is more, this transmission, because always identical in itself, is always akin to the medium of the stick, even the internal

\footnotetext{
${ }^{14}$ Stephen H. Daniel, arguing against many traditional claims that Descartes' concept of light is contradictory or incoherent, argues that Cartesian light is a wave-particle theory. In this moment of the Optics, however, he sympathizes with those who find Descartes' treatment of light contradictory or incoherent. The stick is not the only analogy in the Optics, which is part of the confusion, especially since "the particle character is precisely that which is highlighted in the Dioptrics model of the movement of a ball through different media (i.e., to explain the refraction of light)" (Stephen H. Daniel, "The Nature of Light in Descartes' Physics," The Philosophical Forum: A Quarterly 7:3-4 [1976], p. 324). The potentially contradictory difference between a wave and particle comes down to, for Daniel, the question of the speed of light. If it is infinite, then there is no movement in the sense of temporal duration. This possibility works well with the plenum world because there, no particles moves from one end of the stick to the other in the same way that particles of light would not move through a vacuum. Thus, “The blind man's stick example is as much a denial of a particulate movement theory of light as it is an affirmation of a wave transmission theory" (ibid.). However, this wave theory via an infinite speed of light does not work well with light moving at different speeds through different media, which is where the issue of refraction and the tennis-ball analogy (i.e., that a tennis ball will move at a slower speed after entering water than it did while moving through air) come into play in defense of a particulate movement theory. The third analogy, of the wine vat with half-pressed grapes, opens a different theory, according to Daniel: "not a particulate movement theory or a wave transmission theory, but a particulate transmission theory" (ibid., p. 325). When the wine vat has two holes in the bottom, the wine will move toward them over a period of duration. For Daniel, "If we now interpret the two holes at the bottom of the vat as representing two eyes, we see that the transmission of light through the fluid is instantaneous (i.e., infinite) only if the wine in the vat is considered as constituting one medium ... and when there is some action (which is not infinite in speed) which allows for the fluid to move (i.e., relative to another medium)" (ibid.). This wine-vat analogy is illustrative of a wave-particle theory of light insofar as there are "different media (or types of matter) which can be found in his plenum universe" such that the speeds of light are different in different media, and thereby are not infinite in relation to each other, but infinite within the same medium "because there is no movement in the same medium" (ibid., pp. 325-326). This argument seems to make sense, then, of the different analogies and gives credence to a theory of light as being both wave and particle. In terms of the analogy to thinking, however, one aspect of light that perhaps can be lost in Daniel's reading is that light itself is also a medium (or type of matter). To take Daniel's argument, the movement of light within the medium of light is infinite, and therefore of instantaneous transmission. In this way, the stick analogy is more appropriate for the investigation at hand.
} 
transmission of motion via nerves from sensory organs to mind. ${ }^{15}$ The nerves are composed of three things: enclosing membranes, the nerves proper (or, "their interior substance"), and animal spirits. Animal spirits are "like a very subtle wind or air" that are the source of muscular movement by "flowing through the nerves into the muscles" and hold open the membranes that enclose the nerves. The nerves proper operate like the stick or rays of light in that any movement in a nerve is instantaneously transmitted to the corresponding part of the brain where the nerve's other endpoint is found, “just as pulling one of the ends of a very taut cord makes the other end move at the same instant." Nervous transmission of sensation does not resemble the objects that inaugurate the sensation any more than words resemble what they signify, though if such transmissions or even the images they call forth in the mind do resemble the objects, "it is sufficient for them to resemble the objects in but a

\footnotetext{
${ }^{15}$ Leaving aside for the moment Daniel's wave-particle theory of light, Prendergast distinguishes between motion, tendency, and action to take account of the problem of transmission. Motion is "rectilinear translation" between contiguous bodies (Thomas L. Prendergast, "Motion, Action, and Tendency in Descartes' Physics in Descartes' Physics," Journal of the History of Philosopby 13:4 [1975], p. 454). Tendency is found in the tendency to move in a straight line that an object has, even in the face of circular motion. The circular motion is the result of other forces pressing against the object, but the object itself tends to move in a straight line. Thus, "no motion can occur in an instant, but at any instant the stone's motion is capable of being continued in a fixed direction" (ibid., p. 455). Tendency to move follows the same laws as motion, but it is not the same as potentia because "tendency is a mode of a body" and is thereby only modally distinct from the body itself, as a body in motion or not in motion (ibid., p. 460). This modality of tendency is why "There is...neither a potentiality for motion when a body is at rest nor a potentiality for rest when the body is in motion" (ibid., p. 461). Action is the "instantaneously transmitted tendency to move in a line away from the center of the vortex where we find the sun and fixed stars" (ibid., p. 457). This action is, then, light. Thus, although motion cannot be transmitted instantaneously, "light as action is not an actual motion of a body but instantaneously transmitted motion in which no actual motion of a body takes place" (ibid., pp. 457-458; my emph.). The instantaneity of this transmission is possible because "in the instant what is present is the tendency to move in a straight line" (ibid., p. 462). Prendergast thus is not particularly concerned with the different media through which light travels, as Daniel is. What he finds with light, though, is somewhat similar to Daniel's wave-particle theory insofar as light is an action that is not a bodily motion. Thus, the internal transmission of motion from sensory organs to mind would be the instantaneous transmission of the mode of a tendency to move in a body. The instantaneity of the transmission from sensory organs to mind is possible because of the vis for moving in the nerves and mind (see CSM-K, p. 381; AT V, pp. 403-404). However, not unlike Daniel, Prendergast seems to forget that light is itself an element, and thereby a body. Light is action, light is a medium, light is matter. Thus, it is not merely both action and tendency, but also one of the things that acts and tends to move. In a certain way, this does not disqualify Prendergast's thesis completely, no more than it disqualifies Daniel's, though it does complicate both theses. Insofar as light is a body, it would be a mode of itself to the extent that, when motion is transmitted from light to light, it transfers its own tendency and modality to itself instantaneously. To whatever degree, this situation would appear to make light's action more than a mode, even if not quite an attribute, of light.
} 
few ways."16 Thus far, then, light's movements are instantaneously transmitted from one end

of its rays to the other, on impact with sensory organs, and moves the nerves in those organs

such that this nervous movement is instantaneously transmitted from organ to brain. Animal

spirits in those same nerves move the muscles in reaction to the nervous transmission. ${ }^{17}$ The

transmission from light to body need not resemble the object, though this description of

16 These few ways are the simple natures, in this context shape, but also "fform, extent, movement, and other such things" that Foucault identifies as the mark of Descartes' moving away from resemblance in favor of comparison (Foucault, The Order of Things, p. 52). The order which will emerge from comparison, specifically in the guise of algebraic symbols, establishes knowledge as "based on identity and difference" which in turn ruptures the Renaissance system of resemblance and interpretation: "On the one hand, the general theory of signs, divisions, and classifications; on the other, the problem of immediate resemblances, of the spontaneous movement of the imagination, of nature's repetitions. And between the two, the new forms of knowledge that occupy the area opened by this new split" (ibid., pp. 57 and 58). In particular, because algebraic symbols are no longer "bound to what [they mark] by the solid and secret bonds of resemblance," "resemblance ... can be manifested only by virtue of the imagination, and imagination, in turn, can be exercised only with the aid of resemblance" (ibid., pp. 58 and 68). The result, for Foucault, is an analytic of imagination and an analytic of nature emerging from this relationship between imagination and resemblance. The analytic of imagination and the analytic of nature are united in a negative and positive fashion. The negative fashion claims that "if [the imagination] is able to restore order solely by duplicating representation, it is able to do so only in so far as it would prevent us from perceiving directly, and in their analytic truth, the identities and differences of things. The power [pouvoir] of the imagination is only the inverse, the other side, of its defect" (ibid., p. 70; Les mots et les choses, p. 84). The positive fashion claims that "It is the disorder of nature due to its own history, to its catastrophes, or perhaps merely to its jumbled plurality, which is no longer capable of providing representation with anything but things that resemble one another. So that representing, perpetually bound to contents so very close to one another, repeats itself, recalls itself, duplicates itself quite naturally, causes almost identical impressions to arise again and again, and engenders imagination" (Foucault, The Order of Things, p. 70). According to Foucault, Descartes considers the imagination in the negative fashion, such that it takes on "the stigma of finitude, whether as the sign of a fall outside the area of intelligibility or as the mark of a limited nature" (ibid.). Foucault may be assuming more than he realizes here, when he identifies the power of the imagination as a pouvoir. Indeed, if the imagination were a pouvoir, it would be easily considered simply the stigma of finitude both as what is outside intelligibility and as a mark of a limited nature, but since it is not clear that the imagination's power is a pouvoir, that stigma of finitude could take on a meaning distinct from the one Foucault lays at Descartes' feet. If the imagination's power is rather a puissance, a potentia, then the stigma of finitude may not be quite a stigma nor perhaps limited by the finitude that stigmatizes it. What Foucault seems to miss, in short, is that the algebraic symbolization which ruptures resemblance and establishes knowledge as comparative for identity and difference is itself the result of a an imaginative moment, or at least is possibly comprehended by readers in the wake of an imaginative moment, in particular that moment in the Discourse where Descartes begins discussing the discovery of the method according to which the algebraic truths of the Geometry, Optics, and Meteorology will be revealed, i.e., the moment where Descartes presents his histoire or fable. That is, this positive fashion to unite the analytic of the imagination and the analytic of nature, which Foucault does not identify with Descartes, is already at work within the negative fashion of uniting these analytics, which he does identify with Descartes. The stigma of finitude, the outside of intelligibility and the mark of a limited nature, which Foucault's Descartes considers the unity of the analytic of imagination and the analytic of nature may perhaps not be so stigmatic and the finitude marked out here may not be simply finite. That the imagination, even negatively, is outside intelligibility is a sign of this potentiality.

${ }^{17}$ Sepper considers it odd that the motion is converted from pushing to pulling when it engages the nerves. He concludes that the reason is that the nerves are "too soft and pliant" for a pushing motion to be effective, but, as with a taut rope, a pulling motion will accomplish this task (Sepper, Descartes's Imagination, p. 236). 
light itself need not perfectly resemble the truth of the nature of light not only because words do not resemble what they signify but also because the words qua description are presented only to transmit conception in the mind of the reader. ${ }^{18}$ (E, pp. 87, 88, 89, and 90; AT VI, pp. 110, 111, and 113)

In the Sixth Discourse, Descartes reduces the qualities of what is seen in vision to six principles: "light, color, location, distance, size, and shape [figure]." In that both size and figure are themselves reducible to distance and location respectively, the main concern here is with the latter pair. In discussing both location and distance, he once again turns to the stick analogy. As to location, seeing and touching are again considered as one in that no image is necessary to determine "the direction in which each part of the object lies with respect to our body" but is established so the mind knows how to move, via the animal spirits, the parts of the body and "so that it may transfer its attention from there to any of the locations contained in the straight lines that we can imagine [imaginer] to be drawn from the extremity of each of these parts, and prolonged to infinity." In other words, the imagination is able to imagine lines not unlike the stick that a blind person would use to determine how far away an object is. That we have two eyes does not result in seeing two images for the same reason that a blind person touching the same object with two sticks or two hands does not think he or she is touching two objects: attention is drawn to one object only. It should not be forgotten, however, that the imagination is crucial for knowledge of location, even while images are not, insofar as the imagination 'draws' lines from one's body

\footnotetext{
18 This minimized resemblance indicates for Sepper a new concept of the imagination, where the imagination "takes on figures chiefly in two ways, through sensation and through the act of imagining" (ibid., p. 244). This new concept of the imagination for Descartes in turn gives rise, from the Meditations on, to a new concept, a new idea, of idea, which "refers to the look of things in consciousness, to the form of thoughts" and which is distinct from corporeal forms (ibid., p. 245). However, for Sepper, the new concept of ideas, insofar as it is analogous to corporeal forms (and corporeal ideas), "the workings of pure intellect are understood as analogous to those of imagination, although those workings in the most proper sense exclude the imagination" (ibid., p. 146).
} 
to infinity, finding other objects in the path of those lines. The figure of a body as much as its location, then, is determined by the imagination since figure is "judged by the knowledge, or opinion, that we have of the position of various parts of the objects.” (E, pp. 101, 104, and 107; AT VI, pp. 130, 134-135, and 140)

As to distance, though it does not require any particular images either, the imagination is at the heart of its determination. The first way of determining distance relies on an observed change in distance such that the figure appears differently before and after the change. The second and third ways of determining distance are related to this. In the second way, distance is determined thanks to the 'drawing' of lines from the eyes that meet at the point that is the object in question, in a similar fashion to how the blind person knowing the distance of an object thanks to the sticks in his or her hands. Drawing these lines from the distinct angles of each eye allows the "natural geometry" of triangulation to determine the distance of the object from the eyes, that is to say from the body. Even having only one eye is no necessary impediment to this geometrization of distance because moving that eye from one location to another in immediate succession will still allow two distinct lines to be 'drawn' such that they "combine together in the imagination [fantasie]" in a way similar to the "reasoning [raisonnement" of surveyors, though in this case it occurs not by the use of machines, but "by an action of thought ...., although it is only a simple act of imagination [par vne action de la pensée, qui, n'estant qu'vne imagination tout simple]." The distinctness of the figure is a third way of determining distance, where the rays of light coming from an object at a given distance do not meet with the precision of the rays at another distance. The fourth way of determining distance, however, occurs "when ... we already imagine [imaginons] the size of an object, or its position, or the distinctness of its shape and of its colors, or merely the strength of the light which comes from it." It is 
through this pre-observational imagination that the distance of the object can also be imagined (imaginer). For instance, if a smaller ship is closer to an observer than a larger ship, they may appear to be the same size, but the observer can already imagine the larger ship's size and thereby imagine its distance from the observer to be greater. (E, pp. 106 and 107; AT VI, pp. 137 and 138)

The imagination plays a crucial role in the determination of location and shape, but also in the determination of distance and size. Location and shape are determined thanks to the imagination's drawing of lines from the body to the object, while distance and size can be determined by the imagination's combining of points of visual focus allowing for the mind's natural geometry to do its measuring work, but it can also have a precedent thought of what the size of a given object might be as compared to another and can thus imagine the true size of said object even when it appears equal in size to the other object. Nothing thus far in any way describes an imagination independent of operations of light, and thus images, coming into contact with the eye. In other words, none of this specifically and determinately speaks to an active imagination without passive sensory perception. Light must still press against the sensory organs, inaugurating an immediate transmission of movement in the nerves, which in turn allows the imagination to do its work.

However, it should also be remembered that the point of the Optics is to teach lenscrafters how to "augment the power of sight" via telescopes in order to "[carry] our sight much farther than the imagination [imagination] of our fathers was used to going” (E, p. 65; AT VI, p. 81). What is being recognized in this moment is not only that our fathers' imaginations were limited, but also that their imaginations did do some work. Following from the description of that work in the Sixth Discourse, this imagination would be the natural geometry that can triangulate thanks to the lines that the imagination draws from the 
body to the object to determine location, figure, distance, and size. The imagination has always been at work in everyday vision, correcting appearances so that a truer judgment of the object is possible. Augmenting that everyday vision such that this natural geometry can measure and the lines of the imagination can be drawn with greater clarity and distinctness is the work of these lenscrafters, but it is an augmentation via the work of the imagination. Light operates like a stick in the same way that the lines of the imagination do, pushing instantaneous transmission of motion in the same way that natural geometry measures, that is, along straight lines. These operations are possible thanks to the plenum world that Descartes supposes, fabulates, imagines in The World. Indeed, the Optics was originally intended to be included in The World, but was published independently of the latter text: Descartes writes to Mersenne, in June or July 1635, “As for the eyepieces, I must say that after Galileo's condemnation I revised and completed the treatise I had begun some time ago. I have detached it completely from The World, and am planning on having it published on its own before long" (CSM-K, p. 49; AT I, p. 322). ${ }^{19}$ It is not simply the case that the imagination of our fathers was insufficiently conceived in that it was conceived as an empty vessel, but that the activity of the imagination corrects appearances of location, figure, distance, and size. This imagination also operates in a plenum world that has itself been imagined insofar as it is born from a fable. The remaining question as to the status of the imagination, this imagination that corrects appearances such that geometric measurement is possible, hinges on a return to the fable, to the fable of the plenum world whose rules are generated and followed by light, the fable that itself generates and follows the interpretive

\footnotetext{
${ }^{19}$ In a footnote, Murdoch indicates that "the treatise" refers to the Optics (see CSM-K, p. 49n. 4).
} 
rules to determine the operations of light, a light which does not need to be presented, at least in the Optics, as the truth that it is or in its true nature. ${ }^{20}$

\section{Return to the Fable: The World and the Treatise of Man}

Now that the transmission of motion from the external world to the body has been clarified, along with the role of the imagination in that transmission and the judgment of objects that impact the body, if only visually, it seems appropriate to turn to the motions within the body, as they continue the regularity of motion from the external world. In the Description of the Human Body, written around 1647 or 1648, Descartes explains that there are fluid and solid parts of the body, the fluid parts being "blood, the humours and the spirits" and the solid parts being "bones, flesh, nerves and skin" (CSM I, p. 319; AT XI, p. 247). The solid parts move more slowly than the fluid parts, just as with the three elements described in The World. In the Treatise of Man, the continuation of the fable of The World, he begins his description of the bodies of humans who would inhabit the fabular world of The $W$ orld as being "an earthen machine [machine de terre] formed intentionally by God to be as much as

${ }^{20}$ Merleau-Ponty critiques Descartes for the search for what is ultimately always a homunculus, even if it is ultimately reduced to "a metaphysical point," which perhaps could be a critique of this search for the status of the Cartesian imagination (Merleau-Ponty, The Visible and the Invisible, p. 210). He claims instead, somewhat contra Husserl, that being will disclose itself "before a transcendence, and not before an intentionality" since this disclosure will be in the return of "engulfed brute being" to itself and the sensible's hollowing itself out (ibid.). He distinguishes a hollow from a void insofar as the former is "not absolute non-being with respect to a Being that would be plenitude and hard core," but rather in relation to the "vault" which forms the hollow (ibid., pp. 233 and 232). This is why "the soul is the hollow of the body" and why the soul is not a homunculus, not a little man inside the man, but is the hollow of the mutual sensibility of bodies articulating each other (ibid., p. 233). Such an understanding of the soul as a hollow of the body is at least a step toward "returning to the perceptual faith" which will help overcome Cartesian psycho-physiology where soul and physics are distinct from each other and which will help ruin "every distinction between the true and the false, between methodic knowledge and phantasms, between science and imagination" (ibid., p. 26). On this last note, I believe this focus on the status of the Cartesian imagination, especially as it shows itself not to be the passive faculty of a pre-formed psychology, a showing which results from attending to the fable and the fable-logic or -structure of the Cartesian method, can contribute to the ruining of the psycho-physiology that is associated with Descartes but may in fact be more the result of Cartesians, or at least those who merely take Descartes at his word, as though he were incapable of deceit, even to himself. 
possible like us" (TM, p. 2; AT XI, p. 120). The body is by and large a mixture of solid earth and fluid, or liquid, air. The question, however, is where flame or light would be within the body. Following The World, there are three elements for all matter in the world—light, air, and earth — and, though every piece of matter need not have all of them, the automotivity of animals would suggest that there is some light, some flame in these bodies to set them to motion. Otherwise, the body would operate as sheer reaction, without will of any kind. ${ }^{21}$

At first, it may appear that the heart is the locus of flame or light within the body since it "contains in its pores one of those fires without light [feux sans lumiere]" (TM, p. 9; AT XI, p. 123). However, turning back to the Description, it cannot be the heart per se which is the source of this flame because, if it cools, it expands, becomes composed of larger, more solid parts, and fails to rarefy the blood. Indeed, according to the Description, "it is the rarefaction of the blood, and this alone, that is the cause of the heart's movement," so the blood itself causes the heart to move, to become smaller and more liquid, and not the other way around. (CSM I, pp. 317-318 and 319; AT XI, pp. 242-244)

The substance within the blood that is the fire without light, what could be the equivalent of light in the external world, is the "certain very subtle wind [vent], or rather a

\footnotetext{
${ }^{21}$ To be more careful with Cartesian language, animals do not have a will, at least in the human sense, because they do not have understanding. As Garber points out, the two ways reason displays itself externally in humans are language and "our ability to respond appropriately in an infinite variety of circumstances," as opposed to animals' machine-like reactions (Garber, Descartes's Metaphysical Physics, p. 113). Even the automotivity of animals is really just evidence of, in the Discourse, "the disposition of their organs" (CSM I, p. 141; AT VI, p. 59). However, Descartes does claim, in the Passions, that "all the movements of the spirits and of the gland which produce passions in us are nevertheless present in [animals] too, though in them they serve to maintain and strengthen only the movements of the nerves and the muscles which usually accompany the passions and not, as in us, the passions themselves" (CSM I, p. 348; AT XI, pp. 369-370; pt. 1, art. 50). Thus, a well-trained dog can resist the impulse to chase after a partridge or to run away from the sound of a gun firing. This distinction in the movement of the spirits and the pineal gland between humans and animals leads Garber to conclude that animals "lack all feelings and passions in the sense in which we have them, strictly speaking" (Garber, Descartes" Metaphysical Physics, p. 114; my emph.). It is difficult to disagree with this position, strictly speaking, but what is important about this moment in the Passions for me is that Descartes recognizes, if not volition and will in animals, a passion-like movement of the pineal gland which cannot be purely accounted for as passive, if passions in the soul can be understood as actions in the body. Thus, to be more precise, it may not be will that animals have, but it also seems impossible to consider them absolutely machines in this context if habituation has anything to do with pedagogy.
} 
very lively and very pure flame [flame], which is called the 'animal spirits',' which can reach into the smallest pores of the brain and muscles — even into the pineal gland, the passageways of which "are so narrow that they refuse passage to larger particles"-in the same way that light works its way into the deepest crevices of solid matter in the process of inaugurating and preserving motion. While the larger substances of blood nourish the brain, the animal spirits enter the pineal gland and "cease to have the form of blood and are designated animal spirits." From the pineal gland, the animal spirits enter the nerves and inaugurate muscular movement in the same way that water bursting from a fountain can initiate the parts of a machine to move. The animal spirits can be of different number, size, shape, and intensity of motion, depending on the person's state of mind, surroundings, etc. Meat tends to make them coarser and slower, breathing dry air makes them more lively, a healthy liver makes them "more abundant and more uniformly agitated," an unhealthy gall bladder makes them "more lively and more unevenly agitated," an unhealthy spleen makes them less numerous and slower and less uniformly agitated, and "the little nerve that ends in the heart ... . can cause a thousand differences in the nature of the spirits" because all these things affect the blood, thereby affecting the state of the animals spirits while within the blood before they even have a chance to be affected by the pineal gland. In addition, because they "never stop for a single moment in any one place," their distribution is extremely varied. From their primary distribution into the nerves, they can sometimes leave the pineal gland with such force that they cause sneezing, or they can be forced back into the brain if they fail to leave from certain passages and cause dizziness "which disturbs the functioning of the imagination [imagination]," or they can fill the brain's or nostril's cavities and form phlegm. (TM, pp. 19-20, 21, 73-76, 79, and 80; AT XI, p. 129, 130, 167-70, and 172) 
However, animal spirits are not the equivalent of light, but are, as Descartes puts it in a letter to Vorstius on June 19, 1643, "intermediate between the two: their degree of agitation is taken to be greater than that of the particles in calm air, and less than those of flame" (CSM-K, p. 225; AT III, p. 687). Figures are imprinted on the sensory organs and can be "traced in spirits on the surface of [the pineal gland], where the seat of imagination [imagination] and common sense is," thereby becoming ideas. If the idea is the result of a present object, this idea can be attributed to the common sense, but if the idea is the result of another cause, it is attributed to the imagination. In addition, the force of animal spirits leaving the pineal gland can leave traces of themselves on the brain, which constitutes memory. Because the pineal gland is only attached to the rest of the brain by small arteries, it is moveable "so to dispose the spirits that leave and make their way toward certain regions of the brain rather than toward others." (TM, p. 86 and 91; AT XI, p. 176 and 179)

The pineal gland is moved in one of two ways: (1) from differences in the particles of animal spirits leaving the brain and (2) the action of present objects upon the senses. ${ }^{22}$ The second way of moving the pineal gland is the result of ideas attributable to the common sense insofar as ideas are produced in the pineal gland from traces of forms brought to the brain by animal spirits within the blood. These traces of forms are brought thanks to the instantaneous transmission of motion from the external world upon the body that is instantaneously transmitted to the nerves. The first way of moving the pineal gland, however, is the result of ideas attributable to the imagination. The imagination appears able to cause movement of the pineal gland insofar as it can cause differences in the particles of

\footnotetext{
22 It is for this reason that Fóti sees a problem in the Treatise. That is, because Descartes wants to ascribe imagining to bodily mechanisms, he runs into a problem when dreams are encountered because "the body may be fictive, an illusion spawned by the "unknown faculty' of imagination" (Fóti, "The Cartesian Imagination," p. 640). That is, the body may produce its own fictionality if the imagination can imagine a body that in turn is the source of imagining. For Fóti, this situation requires Descartes to abandon the Rules, with its concealed metaphysical suppositions, and embark on the physiologico-metaphysical problems of "The independent reality of the body" (ibid.).
} 
animal spirits leaving the brain. The imagination can, then, inaugurate motion within the body, though it may still not perhaps be the equivalent of light if only because Descartes has not yet discussed the soul. In the Treatise, he only considers the body qua machine, not in terms of its capacity for inaugurating motion. He writes that, after having created the body, "God will later join a rational soul [Ame Raisonnable] to this machine.” And yet, despite not wanting to discuss the soul, despite not wanting to discuss the noncorporeal by and large, despite being adamant to show that treating the body as a machine subject to the regular laws of motion as much as any other physical object in the world, Descartes never loses track, never forgets that this treatment of the body as a machine is a work of the imagination, and that the people whose bodies he is describing "imitate [imitent] those of a real man," even while acknowledging that this machine "could have even more sorts of movements than I have imagined [imaginer]." That is, once again, the imagination is set to work in the inaugural moments of the text and throughout it. Even more than in The World, the reader must imagine along with Descartes, not only because things such as animal spirits are not observable, where even light is, but also because the discussion of the pineal gland and imagination is impossible to observe. One cannot see thinking, one can only imagine it, but one can imagine thinking if one is imagining the operations of the body from the beginning, if one only treats the description of the human body as a machine as if it were a fable, a hypothesis, etc. ${ }^{23}$ That is, we can see thinking via ideas generated by the imagination

\footnotetext{
${ }^{23}$ Geir Kirkeboen makes an intriguing argument that connects Cartesian optics to twentieth-century cognitive science. In particular for the context here, cognitive science "can be seen as a rediscovery of Descartes' psychology" insofar as "Descartes never studies mind in its essence, as pure thought," but as an embodied consciousness (Geir Kirkeboen, 'Descartes’ Psychology of Vision and Cognitive Science: The 'Optics' (1637) in the Light of Marr's (1982) 'Vision'," Philosophical Psychology 11:2 [1998], p. 171 and 172). (Kirkeboen is here making a strong distinction between Descartes and Malebranche's “decisive step backwards" in his adaptation of Cartesian optics [ibid., p. 172].) This embodied mind "legitimates his [i.e., Descartes'] combined logical (functionalistic) and physical (mechanistic) approach to all kinds of psychological phenomena," which is perfectly in line with cognitive science's approach to an "information processing psychology" (ibid., p. 174). If Cartesian psychology is not incompatible with cognitive science, then, and if the way to 'see' thinking is to
} 
that push the pineal gland in a particular direction, a generation that would have to obey the rules of pineal and ideatic motion of this imagined motion. ${ }^{24}$ This situation is not so much one where the imagination activates itself in order to show itself as passive, but rather that the imagination may be in a strange location, may have a strange function as compared to all other motions in the machine, from nerves to animal spirits to the pineal gland itself. (TM, pp. 36, 113, and 4; AT XI, pp. 143, 202, and 120; my emphs.) However, since Descartes does not specifically answer the question that inaugurated this section, though he does explain that neither the heart nor the animal spirits can be considered the body's equivalent of light, we can surmise that will is this equivalent, at least

\footnotetext{
imagine it embodied in the fable of a mechanistic body, a further question would be what to make of the advances in cognitive science since 1982 or 1998 . Here is where Alva Noë is important. As he explains brain scans, the most localized they get, at least currently, still encompasses "regions in which there are hundreds of thousands of cells" (Alva Noë, Out of Our Heads: Why You Are Not Your Brain, and Other Lessons from the Biology of Consciousness [New York: Hill and Wang, 2009], p. 23). One aspect of this issue is that, just as Descartes "realizes that his limited knowledge of the nervous system does not allow him to give explanations of phenomena he predicts will be explained in the future" (Kirkeboen, "Descartes' Psychology of Vision and Cognitive Science," p. 171), the possible "specialization or differentiation among these cells, won't show up in the picture" (Noë, Out of Our Heads, p. 23). In addition, there is a necessary delay between the phenomenon of neural-hematic activity and its reportage via PET and fMRI scans (even assuming that blood flow and neural activity are equivalent). More to the point here, however, is the methodological approach cognitive scientists have taken to making sense of the scans, which already are not detailed enough nor enough in 'real time' to explicitly claim clear and distinct ideas of brain phenomena. In particular, "Typically, data form different subjects is averaged," and this average is then projected "onto an idealized, stock brain" (ibid.). Such a brain does not exist. It is an ideal, an eidos, or even a fabular brain. In this way, it could appear as though contemporary cognitive science not only rediscovers Cartesian psychology, but, to whatever extent it forgets or covers over the ideality of the averaged brain, is even engaging in a Malebranchian corruption of that selfsame psychology, a psychology that can only project from out of a hypothesized ideal, from out of a fable, what thinking 'looks like'. Attending to these technical, temporal, but especially the methodological limitations on the possibility of cognitive science, then, would suggest a kind of fabularity to this science's scientificity.

${ }^{24}$ On this reading, the imagination in Descartes begins to appear significantly closer to the eidos in Husserl than an idea would be: "The eidos itself is a beheld or beholdable universal, one that is pure, 'unconditioned' ... . It is prior to all "concepts" (Husserl, Cartesian Meditations, p. 71). That is, since ideas are concepts or at least conceptual ideas of things, and since ideas are the condition for the possibility of seeing thinking, the imagination is beginning to appear as though it is what brings about the conditioning that ideas perform. This activity on the imagination's part is not, however, fully unconditioned in the Husserlian sense insofar as the imagination is not precisely pure or unconditioned. It is in a state of flux between being unconditioned and conditioned, which is what prevents it from operating as a transcendental. It is clear that the imagination, even if it does bring forth the ideas which are the condition for the possibility of seeing thinking, is not itself unconditioned because, following Ariew and Grene, the Cartesian idea is (possibly) influenced by Goclenius' account of the distinction between formal and objective concepts and dianoetic species, distinguished "perhaps because the 'species,' the form without the matter, is what is taken up in perception and lingers as an image in the mind" (Ariew and Grene, "Ideas, in and before Descartes," p. 101).
} 
in the human body. A body can move like a machine, reactive to the motions around it, without a soul, but the mark of the human could be that which drives the particularly human motions of chasing after knowledge, so long as we habituate ourselves properly. (CSM I, pp. 233-234 and 344; AT VIII-A, pp. 54-55; AT XI, p. 361; pt. 1, arts. 26 and 43)

And yet, this description does not fully contain the imagination on Descartes' own account. The imagination is the common denominator between the bookends of the fable that is The World and the Treatise on Man, the fable of the mechanistic motions of the external world and our bodies. The imagination is the ability to fabulate a world and humans entirely different from, while simultaneously entirely similar to and descriptive of, our own experience of them. The imagination is also the ability to receive light such that the things of the world are experienced as images. In the imagining of the fabulated world, Descartes imagines the rules which govern that same world, which are justified on their similarity to the universe we see in images impressed upon our eyes as well as the similarity to ourselves that the fabulated humans in that world present. In The World, matter extends "in whatever direction our imagination [imagination] can extend itself," such that our imagination "no longer perceives any place that is empty [vide]." We are expected to "suppose" or imagine that god creates the world as a plenum..$^{25}$ In this same world, when discussing human bodies, we can imagine, we can suppose, that god could create a machine the movements of which

\footnotetext{
25 See Le Robert: Dictionnaire des Synonymes et Nuances, s.vv. "supposer" and “imaginer." These two words are linked under the heading croire (to believe). The supposition that we imagine, imagining what we can suppose, linked through belief is, then, a return to the questions raised by doubt and imagination in the Meditations. In order to believe what Descartes asks us to imagine, we must suppose it to be the case. In order to believe what he asks us to suppose, we must imagine it for ourselves. Even if we are not in the realm of doubt and the suspension of belief when we are in this fable, we are in the realm of the imagination. See also Daniel Brewer where, in the context of The Search, he writes that, "To say that Descartes sub-poses fiction, placing it beneath the discourse of truth, suggests that it is upon the discursive act of producing a fiction that the Cartesian discourse of truth rests. Such a supposition implies that in Descartes, the stating of truth (le vrai) is inextricably bound up with the staging of an imaginary scene (le vraisemblable)" (Brewer, "The Philosophical Dialogue and the Forcing of Truth," p. 1237).
} 
exceed what we, or at least Descartes, can imagine. ${ }^{26}$ What he does imagine, however, is a movement of animal spirits, which are not the equivalent of light within the human body, generated by the imagination. The imagination is the driving force for both fable and light, that which allows for experience and comprehension at all. The experience of light, the motion that generates and maintains motion in the world, is interpretable, and so the world itself is interpretable, only because the imagination can suppose the order of the world, of the body, to operate with a machine-like regularity, a regularity that the imagination perceives through the sensory organs. The fable is the inaugurating, regulated and regulating, motion of the mind that would imagine the world to have regularity. Since the fable is the mental equivalent of light, and thus is not the equivalent of chaos as described in the fable, the mind, the soul, prior to the motion inaugurated by the fable, is of this chaotic character. It is solid, pre-motive chaos, even if cracks appear throughout it. These cracks, taken by academic philosophers as evidence of a pre-formed faculty psychology, are not indicative of pre-formation of the mind any more than the cracks in pre-motive chaos indicate the three elements that appear from out of god's inaugurating motion. The power, the potentia, the puissance of the imagination is more powerful than chaos or poetry, more powerful than light or fable, because it is the force by which even chaos can become writable (as poetry and as

${ }^{26}$ Because of this kind of reasoning, Nancy will write, in the context of the Rules, that "The sup-position will take its sub-stantial value once it lets us see" (Nancy, "Dum Scribo," p. 12). That is, because suppositions clarify so many things, they themselves become judged on their utility in the face of the façade that the suppositions support. Such a position could be grounds for dismissing the Cartesian supposition, but it also seems important to remember the content of the suppositions, in particular that god creates a plenum world and that the human machine's movements exceed what can be imagined of them. In fact, all that is being acknowledged in these suppositions, in particular the latter, is a recognition of the excessive power of the imagination to render itself exceeded. Such is not a position like other faculties, and indeed the other faculties would appear to depend on this imaginative ability in order to find their own places. Thus, it would appear that, from this perspective, from this viewpoint, what the imagination makes visible via suppositions is the limit of the imaginable and, in doing so, it exceeds those very limits in showing them qua limits. The supposition that the human machine's movements exceed the imagination is such a showing of the limit by that which is limited, and it is not thereby grounds for dismissal as much as it is the ground for the possibility of knowing what will be dismissed. 
fable) and experiencable. ${ }^{27}$ The location of the imagination is both inside and outside the world, both inside and outside the mind. ${ }^{28}$ Its function is found in its location in that it functions as that which allows for the line to be drawn between what is experiencable and what is not, between what is writable and what is not. The power or the force of the imagination is to imagine the limits of the imagination. For Descartes, the imagination imagines the imaginable in imagining the unimaginable. (W, p. 10; AT XI, p. 32)

Return to Method: The Form of Reasoning and the Forming of Reason

It is a legitimate question to ask at this point whether all these claims about the Cartesian imagination are legitimate, or if they remain a kind of rhetorical gamesmanship. To answer that, it seems appropriate to turn to the question of logic and rhetoric insofar as they can be understood as they are deployed in analytic or synthetic methods. Insofar as the relationship between analysis and synthesis has been shown above to be one of double supplementarity, where the simplicity of an analytic reduction relies on the duplicity of a rhetorical synthesis and vice-versa, then it could be that the answer is already known. However, a return to Rule

\footnotetext{
${ }^{27}$ Garber makes a similar claim when he argues that experiments are always regulated affairs for Descartes. As Garber points out, however, "neither do experimental phenomena have a role assigned to them in standard hypothetico-deductive conceptions of scientific method, as the touchstone of theory, the a-theoretical facts to which we can appeal to adjudicate between alternative theories" (Garber, "Descartes and Experiment in the Discourse and Essays," in Descartes Embodied, p. 110). This non-standard role would appear to exist because of the importance of the imagination in allowing for the hypothetico-deductive methodology to develop in the first place. For Garber, "His [i.e., Descartes'] genius was in seeing how experience and experiment might play a role in acquiring knowledge without undermining the commitment to a picture of knowledge" (ibid.), but what Garber seems to elide in this context is the role the imagination has in developing that picture.

${ }^{28}$ In this way, Cavaille is exactly correct when he argues that "Space is neither conceived nor conceivable in itself, but as the 'essence' of 'material substance'. The notion of space, first notion of the imagination, is inseparable from material exteriority, from the matter of which the real world is composed. . . Representation is an autoreferential presentation of the imagination only within the measurement where it simultaneously returns, as representation of a material space, to what is beyond and to that beyond itself, to the exteriority of which it is always also the image" (Cavaillé, Descartes: La Fable du Monde, p. 223; my trans. and emph.). Cavaillé is of course emphasizing matter and its enfolded relationship to the imagination, whereas I am emphasizing the imagination in its selfexcessive relationship to the external world.
} 
Ten with attention paid to the possibility of the imagination existing as inside and outside the mind which interprets the world that presents itself in images to the imagination can perhaps more clearly address whether what is at hand here is in fact too focused on the rhetoric of fable.

What is at hand, then, is a question of the form of argumentation, its figure or shape. In the context of an argument that concerns the structure of the self, the self as structured from out of an imagination, the structure of that argument is already a question of the structure of the self, a question of the self that constructs itself in the argumentation of itself and its structure. In Rule Ten, Descartes critiques academic syllogistic synthesis because it "can nevertheless draw a conclusion which is certain simply in virtue of the form [formae].", 29 The result is that those who practice this "[form] of reasoning" can only come to a true conclusion if "they are already in possession of the substance of the conclusion." As a result, Descartes rejects this approach because it can teach nothing new, even if it is useful for explaining arguments already known to others. In rejecting it, he says that synthesis "should therefore be transferred from philosophy to rhetoric.” Beyond its pedagogical quality, Descartes' understanding of rhetoric is that the form of the argument is already given and the form itself gives rise to the content of the truth being concluded. The analytic method is preferable because it is solely concerned with the content of the matter at hand and reduces said matter to its simplest formulation, and is thus more logical, less rhetorical. (CSM I, pp. 36-37; AT X, p. 406)

\footnotetext{
${ }^{29}$ Marion finds Descartes' position here "strange" because it appears that he fails to understand "the importance of the laws of conversion of syllogisms, etc., which precisely assure to an isolated, vague, and insignificant piece of information its rational coherence within a theoretical set" (Marion, "Annotations," pp. 217 and 218; my trans.). He concludes that Descartes does so because "the formally determinant element . . . coincides with the ontically determinant term ...; the form and the genre thus play the formal role of the middle term" (ibid., p. 218; my trans.). Thus, for Marion, "Descartes does not reject the syllogism for reasons of logic, but only for decisions on Being and beings" (ibid.; my trans.).
} 
As has also been shown above, Descartes' concern with the academic approaches to pedagogy is that they rely on a faculty psychology that understands the imagination as an empty vessel to be filled. The shape, the form of the imagination is malformed by the approach because it limits the capacity for comprehension on the part of those who have been shaped by this approach, who confuse passive acceptance of syllogistic formulae for education, for the extracting or leading out of knowledge. Instead, for Descartes the imagination must be deformed and reformed so that such extraction is possible. Like premotive solid matter, then, the mind cannot be taken as pre-formed, but is formed in the inauguration of its movements. The imagination is both part of and distinct from what is moved in the deformation and reformation of the faculties in that it is the faculty from which the faculties will come to form themselves, from which the mind's motions will form themselves into the regulated methods of investigation that Descartes sets out. Analysis is the method that the imagination will lead the mind to take up, in place of the synthesis that finds truth based solely on the form of reasoning. The imagination is the faculty, distinct from and part of the other faculties, which sets the mind into motion such that the form of argumentation called analysis is seen to be preferable. Neither the imagination nor any other faculty would have the capacity to inaugurate such motion were it solely part of a pre-formed faculty psychology, any more than the force which inaugurates the motion of matter would itself be solely part of any of the three elements that emerge from out of pre-motive, solid chaos. Even though the reader finds him- or herself already with a malformed imagination, whether through academic education or through everyday engagement with the world, the imagination necessarily remains, to some degree, distinct from the mind, which is why fables, histoires, dialogues, and so on can have the effect of deforming and reforming the mind at 
all. ${ }^{30}$ This understanding of the imagination is not arrived at through a rhetorical synthesis

\author{
that sees the form of reasoning as equivalent to content. Rather, this understanding of the
}

\begin{abstract}
${ }^{30}$ In the Prolegomena, when Kant distinguishes between bounds (Grenzen) and limits (Schranken), he claims that a bound in extension "always presupposes a space existing outside a certain definite place and inclosing it," while a limit needs no enclosing space, "but are mere negations which affect a quantity so far as it is not absolutely complete" (Immanuel Kant, Prolegomena to Any Future Metaphysics and the Letter to Marcus Herv, February 1772, 2 ed., tr. James W. Ellington [Indianapolis, IN: Hackett Publishing Company, Inc., 2001], p. 86). Reason, for Kant, can see a realm for thinking things in themselves even if the concepts of these things are indeterminate and limited (eingeschränkt) by appearances. As a result, in mathematics and natural science, reason does not admit of bounds, does not admit of an enclosing space external to an extended object, "But metaphysics leads us toward bounds in the dialectical attempts of pure reason" (ibid., p. 87). This leading toward bounds is especially the case insofar as the three transcendental ideas which give reason completion and satisfaction (i.e., the psychological, cosmological, and theological ideas) must be assumed (annehmen) as connected to the sensible
\end{abstract} world in order to give signification to pure concepts of reason (i.e., an immaterial being, a world of understanding, and a supreme being) because then each concept "is conceived as a phenomenon" (ibid., p. 89). Thus, metaphysics becomes the science "at the boundary of all permitted use of reason," and thereby in the positive realm of a presupposed space external to and enclosing the place at which metaphysics is, which is why metaphysics can be a legitimate science if it is limited (einschränken) "merely to the relation which the world may have to a certain being whose very concept lies beyond all the cognition which we can attain within the world" (ibid., pp. 90 and 91). Reason is able to establish this boundary not because of experience, but because, since a boundary is positive, "it is still an actual positive cognition which reason only acquires by enlarging itself to this boundary, yet without attempting to pass it because it there finds itself in the presence of an empty space in which it can think forms of things but not things themselves" (ibid., p. 94). In the Critique of Pure Reason, Kant explains that the transcendental ideas can never be deployed constitutively because doing so would be "pseudorational," though deploying them with the purpose of "directing the understanding towards a certain goal upon which the routes marked out by all its rules converge, as upon their point of intersection. This point is indeed a mere idea, a focus imaginarius, from which, since it lies quite outside the bounds [Grenzen] of possible experience, the concepts of the understanding do not in reality proceed" (Immanuel Kant, Critique of Pure Reason, unabridged ed., tr. Norman Kemp Smith [New York: St. Martin's Press, 1965], A644/B672; Kritik der reinen Vernunft, ed. Thomas Valentiner, in Sämtliche Werke, eds. Otto Buek, et al., vol. 37 [Leipzig: Verlag von Feliz Meiner, 1919], p. 549). This imaginary point which guides the understanding, this regulative 'as if, this rulegenerating hypothesis for metaphysics, is, in itself, beyond the bounds of experience for Kant and therefore is not the source of the pure concepts of the understanding. Insofar as it is beyond the bounds of experience, however, it is in the presupposed space that the positivity which is a bound demands. The imaginary point to direct the understanding would not therefore be an object of metaphysics because it would pass beyond the boundary that establishes the legitimate use of reason, even while its very 'beyond-ness' is the way by which it guides the understanding. This imaginary point, as a point and as a point of the imagination, would thus become the presupposition necessary for any metaphysics to get off the ground, and therefore necessary for reason's establishment of its own positive boundary. That this description of the imaginary point survives into the B edition, as well its connection to the Prolegomena, is perhaps an indication that Kant was not fully able to shrink back from "the transcendental power of imagination," but this power survives to whatever extent against Kant's intent (Heidegger, Kant and the Problem, p. 112). What is more interesting from this context, in relation to Descartes, is the concepts of space being deployed here through the distinction between bound and limit. Metaphysics is dependent, for Kant, on a conceptualization of space as, in some fashion, an empty vessel, as having an outside, even if that space is imaginary. On this point Descartes clearly does not agree, since even the most imaginary space remains a plenum for him. And yet, a Kantian limit does not apply particularly well to the concept of space at hand here to the extent that a limit is merely negative and operates via incompleteness. The plenum that is the Cartesian world, material or mental, is not negative insofar as there is no externality to it, even if the infinite is distinct from the finite and the incorporeal is distinct from the corporeal, precisely by way of the deformative and reformative performance of the fable that is always in operation throughout Descartes' texts. In experiencing a deformation and reformation of the mind on the very ground that there are no vacua, there is a link made between the material and mental worlds, a connection between phusis and psyche whereby both are formed in more than analogous fashion. While this operation may be, for Kant, the result of 
imagination emerges from something closer to an analytic reduction of the phenomena of the relationship between mind and world as laid out in Descartes to a simple: the imagination. This simple emerges from out of an attention paid to fable as the repeated recourse Descartes has to inaugurate his texts, in various contexts, to various readers. This analysis is not overly attentive to the form of reasoning, as synthesis is, but finds that the imagination, the simple that stands outside and inside the realm of experience and interpretation, of world and mind, engages the forming of reason. Reason may be the mental equivalent of light, the movement of which maintains the human mind qua incorporeal substance in its motion and thereby forming the faculties, but the imagination is the force that inaugurates that rational motion, that motion of the natural light. ${ }^{31}$ Thus, the belief that the world is as it presents itself that causes Descartes to suppose the evil genius at the end of the First Meditation is indeed a rational belief, a belief that is the result of the natural light's

maintaining an imaginary point by which the understanding is guided to make metaphysical sense of the world, maintaining that point as imaginary, as a product of the imagination, would undermine the plenum of the world that is to be experienced as metaphysically sensible. Perhaps Kant's response could be that this plenum fable is the result of an overly mathematical or natural scientific approach to metaphysics insofar as it would not admit of a bound, but such a position would be to misrecognize the positivity of the plenum fable as a limit qua negative. It is for this reason that attending to the fable as an operation of the imagination, which will itself carve out the imagination as a faculty, remains important. Such an operation does not in any way indicate an incompleteness on the part of the imagination nor on the part of its movement because what commits the operation is generative of itself. Therefore what the imagination would exceed is not a limit that affects a negation of an incompleteness, but no more would this excessive movement on the part of the operation exceed a bound because there is no 'pure space' which encloses material or mental space. Such a concept of space appears to be beyond Kant's imagination, which could be more the result of his empirical roots (see esp. Locke, An Essay concerning Human Understanding, bk. 2, ch. 4, \$\$1-5). Such a concept of space could also, then, help to answer some of the phenomenological and/or ontological critiques of Kant, in particular why he uncritically assumes the Cartesian subject (or at least the received idea of it) and why he abandons the imagination. If nothing else, it is at least an indication that Descartes' imagination cannot be reduced to a Kantian faculty psychology subsumable to transcendental categorization.

31 On this point, I agree with Rickless that "not everything that is clearly and distinctly perceived is known by the natural light" insofar as the natural light would be separate from the faculty of the understanding (Rickless, "The Cartesian Fallacy Fallacy," p. 310). However, Rickless's appeal to the natural light strategy as a way of coming to terms with how the natural light can avoid doubt as applying only to "perceptions, whether clear or obscure, that derive from the senses or from the imagination" appears to me an over-hasty understanding of the imagination as necessarily and always passive, all the more so considering his appeal at this moment in the essay is to the First Meditation, where the passivity of the imagination is not at all a clear and distinct position on Descartes' part (ibid.). 
having already been inaugurated such that the faculties of doubt and imagination are malformed. ${ }^{32}$ To correct that, the imagination needs to be set to work again, through the doubt that imagines and supposes the world to be other than as it presents itself. ${ }^{33}$ Reason cannot do this work because reason is merely natural light, not the force that inaugurates luminous motion. If this force, this power of imagination finds itself taking on a passive role in the wake of the deformation and reformation of the mind, it is not because the imagination takes on a biplanar structure-now active, now passive-but because the imagination, the power of the imagination is always in potentia, ready to correct too much reliance on the form of reasoning developed by the formation of the faculties. The imagination, when necessary, in its inaugural deformation and reformation of the faculties, also always inaugurates the forming of reason.

\footnotetext{
${ }^{32}$ In this way, there could be a reconciliation between two sentences that could appear contradictory in Daniel Garber. He writes that the story he gives of divine motion "will not be complete until we see how the way in which Descartes' immutable God causes motion leads him to the concept of motion (and its associated forces and laws) which underlies his program in natural philosophy" (Daniel Garber, "How God Causes Motion: Descartes, Divine Sustenance, and Occasionalism," in Descartes Embodied, p. 202). However, he also distinguishes Descartes' motion from followers such as Louis de la Forge on the ground that divine causation does not exclude the possibility of finite causation, if only because we are the model for understanding all nondivine causation as finite, such that "Mind, indeed, can remain as direct a cause of motion for Descartes as God Himself” (ibid.). Garber (and perhaps Descartes himself) would most likely reconcile these two statements by claiming that the divine causation still leads to the concept of motion in such a way that mind cannot because, at the moment of the divine inauguration of motion, no finite cause was available to do so. However, if the natural light would have already been malformed by witnessing finite causes and motions and if mind can cause motion, then the reconciliation between the statements may not necessarily be found in divine infinitude, but in something else, something neither finite nor infinite.
}

${ }_{33}$ Marion cites a letter to Mersenne, dated November 13, 1639, where Descartes claims that "The imagination, which is the part of the mind that most helps mathematics, is more of a hindrance than a help in metaphysical speculation" (CSM-K, p. 141; AT II, p. 622), to himself claim that "the imagination functions as an auxiliary to the pure understanding" (Marion, On Descartes' Metaphysical Prism, p. 15). However, Marion appears not to have noticed that reason requires the work of the imagination in the form of imagining the evil genius if reason is to be able to abstract itself from the things of the world such that the imagination could again "grasp geometrical extension as a real object" (ibid.). Perhaps what Marion has done is to think that Cartesian space is not a plenum but a vessel within which objects appear, thereby giving extension as such an objectifiable existence. But if this is not the case, if the plenum of space is to be taken seriously, then geometrical extension need not be imagined qua object except through the objects that constitute it. In this way, the imagination would still be a hindrance for metaphysical speculation, but the metaphysical speculation under discussion would itself be the problem. The context of this moment in the letter Marion cites is to criticize Parisian geometers, especially Gilles de Roberval, who "defended the possibility of a vacuum against Descartes' identification of space with body" (Historical Dictionary, s.v. "Roberval, Gilles Personne de," p. 223). And indeed, Descartes does go on to criticize the concept of the void (see AT II, pp. 622-623). 


\section{Wonder and Learning}

If the effect of attending to the fable on the imagination is that a pre-formed Cartesian faculty psychology does not exist and that the imagination is located both inside and outside the realm of the faculties as they develop from the imagination's inauguration of mental motion, then a few further issues remain. In particular, the question of the imagination's relationship to the will remains, if only because the imagination is beginning to appear similar if not identical to Descartes' descriptions of the will. Also, the question of the imagination's relationship to the passions remains, especially to wonder. If the imagination is no longer simply active or passive, then the question of what happens to the passions, especially wonder as the passion that prompts learning, arises because the claim concerning the imagination is that it inaugurates a motion which sets the mind to work such that it unlearns what it has learned and learns how to learn. First, however, the distinction between the imagination and the will needs to be clarified.

\section{Imagination and the Will}

In the Third Meditation, when Descartes divides thoughts, he divides them into ideas and thoughts that exceed the likeness of the thing. Ideas are subdivided into innate, adventitious, and invented. ${ }^{34}$ Thoughts that exceed the likeness of the thing are subdivided into judgments

\footnotetext{
34 As Buchdahl points out, what qualifies as an innate idea changes for Descartes at different points in his career, though geometry is paradigmatic with its unimaginably straight lines, etc. Innate ideas in general can be divided into at least four cases according to Buchdahl: "(a) if it is 'occasioned', in the way in which all ideas as such (including those involved in 'sensation') are quite distinct from the physical 'occasioning' situation (brainpattern, etc.); (b) if there is no corresponding perceptual object, as in the case of the perfectly straight line, perfect equality, etc.; (c) in the case of certain abstract category concepts, such as knowledge, doubt, unity, etc.; and finally, (d) if the idea has a special metaphysical backing, as he claims for certain mathematical ideas, or for the ideas of God, perfection, etc." (Buchdahl, Metaphysics and the Philosophy of Science, pp. 117-118).
} 
and "volitions or emotions [voluntates, sive affectus]." "35 Given that Lewis and Short consider sive predominantly to function disjunctively, it seems fair to consider its use here to indicate a tertiary distinction of thoughts that exceed the likeness of the thing under which volitions and emotions would be categorized. ${ }^{36}$ Volitions and emotions (or passions) are thus related, but separate. The will, being the faculty that oversees the thoughts called volitions, is the focus here. The most extensive discussion of the will is found in the Principles, but the discussion above of the will's relationship to error means that a discussion here of error is unnecessary. Instead, the focus will be on how the will as Descartes describes it relates to the imagination as thus far discussed. ${ }^{37}$ (CSM II, p. 26; AT VII, p. 37)

The will is the faculty that allows for hyperbolic doubt and withholding assent.

Because it allows for doubt and withholding assent, the freedom of the will is self-evident. The freedom of the will indicates its scope, which is, "in a certain sense [quodammodo]," infinite because its scope extends as far as any other will can extend, even god's will. Thus,

\footnotetext{
35 This will be more important below, but it is worth noting here that Gilson associates affectus with the passions (see Gilson, Index, p. 9).

${ }^{36}$ See Lewis and Short, s.v. "sive," accessed June 28, 2013, http://www.perseus.tufts.edu/hopper/text?doc =Perseus $\% 3$ Atext $\% 3$ A $1999.04 .0059 \% 3$ Aentry $\% 3$ Dsive.

${ }^{37}$ For Sepper, Descartes develops a new concept of the imagination from the Meditations on, one that relates to a new concept of 'idea' as articulated in the Objections and Replies. The new concept of 'idea' is that it "refers to the look of things in consciousness, to the forms of thought," as opposed to the image of a corporeal thing (Sepper, Descartes's Imagination, p. 245). In particular in reference to the Third Set of Objections with Replies, to Hobbes, Sepper finds this new concept of 'idea' to indicate that "the workings of pure intellect are understood as analogical to those of the imagination, although those workings in the most proper sense exclude the imagination" (ibid., p. 246). For Sepper, this analogy to the imagination whereby the imagination is excluded indicates a transcendent power to the intellect, which is why "The proper objects of intellect are the things that it can perceive even in sensibles and imaginables that do not belong per se to those sensibles and imaginables: the ideas of the essences of things (like the waxness of the wax)" (ibid., p. 248). Sepper is able to build on this claim to show a biplanarity to the imagination, but it would seem odd that he would 'reduce' the imagination to biplararity while giving the intellect the ability to transcend, especially given his claim that the Meditations is dependent on the imagination (see ibid., p. 255). If the Meditations is dependent on the imagination, especially in its imagining a madman's thought processes, as Sepper claims, then why is the imagination not transcending itself, or its own limitations such that the intellect can take up its proper role, function in its proper fashion as a faculty?
} 
enacting this freedom of the will is "The supreme perfection of man." However, in that judgment requires both intellect and the will, and that the intellect's scope is limited "only to the few objects presented to it," error results from the will enacting a volition beyond what the intellect perceives, beyond having a clear and distinct idea. The will is understood as selfevidently free and as the source of error despite the fact that god's power has made everything preordained because "the mind is finite, while the power [potentiam] of God is infinite.” (CSM I, pp. 204, 205, and 206; AT VIII-A, pp. 18 and 20; pt. 1, arts. 6, 39, 34-35, 37 , and 40-42)

Nothing in what has been presented concerning the imagination suggests that the imagination is infinite, at least not in the same mode as the will, whether human or divine. ${ }^{38}$ If the mind in its pre-motive state is akin to the pre-motive solid matter of chaos, it is finite. That the imagination inaugurates the motion which itself brings the mind to carving out its appropriate faculties does not suggest that the imagination is precisely distinct from the mind since one of the faculties which results from this motion is the imagination. The imagination is both within the finitude of the mind and outside it, simultaneously active and passive. It is not, however, the same as the fable that serves as the equivalent of light in the mind's

${ }^{38}$ For Descartes, there are two ways of understanding a modal distinction, between the mode and the substance or between two modes of a substance. A mode is modally distinct from its substance when "we can clearly perceive a substance apart from the mode which we say differs from it, whereas we cannot, conversely, understand the mode apart from the substance," while a mode is modally distinct from another mode when "we are able to arrive at knowledge of one mode apart from another, and vice versa, whereas we cannot know either mode apart from the substance in which they both inhere" (CSM I, p. 214; AT VIII-A, p. 29; pt. 1, art. 61). For Prendergast, this makes modes different from Scholastic real qualities or accidents because, for Descartes, real qualities or accidents are contradictions since accidents and qualities have no reality, "cannot exist separately from substance even by the power of God" (Prendergast, "Motion, Action, and Tendency in Descartes' Physics," p. 460). Modes are also not to be confused with Cartesian substances or attributes, however, since "Substance is a thing which so exists that it needs no other thing to exist" (ibid., p. 461) and, "when we are simply thinking in a more general way of what is in a substance, we use the term attribute" (CSM I, p. 211; AT VIII-A, p. 26; pt. 1, art. 56). The distinction between substance and attribute is a conceptual one for Descartes, "a distinction between a substance and some attribute of that substance without which the substance is unintelligible; alternatively, it is a distinction between two such attributes of a single substance" (ibid., p. 214; p. 30; pt. 1, art. 62), which indicates for Prendergast a Suárezian root to Descartes' thinking here (see Prendergast, "Motion, Action, and Tendency in Descartes' Physics," p. 461). On this last question, see Suárez, On the Various Kinds of Distinction, pp. 18-21, 30-32, 36-37, 44-46, and 60-61. 
motions, that generates and obeys the motions set out by the imagination. Rather, as when material motion settles into its motions regardless of the precise details of the inaugural motion, the imagination does not generate the rules of the mind's motions. However, this quality does not make the imagination infinite in the same mode as god since it also always remains inside the realm of the faculties. In other words, it is insufficient to focus on the quality of the imagination whereby its capacity to imagine the unimaginable is always in potentia. The quality of the imagination whereby it is finite, limited, conditioned by the world that presents itself to the imagination must be kept in mind. The imagination is infinite, though in a different mode from the will or from god. It is infinite in that it can imagine the unimaginable, which requires the condition of the imaginable as what is to be negated. ${ }^{39}$ Thus, the infinitude of the imagination is somewhere between infinity and the indefinition of "the extension of the world, the division of the parts of matter, the number of stars, and so on."

\footnotetext{
39 There is, then, something similar to the Husserlian horizon structure of intentional analysis in the Cartesian imagination. As Husserl explains it, the horizon structure "prescribes for phenomenological analysis and description methods of a totally new kind, which come into action wherever consciousness and object, wherever intending and sense, real and ideal actuality, possibility, necessity, illusion, truth, and, on the other hand, experience, judgment, evidence, and so forth, present themselves as names for transcendental problems, to be taken in hand as genuine problems concerning 'subjective origins"' (Husserl, Cartesian Meditations, pp. 48-49). For Husserl, such horizons make possible a phenomenological engagement with the world. We have already seen how the fable sets out the need for a new method in Descartes, but the fable is also only in service to the imagination's imagining the unimaginable. It is that by which Descartes' readers can begin to, along with him, imagine a whole new world or other people. It is the imagination, then, that sets out the horizon structure within which the motions that the fable will inaugurate are made possible. Now, Husserl also claims that "Only an uncovering of the horizon of experience clarifies the 'actuality' and the 'transcendency' of the world, at the same time showing the world to be inseparable from transcendental subjectivity" and that the horizon of experience opens onto a world, which "is an infinite idea, related to infinities of harmoniously combinable experiences—an idea that is the correlate of a perfect experiential evidence, a complete synthesis of possible experiences" (ibid., p. 62). Descartes would probably disagree with at least the latter claim by Husserl insofar as there is a difference between infinitude and indefiniton.
}

${ }^{40}$ In the Conversation with Burman, Descartes clarifies this distinction, which is Descartes' own, by saying that it may be possible to discuss the world or number as infinite, "But as far as God is concerned, maybe he has a conception and understanding of fixed limits in the world, and in number, quantity, etc. He may be aware of something greater than the world, or number, and so on, and so for him these things may be finite. As for us, we see that the nature of these things is beyond our powers [vires], and realize that we cannot comprehend them since we are finite beings. Thus, from our point of view, they are indefinite or infinite" (DCB, pp. 33-34; AT V, p. 167). In his commentary on this moment in the Conversation, Cottingham explains that for something to be infinite in Descartes' stricter meaning, it "has no bounds" (Cottingham, "Commentary," p. 101). What is more, as he points out, "In less informal situations, however, Descartes remained reluctant to apply to term 'infinite' 
the imagination is transfinite, while the will could remain, especially insofar as it is linked with god, absolutely infinite. That the imagination can imagine the unimaginable does not make it infinite in the divine mode, but suggests a potential to exceed what contains it. ${ }^{41}$ If the transfinite is a distinct mode of infinity, it is a mode distinct from the mode in which the will, human and divine will, participate. ${ }^{42}$ That the imagination is transfinite is what allows it to be active and passive, that it is contained by the conditioned and limited qualities of the

to anything except God" (ibid., p. 102). Merleau-Ponty, perhaps in a similar fashion as Cottingham, links Descartes and Kant on this point because, for both of them, "the world is neither finite nor infinite, it is indefinite-i.e. it is to be thought as buman experience — of a finite understanding faced with an infinite Being (or Kant: with an abyss of human thought)" Merleau-Ponty, The Visible and the Invisible, p. 185). Such a position is, for Merleau-Ponty distinct from Husserlian Offenheit insofar as, for Husserl (and Heidegger), "the ontological milieu is not thought of as an order of 'human representation' in contrast with an order of the in itself' (ibid.). Yet, what Merleau-Ponty once again appears to elide or overlook is the fabulation at the heart of the Cartesian project whereby the world becomes interpretable and imagined, the operation of the imagination's imagining the unimaginable, the horizon of which imagining already includes what the in-itself would be or become. And all of this must be done without the imagination becoming infinite, since only god (and the will) will remain infinite on the strictest of Cartesian schemas.

${ }^{41}$ In this way, the imagination can be understood as the opposed to Foucault's description of the beginning of madness in Robert Whytt's eighteenth-century analysis of the passions, where the movement in the passions inaugurated by a strong emotion can set off madness such that "the movement can be checked by its own excess, bringing a form of immobility that sometimes goes as far as death. It is as though in the mechanics of madness rest is not the same thing as an absence of movement, but can also be a brutal rupture within the self' (Foucault, History of Madness, p. 229). Where this understanding of madness brings about immobility and a rupture of the self, the imagination's excesses inaugurate the motion that will generate the self. Thus, while "Madness is no more than a disordering of the imagination"' insofar as the unity of body and soul is uncoupled and "the rationality of the mechanical" is undercut by the movements in the soul that passionate madness or mad passions set off, the imagination which is disordered in this case is of a late sort, of that 'purely' passive faculty to the imagination which emerges after the self has carved itself into faculties (ibid., p. 231). The madness that disorders the imagination here would be related to the madness which Descartes wants to inaugurate in his readers, at least in the Meditations, insofar as it would involve a disruption of what had appeared unified, but it is not an immobilizing movement as this description of madness entails.

${ }^{42}$ Marion claims that the infinite precedes the finite not merely as a matter of logic but also insofar as "it marks the priority of an a priori," and so "as a transcendental condition for the possibility of the finite" (Marion, On Descartes' Metaphysical Prism, p. 229). In being a transcendental condition for the finite, independence is an immediately deducible attribute of the infinite because "the idea of God implies independence as necessarily as it does noncreation and substantiality par excellence," which means that independence determines "all that is not God as dependent" (ibid., pp. 232 and 233). The human will and mathematical truths, then, remain dependent even though infinite, eternal, and/or immutable because, as Descartes puts it in the Fifth Set of Replies, "God willed and decreed that they should be so" (CSM II, p. 261; AT VII, p. 380). The mode of infinity that is the human will could be explained, then, following Marion, in that the will "experiences the infinite within the perspective of power [puissance]" (Marion, On Descartes' Metaphysical Prism, p. 250n. 67; see also CSM-K, p. 25; AT I, p. 150). At the very least, there is nothing in the context of Descartes that Marion cites to suggest that the modes of infinity need to be isolated to the divine and human wills and mathematical truths, and if the transfinitude of the imagination is a mode of infinity distinct from the human and divine wills, it is no less distinct from mathematical truths. 
finite and indefinite world and finite faculties while also exceeding those conditions beyond the indefinition of the number of stars, etc. in actively imagining beyond what can be imagined in the passive sense, in imagining a whole other world, entirely different people from those experienced that also happen to match what has been experienced and interpreted in better and worse fashions. It is why the method is schismatic, moving simultaneously between analysis and synthesis, requiring a history to tell an histoire of a different kind. The absolute infinity of god's will and potentia may condition the imagination and the possible interpretations of the finite world, but, with Descartes, with Descartes' imagination, we can imagine in excess of those conditions, which is why he so frequently has recourse to asking us to imagine, suppose, hypothesize into the most serious realms of the most laughable beliefs that the world is not what we have been taught, what we have imagined. We are able to imagine along with Descartes, able to follow his fables in generating our own stories of rule-obedience, because of this transfinite quality to the imagination, because we can imagine the unimaginable. ${ }^{43}$ (CSM I, p. 201; AT VIII-A, p. 14; pt. 1, art. 26)

Imagination, the Will, and the Passions

If the imagination is modally distinct from the will insofar as the will is absolutely infinite while the imagination is transfinite, then the question is whether the imagination is also

\footnotetext{
43 Thus, following Stephen H. Daniel, that the Meditations and the Principles establish a metaphysics and epistemology for a treatment of the self "does not disavow its [i.e., the treatment's] imaginative source in human ingenuity" (Daniel, "Descartes on Myth and Ingenuity/Ingenium," p. 165). This claim, of course, depends on an understanding of ingenium as distinct from fancy insofar as the former is regulated and the latter "undisciplined and irresponsible"” (ibid., p. 160). However, Daniel still maintains an imaginative quality and source to this regulative ingenium, which should not be dismissed too easily.
} 
distinct from the passions. To answer this question, however, it is first necessary to distinguish the will from the passions as explained in The Passions.

In his most general definition of passions, Descartes gives credence to the complication of activity and passivity that has been laid out thus far. For him, "an action and passion must always be a single thing" because the same occurrence is called an action in reference to that which causes the occurrence, while it is called a passion in regard to that to which the occurrence happens. Thus, the reactions of the body that Descartes explains in the Treatise of Man, the Optics, the Description, and other works on anatomy and physics are passions, while the external world which causes the occurrences to which the body reacts is engaged in action. Since these bodily passions can engage the pineal gland so that it moves in such a way as to point animal spirits toward the appropriate openings in the brain leading to the nerves and muscles, so that they can themselves react to the action that caused the passion in the body, a distinction must be made between passions of the body and passions of the soul. What is more, the soul's actions on the body, those generated from the imagination, are the most direct action there is, so that Descartes is willing to say that "what is a passion in the soul is usually an action in the body" because the reactions, the passive reception of input into the soul, are immediately transmitted into actions, reactions in fact of the body. Thus, the flushed cheeks of embarrassment, etc. are distinct from their associated passions by way of a methodical distinction between soul (patient) and body (agent). Bodily actions that can be entirely attributed to physical rebound from the external world - the flushed cheeks of a fever, etc.- - are the equivalent of the reactivity of the external world and so are only actions of the body. However, other bodily actions are attributed the soul and its passions. (CSM I, p. 328; AT XI, p. 328; arts. 1-3) 
The two kinds of thoughts that exceed the likeness of the thing which are not judgments—volitions and passions_-are both within the soul. Volitions are the soul's actions, while the "the various perceptions or modes of knowledge present in us [les sortes de perceptions ou connoissances qui se trouvent en nous]" are its passions "in a general sense [à cause que souvent." There are two kinds of volitions, actions that are isolated only to the soul, as in the will to love god, and actions that extend to the body, as in willing to walk. The perceptions are of two kinds as well, those caused by the soul and those caused by the body. Perceptions caused by the soul Descartes defines as "perceptions of our volitions and of all the imaginings [imaginations] or other thoughts which depend on them [i.e., volitions].” Because perceptions of a volition are ultimately the same as the volition itself, since one cannot will something without being aware that one is willing it, these perceptions are normally considered actions. Imaginings and other thoughts are understood as imagining "something non-existent" or considering "something that is purely intelligible and not imaginable [non point imaginable]," and the dependence of these thoughts on the will makes the soul aware of the perceptions, placing them in the category of action. Perceptions caused by the body primarily depend on the nerves, but those independent of the nerves and formed independent of the will are also considered "“imaginings' [imaginations]." Such imaginings, understood as dreams and daydreams, are caused by animal spirits coming through certain openings in the brain as opposed to others. The perceptions caused by the body that depend on the nerves are of three types: those that refer to the external world, those that refer to the body (appetites), and those that refer to the soul (passions proper). The imaginings caused by the animal spirits, while generally less lively than the perceptions dependent on the nerves, can "mislead [trompe] us regarding the perceptions which refer to objects outside us, or even those which refer to certain parts of our body," hence hallucinations or a runaway 
imagination. Such deception cannot occur with the passions proper because "they are so close and so internal to our soul that it cannot possibly [il est impossible] feel them unless they are truly as it feels them to be." In other words, we cannot deceive ourselves that we feel anger, joy, or sadness. We clearly and distinctly feel these passions when we feel them. (CSM I, pp. 335, 336, and 338; AT XI, 342, 343, 344, and 348; arts. 17-26)

So the imagination, whether in the form of perceptions that depend on the will or in the form of imaginings caused by the animal spirits, is distinct from the passions proper insofar as the passions proper are independent of the will, depend on the nerves, are nondeceptive, are caused by the body, and refer to the soul. The imagination, when in the form of perceptions that depend on the will, is caused by the soul. It may be a passion in the general sense, but it is not a passion in specific sense of The Passions. When in the form of perceptions caused by animal spirits, the imagination is independent of the nerves and can be deceptive.

However, the will and the passions have their own relationship. Objects presented to the senses can excite passions insofar as these objects "may harm or benefit us, or in general have importance for us." The passions, in turn, have a sole function, to "dispose our soul to want [vouloir] the things which nature deems useful for us, and to persist in this volition [volonte]." When the passions are stirred by these objects, the passions are transmitted into bodily movement to obtain (servir à l'execution) what is useful, avoid what is harmful. In this way, the passions inaugurate a volition, direct the will in a given direction. However, there is also the question of language and habit to consider. Habituating ourselves to join certain movements of the pineal gland, certain thoughts, can be joined to other thoughts "through habit," the most obvious example of this being language acquisition. Words are things, independent of other things, but habit associates these words with the things to which they 
refer, yet with which they have nothing in common. ${ }^{44}$ Another example is coming across something disgusting while eating a favorite dish, thus redirecting the passions such that one does not want to consider eating that dish again. Descartes' final example comes from training dogs, such that they do not run after partridges, but to stop and wait for the sound of the gun even though their natural disposition, their natural passion, would be to chase them. These examples lead Descartes to conclude that everyone, even "the weakest souls," can control his or her passions, especially but not exclusively through reason. The example of trained dogs demonstrates that this control over the passions is not exclusive to reason because beasts "lack reason, and perhaps even thought." Thus, the passions can direct or dispose the will in a given direction, but we can habituate the passions in other directions, thereby redirecting or redisposing the will toward obtaining or avoiding other objects. (CSM I, pp. 349 and 348; AT XI, pp. 372, 369, and 370; arts. 52 and 50)

\footnotetext{
44 It is on this point that it is somewhat difficult to entirely agree with Foucault when he writes: "The threshold between Classicism and modernity (though the terms themselves have no importance-let us say between our prehistory and what is still contemporary) had been definitively crossed when words [mots] ceased to intersect with representations" (Foucault, The Order of Things, p. 304; Les mots et les choses, p. 315). For Foucault, decoupling words and representations opens up language to a dispersed existence of philologico-historical objectiveness, of universal formalization, or for its own sake. But it is fair to wonder, whether words for Descartes do not have some kind of objectiveness, if not necessarily of a philologico-historical kind, when he writes that "Words produce in the gland movements [paroles ... excitent des mouvemens] which are ordained by nature to represent to the soul only the sounds of their syllables when they are written, because we have acquired the habit of thinking of this meaning when we hear them spoken or see them written" (CSM I, p. 548; AT XI, p. 369; art. 50). Note that the representing capacity here is accomplished by the movements of the pineal gland, not by the words themselves. The words themselves produce pineal movements. Words would not themselves be able to produce motion were they not things in some fashion, and so somewhat distanced from the representations given in the soul thanks to the movements of the pineal gland. Words cause, inaugurate pineal motion, and they could not do that without having some kind of objective status, at least in Descartes, distinct from that of mere media for representation between world and mind that Foucault implies in his discourse as that which was lost in crossing from Classicism to modernity and as that "which ensured the initial, spontaneous, unconsidered deployment of representation in a table" (Foucault, The Order of Things, p. 304). To be sure, Foucault's analysis of the age seems accurate, and is even accurate in terms of the general attitude that Descartes himself will take, but one of the questions at hand here is always whether Descartes is in fact the figure we have made him out to be, whether he does not perhaps exceed his self-imposed limitations, and whether Descartes if not his age might not be re-readable, reinterpretable to become both more and less familiar, more familiar in the sense that he might have been ahead of his time and so closer to our own, less familiar in that he may not be the comfortable figure of a comfortable early modernity that we tell ourselves in laying out the trajectory (not to say 'progress') of Western philosophy.
} 
The relationship between the imagination, the will, and the passions, is thus the following: The imagination can take one of two forms, as a perception caused by the soul dependent on the will, and that is a passion only in the general sense in that it is the soul's passivity though its dependence on the will makes it normally considered an action; or as a perception caused by the animal spirits, that is independent of the nerves, and can be deceptive. The will is an action of the soul that can be isolated to the soul or extend to the body. The passions proper are perceptions caused by the body that depend on the nerves, refer to the soul alone, and do not deceive. The passions proper can direct the will to perform its action of the soul in accord with the apparent utility of objects that come into contact with the nerves in some way, but these passions can be habituated in ways not limited to reason such that the will's actions are changed. In that the form of the imagination that depends on the will is dependent in this way, and in that it is a passion in the general sense, habitual control over the passions would appear to also control this form of the imagination such that imaginings of this kind, whether of something non-existent or of something purely intelligible and unimaginable, can be controlled through the control over the passions. The second form of the imagination, which is independent of the nerves and of the will, would thereby also appear to be independent of the passions as well as control over them. However, in that the passions direct and dispose the will in the release of animal spirits and in that the second form of the imagination is caused by animal spirits returning to the brain through certain paths as opposed to others, there may be a certain way in which control over the passions through habituation can also lead to a control over this second form of the imagination, though such control would be even more indirect than the control over the first form of the imagination. 
Such a structure could suggest giving credence to the concept that the imagination is biplanar. ${ }^{45}$ There are, after all, two forms of the imagination laid out which appear to be fairly distinct from each other, only and tenuously linked through the will, animal spirits, and the passions. If there is legitimacy to the concept that the imagination has something more like a transfinite structure, exceeding its indefinite limitations while remaining distinct from absolute infinity, more needs to be argued. The source of that argumentation will come from focusing on one passion in particular, wonder, especially insofar as it is related to habituation and learning.

\section{Imagination and Wonder}

Wonder is the first passion, and it is without any contrary. Most of the six primitive passions

(wonder, love, hatred, desire, joy, and sadness) have some opposing passion which, depending on the object presented being considered useful or not, generates esteem or contempt, joy or sadness, etc., in the soul. Only wonder and desire have no contraries.

However, desire's motion is already infused with the consideration of the utility or good, the harmfulness or evil of the object in question. ${ }^{46}$ With wonder or astonishment (admiration or

45 Véronique Fóti articulates a biplanar structure to the imagination in the Passions as well when she distinguishes between passive and active imagination: "Passive imagination, so-called because it is involuntary, albeit spontaneous, arises from the physiological causes already delineated in the Traité.... Active or controlled imagination, on the other hand, involves an act of will; and will can and must be contained within the range and competence of the intellect" (Fóti, "The Cartesian Imagination," pp. 640-641). For Fóti, however, even this active imagination is in fact passive because, insofar as it is controlled, it is controlled by reason. Thus, even the biplanar structure she offers does not appear entirely biplanar.

46 The non-contrariness of wonder and desire are different from the non-contrariness, or lack thereof, of the Greek logos mentioned by Foucault, the mention of which is discussed by Derrida. For Foucault, it would seem that that the Greek logos contained both reason and unreason, the latter of which was silenced in the Freudian moment (see Foucault, History of Madness, pp. xxix and 547). For Derrida, this Foucauldian circumstance would demand that the history of Western philosophy "had already fallen outside and been exiled from this Greek logos that had no contrary," and the attempt to write a history of such an originary exile or division between the non-contrary logos and Western philosophy "runs the risk of construing the division as an 
étonnement), however, all that occurs is surprise, such that the object encountered is considered novel (nouveau) or different "from what we supposed [supposions] it ought to be." Such wonder cannot have a contrary passion because there is no awareness of utility or lack thereof in terms of the object's relationship to ourselves. If there is no surprise, no difference from precedent supposition, there is no wonder at all, and therefore no passionate relationship to the object. There are two causes of wonder (admiration):

first, an impression in the brain, which represents the object as something unusual and consequently worthy of special consideration; and secondly, a movement of the spirits, which the impression disposes both to flow with great force to the place in the brain where it is located so as to strengthen and preserve it there, and also to pass into the muscles which serve to keep the sense organs fixed in the same orientation ....

Wonder, then, is caused by the body and is dependent on the nerves that disposes the will to continue the body attending to the wondrous object. It is different from astonishment (étonnement) in that the latter "is an excess [exces] of wonder," resulting in the body being immobilized by the surprise, preventing knowledge from being acquired because the object in its sheer presentational qualities alone is what is considered, not a further investigation. (CSM I, p. 35, 353, and 354; AT XI, p. 373, 380-381, and 383; arts. 53, 86-87, 70, and 73) The passions themselves have useful and harmful qualities, based on the strengthening thoughts to preserve what is worth preserving and on preserving thoughts "beyond what is required [plus qu'il n'est besoin]," and wonder is no exception. Wonder's utility

event or a structure subsequent to the unity of an original presence, thereby confirming metaphysics in its fundamental operation" (Derrida, "Cogito and the History of Madness," p. 40). Regardless of the debate between Foucault and Derrida, wonder and desire have no contrary in a manner distinct from this supposition on and/or discussion of the Greek logos because neither are originary. This non-originarity is meant in at least three ways. First, even if wonder is the first passion, that does not make it originary. It remains a passion, and thereby passive as a reaction to the wonders of the world. Second, insofar as both wonder and desire are two among a list of six primitive passions, neither could be originary of the other four. Neither wonder nor desire produce love, hatred, joy, or sadness because these passions emerge of their own accord, even if within a complicated set of actions and reactions which could involve either wonder or desire. Third, in that wonder and desire have no contraries, they are not originary in that there are two of them. A discussion of these passions is not indicative of an exile from their originary unity because, even if they were originary, they would not be unified. Thus, a discussion of them is not a discussion of a metaphysics of presence. There may very well be a metaphysics of presence in Descartes, but it is not necessarily found in wonder or desire. 
is found in the way that "it makes us learn and retain [apprenons \& retenons] in our memory things of which we were previously ignorant." When a previously unknown or an unusual object is presented before the sensory organs, it is retained in the memory only because of the passion which attends to it as previously unknown or as unusual, "or perhaps also by an application of our intellect as fixed by our will," though the will is disposed to fix the intellect thanks to the passion itself. Wonder's harmfulness is found in astonishment, in the way the excess of wonder can generate attention to what does not deserve the attention, thus removing or perverting (oter or pervertir) reason, the remedy for which is the acquisition of knowledge such that memory serves as a bulwark against perpetual wonder. Astonishment can itself become a habit in that the lack of further investigation by reason and intellect disposes the soul to treat every appearance of every object as novel, regardless of their importance. The bad habits that other passions (love, hatred, desire, joy, sadness, and their derivatives) might instill can be corrected through "experience and reason" by attending to the "true value [juste valeur]" in terms of their good and evil. However, it appears that reason is not necessarily able to correct astonishment insofar as astonishment removes or perverts reason. Only experience, memory, knowledge can correct the bad habit of astonishment back to the good habit of wonder. (CSM I, pp. 354, 355, and 377; AT XI, pp. 383, 384, and 431; arts. 74-76, 78, and 139)

The steps of the general remedy against the passions give credence to this position on astonishment. Because no one can prepare him- or herself for every circumstance of life ahead of time, we can take steps to prevent being overwhelmed by passions such that they lead to bad habits. The first step in controlling the passions is to "take heed, and recollect [averti, \& se souvenir]" the deceptions that objects can generate in our imagination. If the passion urges action that will take time, "we must refrain from making any immediate 
judgement about them" until we have calmed down. If the passion urges immediate action, "the will must devote itself mainly to considering and following reasons which are opposed to those presented by the passion, even if they appear less strong." Exerting control over the passions in this way will make manageable the bad habits to which the passions can give rise. What is more, this control itself can "even become a source of joy [Ioye]." In general, the passion of joy occurs when the soul "enjoys [jouissance] a good which impressions in the brain represent to it as its own." The impressions' representing this good to the soul as its own is what distinguishes the passion of joy from intellectual joy, the latter of which "arises in the soul through an action of the soul alone." However, so long as the soul is joined to the body, intellectual joy is always accompanied by the passion of joy because the perception that a good is possessed, "even one so different from anything belonging to the body as to be wholly unimaginable [il ne soit point du tout imaginable]," forms an impression in the brain that moves the animal spirits through the imagination. Control over the passions then appears to give rise to an intellectual joy, where the intellect perceives that the good of self-control, which the soul can only arouse in itself, is possessed, but this possession forms an impression in the brain thanks to the imagination, giving rise to the passion of joy, the joyous passion of control over the passions. ${ }^{47}$ (CSM I, pp. 403, 404, 360, and 361; AT XI, pp. 487, 488, 396, and 397; arts. 211, 212, and 91)

However, correcting astonishment would still appear to be possible only in the first step of control: recollection or memory. All other elements of the general remedy involve

\footnotetext{
${ }^{47}$ Such is the "moral discipline of fatalism which Descartes was so concerned to educate men to" (Kuspit, "Epoché and Fable in Descartes," p. 34). For Kuspit, Descartes' concern arises from an unrealized ambition for a fully materialistic philosophy as well as allowing people to develop a stoic passivity in the face of a world hostile to such materialism. However, Kuspit does not precisely take account of the passion found in controlling the passions on Descartes' articulation. This passion of or this joy in control can be taken as a typical philosophical praise of steadfastness, of the type found in Plato, Aristotle, Nietzsche, and Heidegger, but it should also be remembered that it is a joy, and therefore an experience of one of the six principle passions, and so not simply a subtraction from the passions.
} 
reason, which astonishment removes or perverts, preventing the intellectual joy of the general remedy's control and thereby the passionate joy to which this intellectual joy would give rise via the imagination's imagining the unimaginable. What can be done to correct astonishment and habituate ourselves toward wonder, then, requires attending to recollection, memory, our own personal histoires. ${ }^{48}$ How we do this, how Descartes does this, is to tell a story, a fable that tells the story of the wondrousness of the objects of the world as other than how it presents itself. Such a fable is the story of a world made wondrous, made uninterpreted (or thus far inappropriately, unreasonably interpreted). This fable is possible only if the imagination can imagine beyond its conditions, can imagine what is otherwise unimaginable. The imagination can do this both insofar as it is dependent on the will and insofar as it can daydream and deceive itself into imagining not only another world entirely but one which perfectly well matches the one which has in fact presented itself to us. In imagining that world as perfectly matched to what has presented itself to us, but matched through a willful imagination that it is other than how it has presented itself, the imagination is working, within itself, to exceed the limitation that it would otherwise appear to have. The

\footnotetext{
${ }^{48}$ It would be interesting to spend some time looking at how the Cartesian concept of recollection of one's own histoire with the "different degrees on a scale of arduousness" that Ricoeur describes the effort of recollection as having (Ricoeur, Memory, History, Forgetting, p. 444). The different degrees involve blocked memory, manipulated memory, and commanded forgetting. Blocked memory, associated with Freud, "is a forgetful memory" where a patient repeats rather than remembers (ibid., p. 445). Manipulated memory, which depends on the fact that "narrative necessarily contains a selective dimension," most properly occurs "when higher powers take over this emplotment and impose a canonical narrative by means of intimidation or seduction, fear or flattery" (ibid., p. 448). Commanded forgetting is associated with amnesties and the enforced amnesia associated with them and "It is certainly useful — this is the right word — to recall that everyone has committed crimes, to set a limit to the revenge of the conquerors. . . But is it not a defect in this imaginary unity that it erases from the official memory the examples of crimes likely to protect the future from the errors of the past . . ? " (ibid., p. 455). A turn to that fable or histoire of the Discourse would seem to be a prime example of a Cartesian recollection that operates with all these levels of arduousness at hand, the personal memory which may be blocked, the personal incorporation of a taught narrative which explains the world and which appears to be manipulated, and even a command to forget but give amnesty to past lessons by those who manipulated memory in the first place (giving amnesty because they were pleasant and sometimes useful things to learn). That Descartes makes his recollection public yet encourages others to follow suit in their own ways makes the potential manipulation of his readers' memories at least more complicated than the Scholastic approach to a mind as an empty vessel, to say nothing of the complications of Descartes' personal memories, blocked or otherwise.
} 
imagination instills wonder, inaugurates it through the telling of the fable of the world as comprehensible yet other than as it presents itself. That this fabular world is perfectly matched to the one we have experienced, while remaining as other than our experience, and is yet perfectly comprehensible and interpretable thanks to the rules generated in the telling of the fable, rules that the fable itself obeys in the story told, thereby establishes a regulation to wonder such that astonishment does not remove or pervert reason. Rather, it cultivates, habituates reason as the regulator of wonder to prevent astonishment because the story as it is told and in its very telling lays out that to which it is important to attend insofar as the story is a story of the inauguration of a motion that results in three elements which themselves are the motion of the world. ${ }^{49}$ In its telling, in the imagination required to follow the story's inauguration of light, the imagination imagines what is otherwise unimaginable and sets reason, wonder, and the imagination itself into the motion required to attend to what deserves attention. Without the imagination, and without the imagination inaugurating a mental motion that sets the mind into the motion to deform and reform its faculties' functions (including the imagination's), reason, wonder, will, intellect, and so on remain malformed and unable to move with attention to what should be attended to. Without the transfinitude of the imagination, then, without the imagination imagining what is truly, justly wondrous, reason is non-existent and the absolute infinity of the will impotent. ${ }^{50}$

\footnotetext{
${ }^{49}$ In this regulation of wonder against the risk of astonishment, some credence would appear to be given to Reiss's claim that the Passions is connected to Descartes' earliest work on music because both engage in a "search to balance rule against experience, to explain the effects of art, to understand how aesthetic pleasure operated, and what it was that one might call the beautiful, the good, or the true" (Reiss, Knowledge, Discovery, and Imagination in Early Modern Europe, p. 196). The rules generated in the telling of the fable are interpretable then, qua rules, as rules that will habituate reason such that it seeks out the rules by which it will come to understand experience. Were experience astonishing and not wondrous, reason would not be cultivated, rules would remain undiscovered, aesthetic pleasure operative but merely dumbfounding, and therefore not cultivating the intellectual joy found in the habits of reason, all set to motion by the fable.

${ }^{50} \mathrm{John}$ Sallis attempts to find a twofold relation between imagination and metaphysics where there is " $\mathrm{a}$ metaphysical theory about imagination and ... a metaphysics which would be the work — or, perhaps better, the play_of imagination” John Sallis, "Imagination, Metaphysics, Wonder," in American Continental Philosophy:
} 


\title{
Imagination and Comedy
}

\author{
Perhaps all of this appears as a bad joke, an attempt to instill astonishment at what does not \\ deserve the attention but should rather invite derision. However, if putting the imagination
}

\begin{abstract}
A Reader, ed. Walter Brogan and James Risser [Bloomington, IN: Indiana University Press, 2000], p. 19). He does this by an investigation primarily of Plato, Gianfrancesco Pico della Mirandola, and Kant and the work they did to separate reason from imagination. In Plato, "imagination both empowers and inhibits the metaphysical drive to presence, and metaphysics must, accordingly, both appropriate and take distance from imagination"; in Pico, "his metaphysical theory regarding the nature of imagination, belongs to metaphysics ... as a necessarily limited taking of distance from imagination and thus from the threat which it poses to metaphysics"; and, in Kant, "However much imagination is appropriated to theoretical reason, to the metaphysics of nature, it is with equal rigor excluded, distanced, from practical reason, from the metaphysics of morals" (ibid., pp. 21, 23-24, and 26). These moments of distancing metaphysics from imagination are also intertwined, in the same philosophers, with "a moment that supervenes upon that dynamic relation between metaphysics and imagination," linked with the "shift from eikasia to phantasia" whereby both Latin words imaginatio and phantasia translate the Greek (ibid., pp. 26 and 21). Eikasia is "a matter of . . . apprehending images," and its strategic suppression "belongs to the very constitution of metaphysics as such" insofar as it subordinates imagination to a telos and "This telos is equally arche, the original which grounds" (ibid., pp. 20 and 28). For Sallis, the end of metaphysics will also thus be a releasing of the eikastic imagination from its suppression as "an oriented field, a field in which certain lines of directionality mark the difference between image an original, prescribing the movement in the field" (ibid., p. 28). Wonder-as thaumazein, as wundor, and as "the wonder of a vision in which one comes to see the world anew" - can achieve this new orientation for Sallis because, though it has also been repressed as the arche of the superior 'knowledge', "now, in the end, in the future perfect, wonder will have remained the beginning" (ibid., pp. 30 and 34). Wonder itself, however, cannot be investigated philosophically if it takes wonder as "a passion of the soul, in assimilating it, for instance, to intuition" (ibid., p. 36). Philosophy can only investigate wonder in terms that wonder will have determined. Thus, Sallis calls for an archaic provocation of wonder, an provocation through "the opening, the openness, within which sense could be exceeded" such that "One would return ... to a wonder placed at an opening from and within the sensible, an opening that in a sense-in sense itself, if there could be sense itself would precede even the play of beings in the Being, a foreplay, a prelude" (ibid., pp. 38 and 40). And yet, for all of this, Sallis places Descartes squarely, almost simplistically within the tradition of the suppression of the imagination, and therefore of wonder. Descartes deploys "strategies by which he would protect properly metaphysical understanding from the corruptive intrusion of imagination" and of course names wonder as a passion of the soul, thus assimilating it to intuition (ibid., p. 17). Sallis seems unaware that, through the fable, the fabulation of a new world, through the wonder of failed expectations and the imagination's inauguration of a fable that the world is other than as given, Descartes' imagination begins to appear significantly more like the orienting eikasia to which he hopes to lead us to return than the imaginatio of the tradition he invokes. Perhaps this is a perspective or orientation on Descartes possible only at the end of the metaphysics that Sallis invokes as suppressive of the imagination and wonder, but that does not mean it is an impossible orientation. After all, the question of modernity, and of Descartes as the father of modernity, is the question not only of beginnings, but also of beginning anew, of finding new ways of beginning the orientation on the world. As Sallis himself points out, "When one comes to pose a question of the beginning, that beginning will already, long since, have been in play" (ibid., p. 30). He is correct, of course, and the moderns, or at least the father of modernity, knew this. The beginning, as a modern beginning, can never be archaic in this foundational sense any more than another questioning of an arche can. However, Descartes is not simply concerned with questioning an arche. He is concerned with making or showing one, and that requires the transfinitude of an imagination which moves, or, in Sallis's word, hovers, between the infinite and the finite such that a wonder at the world which is not mere astonishment is possible, a requirement achieved via the Cartesian fable. This could mean both that Descartes is engaged in something close to the archaic eikastic imagination that Sallis invokes, and that Sallis himself remains much more metaphysical than he would perhaps prefer to acknowledge.
\end{abstract}


in a transfinite position in relation to the faculties is laughable, perhaps it should be remembered that the self-styled seriousness of the method has already shown itself as unserious in its seriality, its interweaving of analysis and synthesis. What is more, the laughability of such a positioning of the imagination should be accounted for as the passionate, impassioned response that it is. To do so, it is necessary to investigate laughter, what causes it and what its functions are. Doing so will give perspective on the extra work of the imagination and hyperbolic doubt.

\section{Laughter}

Laughter arises when blood moves through the heart such that the lungs suddenly swell, which forces the air out in the form of "an inarticulate, explosive sound [une voix inarticulaulée \& esclatante." It is caused either by wonder, sometimes combining with joy, or a mixture of a liquid from the spleen that can cause rarefaction in the blood. Joy can only cause laughter when combined with wonder or hatred, so laughter can be a sign of joy but not all joy, the greatest joys in particular, is signified in laughter. (CSM I, p. 371; AT XI, p. 419; arts. 124-

Three things are most associated with laughter: indignation, derision (moquerie), and mockery (raillerie). Indignation is the hatred felt toward someone who has done evil, specifically focused on someone who has done good or evil to another who did not deserve it, envy mixing with indignation if the other receives an undeserved good, pity if the other receives an undeserved evil. It serves those who prefer to appear (paroistre) more virtuous than those who are truly virtuous in that the indignant become vexed over trivial issues (peevishness), over what can be blamed on no one, or extend their indignation 
inappropriately to god instead of finding contentment in their conditions. Thus, the laughter of indignation "is usually artificial and feigned [artificiel \& feint]," though if natural it is the result of the joy at not being able to be harmed by the evil in question and by the surprise. Descartes is willing to concede a joyless, and presumably wonderless, indignant laughter, resulting only from an aversion that sends blood from spleen to heart to lungs. Indignation is linked to wonder and joy because the evil or good to an undeserving other surprises our judgment of who deserves what and because, if the evil cannot harm ourselves while considering ourselves unwilling to do such evil (ne pas en vouloir), we gain pleasure from this distance, resulting in laughter. In terms of its assessment of the one who does evil or good to an undeserving other, indignation is linked with pity toward those to whom the indignant has good will but is linked with derision toward those to whom they have ill will. (CSM I, p. 372; AT XI, p. 421; arts. 195-198, and 127)

Derision only results from insignificant evils visited upon one who deserves it, and is a mixture of joy and hatred: hatred for the evil, joy in seeing it visited upon one who deserves it. An unexpected evil visited upon one who deserves it results in wonder and causes laughter, but one who laughs at a great evil visited upon even a deserving person either has a bad nature or extraordinary hatred toward the one upon whom the evil is visited. Descartes does not indicate whether the "most imperfect people," like the lame or those who are otherwise deformed, who are inclined to derision because they take pleasure in evils like their own being visited upon others and because they hold all others as deserving evils, take this pleasure and make this judgment even in the face of great evils, but it seems safe to assume their individual natures and everyday level of hatred would be unique to each of them. Derision is linked with envy and pity in that all of them concern a present or future evil or good belonging to another. If we judge the good to be deserved, the result is only joy, 
though not wonder, but if we judge the evil to be deserved, then the joy aroused "is accompanied by laughter and derision." Judging an evil as undeserved results in pity and a good as undeserved results in envy in that both are forms of sadness. (CSM I, pp. 393 and 351; AT XI, pp. 465 and 377; arts. 178, 179, and 62)

While indignation and derision appear to be passions, mockery is not. It is in fact "the trait of a good man [honneste homme]." It serves the function of presenting vices in their proper, ridiculous (ridicules) light "without laughing at them and without showing any hatred for those who have them [sans toutefois qu'on en rie soy mesme, ny qu'on tesmoigne aucune baine contre les personnes]." Mockery is the mark of a cheerful temper, a tranquil soul, and a quick mind. While it is not bad or dishonest (deshonneste) for laughter to sometimes accompany mockery and the mocker may find it difficult, it is better not to laugh when mocking "so as not to seem [sembler] to be surprised by the things we say or to wonder at our wit in thinking [inventer] them up," but also because not laughing at the moment of mocking can make it "all the more surprising to those who hear them.” (CSM I, p. 393; AT XI, pp. 465 and 466; arts. 180 and 181)

So laughter can be caused by passions or by something other than passions, by the trait of a good, honest man who mocks vices. If it is caused by passions, those passions are indignation and derision. Indignation combines wonder, joy, and hatred as regards a surprising good or evil visited upon one who does not deserve it and the laughter it causes is usually feigned, though not always. Derision is a form of indignation that combines wonder, hatred, and joy aimed at the one who receives a surprising and usually insignificant evil upon witnessing or expecting to witness the good or evil and its laughter is caused by judging that this person deserves the evil. Mockery, the trait of a good, honest man, gently exposes vices for what they are and should not cause laughter if it is to be effective in instilling wonder in 
the other who would then learn, but sometimes this good, honest man cannot help but be surprised by his own wit.

"ut risu dignae, sunt explodendae"

At the end of the Meditations, Descartes can finally put his doubts to rest. However, he does not merely put them to rest, does not merely set them aside. Instead, "the exaggerated doubts of the last few days should be dismissed as laughable [byperbolicae superiorum dierum dubitationes, ut risu dignae, sunt explodendae]" (CSM II, p. 61; AT VII, p. 89). More literally, the hyperbolic doubts of the last few days, as deserving laughter, are driven or booed off the stage. In French, this passage is changed: "And I ought to set aside all the doubts of these past days as hyperbolical and ridiculous [Et ie dois rejetter les doutes de ces iours passez, comme byperboliques \& ridicules]” (HR I, pp. 198-199; AT IX-A, p. 71). The laughability of these doubts in particular applies to the doubt generated from being unable to distinguish between waking life and dreamworld since, now that memory is trustworthy, the lack of a connection between memory and dreams allows him to distinguish between those worlds again.

However, the question is what kind of laughter is being presented here. The difference between the Latin and French passages should not be ignored in that the French does not explicitly mention laughter, although the doubts in French are characterized as hyperbolic and ridiculous, the latter of which does connect them to laughability. That the French does not explicitly laugh, however, is important, and telling as to the kind of laughter being indicated in the Latin.

There are, again, three main forms of laughter: indignant, derisive, and mocking. Indignant and derisive laughter are passionate. The laughter at these hyperbolic doubts is not 
of the indignant form, first, because it is not a laughter to find oneself more virtuous than one is because either, in discovering how to correct errors, sin will be corrected, so the doubts help Descartes discover how to be, or the doubts have nothing to do with good and evil; nor is it laughter at something trivial, for nothing can be more serious than concern over the self, god, and the trustworthiness of the world as it presents itself; nor is it laughter at being unable to find contentment in one's station in life because the recognition of the pragmatics of being unable to carefully investigate every aspect of life at all times-which is why he must stop writing each Meditation, rest, and return to life, and is also why he closes the Sixth Meditation with an appeal to recognizing the weakness of human nature-places him in a state of relative contentment. Second, this is not an indignant laughter because these doubts, whether they are evil or good, have been visited by Descartes upon himself, while the indignant person always laughs at a situation removed from him- or herself. (CSM II, pp. 41, 11, and 62; AT VII, pp. 58, 15, and 90)

Derisive laughter is a particular form of indignant laughter, and is directed at someone who deserves an insignificant and present or expected evil visited upon him or her. If the laughter at the hyperbolic doubts is not an indignant laughter, it cannot be a derisive laughter either. What is more, however, it is at least an open question whether the doubts are evil or good. If they are evil, there is no indication that Descartes thinks he deserves them, except perhaps insofar as he had been struck by falsehoods, which is an evil only if one believes recognizing falsehoods is evil. If they are not evil, then the laughter cannot be derisive since the doubts are what are visited upon him. Finally, the laughter in the Sixth Meditation does not in any way concern something insignificant, regardless of the good or evil quality of the doubts themselves, since the doubts concern the self, god, and the trustworthiness of the world. 
Mockery is the only option left. Mocking laughter laughs at one's having the wit to present vices in a ridiculous light such that the one who hears what is mocked is brought to the first of all passions, wonder, and is set on the path of learning. It is laughter at oneself, specifically at one's own wit. Laughing at one's wit is not recommended as a pedagogical tool because it can diminish the surprise of the hearer and undermine the learning it is meant to begin, but sometimes it cannot be helped. Such laughter is the laughter indicated by the Sixth Meditation. The doubts are dismissed, driven or booed off the stage, treated as laughable as bad actors. The difference between the Latin and French passages, where the Latin laughs and the French does not, would then appear to indicate a shift where Descartes catches himself. He laughed in the Latin because he could not help it, but in the French translation he has realized that it is more effective not to laugh at his wit at setting up all these hyperbolic, ridiculous doubts. ${ }^{51}$ The connection between laughter and the Sixth Meditation is even stronger when looking at the Latin of the Meditations and the French of The Passions. These doubts are dismissed in that they are explodendae, which means to boo someone off the stage. Mockery in Descartes' French is raillerie, which also means to boo. Thus, the laughter in the Meditationes that does not appear in Les Méditations is the kind of laughter, the kind of treatment, that the French of The Passions takes up as mockery.

\footnotetext{
51 One wonders, then, what Descartes' silencing of his laughter (or d'Albert's silencing of Descartes) in the French translation of the Meditations, as a silencing of a laughter that has already exploded onto the scene, says in response to Foucault's claim that "Descartes, in his movement towards truth, made impossible the lyricism of unreason" (Foucault, History of Madness, p. 517). On Foucault's reading, of course, madness in itself for the seventeenth century "was a silent thing: there was no place in the classical age for a literature of madness, in that there was no autonomous language for madness, and no possibility that it might express itself in a language that spoke its truth" (ibid., p. 516). But this laughter at the madness of the hyperbolic doubt is itself silenced. It is silenced, seemingly, in deference to the preferable pedagogical position that a mocking joke should not be laughed at by the jokester. If the Meditations is a joke, a comedy, then it follows a mad logic, and thereby speaks a kind of madness, seemingly in madness's own language, and it does so with the pedagogical purpose of undermining what only appeared to be the logic of accepting the world as it appears, an apparent logic that is itself mad, as exposed by the madness of the joke of the hyperbolicity the Meditations. Is this perhaps a defense and explanation of the lyricism of the Meditations, that it is itself a lyricism of unreason?
} 
Descartes is laughing at himself at having the wit to have had all these doubts, all these laughable doubts, for himself. In one sense, then, he had set himself on the passionate path of wonder — wonder at his ability to doubt to such a degree, wonder at the solution to those extensive doubts, wonder at the relative ease by which they are resolved, wonder that he had ever honestly had them to the extent and degree that he had. But he is a good, honest man and knows that he honestly had these doubts that now deserve laughter, that have gained the dignity of laughter. It is only by honestly having them, by taking them seriously, that they can be shown in their ridiculous, laughable light. It is only by giving them the dignity of being taken seriously that they can gain the dignity of deserving laughter. And these doubts began by the failure of expectations in the images of the world, failures which led to doubt to such a ridiculous degree that the non-existence of the world and self had to be imagined, to imagining a non-god, to finding a solution in the imagining of what else the mind can do. These hyperbolic doubts of his are ridiculous, are imaginary, but were only imagined thanks to the failure of the imagination. ${ }^{52}$ This is what he has learned in the

\footnotetext{
${ }^{52}$ For Marion, the doubts are laughable "because their hyperbole is shown in the end to be false," which is perfectly acceptable, but he goes on to say that "The tenuity beyond what is common had nothing laughable about it, since by definition and in strict consequence of the metaphysical abstraction, doubt (and the certainty that alone lifts it) can be stated only as an extreme limit, beyond all (sensible and physical) perception and all (mathematical) imagination" (Marion, On Descartes' Metaphysical Prism, p. 29). Marion is half right here, in that what is beyond the common is of the utmost seriousness, but he is wrong to think that this also means it is not laughable. Again, he does not seem to have noticed the dynamics of the comedy involved here, where what is most serious appears as a bad joke to the foolish. The hyperbole shows itself as laughable at the end of the Meditations because it has come to be seen as false, but it was always laughable, and in that laughability lays its seriousness. What is more, the doubt may be at the limit or bound of the serious and the comic in a Kantian metaphysical sense and it may even be beyond mathematical imagination, but that does not make it beyond all imagination, not beyond the imagination which imagines the ridiculous world of the dubitable self and an evil genius. Marion's parentheses in this case accomplishes more than he perhaps would like. In placing 'mathematical' within them, it would appear that he wanted to hint that the doubt is beyond all imagination, all of which may be mathematic for Descartes. However, the parentheses also appear to act as italics, emphasizing what aspect of the imagination the hyperbolic doubt may be beyond. The doubt is not beyond all imagination. The doubt emerges from the imagination, like a fable, and the transfinitude of the imagination is what gives the doubt its hyperbolicity.
} 
dispassionate laughter that mocks his imagination: that the imagination can extend itself

beyond itself in hyperbole, but that this transfinite extension is to be booed off the stage. ${ }^{53}$

But Descartes is not the only person being mocked in this laughter that does not

laugh, at least not in French. The reader is being mocked as well because he or she has

followed Descartes in his hyperbolic and ridiculous doubts. The reader, however, must take

Descartes seriously in these doubts because they are doubts of the most serious nature. The

reader must imagine, along with Descartes, the doubt from the imagined evil genius, must

imagine the imagination's limitations, must imagine the non-existence of the world, imagine

that the world is other than as it presents itself. The reader can imagine the world as other

than as it presents itself because of the seriousness of the failure of expectations, and if the

world can be other than as it presents itself, which the failure of expectations shows as the

failure of experience, if the world can be entirely other, then an entirely other world is

imaginable. However, the reader can only imagine the world in this way if he or she imagines

Descartes in his room, writing, looking at wax, at least imagines Descartes in this way

enough to take these ridiculous doubts seriously, imagines a willing suspension of belief-

impractical, ridiculous as this suspension may be-because the ridiculousness of the

\footnotetext{
53 Thus, Derrida claims, "I think, therefore, that (in Descartes) everything can be reduced to a determined historical totality except the hyperbolic project" insofar as this project is "narration narrating itself" (Derrida, "Cogito and the History of Madness," pp. 57 and 58). In being a project where narration narrates itself, it is a "project of exceeding the totality of the world" since the world for Derrida is the world of history, logic, and philosophy (ibid., p. 56). The cogito, the point from whence doubts begin to be laughed and booed at, "is embedded" within the project of thinking a world which is exceeded in the thinking of it, and so necessitates a meta-physical and excessive figure like the evil genius which can be resisted (ibid.). Because Foucault is determined to 'give voice' to what is silent, to make sense of what is senseless, he "risks erasing the excess by which every philosophy (of meaning) is related, in some region of its discourse, to the nonfoundation of unmeaning" (ibid., p. 309n. 26). If I disagree with Derrida on any point in this point of his argument, it would be that he at least comes extraordinarily close to identifying the point of excess as the cogito, whereas I contend that the cogito must be formed, as that which can prove itself to itself as well as through that proof, via the fable of a world of totality which the imagination's transfinitude makes possible insofar as that transfinitude allows for the imagination to exceed the limits it places on itself in the fabulation. It is in this way that Derrida at least comes extremely close to making the same assumption of a pre-formed faculty psychology, a pre-formed self such that the reading of Descartes rests on a psychologized understanding of the selfdeception at work in the Meditations.
} 
imagined suspension is only clear after having taken them seriously enough to resolve them, along with Descartes in his imagined few days.

In short, then, the laughter is imaginary, is the product of an imagination which exceeds its own limitations, can turn the will in a given direction such that the limitations of the imagination come to be exposed and the imaginary doubt is exposed as ridiculous. This laughter may not be the laughter of the gods, it is not an infinite laughter, though it is not a passionate one, either. The laughter of mockery is a laughter to instill wonder, to set learning to work, but it can only do this by imagining that what one has learned is malformed. In instilling wonder thanks to the malformed lessons of the imagination, this laughter is dispassionate, as dispassionate as the imagination itself according to the structure laid out by The Passions. And therefore, the joy of this laughter is of the dispassionate, intellectual sort associated with the joy of controlling the passions. Neither is this laughter infinite, divine, in the way the will is according to the structure of the Meditations. It is a laughter of the imagination: transfinite, recognizing the ridiculousness of its own position, showing what it imagined to be deserving of being dispassionately booed off the stage. The Meditations is a comedy, made possible by the imagination and the willing suspension of belief in the wake of the failure of expectation, but it is not a divine or immortal comedy. To laugh indignantly at this joke is to laugh like the deformed, which is why various objectors to the comedy of the Meditations, with their malformed minds, find it unimaginably perverse. ${ }^{54}$ Descartes'

\footnotetext{
${ }^{54}$ For different reasons, this assessment of Descartes' perversity lasts more than three hundred years, from the Seventh Set of Objections through the History of Madness. For Bourdin, "What the method contains is either unsound or nothing new, and for the most part it is superfluous," and it is unsound in its "renunciation of what is doubtful," in its proof of the self, and in its supposed claim that only humans can think or imagine or have sensations (CSM II, pp. 363-364; AT VII, pp. 532-535). For Foucault, "The path taken by Cartesian doubt seems to indicate that by the seventeenth century the danger has been excluded, and that madness is no longer a peril lurking in the domain where the thinking subject holds rights over truth: and for classical thought, that domain is the domain of reason itself. Madness has been banished. While man can still go mad, thought, as the sovereign exercise carries out by a subject seeking the truth, can no longer be devoid of reason" (Foucault, History of Madness, pp. 46-47).
} 
laughter is, like the imagination, transfinite, an a-mortal comedy that establishes limits which it exceeds in its very performing of itself, in its histoire, deforming and reforming its own malformed origin in a performance which it dismisses or explodes as deserving of laughter.

The Work of the Imagination

Now that we have seen Descartes laugh despite himself, now that he has mocked himself as concerns the doubts that had seemed so serious, it is worth turning back to how he assured himself against these doubts. He does this, he finds the comedy in his serious doubts, in finding good reason to trust the world as it appears, though not insofar as it appears. That is, he finds good reason to trust the world as it appears insofar as its appearance is indicative of mathematical truths and because god is no deceiver.

According to the Fifth Meditation, the proofs of mathematics are true and therefore exist distinct from the mind and god because the intellect clearly and distinctly perceives them, because they are not themselves god, and because god is no deceiver. In the Sixth Meditation, then, it is possible for things to exist because they would be objects of mathematics. In addition, the imagination suggests that things exist because of the sheer fact of the images that the mind has of material things. ${ }^{55}$ However, although the mind can clearly

\footnotetext{
${ }^{55}$ For Sepper, "The Sixth Meditation does not intend to investigate imagination for its own sake but tries to determine whether imagination as a faculty of mind is sufficient to establish the existence of something corporeal" (Sepper, Descartes's Imagination, p. 248). That the intellect clearly and distinctly perceives what the imagination suggests means that the imagination's imaginings are only probable. Sepper's answer to the question how a chiliagon can be understood without an image, more charitable than claiming that it is impossible, is that "extension is imagined as such in this custom of cogitation [whereby I can represent a confused image to myself of what I could call a chiliagon or a myriagon], only it is not carefully articulated by the mind's distinct attention to its parts" for the purpose of a virtual realization which is possible because "extension is so constituted (by God) that having the general idea of it (in imagination), or further articulating it in accordance with 'true and immutable natures,' as the next paragraph calls them, is implicit and in perfect agreement with my nature" (ibid., pp. 250 and 251). Extension as such already implies images and imagination for Sepper, and so even the unimaginable chiliagon or myriagon must be imagined as existing 'in' space. This
} 
and distinctly imagine relatively simple images like a triangle or a pentagon, it cannot clearly and distinctly imagine more multiple-sided images like a chiliagon or a myriagon, while the intellect can clearly and distinctly perceive the mathematical properties of the chiliagon or myriagon independent of any image of it. ${ }^{56}$ Thus, Descartes concludes, the imagination "requires a peculiar effort [peculiari . . contentione]," an "additional effort [nova . . contentio]" that the intellect does not require. Thus, the strengths (vires) of the imagination and the intellect are distinct, that of the imagination being inessential to the mind and that of the intellect being essential, since the mind, which has not yet been shown as attached to a body, could exist as it does with merely itself, god, and purely mathematical objects. Thus, if things exist, the imagination depends on bodies, turns the mind toward bodies, and "looks at something in the body which conforms to an idea understood by the mind or perceived by the senses." Things may not exist, however, and so the imagination's dependence on them is no proof of their existence. (CSM II, p. 51; AT VII, pp. 72-73)

What is more daunting is that the imagination is accustomed (solere) to imagining more about things than (multa quae) is reducible to them as objects of mathematics: sight, sound, taste, touch, and smell. It imagines these qualities of things either in sense perception or in memory. The ideas of things, dependent on sense perception and memory, are adventitious, and invented or remembered ideas are less vivid than those from sense perception, even those ideas invented in meditation. Because of this vividness, Descartes had

does not make the imagination sufficient to establish corporeal things, but it does allow for it to strongly suggest them.

${ }^{56} \mathrm{It}$ is because of this distinction between the clear and distinct perceptions of the imagination and those of the intellect that Rickless claims that Descartes never commits the fallacy of circularity, because "the natural light isn't the faculty of distinct perception in general, but rather the familiar (and narrower) faculty of the understanding. The distinct perceptions that are subject to doubt in the First Meditation belong to the senses and to the imagination, but not to the understanding" (Rickless, "The Cartesian Fallacy Fallacy," p. 318). Rickless's argument is the correct one on this point. However, not only Rickless's argument but also the debate into which he wades is dependent on the assumption that the faculties are pre-formed, an assumption for which there is little to no justification. 
thought that sense perception, and the extra work of the imagination tied to it, was the source of his ideas. However, "many experiences [multa . . experimenta]" showed him that judgments based on both internal and external senses were frequently mistaken, leading him to doubt them. ${ }^{57}$ From these experiences, these sense perceptions that failed to meet expected sense perceptions, doubt of the imagination and its judgments entered his mind to such a degree that he began to doubt hyperbolically, specifically by noticing the difficulty of discerning between dreamworld and experience proper and by "at least pretending not to [vel saltem ignorare me fingerem]" know whether god was no deceiver or an evil genius. (CSM II, p. 53; AT VII, pp. 76 and 77)

The hyperbolic doubt generated from out of the failure of experience to match expected experience, the failure of perception's images to match the imagination's judgments, is resolved from two things. First, it is possible for god to create things in such a way as to correspond with the intellect's clear and distinct perceptions, which it has with the intellect's perception of itself as a thinking thing, and there is also a distinct idea of body, distinct from the mind, distinctly distinct from the mind insofar as the body is inessential for the self as thinking thing. Second, "I find [invenio] in myself certain special modes of thinking,

\footnotetext{
${ }^{57}$ This relationship between doubt and experience is what leads Kuspit to find an epoché in the Cartesian fable: "the doubt and the experience of the world...require one another. . . The doubt believes in the existence of the experience of the natural world. But it wants a coign of vantage from which to look at this world. It must isolate the world, and contain it in some way. In the case of the all-powerful God, doubt does this by declaring the all-powerful God to be a fable" (Kuspit, "Epoché and Fable in Descartes," p. 41). This use of fable is a result of Kuspit's reliance on the Haldane and Ross translation, which itself relies on d'Albert's French translation of the Meditationes. There, what Cottingham translates from the Latin as "Let us not argue with them [i.e., atheists], but grant them that everything said about God is a fiction [Sed iis non repugnemus, totumque hoc de Deo demus esse fictitium]" (CSM II, p. 14; AT VII, p. 21; my emph.), reads in Haldane and Ross as "But let us not oppose them for the present, and grant them that all that is here said of God is a fable [Mais ne leur resistons pas pour le present, et supposons que, en leur faeueur, que tout ce qui est dit icy d'vn Dieu soit une fable]" (HR I, p. 147; AT IXA, p. 16; my emph.). Given the difficulty of knowing to what extent Descartes approved or disapproved of any particular change d'Albert made in his translation, it is difficult to know if Descartes even noticed this change, let alone approved or disapproved. D’Albert's translation was published only three years before Descartes' death, however, and so there are limited possibilities to confirm this. To my knowledge, no second edition of the French translation was published within Descartes' lifetime. However, none of this argues against the claim that experience and doubt require each other.
} 
namely imagination and sensory perception," which depend on the intellect while the intellect is independent of them. These inventa depend on the intellect "because there is an intellectual act included in their essential definition" insofar as imagining and perceiving are modes of thinking. Sense perception in particular is passive as "a faculty for receiving and recognizing the ideas of sensible objects," which would be useless without an active faculty that generated the ideas. This faculty cannot be in the mind because it requires no intellectual act and cannot be in god because generating ideas of non-existing things is deceptive and god is no deceiver, so it must be in the things. Thus, things exist and sense perception's reception of them is more or less accurate and correctable by the intellect insofar as they are objects of mathematics. Non-mathematical sensory input (sight, sound, taste, touch, smell) is trustworthy insofar as god is no deceiver and insofar as responses to this input drive one toward or away from these objects, according to the pleasure or pain they may give, regardless whether that input resembles something in the object proper or whether the lack of such input indicates that there is no body in a given place (i.e., whether heat as felt is in the fire).$^{58}$ As a result, this non-mathematical input is trustworthy as to the body that it is reasonable to believe one has, to the extent that the body does not deceive.

\footnotetext{
${ }^{58}$ Here I would like to contend that Michel Henry is wrong for reasons that disagree with Lillian Alweiss's contention that he is wrong. As Alweiss explains Henry, the Cartesian cogito "goes far beyond what we call thinking" in that thinking is affective, is "accompanied by sensory awareness" (Lillian Alweiss, "The Bifurcated Subject," International Journal of Philosophical Studies 17:3 [2009], p. 423). This, in Henry's terminology, autoaffection, is demonstrated in the fact that one's own bodily sensations are only one's own, and so there is no need for another for the cogito. Thus, "In Henry's view, Descartes thereby shows how the self manifests itself without leaving itself' and 'has paved the way for what [Henry] calls a 'material phenomenology'; the self is no longer understood as an empty vessel” (ibid., pp. 424 and 425). Alweiss critiques Henry on the point of solitude here, drawing from Husserl that "a life without others and the world is not only impoverished and bereft of meaning, but remains entirely indeterminate" (ibid., p. 425). All of this eventually leads her to claim that "the subject is necessarily bifurcated. This does not mean that it is alienated, but that it has a dual nature. It is something in itself - namely a sensing bodily consciousness — and, at the same time, it is necessarily outside itself toward the world" (ibid., p. 430). I agree in the main with Alweiss's conclusions on the Cartesian self, though I put the matter in terms of a transfinitude of the imagination such that the self can engage the world anew through the fabulations which allows the self to prove itself to itself, therefore making the subject not merely bifurcated, not merely two branches, but moving between the finite and the infinite in a methodology that opens more than even two paths simultaneously (depending on the number of readers who are shown this
} 
The failure of experience to match expectations is a result of an overly dependent relationship to sensory input, and thus to the work of the imagination. It is this dependence that sets Descartes to work to figure out the simple source of knowledge such that expectations can match experience. He discovers that it is the intellect that allows him to prove the existence first of himself, then of god, then of mathematics as that which takes the material world as its object. It is for this reason that the failures of experience to match expectation, failures which inaugurated so much serious doubt in himself, seem so laughable by the end of the Meditations, and so laughable because the imagination emerges as dependent on the intellect's work to take material things as objects of mathematical truths insofar as the imagination is exposed as dependent on these things which are the objects of that with which the intellect alone is capable of working (i.e., mathematics). However, from the beginning, it is not the intellect that has inaugurated this investigation, but the imagination, insofar as its work appears to fail. In this way, the whole project begins not from the intellect, but from the imagination.

Everything depends on the imagination, including the imagination's dependence on the intellect. The failure of the imagination's expectations, the wonder of that failure of expectation, sets off an imagining of the world as other than as it presents itself, leading to self-deception and making oneself believe in the deceptive god of the evil genius, an invention of the imagination the invented quality of which leads to the conclusion that the thinking thing necessarily exists even within the potential for self-deception and in turn leads

method) such that the self forms itself. However, what Alweiss does not critique in Henry would be perhaps more problematic for him than the critique she does lay out. Henry claims that the body is in itself an immediate knowledge of the self insofar as the body "is an internal transcendental experience" (Michel Henry, Philosophy and Phenomenology of the Body, tr. Girard Etzkorn [The Hague: Martinis Nijhoff, 1975], p. 92). However, the body as a transcendental experience, as an experience of the conditions for the possibility of, in Henry's case, thinking, already enters the question of the cogito too late. The non-transcendental, non-metaphysical (in the transcendental sense) transfinite imagination inaugurates the motion that will form the mind and body such that the body can become a transcendental experience for the auto-affection of the cogito. 
to imagining what other modes of thinking there are, including imagining as dependent on the inventa of the imagination. This self-deception, this fiction is understood as deceptive in its very telling, a deception of which all readers are aware, especially if they read the letter to the faculty of the Sorbonne and even more if they read the Objections and Replies. The hyperbolic doubt, in its hyperbolicity, is an imaginary doubt, both in the sense that it is not a real or practical doubt and in the sense that it requires the imagination to occur at all. This imaginary, hyperbolic doubt is set off because of the limitations of the imagination to accurately expect the operations of the world, and so the imagination exceeds its own limitations, is transfinite, such that it is able to initiate the mental motions that will expose it as limited. The imagination, the work of the imagination, is always more and less than is imagined-more than is imagined in that it imagines the unimaginable (a world that is other than as it presents itself, a god that is no god in that it is deceptive), less in that it is dependent on the other faculties of the mind. To doubt, one must imagine, and this doubt leads to the rational conclusion that the imagination is limited, but it does so through hyperbolicity, by which the imagination throws the mind beyond itself, beyond the images it remembers and remembers as unexpected, beyond the world and its rules, such that the world can be reimagined, fabulated anew, given a new bistoire as rule-obedient according to rules generated in the telling of a story, a fiction, a work of the imagination. ${ }^{59}$

\footnotetext{
${ }^{59}$ In this way, Merleau-Ponty is correct when he identifies his 'tacit cogito' as impossible to think: "The tacit Cogito, the presence of self to self, being existence itself, is prior to every philosophy, but it only knows itself in limit situations in which it is threatened, such as in the fear of death or in the anxiety caused by another person's gaze upon me. What is believed to be the thinking of thinking, as a pure self-affection, still cannot be thought and must rather be revealed" (Maurice Merleau-Ponty, Phenomenology of Perception, tr. Donald A. Landes [New York: Routledge, 2012], p. 426). None of the tacit cogito's thinking or reduction can happen without words for him: "It is by the combination of words (with their charge of sedimented significations, which are in principle capable of entering into other relations than the relations that have served to form them) that I form the transcendental attitude, that I constitute the constitutive consciousness. . . Mythology of a selfconsciousness to which the word 'consciousness' would refer-There are only differences between significations" (Merleau-Ponty, The Visible and the Invisible, p. 171). Descartes' metaphysics falls under the category of a myth for Merleau-Ponty, though "myth, mystification, alienation etc. are second-order concepts" which follow from the presupposition of "non-mythical positivity" (ibid., p. 188). The truth in Cartesian
} 
metaphysics, as with all myths for Merleau-Ponty, is read 'between the lines; the atmosphere of Descartes' thought, the Cartesian functioning" (ibid.). 


\section{By Way of a Conclusion: An Objective Formality}

There is an odd moment in a note to Garber's Descartes' Metaphysical Physics where he criticizes Marion for going too far. Garber takes up two of Marion's positions for critique.

First, for Marion, order is "created by us," but for Garber, this is only true when dealing with "certain kinds of word games and riddles" because an order must be imposed. ${ }^{1}$ When dealing with epistemological questions of order, there is "a kind of natural and nonarbitrary order in at least the most interesting cases that the method treats," in particular citing Rule Six's demand to observe a natural order and connection between things (see CSM I, p. 22; AT X, p. 382). ${ }^{2}$ Second, for Marion, insofar as order is dependent on and created by us, and insofar as science is unified in a unified mind and as Aristotelian natures and categories become simple natures in Descartes, this allows him to claim that the Rules represents a shift "from a kind of Aristotelian realism to a kind of idealism." 3 For Garber, this claim goes too far, first, because Descartes "was certainly not pressing such a view in any explicit way" and, second, because "it is a view that seems quite distant from any of Descartes' philosophical concerns at this stage in his development."4

I hope that it is clear why I cannot bring myself to agree with Garber's first critique of Marion, but I would like to state it clearly here. There are two levels to that disagreement. The first level begins from the point that Garber himself makes, that the epistemological

\footnotetext{
${ }^{1}$ Garber, Descartes' Metaphysical Physics, p. 321n. 17.

2 Ibid.

${ }^{3}$ Ibid.

${ }^{4}$ Ibid.
} 
order "is dependent on us" because epistemological order is for him "strictly with relation to us and our ability to see truths through intuition and perform deductions." ${ }^{5}$ That Garber understands this dependence as operating through intuition and deduction does not excise it from the structure or logic of fictionalizing, or what I have called the fable-logic or -structure at work throughout Descartes' corpus, which leads to the second level of my disagreement with Garber. To name something fabular (or fictive) is not to make it untrue, least of all when the imagination's fables are what structure the capacity to observe what will be intuited and observed as intuitible and deducible. Indeed, as I hope to have made clear, to be able to distinguish between the fabular and the true in Descartes is, if not impossible, much more complicated than perhaps even Descartes himself recognized.

This point leads to why I cannot agree with the second point of Garber's critique. This disagreement has little to do with the content of the critique. It is not especially important to me here whether the Rules marks a significant conceptual shift in the history of Descartes' intellectual development. What is important is what Garber writes when introducing his disagreement with Marion: "While it may perbaps be a philosophical consequence of the position Descartes took, he was certainly not pressing such a view in any explicit way." Garber seems to take this point as damning in itself, which is, at best, a questionable position. Indeed, Marion himself seems to have an at least oblique response to this critique in the Preface to the American Edition of On Descartes' Metaphysical Prism. There, he distinguishes the history of philosophy from the history of ideas, where "the former implies a philosophical vision while the latter attempts to get by without one (perhaps without succeeding). Further, not only does the history of philosophy imply a philosophical

\footnotetext{
5 Ibid., pp. 321n. 17 and 39.

${ }^{6}$ Ibid., p. 321n. 17; my emphasis.
} 
experience, but, reciprocally, philosophy always implies, in each moment of its evolution, a reappropriation of history." ${ }^{7}$ In addition, Marion works on the assumption that "there is no contradiction between, on the one hand, a conceptual, speculative, and even (within certain limits) systematic interpretation of an author and, on the other, erudition," which is why it is possible for him to deploy Kantian, Hegelian, Husserlian, Heideggerian, and Nietzschean “interpretive models" to understand "certain of Descartes' most difficult texts," and to understand them as well as or better "than the troops of critics who pride themselves on ignoring the contributions of these philosophers."

A more direct response to the critique of Marion by Garber emphasized above could very well be to ask why this suffices as a critique. Neither the fact that Descartes does not explicitly take such a position nor that it may be distant from his explicit concerns at this stage in his career seem to me to account for the fact that Marion's position might be a philosophical consequence of what Descartes does in fact state, of that with which he is in fact concerned. There are few things less philosophically interesting than being right. Being wrong is one of them, but that is not the concern here since, by Garber's own admission, Marion's position may very well be philosophically tenable.

To be fair, Garber does offer a defense of his approach to historical philosophical texts. He claims it to be complementary to the approach which thinks "the history of philosophy is a kind of storehouse of positions and arguments" from which we can take what we want as needed, even the false or failed arguments and positions, insofar as they

\footnotetext{
${ }^{7}$ Jean-Luc Marion, On Descartes' Metaphysical Prism, p. xi.

8 Ibid., p. xiii.
} 
teach something about a philosophical truth. ${ }^{9}$ Garber's complementary approach, which he calls a disinterested history, seeks out not philosophical truth but philosophical questions, specifically questions where we ask ourselves why we believe certain truths to be clear which those past masters whom we study did not. These questions are clarified and specified when the historian of philosophy attempts "to learn historical figures on their own terms." ${ }^{10}$ Indeed, he finds a similarity between this distinterested history of philosophy and anthropological field work to the extent that there is a process where, at the beginning, "it is all very alien," then "the language and customs become familiar, and one is inclined to think that the differences are only superficial," and finally "the similarities and differences come into focus."11

Yet it is in this very comparison to anthropological fieldwork that the problem with Garber's approach comes to the fore, an approach which leads him to criticize Marion for drawing philosophical conclusions from Descartes' philosophy with which Descartes himself might have disagreed. For Garber, the history of philosophy is an objective science (in a perhaps broader sense than normally used in contemporary language, though in a narrower sense than in other eras). Therefore, the study of that science, of historical philosophical figures (or at least their works), is a study of objects. History, historical figures, and historical texts are objects for Garber, observable phenomena with empirical contestability, distinct from the observer, even if he questions the separation of philosophy and science based on the idea that "philosophy makes use of conceptual analysis, whereas science makes use of

\footnotetext{
${ }^{9}$ Garber, "Does History have a Future? Some Reflections on Bennett and Doing Philosophy Historically," in Descartes Embodied, p. 14.

${ }^{10}$ Ibid., p 23.

${ }^{11}$ Ibid., p. 30.
} 
observation and experience," at least for seventeenth-century thinkers. ${ }^{12}$ It never seems to occur to Garber, however, that history is not something from which the observer can ever extract him- or herself, that it is always at work on the observer and observed even in the interpretation of historical facts. For these reasons, perhaps, Garber demands that philosophers, historians of philosophy, and/or historical philosophers ask themselves why and how history is important to philosophy, but never, at least in this essay, does he ask that originary philosophical question, "What is history?" If history is not an object in the way a book (as distinct from a text) is, but rather a concept at work in its practice, then the history of philosophy as a science is already collapsing the contemporary distinction between philosophy and science insofar as what is observed is itself conceptual. Then, what Garber attempts to make objective, the history of philosophy or historical philosophy, would resist said objectivity insofar as the history of philosophy is always already participating in the conceptual work that philosophy, whether historical or not, demands.

If the above is correct, at least as concerns the history of philosophy or historical philosophy, it would explain Garber's rejection or critique of Marion's drawing out legitimate philosophical consequences from Cartesian positions on the grounds that Descartes would not himself have drawn those consequences. For Garber, the Cartesian corpus appears in a certain way to be a corpse. Much can be learned about and from the corpse, much can be seen when it is autopsied or exhumed that has been lost, but it remains a corpse. ${ }^{13}$ All this would be well and good were the Cartesian corpus an actual corpse, but it is not, and treating it as such is to deny one's involvement in the thing being objectified, which may ultimately rely on a problematic concept of subject and object when it comes to historical readings of

\footnotetext{
12 Ibid., p. 25.

${ }^{13}$ Garber even suggests that he is not interested in "mak[ing] philosophy breathe" (ibid., p. 18).
} 
philosophy, if only because the systematics and consequences at work in the texts can only be what the history, the history qua object, has already told us. With Descartes in particular, it may be all the more problematic in that it may be an ahistorical, retroactive imposition of post-scientistic, or at least post-Kantian, concepts of subject and object upon a philosopher for whom the distinction is never articulated quite as clearly, quite as dogmatically as would seem to be implied by Garber's association of the history of philosophy with anthropological fieldwork. Indeed, in terms of Descartes, such an imposition could even mark a violation of Garber's imperative for distinterested history to think on the thinker's terms, or to think along with Descartes.

Perhaps, then, a better way to think along with Descartes, a more Cartesian way to think what is at stake in philosophical interpretation of historical philosophical texts, or at least Cartesian texts, is to turn to how Descartes thinks about objects, and what those objects teach about what causes them-in other words, to turn to objective and formal reality (or perfection or being). Even if this is a dead concept, a failed philosophical object held in philosophy's historical storehouse, there is no need to turn to objective and formal reality because these concepts can 'teach' us something about Descartes insofar as it is a failure. Rather, it is helpful to turn to it because objective and formal reality were living concepts for Descartes and their application to an interpretation of Descartes can illuminate or breathe Cartesian life into said interpretation.

In the Third Meditation and the Principles, Descartes gives the famous first proof for the existence of god. The argument runs as follows: If we take ideas not as modes of thinking but as representations of things, they differ from each other on a scale of objective 
reality (or perfection or being), on a scale of perfection qua object. ${ }^{14}$ Since ideas are representations, they are themselves things and therefore also have some degree of objective reality. All things are caused by something. The thing which causes other things has formal reality (or perfection or being), which also exists on a scale of perfection. The more perfect the causing thing, the more formal reality it has. According to the Third Meditation, "it is manifest by the natural light that there must be at least as much reality in the efficient and total cause as in the effect of that cause" (CSM I, p. 28; AT VII, p. 40) and, according to the Principles, "it is evident by the natural light ... that what is more perfect cannot be produced by...what is less perfect” (CSM I, p. 199; AT VIII-A, pp. 11-12; pt. 1, art. 18). Thus, to whatever degree an idea is objectively perfect, the thing that the idea represents must itself be at least as perfect in its formal reality since the idea is caused by, is the effect of, the thing which the idea represents. ${ }^{15}$ Descartes gives this position some more nuance when he writes in a letter to Mersenne, dated March 1642, that, "although the objective being of an idea must have a real cause, it is not always necessary that this cause should contain it formally, but only eminently" (CSM-K, p. 211; AT III, p. 544). This claim then means that it is not necessary for god to have the precise types or modes of perfection of physical objects in a formal sense-i.e., that god contain in the godhead any physical characteristics-because god can cause such things eminently—i.e., from a more perfect or higher form.

\footnotetext{
14 As Grene points out, Descartes' use of objective and formal reality is "peculiar" in comparison to the Scholastic tradition from which he draws it (Grene, Descartes among the Scholastics, p. 12). She concludes that he must have "held at the back of his mind a rather mixed conceptual apparatus, derived from a variety of scholastic sources" which he would have learned as a student, including Thomas Cajetan, Suàrez, Gabriel Vasquez, and Durand of St.-Pourçain (ibid., p. 14).

15 To complete the proof of the existence of god, this means that the idea of god, since it is the idea of a being with all perfections, cannot be more perfect than that which it represents (which cannot be the self since the self does not think of itself as having all perfections), and so god must have both caused this idea and be at least as perfect as having all perfections.
} 
What is more important than the details of this argument is the now-debunked theory of causation at work in this crucial moment in the Cartesian corpus. If this is the theory of causation at work, then it would appear legitimate, or at least not ahistorical, to apply such a theory back upon the corpus itself.

This has been a work of effects. It has been a work that considers the effect that attending to Descartes' use and mention of the fable has on the traditional conceptualizations of Cartesian method and imagination. This is not to say that the fable has a formal reality that causes the objective realities of the method and imagination. Rather, attending to the fable, gaining an idea of what the fable is and how it functions in Descartes, has an effect on our ideas of Cartesian method and imagination. If anything, the fable would itself have an objective reality that would be an effect of an overlooked formal reality on the part of the imagination. However, the imagination's formal reality — as a transfinite faculty which establishes the faculties of reason, will, imagination, etc.-can only be understood through an understanding of the method, the analytically reductive method, as affected by a fable-structure or -logic. Thus, the fable has a formal reality which brings about the objective reality of the method at the same time that the fable also has an objective reality brought about by the formal reality of the imagination, even while the imagination's formal reality can only be understood via the method's objective reality. It is for this reason that attending to the fable, as well as extending the idea of it, needed to occur first and that the effect that the fable has on the idea of the method needed to occur second. It is only once it has become clear that the fable is a rhetorical device at work throughout the Cartesian corpus, one which runs to the very inaugural points of Cartesian philosophy proper, that the method can become understood as interwoven with the very synthetic and syllogistic elements which Descartes would otherwise disdain. That these synthetic and syllogistic elements operate in 
the service of a fable which allows for the imagining of a new world, new human beings, and the very possibility of learning as such thus shows that the imagination's role is more complicated than Descartes would seem to have himself believed, even more complicated than the biplanar structure offered up by contemporary interpretations. The fable-structure or -logic which runs to the very heart of Descartes' work and the attending to which exposes the method as more complicated than it would at first appear is possible only because the imagination is able to exceed the bounds which it itself sets for itself. This operation of exceeding is what makes the imagination neither a metaphysical nor a transcendental faculty. It is not metaphysical because there is always an element of the finite in it - it is not infinite in the way the will is - and it is not transcendental because it does not establish the conditions for the possibility of experience for the other faculties. The imagination, as excessive of itself, moves, shifts, transitions between the finite and the infinite. This is what is meant by calling it a transfinite faculty. It accomplishes this transfinite movement by means of a fable, and especially those fables that imagine new worlds and new humans that happen to coincide exactly with how they have been experienced. Yet, to make sense of this understanding of the imagination, it was necessary to affect, to cause a change in, the understanding of the method such that an analytic reduction is never taken for a reduction to simples in the way that Descartes, or at least Cartesians, assumed. Within the language of Descartes' philosophy proper, seeing that the method is never precisely methodological, but is always split in at least two directions, is always schismatic-whether in reference to readers, to history, or to oneself — is most clearly and distinctly achieved through attending to the language and meaning of the concept of the fable for Descartes.

In sum, then: Method can never simply inaugurate itself because it would always already need to have been justified, but method is also always a method of justification. In 
the beginning and end of Descartes' career, as well as throughout it, there are consistent references to works of the imagination, in particular fables. Fables have always been associated with rhetorical and pedagogical tropes, in addition to being works of the imagination, but in ways distinct from other, similar literary forms like folktales, fairy tales, and myths. Descartes' is a time where the form and content of education is in flux, which distinguishes his time from later periods, in particular the nineteenth century, but brings it closer to other periods, in particular the twentieth century. It is for this reason that an assessment of the Cartesian fable from the perspective of a period where so much is in flux seems called for. In the earliest Cartesian fable, The World, the fable is associated with light insofar as both are rule-generative and rule-obedient as concerns the mind and the elements, respectively, but is dissociated from poetry insofar as this is associated with the chaos that precedes the divine inaugural movement which creates the world. In the Discourse, the fable is associated with histoire, taken in both its possible translations, which all the more associates it with an inauguration of a new form of pedagogy, whereby one learns to unlearn what one has learned and, simultaneously, to instruct oneself. This association with histoire justifies a more expansive view on what the Cartesian fable would be and how it would operate, thus allowing it to be linked with the treatise, the dialogue, hypothesis, and the novel, which is how Descartes characterizes in different ways at different moments throughout his career various of his works, though they all begin with the concern for how to begin to unlearn and learn. Through such expansion of the fable, it is possible to make sense of the deception and self-deception involved in hyperbolic doubt as a methodologization of the fable, making the fable a logic or structure at the heart of the Cartesian project, and making hyperbole the most serious approach to Descartes' philosophy even and especially at its apparently least serious moments. As a result of attending to how the fable structures or gives logic to the 
Cartesian project, the method can no longer appear as a simple analytic reduction to the simples of the self, god, or geometric essences, but is constantly interwoven with the synthesis Descartes would seemingly reject. This complex relationship between analysis and synthesis then knots the inexactness of history and etymology up with the seemingly exact sciences that would presume to strictly follow the assumptions of Cartesian analysis, because there is a consistent reference to the literary and politico-religious history involved with the descriptions of the development of the method. This relationship between the exact and inexact sciences then exposes a supplementarity between justifications for the ordering of the life of the metaphysician and that of practical life, which in turn exposes a similar supplementarity between rule-generation and rule-obedience, which is what the fable exposed as early as The World. The complexity, interwovenness, and supplementarity at hand in the method, shown as an effect of attending to the fable, then gives way to an understanding of the Cartesian mind as precisely not pre-formed into distinct and discrete faculties, which is precisely why the fable and the method can operate with the complicated relationship between rule-obedience and rule-generation that they do. To be clear about this, it was necessary to show how Descartes' conception of physical space as plenum then necessarily applies to the imaginary space wherein the fable of The World is told, meaning that the imagination does exist in a biplanar fashion. Rather, the imagination is able to move between the infinity of the will and the finitude of intellectual perception, which an examination of the passion of wonder exposes, thereby making the imagination a transfinite faculty that exceeds the limitations it places upon itself. Ultimately, this means that the serious work of the imagination is in its apparently comic unseriousness, where it appears to depend on the work of the intellect, when in fact even the intellect depends on the 
imagination to imagine what would seem to be unimaginable in order for the intellect and will to have the capacity for judging.

I would thus like to end approximately where I began, with the Weenix portrait, made so near Descartes' end. What are we to make of this portrait? It is in many ways typical of the Dutch Golden Age. Descartes is shown from the waist up, in modest black clothing except a white collar, against a plain background. However, in some ways it breaks from some of the traditions. The background is significantly lighter, gray or even brown, and so does not achieve the full chiaroscuro vision of the Renaissance or some other Dutch Masters. In addition, Descartes the scientist and mathematician is not shown with the instruments of his fame. Instead, he is shown holding a book in his hands- they do not appear to be glovednearly gray themselves, with the words "Mundus EST fabula" visible on the verso page. Descartes' head is cocked to the side, his eyes gazing at us, his thin hair flowing, and the beginnings of jowls forming. He looks serious, or perhaps deadpan, with the slightest hint of a smile creeping in the right corner of his mouth. So what are we to make of this portrait?

Mundus est fabula. The world is a fable. What is said, signified in these words, what story told? The copula connects subject and direct object in something of an equation of nominatives. The world is a story, it signifies something, tells the story of itself. The world is its own moral, generates its own narrative rules. This sentence, this moral for the world that is a fable, signifies that the rules of the world remain that: rules, which can be generated as well as obeyed, and both in the same gesture. This makes the fable, then, equal to the world. Fabula est mundus. The fable is a world. Here is the ultimate result of all Descartes' analytic reduction, to find, at the end, that the world is a fable and the fable is a world, a world unto itself, a world of the imagination. It is thanks to the imaginative fable that the world becomes 
as such, that it comes to be the world, a world whose rules can be discovered. The story of the world, the story that is the world, remains words in a book, held in the hands of a man who was soon to be dead. These words, this equation, "Mundus EST fabula," need not resemble what they or it signify, the world or the fable, and they do not insofar as they remain the moral of the fable that is the Cartesian world. And yet they do resemble what they signify insofar as they, as words, are things, and things that signify words themselves, the words of stories and fables. So here, in this final statement, this final fable, Descartes (or perhaps Weenix, who would then be the greatest Cartesian of all) signifies the words that are the world and the world of words as fabular, words signifying only themselves and, in so doing, are in fact the world itself. Words are things, things are words, mundus est fabula, fabula est mundus. 


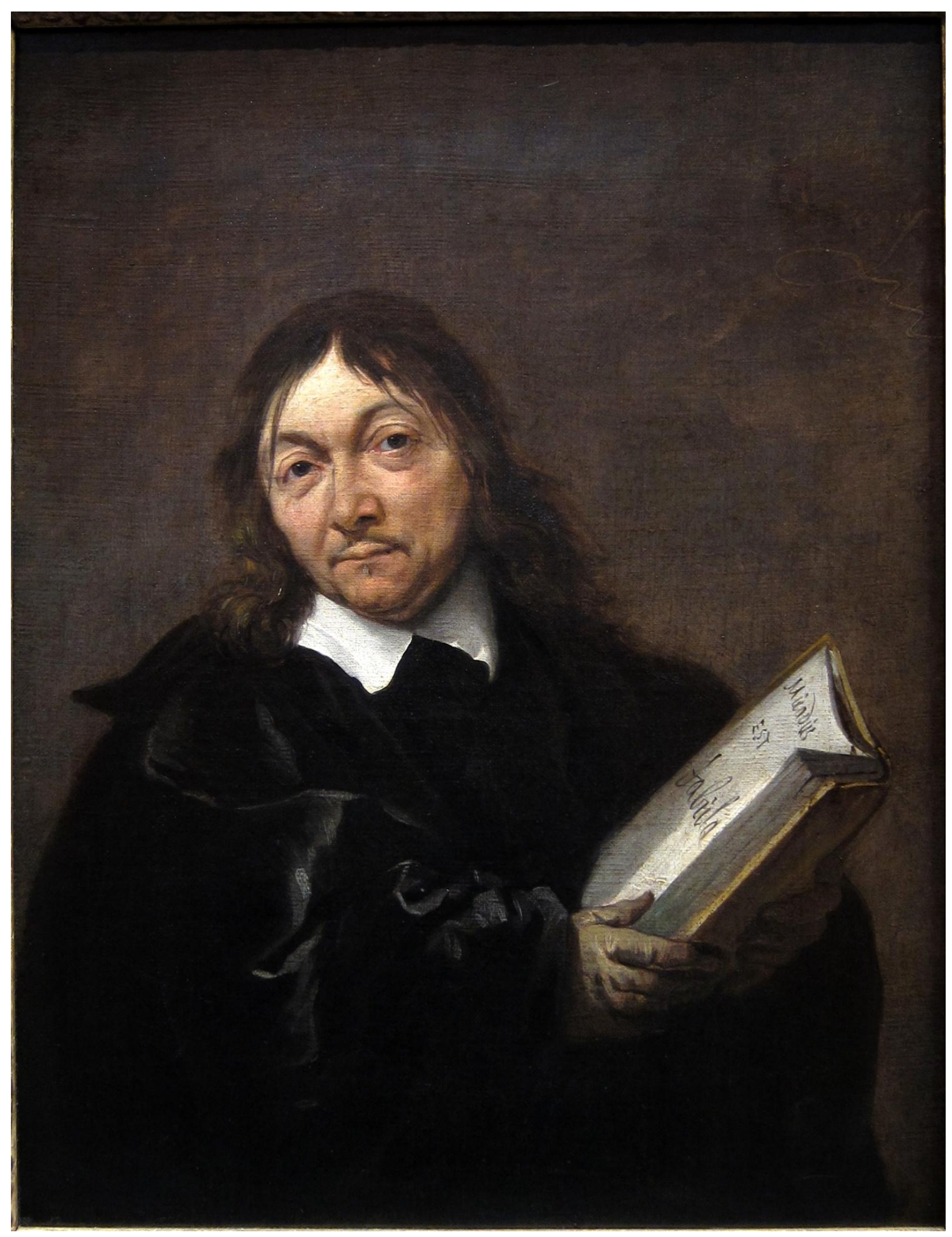

Jan Baptist Weenix, Portrait of René Descartes (1647-1649), Centraal Museum, Utrecht, Netherlands 


\section{Bibliography}

Aesop, The Complete Fables, tr. Olivia and Robert Temple (New York: Penguin Books, 1998).

Alweiss, Lilian, “The Bifurcated Subject,” International Journal of Philosophical Studies 17:3 (2009), pp. 415-434.

Ariew, Roger, "Descartes's Fable and Scientific Methodology," Annales Internationales d'Histoire des Sciences 55 (2005), pp. 127-138.

— , and Marjorie Grene, "Ideas, in and before Descartes," Journal of the History of Ideas 56:1 (1995), pp. 87-106.

—, Dennis Des Chene, Douglas M. Jesseph, Tad M. Schmaltz, and Theo Verbeek, Historical Dictionary of Descartes and Cartesian Philosophy (Lanham, MD: The Scarecrow Press, 2003).

Aristotle, Aristotle's Physics, tr. Hippocrates G. Apostle (Grinnell, IA: The Peripatetic Press, 1980).

_- Aristotle's Posterior Analytics, tr. Hippocrates G. Apostle (Grinnell, IA: The Peripatetic Press, 1981).

$\longrightarrow$, De Anima.

- Rhetoric, tr. W. Rhys Roberts, in The Rhetoric and the Poetics of Aristotle, tr. W. Rhys Roberts and Ingram Bywater (New York: Random House, Inc., 1984).

Baillet, Adrien, The Life of Monsieur Des Cartes, Containing the History of his Philosophy and Works: as also, The most Remarkable Things that befell him during the whole Course of his Life (abridged), tr. S. R. (1693).

— La Vie de Monsieur Des-Cartes, 2 vols., (1691).

Becker, Marvin B., The Emergence of Civil Society in the Eighteenth Century: A Privileged Moment in the History of England, Scotland, and France (Bloomington, IN: Indiana University Press, 1994).

Bellarmine, Cardinal Robert, "Bellarminus ad Foscarini 12.04.1615,” http://apologia.sk/1615-04-12, accessed 3/25/2013.

Bennington, Geoffrey, Sententiousness and the Novel: Laying Down the Law in Eighteenth-Century French Fiction (2008).

Bergoffen, Debra B., "Cartesian Doubt as Methodology: Reflective Imagination and Philosophical Freedom," Proceedings of the American Catholic Philosophical Association 50 (1976), pp. 186-195.

Bettelheim, Bruno, The Uses of Enchantment: The Meaning and Importance of Fairy Tales (New York: Vintage Books, 2010). 
Blanchot, Maurice, The Station Hill Blanchot Reader, tr. Lydia Davis, Paul Auster, and Robert Lamberton, ed. George Quasha (Barrytown, NY: Station Hill Press, 1999).

- The Infinite Conversation, tr. Susan Hanson (Minneapolis, MN: The University of Minnesota Press, 1993).

$\longrightarrow$, L'Entretien Infini (Paris: Éditions Gallimard, 1969).

Blizman, James, "Models, Analogies, and Degrees of Certainty in Descartes," The Modern Schoolman 50 (1973), pp. 183-208.

Bloch, Marc, The Historian's Craft, tr. Peter Putnam (New York: Vintage Books, 1964).

Blumenberg, Hans, Work on Myth, tr. Robert M. Wallace (Cambridge, MA: The MIT Press, 1985).

Bok, Sissela, Secrets: On the Ethics of Concealment and Revelation (New York: Vintage Books, 1984).

Bottigheimer, Ruth B., Fairy Tales: A New History (Albany, NY: SUNY Press, 2009).

Brann, Eva T.H., The World of the Imagination: Sum and Substance (Lanham, MD: Rowman \& Littlefield Publishers, Inc., 1991).

Brewer, Daniel, “The Philosophical Dialogue and the Forcing of Truth,” MLN 98:5 (1983), pp. 1234-1247.

Brogan, Walter, and James Risser, eds., American Continental Philosophy: A Reader (Bloomington, IN: Indiana University Press, 2000).

Buchdahl, Gerd, Metaphysics and the Philosophy of Science: The Classical Origins, Descartes to Kant (Oxford: Basil Blackwell, 1969).

Bulfinch, Thomas, Bulfinch's Mythology: The Age of Fable (1855).

Burnett, D. Graham, Descartes and the Hyperbolic Quest: Lens Making Machines and Their Significance in the Seventeenth Century (Philadelphia: American Philosophical Society, 2005).

Bossuyt, Ignace, Nele Gabriëls, and Demmy Verbeke, eds., Cui Dono Lepidum Novum Libellum?: Dedicating Latin Works and Motets in the Sixteenth Century (Leuven: Leuven University Press, 2008).

Carter, Richard B., "Ethics as Drawn from the Method,” Philosophica 46:2 (1990), pp. 107-117.

Cavaillé, Jean-Pierre, Descartes: La Fable du Monde (Paris: Librairie Philosophique J. Vrin, 1991).

- "Politics Disavowed: Remarks on the Status of Politics in the Philosophy of Descartes," tr. R. Scott Walker, Diogenes 35 (1987), pp. 118-138.

Cicero, De Inventione, De Optimum Genere Oratorum, and Topica, tr. H. M. Hubbell (Cambridge, MA: Harvard University Press, 2006).

Cottingham, John, The Rationalists (New York: Oxford University Press, 1988).

__, "The Role of the Malignant Demon," Studia Leibnitiana 8:2 (1976), pp. 257-264. 
Daniel, Stephen H., “The Nature of Light in Descartes' Physics," The Philosophical Forum 7:3-4 (1976), pp. 323-344.

—_, "Descartes on Myth and Ingenuity/Ingenium," The Southern Journal of Philosophy 23:2 (1985), pp. 157-170.

__, "Descartes' Treatment of 'lumen naturale'," Studia Lebnitiana 10:1 (1978), pp. 92-100.

Deleuze, Gilles, Empiricism and Subjectivity: An Essay on Hume's Theory of Human Nature, tr. Constantin V. Boundas (New York: Columbia University Press: 1991).

—, Expressionism in Philosophy: Spinoza, tr. Martin Joughin (New York: Zone Books, 1990).

_- Spinoza et le problème de l'expression (Paris: Les Editions de Minuit, 1968).

Derrida, Jacques, Acts of Literature, ed. Derek Attridge (New York: Routledge, 1992).

—, The Beast and the Sovereign, tr. Geoffrey Bennington, ed. Michel Lisse, Marie-Louise Mallet, and Ginette Michaud, 2 vols. (Chicago: University of Chicago Press, 2009-2010).

— Du droit à la philosophie (Paris: Éditions Gallilée, 1990).

— L'écriture et la difference (Paris: Éditions du Seuil, 1967).

—, Eyes of the University: Right to Philosophy 2, tr. Jan Plug and Others, (Stanford, CA: Stanford University Press, 2004).

—_, "La langue et le discours de la méthode," Recherche sur la philosophie et le langage: Cabier du Groupe de recherches sur la philosophie et le langage 3 (1983), pp. 35-51.

—, Of Grammatology, tr. Gayatri Chakravorty Spivak (Baltimore, MD: The Johns Hopkins University Press, 1997).

—, Psyche: Inventions of the Other, vol. 1, ed. Peggy Kamuf and Elizabeth Rottenberg (Stanford, CA: Stanford University Press, 2007).

- Séminaire: La bête et le souverain, 2 vols., ed. Michel Lisse, Marie-Louise Mallet, and Ginette Michaud (Paris: Galilée, 2008-2009).

—, Writing and Difference, tr. Alan Bass (Chicago: University of Chicago Press, 1978).

Descartes, René, “1616 Law Thesis-English Translation,” tr. Holly Johnson and Kurt Smith, http://plato.stanford.edu/archives/fall2005/entries/descartes-works/tenglish.html, accessed 1/30/2008.

_- "1616 Law Thesis_Latin Transcription,” http://plato.stanford.edu/entries /descartesworks/tlatin.html, accessed 11/1/2010.

, "Descartes to Marin Mersenne, [Endegeest castle] 27 May 1641," tr. Erik-Jan Bos, Charles Roberts Autograph Collection, Haverford College, Haverford, PA, http://www.phil.uu.nl/ bos/transcript shtml, accessed 8/6/2012. 
—, Descartes' Conversation with Burman, tr. John Cottingham (Oxford: Clarendon Press, 1976).

- Discours de la Méthode: Texte et Commentaire par Étienne Gilson (Paris: Librairie Philosophique J. Vrin, 1947).

$\longrightarrow$, Discourse on Method, tr. Donald A. Cress (Indianapolis, IN: Hackett Publishing Company, Inc., 1998).

—, Discourse on Method, Optics, Geometry, and Meteorology, tr. Paul J. Olscamp (Indianapolis, IN: Hackett Publishing Company, Inc., 2001).

- Oewres de Descartes, ed. Charles Adam and Paul Tannery, 12 vols. (Paris: Librairie Philosophique J. Vrin, 1897-1913).

- The Philosophical Writings of Descartes, tr. John Cottingham, Robert Stoothoff, Dugald Murdoch, and Anthony Kenny, 3 vols., (Cambridge: Cambridge University Press, 19841991).

—, The Philosophical Works of Descartes, tr. Elizabeth S. Haldane and G. R. T. Ross, 2 vols. (Cambridge, University of Cambridge Press: 1985).

- Règles Utiles et Claires pour la Direction de l'Esprit en la Recherche de la Vérité, tr. Jean-Luc Marion, conceptual notes Jean-Luc Marion, mathematical notes Pierre Costabel (The Hague: Martinus Nijhoff, 1977).

—, The World, or Treatise on Light, tr. Michael S. Mahoney, http://princeton.edu/ hos/ mike/texts/descartes/world/world.htm, accessed 1/10/2008.

—, Treatise of Man, tr. Thomas Steele Hall (Amherst, NY: Prometheus Books, 2003).

Du Bartas, Guillaume de Salluste, La Sepmaine; ou, Creation du Monde (1581).

Dunn, Kevin, “'A Great City Is a Great Solitude’: Descartes’s Urban Pastoral,” Yale French Studies 80 (1991), pp. 93-107.

Elisabeth of Bohemia, Princess Palatine, and René Descartes, The Correspondence between Princess Elisabeth of Bohemia and René Descartes, ed. and tr. Lisa Shapiro (Chicago: The University of Chicago Press, 2007).

Estienne, Robert, Dictionnaire françois-latin (1594).

Fink, Eugen, Sixth Cartesian Meditation: The Idea of a Transcendental Theory of Method, tr. Ronald Bruzina (Bloomington, IN: Indiana University Press, 1995).

Flynn, Bernard Charles, "Descartes and the Ontology of Subjectivity," Man and World: An International Philosophical Review 16:1 (1983), pp. 3-23.

Fontenelle, Bernard le Bovier de, "De l'origine des fables," http://www.eliohs.unifi.it/testi L700/fontenelle/fables.htm, accessed 5/28/2013. 
Fòti, Véronqiue M. “The Cartesian Imagination,” Philosophy and Phenomenological Research 46:4 (1986), pp. 631-642.

Foucault, Michel, Aesthetics, Method, and Epistemology: Essential Works of Foucault, 1954-1984, vol. 2, ed. James D. Faubion (New York: The New Press, 1998).

—, The History of Madness, tr. Jonathan Murphy (Oxford: Routledge, 2006).

— Les mots et les choses: Une archéologie des sciences humaines (Paris: Éditions Gallimard, 1966).

- The Order of Things: An Archeology of the Human Sciences, tr. unnamed (New York: Vintage Books, 1994).

France, Marie de, The Fables of Marie de France: An English Translation, tr. Mary Lou Martin (Birmingham, AL: Summa Publications, Inc., 1984).

Easton Patricia A., ed., Logic and the Workings of the Mind: The Logic of Ideas and Faculty Psychology in Early Modern Philosophy, North American Kant Society Studies in Philosopby 5 (1997).

Gadamer, Hans-Georg, Philosophical Hermeneutics, ed. and tr. David E. Linge (Berkeley, CA: University of California Press, 2008).

Galilei, Galileo, The Essential Galileo, ed. and tr. Maurice A. Finocchiaro (Indianaoplis, IN: Hackett Publishing Company, Inc., 2008).

_-, Dialogo sopra i due massimi sistemi (Turin: Giulio Einaudi editore, 1970).

Garber, Daniel, Descartes Embodied: Reading Cartesian Philosophy through Cartesian Science (Cambridge, UK: Cambridge University Press, 2001).

—, Descartes’ Metaphysical Physics (Chicago: The University of Chicago Press, 1992).

and Steven Nadler, eds., Oxford Studies in Early Modern Philosophy, vol. 3 (Oxford: Clarendon Press, 2006).

Gaukroger, Stephen, Descartes: An Intellectual Biography (Oxford: Clarendon Press, 1995).

— ed., Descartes: Philosophy, Mathematics, and Physics (Sussex, NJ: The Harvester Press, 1980).

Gilson, Étienne, Index Scolastico-Cartésien (New York: Burt Franklin, 1964 [Paris: 1912]).

Goclenius, Rudolph, Lexicon philosophicum (1613).

Grene, Marjorie, Descartes among the Scholastics, (Milwaukee, WI: Marquette University Press, 1991).

Grimm, Jacob, and Wilhelm Grimm, The Complete Grimm's Fairy Tales, tr. Margaret Hunt and James Stern (New York: Pantheon Books, 1972).

Hegel, G. W. F., Aesthetics: Lectures on Fine Art, tr. T. M. Knox, vol. 1 (Oxford: Clarendon Press, 1975).

Henry, Michel, Philosophy and Phenomenology of the Body, tr. Girard Etzkorn (The Hague: Nijhoff, 1975). 
Heidegger, Martin, Being and Time, tr. John Macquarrie and Edward Robinson (Malden, MA: Blackwell Publishing Inc., 1962).

- Kant and the Problem of Metaphysics, tr. Richard Taft, 5 ed., enlarged (Indianapolis, IN: Indiana University Press, 1997).

—, Kant und das Problem der Metaphysik (Frankfurt am Main: Vittorio Klostermann GmbH, 1951).

— Parmenides, tr. André Schuwer and Richard Rojcewicz (Bloomington, IN: Indiana University Press, 1992).

—, Sein und Zeit (Tübingen: Max Neimeyer Verlag, 1967).

Holzberg, Niklas, The Ancient Fable: An Introduction, tr. Christine Jackson-Holzberg (Bloomington, IN: Indiana University Press, 2002).

Hugh of St. Victor, Six Opuscules Spirituels, ed. Roger Baron (Paris: Editions du Cerf, 1969).

Husserl, Edmund, Cartesian Meditations: An Introduction to Phenomenology, tr. Dorion Cairns (Boston: Kluwer Academic Publishers, 1999).

—, Cartesianische Meditationen: Eine Einleitung in die Phänomenologie und Pariser Vorträge, in Husserliana, vol. 1, ed. Stephan Strasser (The Hague: Martinus Nijhoff, 1963).

Jesuit Ratio Studiorum of 1599, The, tr. Allan P. Farrell, S. J. (Washington, DC: Conference of Major Superiors of Jesuits, 1970).

Judovitz, Dalia, “Autobiographical Discourse and Critical Praxis in Descartes," Philosophy and Literature 5:1 (1981), pp. 91-107.

Kant, Immanuel, Critique of Judgment, tr. Werner S. Pluhar (Indianapolis, IN: Hackett Publishing Company, Inc., 1987).

—, Critique of Pure Reason, unabridged ed., tr. Norman Kemp Smith (New York: St. Martin's Press, 1965).

—, Kritik der reinen Vernunft, ed. Thomas Valentiner, in Sämtliche Werke, eds. Otto Buek, et al., vol. 37 (Leipzig: Verlag von Feliz Meiner, 1919).

—, Prolegomena to Any Future Metaphysics and the Letter to Marcus Herr, February 1772, 2 ed., tr. James W. Ellington (Indianapolis, IN: Hackett Publishing Company, Inc., 2001).

Keefer, Michael H., “The Dreamer's Path: Descartes and the Sixteenth Century,” Renaissance Quarterly 49:1 (1996), pp. 30-76.

Kirkeboen, Geir, 'Descartes' Psychology of Vision and Cognitive Science: The 'Optics' (1637) in the Light of Marr's (1982) 'Vision',” Philosophical Psychology, 11:2 (1998), pp. 161-182.

Kuhn, Thomas S., The Structure of Scientific Revolutions, 3 ed. (Chicago: University of Chicago Press, 1996). 
Kukenheim, Louis and Henri Roussel, Guide de la Litterature Française du Moyen Age, 3 ed., (Leiden: Universitaire Pers Leiden, 1963).

Kuspit, Donald B., "Epoché and Fable in Descartes," Philosophy and Phenomenological Research 25:1 (1964), pp. 30-51.

Lacoue-Labarthe, Philippe, The Subject of Philosophy, ed. Thomas Trezise, tr. Thomas Trezise, et al., (Minneapolis, MN: University of Minnesota Press, 1993).

La Fontaine, Jean de, Selected Fables/Fables Choisies: A Dual-Language Book, ed. and tr. Stanley Applebaum (Mineola, NY: Dover Publications, Inc., 1997).

Le Bossu, René, Parallele des Principes de la Physique d'Aristote et de celle de René Des Cartes (1674).

—_, Traité du Poëme Epique (1708).

Le Robert: Dictionnaire des Synonymes et Nuances.

Lewis, Charlton T., and Charles Short, A Latin Dictionary (1879).

Liddell, Henry George, and Robert Scott, A Greek-English Lexicon, revised and augmented by Sir Henry Stuart Jones and Roderick McKenzie (Oxford: Clarendon Press, 1940).

Locke, John, An Essay concerning Human Understanding, abridged and ed. John W. Yolton (London: J. M. Dent, 1996).

Macbeth, Danielle, "Viète, Descartes, and the Emergence of Modern Mathematics," Graduate Faculty Philosophy Journal, 25:2 (2004), pp. 87-117.

Magnus, Bernd, and James B. Wilbur, eds., Cartesian Essays: A Collection of Critical Studies (The Hague: Martinus Nijhoff, 1969).

Mandeville, Bernard, The Fable of the Bees (New York: Penguin Books, 1970).

Marion, Jean-Luc, On the Ego and on God: Further Cartesian Questions, tr. Christina M. Gschwandtner (New York: Fordham University Press, 2007).

, "Is the Ontological Argument Ontological? An Argument According to Anselm and Its Metaphysical Interpretation According to Kant," Journal of the History of Philosophy 30:2 (1992), pp. 201-218.

—, On Descartes' Metaphysical Prism: The Constitution and the Limits of Onto-theo-logy in Cartesian Thought, tr. Jeffrey L. Kosky (Chicago: The University of Chicago Press, 1999).

Maull, Nancy L., "Cartesian Optics and the Geometrization of Nature," Review of Metaphysics, 32:2 (1978), pp. 253-273.

Merleau-Ponty, Maurice, The Visible and the Invisible: Followed by Working Notes, tr. Alphonso Lingis (Evanston, IL: Northwestern University Press, 1968).

—, Phenomenology of Perception, tr. Donald A. Landes (New York: Routledge, 2012). 
Meyering, Theo C., Historical Roots of Cognitive Science: The Rise of a Cognitive Theory of Perception from Antiquity to the Nineteenth Century (Dordrecht, Netherlands: Kluwer Academic Publishers, 1989).

Morin, Marie-Eve, Jean-Luc Nancy (Cambridge: Polity Press, 2012).

Na-Hakdan, Berechiah, Fables of a Jewish Aesop, tr. Moses Hadan (Boston: Nonpareil Books, 2001).

Nancy, Jean-Luc, Ego Sum (Paris, Flammarion: 1979).

—_, "Dum Scribo," tr. Ian McLeod, Oxford Literary Review 3:2 (1978), pp. 6-21.

—, "Larvatus Pro Deo," tr. Daniel A. Brewer, Glyph II: Johns Hopkins Textual Studies (1977), pp. 14-36.

—_, "Mundus Est Fabula," tr. Daniel Brewer, MLN 93 (1978), pp. 635-653.

Nederman, Cary J., “The Meaning of 'Aristotelianism' in Medieval Moral and Political Thought," Journal of the History of Ideas 57:4 (1996), pp. 563-585.

Newton, Sir Isaac, Newton's Principia: The Mathematical Principles of Natural Philosophy, tr. Andrew Motte (1846).

Nietzsche, Friedrich, Basic Writings of Nietzsche, tr. and ed. Walter Kaufmann (New York: The Modern Library, 2000).

—, Twilight of the Idols and The Anti-Christ, R. J. Hollingdale (London: Penguin Books, 2003).

Noë, Alva, Out of Our Heads: Why You Are Not Your Brain, and Other Lessons from the Biology of Consciousness (New York: Hill and Wang, 2009).

Page, Carl, "Symbolic Mathematics and the Intellect Militant: On Modern Philosophy's Revolutionary Spirit," Journal of the History of Ideas 57:2 (1996), pp. 233-253.

Pappus of Alexandria, Book 7 of the Collection, pt. 1, ed. and tr. Alexander Jones (New York: Springer-Verlag, 1986).

Plato, Republic.

Port-Royal Logic, The, tr. Thomas Spencer Baynes (1861).

Prendergast, Thomas L., "Motion, Action, and Tendency in Descartes' Physics," Journal of the History of Philosophy 13:4 (1975), pp. 453-462.

Reif, Sister Patricia, “The Textbook Tradition in Natural Philosophy, 1600-1650," Journal of the History of Ideas 30:1 (1969), pp. 17-32.

Renard the Fox, tr. Patricia Terry (Berkeley, CA: University of California Press, p. 1992).

Ribe, Neil M., "Cartesian Optics and the Mastery of Nature,” Isis, 88:1 (1997), pp. 42-61.

Rickless, Samuel C., “The Cartesian Fallacy Fallacy,” NOÛS 39:2 (2005), pp. 308-336. 
Ricoeur, Paul, Memory, History, Forgetting, tr. Kathleen Blamely and David Pellauer (Chicago: University of Chicago Press, 2004).

Reiss, Timothy J., "Descartes, the Palatinate, and the Thirty Years War: Political Theory and Political Practice," Yale French Studies 80 (1991), pp. 108-145.

—, Knowledge, Discovery, and Imagination in Early Modern Europe: The Rise of Aesthetic Rationalism (New York: Cambridge University Press, 1997).

Rodis-Lewis, Geneviève, L’oeuvre de Descartes, 2 vols. (Paris: Librarie Philosophique J. Vrin, 1971).

Rousseau, Jean-Jacques, Émile, or On Education, tr. Alan Bloom (New York: Basic Books, 1979).

Rubidge, Bradley, "Descartes's Meditations and Devotional Meditations," Journal of the History of Ideas 51:1 (1990), pp. 27-49.

Schmitt, Carl, The Concept of the Political, tr. George Schwab (Chicago: The University of Chicago Press, 1996).

Sepper, Dennis L., Descartes's Imagination: Proportion, Images, and the Activity of Thinking (Berkeley, CA: University of California Press, 1996).

Smith, Kurt, “Descartes' Law Thesis,” http://plato.stanford.edu/entries/descartes-works/history .html, accessed 11/1/2010.

Smith, Russell, "Optical Reflection and Mechanical Rebound: The Shift from Analogy to Axiomatization in the Seventeenth Century. Part 2," British Society for the History of Science, 41:2 (2008), pp. 187-207.

Spinoza, Benedictus, The Principles of Descartes' Philosophy, tr. Halbert Hains Britan (La Salle, IL: The Open Court Publishing Company, 1961).

Stewart, William, "Descartes and Poetry," The Romanic Review 29 (1938), pp. 212-242.

Strauss, Leo, and Joseph Cropsey, eds., History of Political Philosophy, 3 ed. (Chicago: The University of Chicago Press, 1987).

Suárez, Francisco, On the Various Kinds of Distinction, tr. Cyril Vollert, S. J. (Milwaukee, WI: Marquette University Press, 2007).

—, Disputationes Metaphysicae VII, I.21 and 4, http://homepage.ruhr-uni-bochum.de/michael .renemann/suarez/suarez dm7.html, accessed 6/4/13.

Vaihinger, Hans, The Philosophy of 'As If': A System of the Theoretical, Practical and Religious Fictions of Mankind, tr. C. K. Ogden (Mansfield Centre, CT: Martino Publishing, 2009).

Verene, Donald Phillip, "Philosophical Aesthetics," Journal of Aesthetic Education, 40:4 (2006), pp. 89103.

—_, "Philosophy, Argument, and Narration," Philosophy \& Rhetoric 22:2 (1989), pp. 141-144. 
Vermeulen, Corinna Lucia, "René Descartes, Specimina Philosophiae. Introduction and Critical Edition," PhD diss., Utrecht University, 2007.

Vidricaire, André, "La vision comme procédé de communication dans le Discours de la Méthode," Philosophiques 15:1 (1988), pp. 95-105.

Wahl, Jean, Du rôle de l'idée de l'instinct dans la philosophie de Descartes (Paris: F. Alcan, 1920).

Weenix, Jan Baptist, Portrait of René Descartes (1647-1649).

Weinrich, Harald, Lethe: The Art and Critique of Forgetting, tr. Steven Rendall (Ithaca, NY: Cornell University Press, 2004).

Wittgenstein, Ludwig, Tractatus Logico-Philosophicus, tr. D. F. Pears and B. F. McGuinness (London: Routledge \& Kegan Paul, 1966).

Wilson, Catherine, "What Is the Importance of Descartes's Meditation Six?" Philosophica 76 (2005), pp. 87-90.

Zarka, Yves Charles, La Décision Métaphysique de Hobbes: Conditions de la Politique, 2 ed. (Paris: Librairie Philosophique J. Vrin, 1999).

Zipes, Jack, Fairy Tale as Myth/Myth as Fairy Tale (Lexington, KY: The University Press of Kentucky, 1994). 